\title{
Religiosity, Generational Cohort and Buying Behaviour of Islamic Financial Products in Bangladesh
}

\section{By}

Farhana Tahmida Newaz

\author{
A thesis \\ submitted to the Victoria University of Wellington \\ in fulfillment of the requirements for the degree of \\ Doctor of Philosophy \\ in Marketing
}

Victoria University of Wellington

2014 


\begin{abstract}
The role of religiosity on consumers' buying decisions is increasingly gaining the attention of researchers and practitioners. However, its role in consumer behaviour is not yet well established, particularly in the behaviour of Muslim consumers when buying financial products. The rapid growth of Islamic finance during the last 10 years across regions for various Islamic Financial Products (IFPs) provides opportunities and challenges to managers and researchers. Considering the rapid growth of IFPs and the limited research on Muslims' buying behaviour of such products, this research examined the relationship between religiosity, consumer buying attitude and purchase intention towards IFPs, to develop and understand how Muslims' religiosity impacts on their buying decisions.
\end{abstract}

A conceptual model has been developed based on extant literature. The model is guided by the theoretical premise of religious consumer behaviour and the Theory of Reasoned Action (TRA). The model included key religious dimensions: religious belief, practice, knowledge, experience and consequences, to measure the overall religiosity of consumers. The model investigated the effect of religiosity on consumer buying attitude and purchase intention towards IFPs. The model also investigated the moderating effects of generation cohorts on the relationship between religiosity, buying attitude and purchase intention. The analysis is based on a sample of 1,292 Muslim consumers in five major cities from three different generational cohorts in Bangladesh. The data was collected through a questionnaire survey, which was dropped off and collected by the researcher. The main findings suggest that religiosity positively and directly influences consumer buying attitude and purchase intention towards IFPs. It also finds that consumer buying attitude mediates the effects of religiosity on purchase intention and generational cohort has a partial-moderating effect on these relationships.

This research contributes to the literature in several ways. Firstly, it enhances the understanding of Muslim consumers buying behaviours of IFPs. It extends the current research by examining the complex mediating and moderating relationship. Thus, the findings suggest the mechanism of how religiosity influences Muslims' buying behaviour of IFPs. Secondly, it provides empirical support to the Theory of Reasoned Action (TRA) to understand religious-driven behaviours influenced by religious commitment. Thirdly, it utilised the generational cohort theory to identify generational cohorts in Bangladesh and extend the current research by examining their moderation effect on the relationship between 
religiosity and consumer behaviour. Fourthly, it enhances the understanding of the buying behaviour of Muslims from a democratic developing country, which is likely to differ from that of Muslims from Shariah-governed countries.

The findings have implications for practitioners too as they provide an understanding of Muslim consumers in a more predictive and comprehensive manner, by considering religiosity as a predictor of consumer behaviour rather than simply as a correlate of product purchasing. The results of this study may help Islamic financial service providers to identify potential customers and segment the target market on the basis of religiosity and generational cohort in order to expand their services globally. 
I would like to dedicate this thesis to those I lost during my PhD journey:

- My father, Garib Newaz Khan

- My sister, Sultana Nahida Newaz

- My aunt, Rashida Khatoon. 


\section{ACKNOWLEDGEMENT}

In the name of God, most gracious, most merciful. Praise be to God for His mercy and for giving me perseverance, energy and love.

I would like to express my sincere gratitude to all those who supported me through the process of completing this thesis. My sincere thanks go to my supervisors, Professor KimShyan Fam and Dr Revti Raman, for their time, effort and advice freely given to me throughout the project. I have learned so much from them and will be forever grateful for their support and patience.

Throughout the research, many people have played various supportive roles, and I need to give special thanks to these people: Dr Ainul Islam, Dr Bhagwan Khanna and Professor Val Lindsay. I would also like to thank the Research Committee at the School of Marketing and International Business for their financial support of this research. Special thanks to Jacqui Fitzgerald, Kim Hann, Jessie Johnston and Helen Hynes for their administrative assistance.

I would like to acknowledge all the institutions that contributed to this research by participating in the surveys. Without the fantastic response, this study would not have been possible.

I would not have been able to complete my studies without the support and encouragement of my parents, aunty, sisters and brother. Thanks to all of you for your love and sacrifice in support of my education. Last but not least, I wish to thank my niece, Fariha, for her unconditional love and for always having a fun fight with me when I came home from university. 


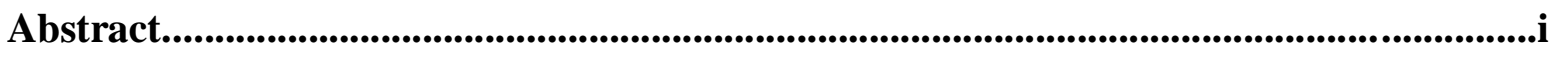

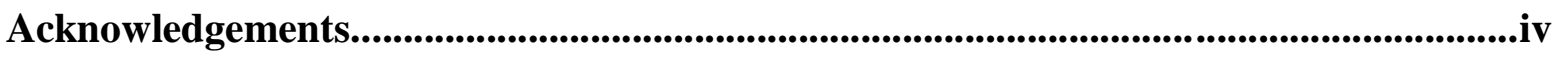

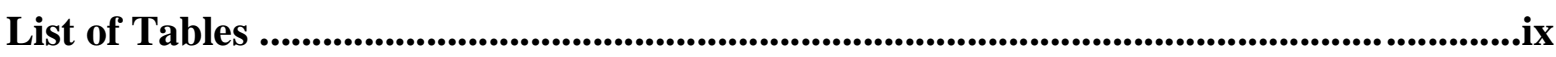

List of Figures....................................................................................................................................
\end{abstract}

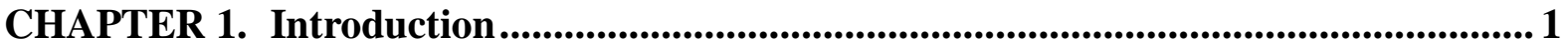

1.1. Background and Rationale of the Study ..................................................... 1

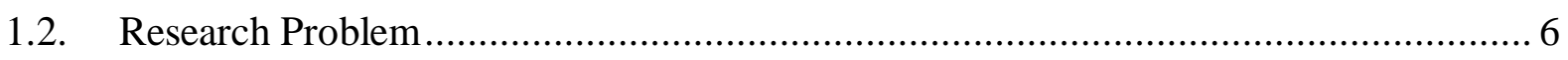

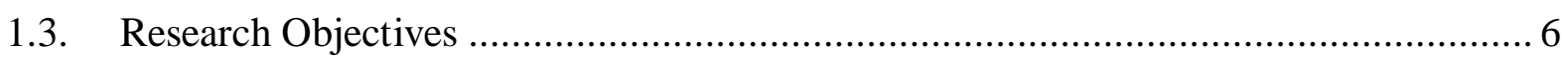

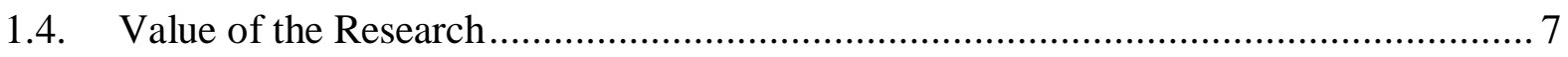

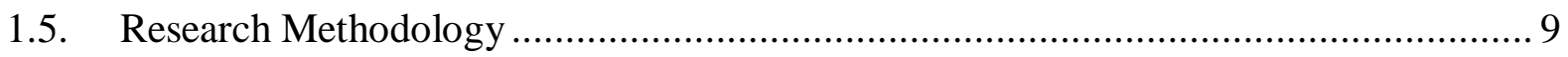

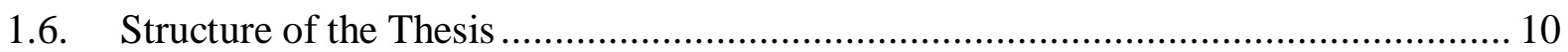

CHAPTER 2. An Overview of Islamic Financial Services and Bangladesh ................. 11

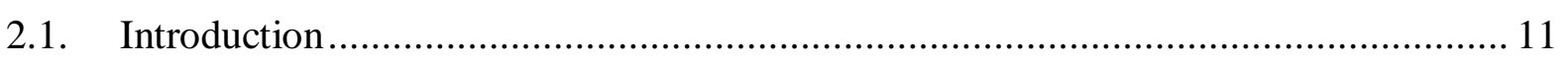

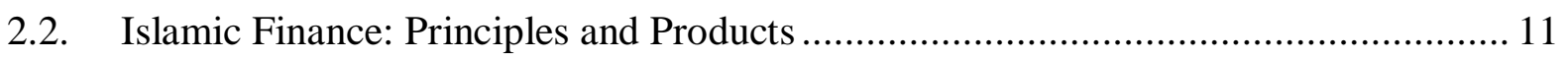

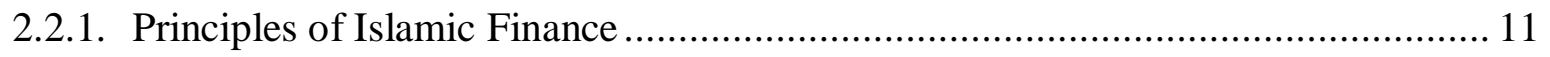

2.2.2. Categories of Islamic Financial Products ........................................................ 12

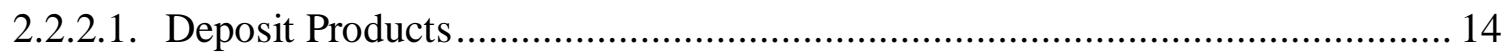

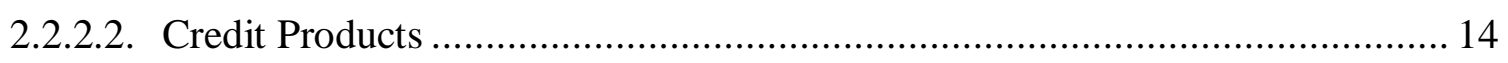

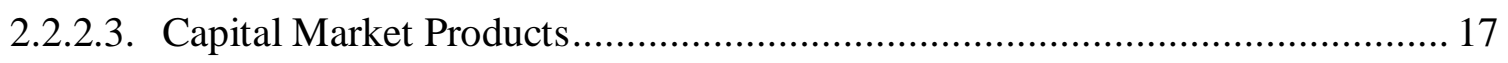

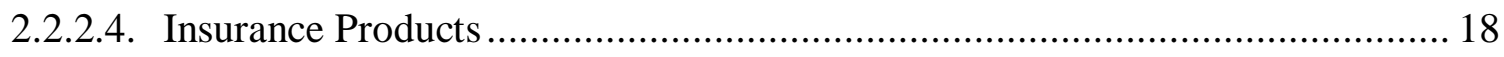

2.3. Global Market for Islamic Financial Products .......................................................... 18

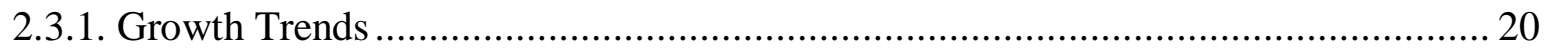

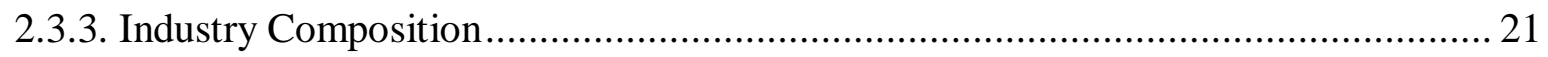

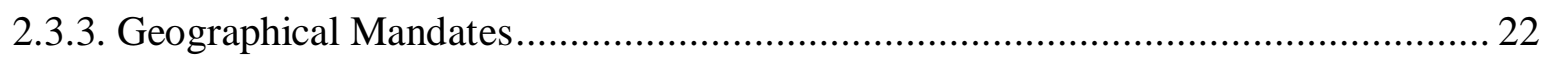

2.3.4. Islamic Finance Scenario in Bangladesh ..................................................... 25

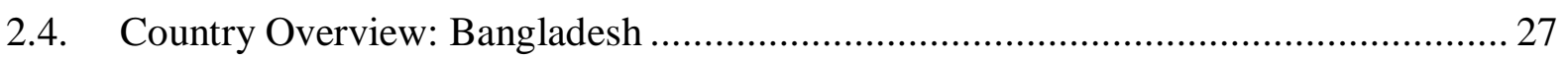

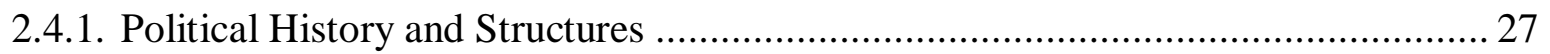

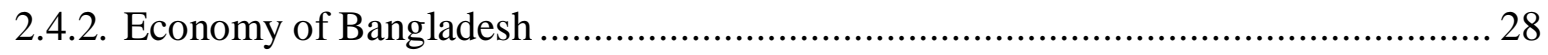

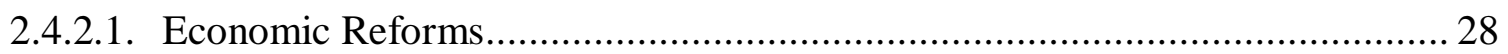

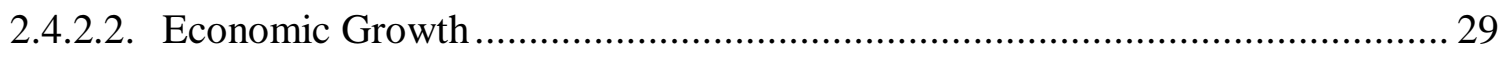

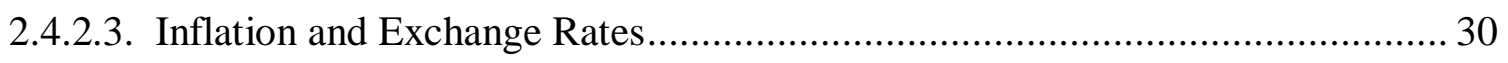


2.4.2.4. Constraints of Bangladesh Economic Development

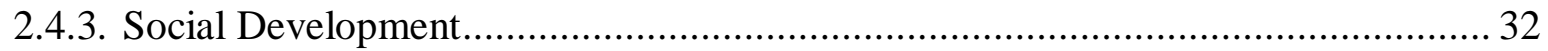

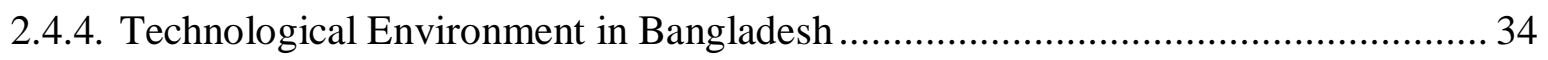

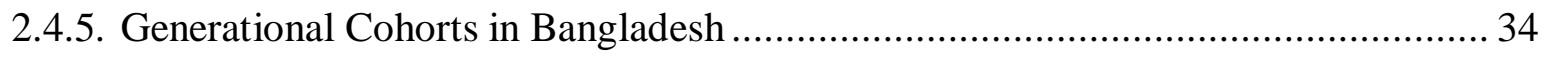

2.4.6. Role of Bangladesh Government in the Development of Islamic Finance .............. 38

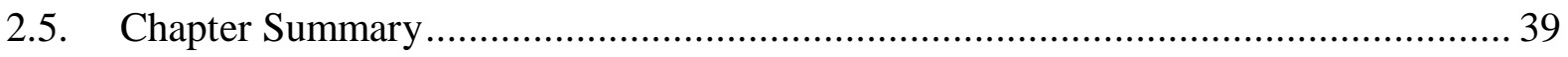

CHAPTER 3. Literature Review and Theoretical Framework .................................... 41

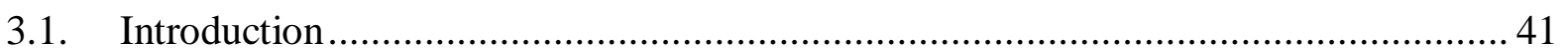

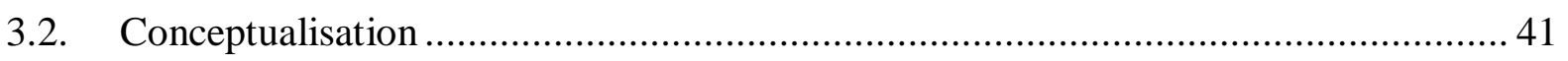

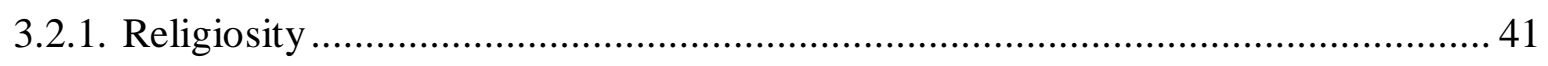

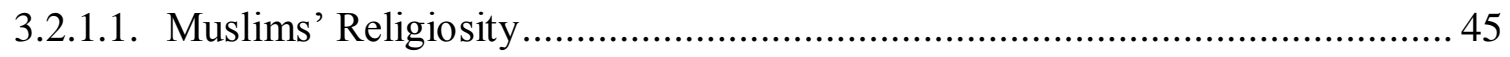

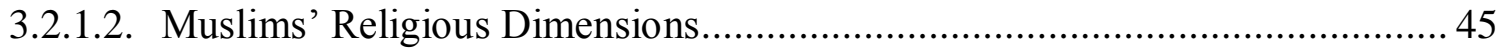

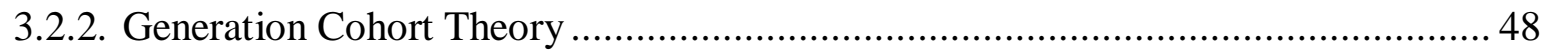

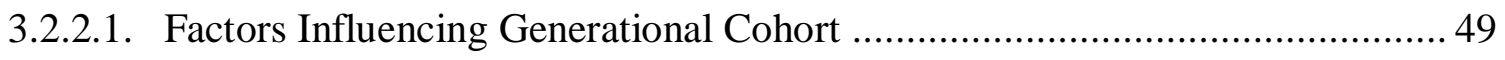

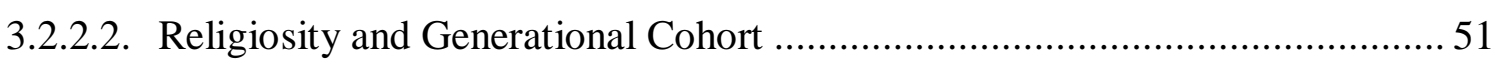

3.2.2.3. Generational Cohort as Consumers ...................................................... 51

3.3. Overview of Religiosity and Buying Behaviour Literature ...................................53

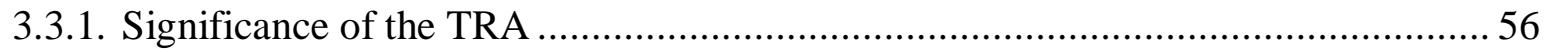

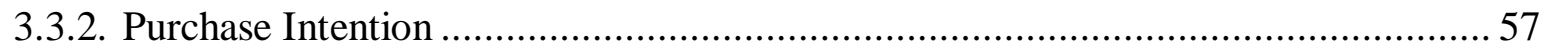

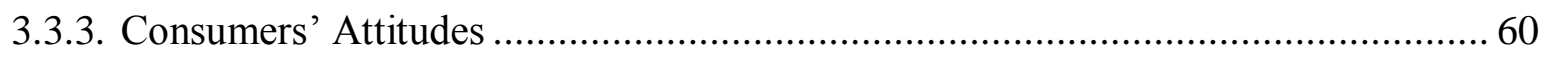

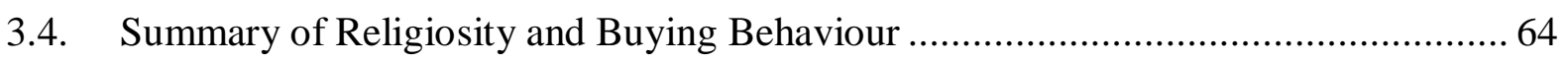

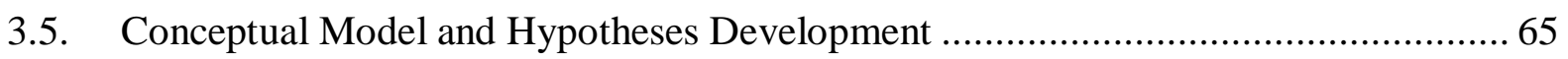

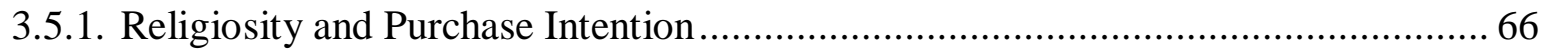

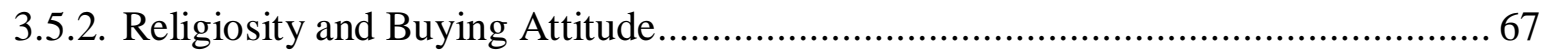

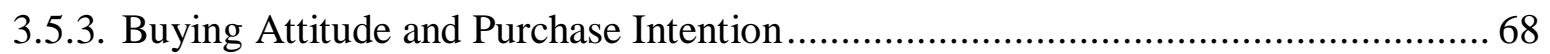

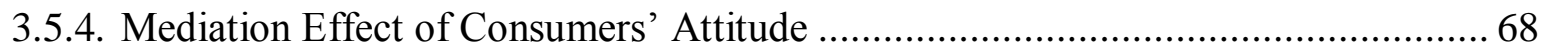

3.5.5. Islamic Financial Product Categories and Purchase Intention .............................. 69

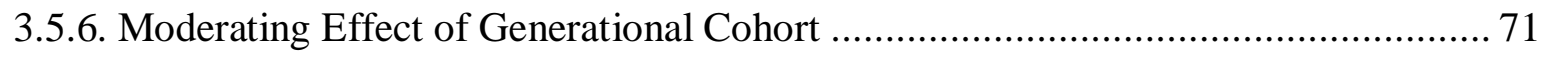

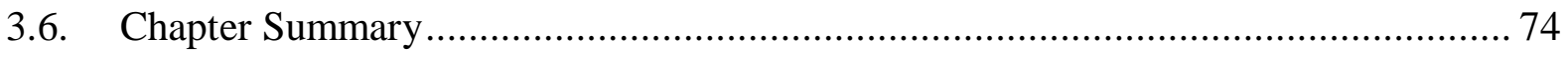

CHAPTER 4. Methods and Data ................................................................................. 76

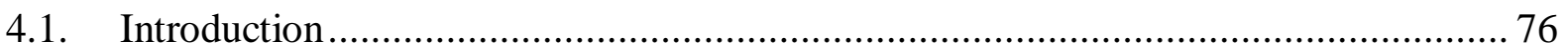

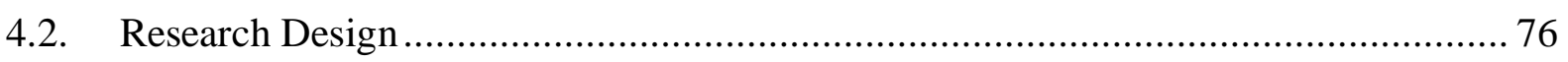

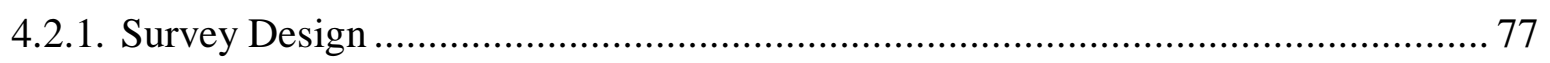




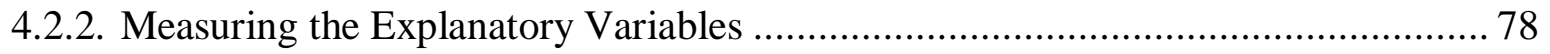

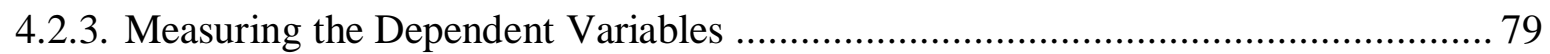

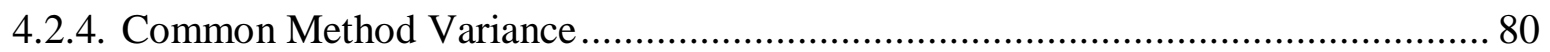

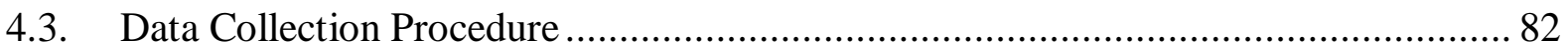

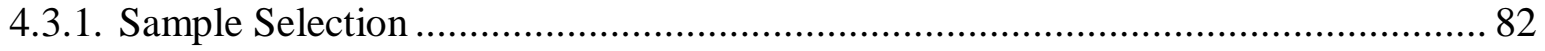

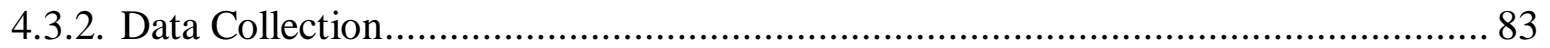

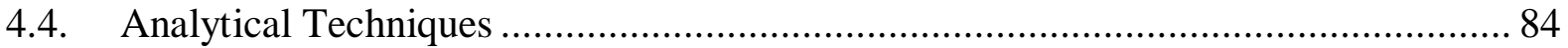

4.4.1. Structural Equation Modelling ........................................................................... 84

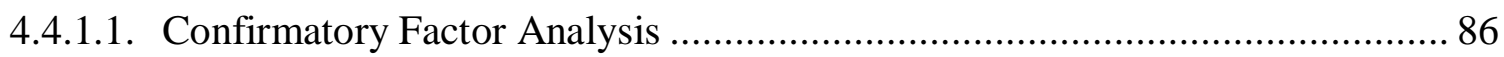

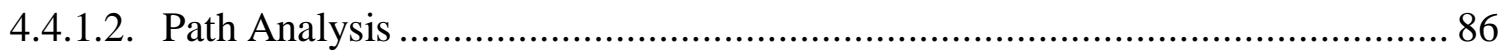

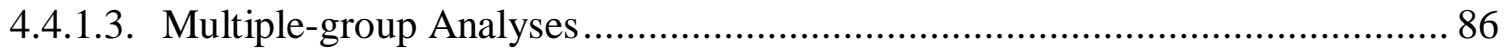

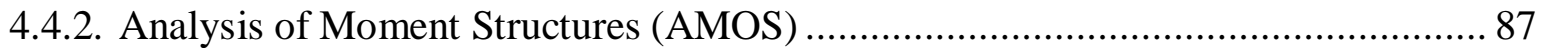

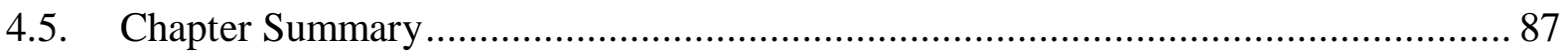

CHAPTER 5. Data Analysis and Results .......................................................................... 89

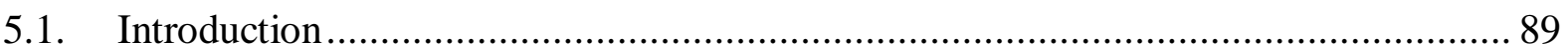

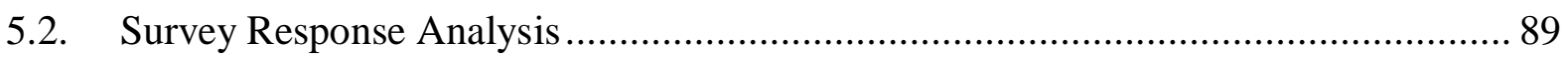

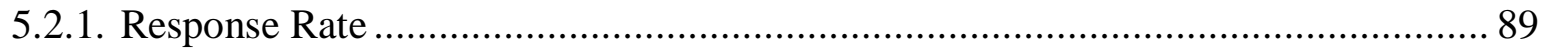

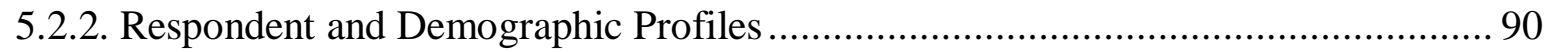

5.3. Measurement Refinement and Initial Analysis ................................................... 93

5.4. Confirmatory Factor Analysis and Measurement Model ....................................... 93

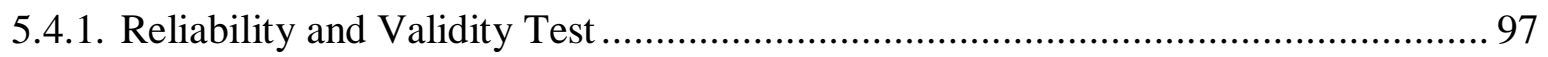

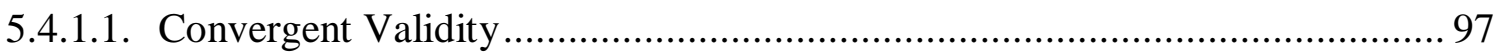

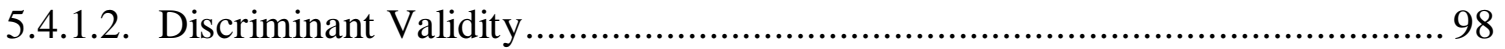

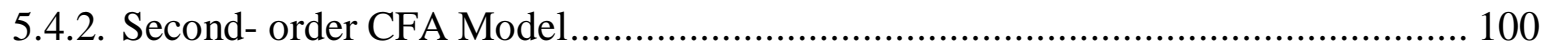

5.4.2.1. Final Measurement Model................................................................................ 102

5.5. Model Construction and Evaluation ..................................................................... 104

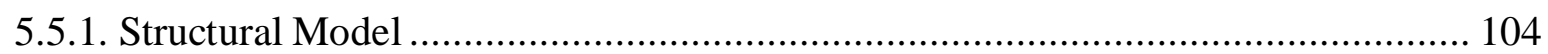

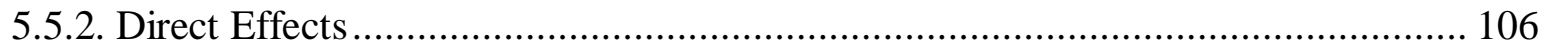

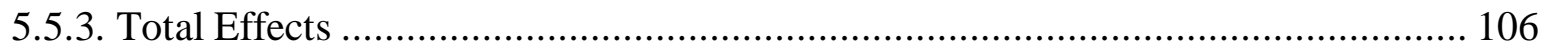

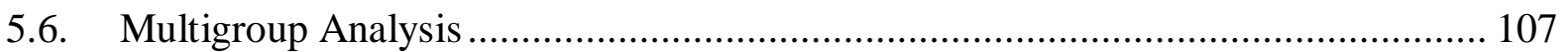

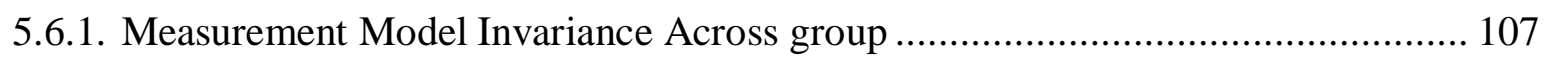

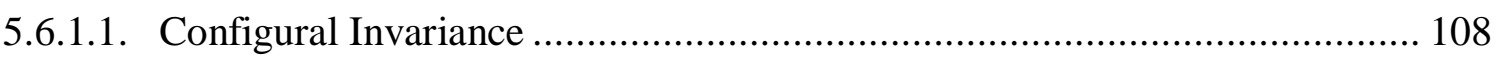

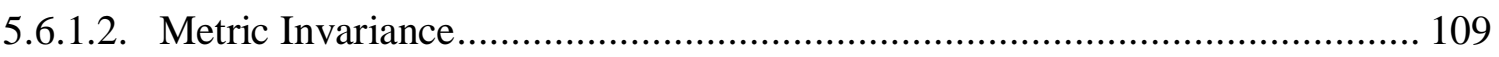


5.6.1.3. Scalar invariance

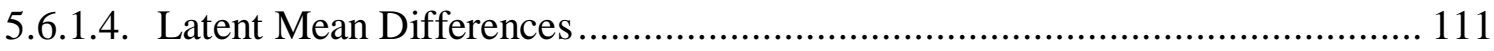

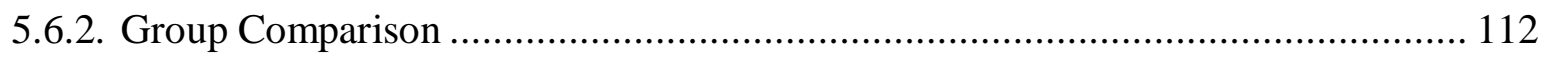

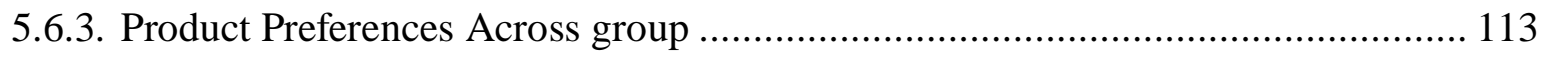

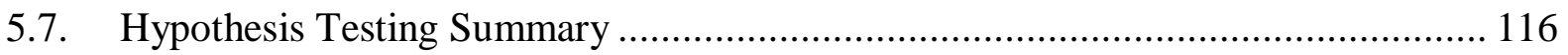

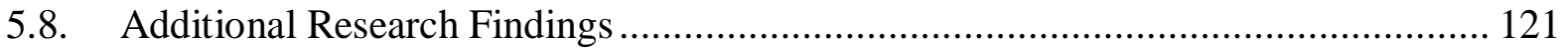

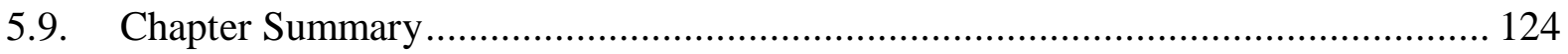

CHAPTER 6. Discussion and Conclusions ........................................................ 126

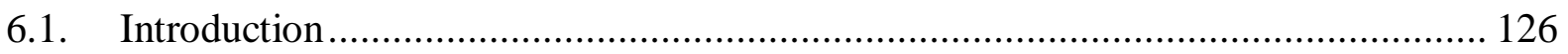

6.2. Effects of Religiosity on Consumer Buying Behaviour ...................................... 126

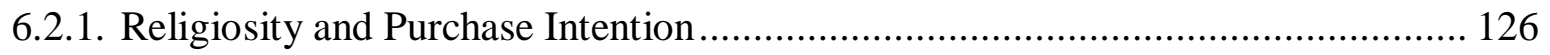

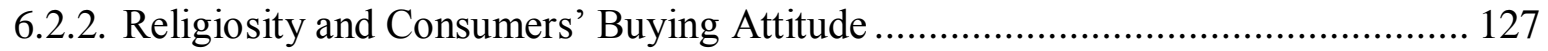

6.2.3. Consumer Buying Attitude and Purchase Intention ......................................... 128

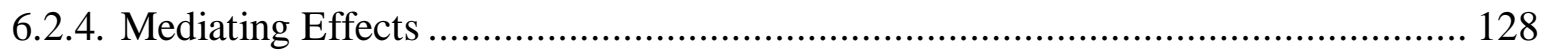

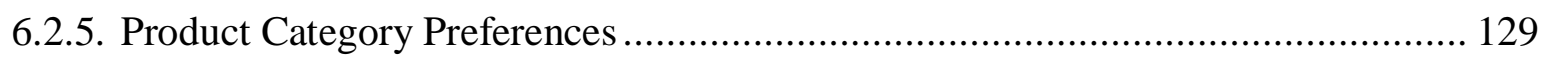

6.2.6. Moderating Effects of Generational Cohort .................................................... 131

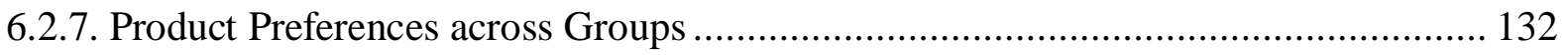

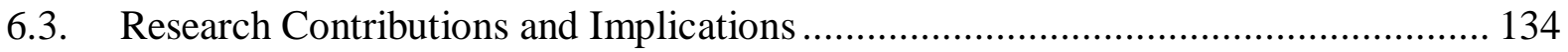

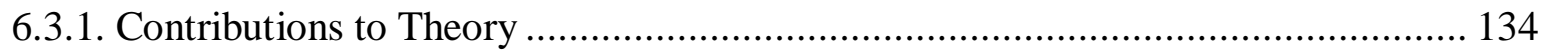

6.3.2. Managerial Implications .............................................................................. 140

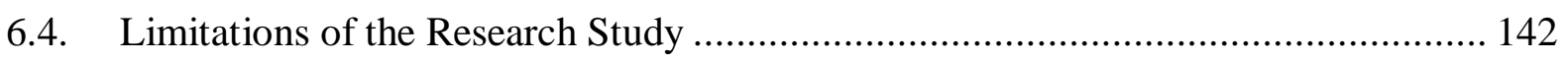

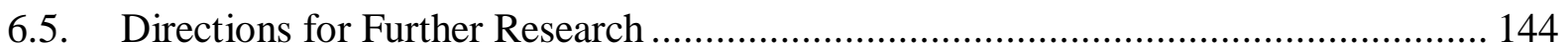

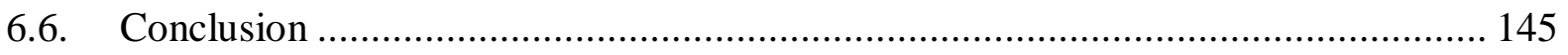

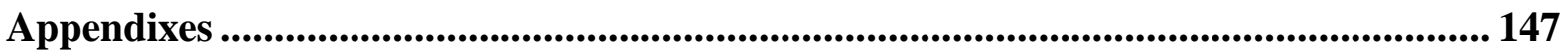

Appendix A1: Copy of Participant Information Sheet in English ................................... 147

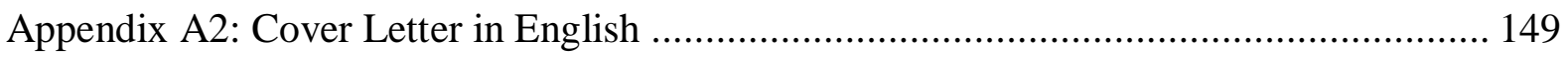

Appendix A3: Copy of Survey Questionnaire in English .......................................... 150

Appendix A4: Copy of Participant Information Sheet in Bengali .................................... 155

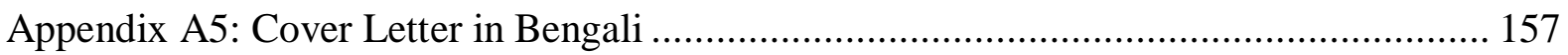

Appendix A6: Copy of Survey Questionnaire in Bengali ............................................. 158

Appendix A7: Summary of Organization and Respondent Information........................... 163

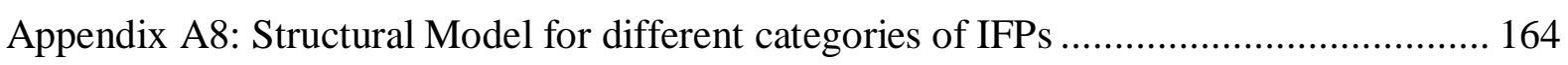

References.............................................................................................................. 165 


\section{List of Tables}

Table 2.1: Breakdown of Islamic Assets by Institution and Region ............................. 23

Table 2.2: Countries by Largest Shariah-compliant Assets, US\$ Billion, 2011 ............. 25

Table 2.3: Growth Trend of Main Sectors …................................................................. 30

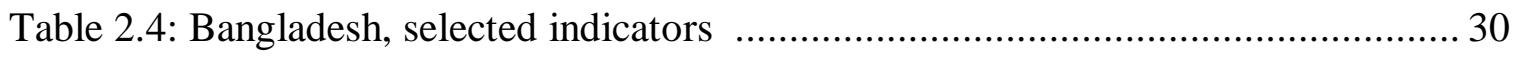

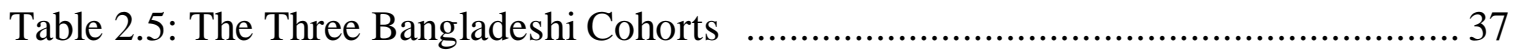

Table 3.1: Comparison between Glock and Ilyas' Conception of Religiosity ................ 46

Table 5.1: Respondent Profiles .................................................................................... 92

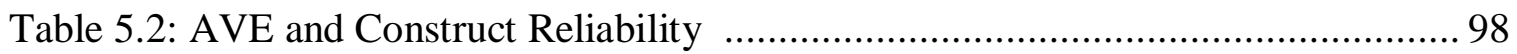

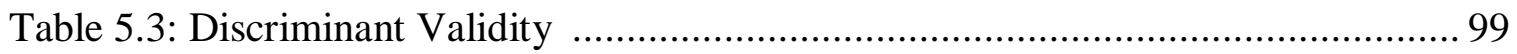

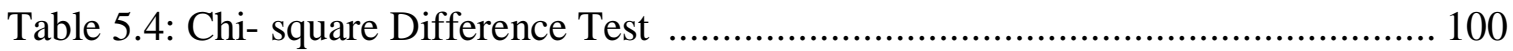

Table 5.5: Final Measurement Model Items, Loadings and Significance Values ....... 103

Table 5.6: Structural Model Path Coefficients and Significance Level...................106

Table 5.7: Direct, Indirect and Total Effects of Religiosity on Buying Attitude and Purchase Intention .......................................................................... 107

Table 5.8: Latent Means Differences of the Constructs ............................................. 112

Table 5.9: Group Comparison on the Basis of Cohort ................................................. 113

Table 5.10: Comparison of Traditionalist, Swing and GenY Cohorts for Path Parameters across Product Categories .......................................... 115

Table 5.11: Summary of Hypotheses Testing ............................................................ 120

Table 5.12: Effect of Demographic Variables on the Relationship between Religiosity, Consumer Buying Attitude and Purchase Intention 123 


\section{List of Figures}

Figure 2.1: Categories of Islamic Financial Products ............................................... 13

Figure 2.2: Significant Developments in Islamic Finance ........................................ 19

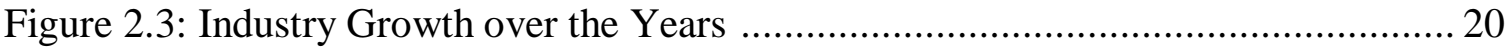

Figure 2.4: Global Assets of Islamic Finance ….................................................. 21

Figure 3.1: Proposed Dimensions of the Conventional Measurement of Religiosity....... 44

Figure 3.2: Religiosity-Consumer Behaviour: Conceptual Model ................................. 66

Figure 5.1: Original measurement model used for confirmatory factor analysis ............95

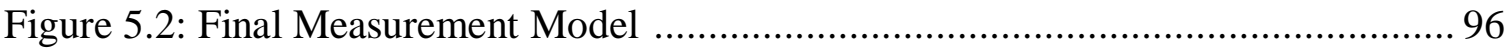

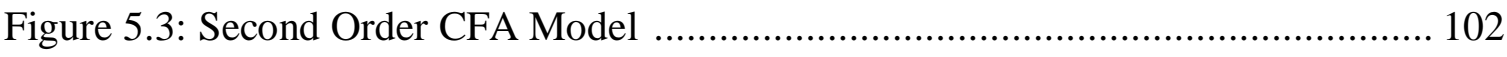

Figure 5.4: Second-order Structural Model ........................................................ 105 


\section{CHAPTER 1. Introduction}

This chapter provides the research background and rationale for the topic of the study. In addition, the research problem and objectives are discussed, and the value of this study is outlined. The last section concludes with an overview of the organisation of the thesis.

\subsection{Background and Rationale of the Study}

In a dynamic and increasingly globalised market, cultural constructs have become increasingly central to consumer behaviour literature (Khraim, 2010). Religion, being an inseparable part of the culture, has been identified as influencing the consumption behaviour of individuals (Delener, 1990a; Mokhlis, 2009). It is related to people's lifestyle, which, in turn, affects their buying decision behaviour as consumers (Wilkes, Burnett, \& Howell, 1986). Religion either encourages or restrains them in particular choice behaviour (Delener, 1994) and consumers from different religious backgrounds have different buying behaviour in the market (Bailey \& Sood, 1993). From a marketing perspective, the constancy of religion underlying consumer behaviour suggests the potential of religion as the basis for market targeting, with a clear understanding of consumer choice with reference to religious commitment. Through this insightful knowledge, marketers would be able to advance their market projection and information processing within the organisation, potentially leading to better responses to consumers' requirements (Khraim, 2010).

Religion plays an important role in shaping people's attitudes and behaviour, and the current trend is towards a global renaissance of organised religiosity (Armstrong, 2001; Arnould, Price, \& Zikhan, 2004). But religion has not yet received much attention from marketing scholars (Mokhlis, 2006a). This lack of attention in consumer behaviour literature is because of less awareness of the possible links between religion and consumption patterns, and the existence of perceived prejudice against religion within the research community. Religion has been considered a taboo subject and too sensitive to be submitted for investigation because of the potential for inadvertent offence and the legal protection afforded freedom of religion. Moreover, religion is everywhere in our lives and therefore may have been overlooked by researchers as an obvious variable for investigation in the field (Hirschman, 1983). Only 35 articles written prior to 1990 have been found to have a religious focus, and only six of the se concentrated on the area of consumer behaviour (Cutler, 1991). "Religious revival" as one of the ten megatrends that appeared in the new millennium (Arnould, et al., 2004; Naisbitt \& 
Aburdene, 1990) has transformed this situation and triggered the motivation to gain a better understanding of the impact of religion on consumer behaviour (Razzaque \& Chaudhry, 2013). During last two decades, the trends show that scholars have embraced religion as a significant cultural effect in modern-day consumer behaviours (Hashim \& Mizerski, 2010).

Religious affiliation and religiosity are two important constructs of religion in explaining consumers' behaviours (McDaniel \& Burnett, 1990). Religious affiliation is denominational membership or religious identification of the individual (e.g. Christian, Islam, Hindu, Buddhist), whereas religiosity is an individual's level of commitment to a particular religious group (Delener, 1990a; McDaniel \& Burnett, 1990). It has been suggested that future research focuses on the religiosity of consumers, rather than their religious affiliation (Armstrong, 2001; Arnould, et al., 2004; McDaniel \& Burnett, 1990). Some people may claim to be affiliated with a particular religion, but they may not truly follow the teaching and conduct of the religion. Religiosity, rather than religion, plays a dominant and influential role in attitude formation and is related to questions around why people consume (Hirschman, 1981, 1983). Individual differences in religiosity are also related to established differences in perception that may guide the individual in the process of selecting solutions for a particular need (La Barbera, 1987). The investigation of religiosity seems justified, as religiosity represents an inherent human value; many of the elements of religiosity are observable and therefore provide practical value to marketers. As religiosity has significant influence on consumers' behaviour, a better understanding of religiosity and consumers' buying behaviour relationships is likely to allow the development of more effective strategies for different religious or national markets (Essoo \& Dibb, 2004; Sood \& Nasu, 1995). Moreover, organisations will be able to better observe their competitors and stay ahead of their strategic moves in the target market.

While considerable marketing and consumer research specifically identifies the important effects that religion can have on international marketing decisions, the concept of religiosity in the context of Islam remains limited (Shukor \& Jamal, 2013). Most of the current research on religiosity focuses on Christianity in the context of the Western world (Gait \& Worthington, 2008). In addition, the empirical evidence regarding the impact of religiosity on consumer behaviour is mixed. One of the explanations for the mixed findings is the likely existence of moderators and mediators influencing the relationship between religiosity and buying behaviour (Loroz, 2006). One of these intermediary variables gaining recent attention 
is generational cohorts of consumers (Motta, Rossi, \& Schewe, 2002; Loroz, 2006; Gay \& Lynxwiler, 2013). Cohorts' characteristics and links to religiosity, and the connection between religiosity and consumer behaviour are also new to the literature. This study attempts to fill some of the gaps in extant knowledge by examining how generational cohorts' characteristics and values may act as moderators on the relationship between religiosity, consumers' buying attitude and purchase intention towards IFPs (McKenzie, 2001).

The growth in the number of Muslims worldwide has stimulated peoples' interest in gaining a better understanding of Islamic religion and Muslim consumers' behaviour (Porter \& Schwab, 2009). There is a clear differentiation between degrees of religiosity among Muslims: some Muslims are seen as pious and others are not (Youssef, Kortam, Aish, \& ElBassiouny, 2011). The common belief, upon which all Muslims agree, is the monotheism baseline (belief in the oneness of God and the prophet hood of Muhammad). On the other hand, the Quran and Hadith are assumed and implemented differently in different countries, which leads to differences in the application of Islam worldwide (Porter \& Schwab, 2009). Islamic law, or Shariah ${ }^{1}$, provides criteria for judgement on every aspect of one's individual and social life. Yet still some controversies exist around halal (permitted in Islam) and haram (not permitted in Islam) (Harold, 2004; Youssef, et al., 2011).

Because large, multinational companies are becoming more attracted to the fast growing Muslim market, marketers need to gain a more appropriate understanding of Muslim consumers, rather than treating them in a traditional and secular way (Razzaque \& Chaudhry, 2013). Shariah affects many aspects of marketing, including selection of products and services (Ahmed, 2008; Bonne, Vermeir, Bergeaud-Blackler, \& Verbeke, 2007). Marketing ethics bound by Islam differ in two major characteristics from other marketing ethics (Saeed,

\footnotetext{
${ }^{1}$ Shariah (in Arabic means "way" or "path") is the sacred Islam law. Muslims believe Shariah is derived from two primary sources of Islamic law; namely, the divine revelations set forth in the Qur'an, and the sayings and example set by the Prophet Muhammad (SWS) through specific words, habits, practices, and silent approvals (Sunnah). Jurisprudence interprets and extends the application of Shariah to questions not directly addressed in the primary sources but also including secondary sources. These secondary sources usually include the consensus of the religious scholars. Therefore, Sharia law is the framework of ultimate reality and the ethical guidance that Muslim scholars have derived from the direct Revelation of Allah to man and the Sunnah set by the Prophet Muhammad (SWS). Since Islamic Law touches on both transcendent and material experience, all aspects of every person's spiritual understandings and undertakings should be consciously subject to the realitycheck of Islamic law. Therefore, Shariah provides the ultimate criteria for judgment on every aspect of one's individual and social life.
} 
Ahmed, \& Mukhhar, 2001). Firstly, Islamic marketing ethics are based on Shariah; secondly, Islamic marketing ethics aim to maximise value for the benefit of the entire society, rather than only maximising profits (Chapra, 2008; Marinov, 2007; Saeed, et al., 2001; Youssef, et al., 2011). Islamic laws also deal with financial services regarding interest, non-Islamic investments, and speculation. Marketers cannot violate these Islamic principles when providing financial service and promoting interest. Conventional financial services are not accepted by the majority of Muslim consumers (Marinov, 2007).

The global assets of the Islamic financial services industry reached USD1.6 trillion at the end of 2012, which represents a 20.4\% year over year growth since the end of 2011 (Grewal, 2013). Total Islamic financial assets are mainly concentrated in the Middle East and Asia and focus heavily on Islamic banks (IFSB, 2013). As one of the most significant developing segments in the global finance industry, Islamic finance has become desirable for its competitiveness and efficiency not only within the Muslim community, but also within nonMuslim communities (Zaher \& Hassan, 2001). Islamic financial products and services have been directly competing with the products and services of conventional finance institutions in most of the Muslim countries. The limited amount of current empirical research has identified that religion is a potential variable for determining the buying behaviour of Islamic financial products (IFPs). However, most of the research on IFPs primarily focuses on Islamic banking services, rather than other categories of Islamic financial products and services. In order to promote Islamic financial products and services in these markets, the target participants' attitudes towards, and perceptions and knowledge of, these new methods of financing should be considered, in order to establish to what extent the customer will choose these new products and services (Gait \& Worthington, 2008). Therefore, Islamic financial and banking organisations are eager to better understand their customers' specific needs and how the degree of religiosity is affecting beliefs, attitudes and buying patterns, so that they can develop suitable services for the satisfaction of their customers.

While some countries, such as Iran and Sudan, have established fully Shariah-compliant financial systems, others (some GCC states, Bangladesh and Malaysia) are becoming focal markets due to the growing market share of Islamic finance (IFSB, 2013). The Islamic finance industry seeks to promote inclusive growth, equitable risk-sharing and social justice through the use of instruments that comply with Shariah, so is benefiting from a large and ever-growing international Muslim population. Identifying the growth potential, financial 
capitals across Europe and Southeast Asia are striving to become hubs for Islamic finance (Steffensen, 2013).

Bangladesh is one of the largest Muslim countries in the world, with over 130 million Muslims with a potential demand for IFPs. Although the Islamic banking market in Bangladesh started with a very limited resource base, it has shown strong growth throughout the past two decades to date. Bangladesh has reached 11th position among the top 15 countries in terms of Shariah-compliant assets, with $1 \%$ market share of the global Islamic finance industry (OIC, 2012; UKIFS, 2012). Its on-going development signals a high level of acceptance by the public in general. Coupled with the country's economic growth, the market share of Islamic financial institutions continues its increase in terms of assets, financing and deposits (NewHorizon, 2009).

To summarise, this study aims to plug an important gap in research by analysing the effect of religiosity on the buying behaviour of Muslim people for selecting IFPs in Bangladesh for the following reasons:

i) The study of the influence of religiosity on consumer behaviour remains under-researched.

ii) Existing literature has based its measures on a Western population that is predominantly Jewish, Catholic or Protestant, and little can be said about the robustness of previous findings in an Islamic religious context.

iii) There is a rapidly increasing market for IFPs, but scant literature on such products.

iv) There has been minimal research on generational cohorts as a defining characteristic in terms of their unique webs of meaning and the implications these shared meanings have on consumers' behaviours.

v) People in different country contexts - for example, Muslims in a Muslimdominated democratic country, such as Bangladesh - may behave differently from those in a Shariah-governed or Western democratic country.

The findings of this study may assist Islamic finance practitioners' to identify potential consumers and segmenting the target market based on religiosity, IFP category and generational cohort to increase their businesses worldwide. Having a complete picture of such relationships, and therefore an understanding of the impact of religiosity on buying 
behaviour in a Muslim-majority democratic country context, is also expected to provide insights for academics and managers.

\subsection{Research Problem}

Theoretically, in Islamic religion, both Islamic laws and awareness of Islamic teachings affect the buying decisions of Muslim consumers (Alam, Mohd, \& Hisham, 2011). But it is religiosity, rather than religion, that better explains the behavioural differences between the various consumer segments (Delener, 1990a). For some individuals, religious commitment and involvement is high, whereas for others it is not (Kahle, Kau, Tambyah, Tan, \& Jung, 2005). There has been limited empirical research on measuring religious influences in Muslim consumers' buying behaviour (Muhamad \& Mizerski, 2010). Religiosity can be investigated with the same degree of objectivity as other influential social characteristics, in order to advance a complete understanding of consumer behaviour (Kahle, et al., 2005). One of the issues leading to problems in the research is the lack of an established Muslim religiosity measurement scale and how the outcomes determine an understanding of consumers' buying behaviour. This leads us to the research question:

What is the impact of religiosity on Muslim consumers' behaviour when selecting Islamic financial products?

\subsection{Research Objectives}

The objectives of this research are to:

- Investigate whether religiosity has a positive effect on consumers' buying attitude and purchase intention of IFPs and the extent of that impact

- Investigate whether religiosity has a positive effect on the buying attitude and purchase intention of different categories of IFPs and the extent of that impact

- Examine the effect of generational cohorts on the relationship between religiosity, consumers' buying attitude and purchase intention of IFPs and its different categories

- Contribute to the current sociology and marketing literature on religiosity and consumer behaviour

- Inform marketing practitioners engaged in designing and providing Islamic financial services. 


\subsection{Value of the Research}

Given the importance of consumer religiosity as it relates to consumer behaviour, the examination of the process by which consumers' religiosity contributes to determining their buying decisions provides an invaluable research opportunity. This research adds to the existing consumer behaviour literature by extending several aspects in relation to religious commitment as discussed below:

'Religiosity-Consumer Behaviour' conceptual model: From reviewing the literature, a conceptual model with well-defined and measurable variables and hypotheses is presented. The model considers the role of religiosity in Muslim consumer behaviour by providing insight into how religiosity influences buying attitude and purchase intention towards IFPs. The model proposes that buying attitude mediates the relationships between religiosity and purchase intention of IFPs. In other words, the model explains the mechanism (buying attitude) through which religiosity influences purchase intention of IFPs. The model also incorporates the moderating effects of cohort groups on religiosity, buying attitude, and purchase intention relationships.

Cohort groups and IFP purchase intention: Generational cohort theory has underlined significant intergenerational variances in values and attitudes among different generations (Lu \& Alon, 2004; Yardley, 2003). Religiosity and consumption-related attitudes may also differ between different generational cohorts (Loroz, 2006). The results of this research indicate that the generational cohorts differ to some extent in terms of the effects that religiosity and other psychographic factors have on their behaviour towards IFP and its different categories. This outcome contributes to the consumer behaviour literature by including cohort groups as a moderator in the model. Generational cohort is defined in Bangladesh context. Identified characteristics of three cohorts, such as Traditionalist, Swing and GenY, can be employed in understanding Bangladeshi consumers' behaviour for future research.

Purchase intention for different product categories: Although all categories of IFP are principally compliant with Shariah (Gait \& Worthington, 2008; Gait \& Worthington, 2009a), standard interpretations for each category of IFP (such as Islamic deposit, Islamic credit, Islamic capital market and Islamic Insurance products) are still lacking for the wider Muslim population (El-Gamal, 2006; Sadiq \& Black, 2012). This may have an influence on whether 
or not customers may choose to buy a particular product. This study measured religiosity to assess consumers' attitudes towards purchasing a particular category of IFPs, in addition to the outcomes of the relationship between religiosity and purchase intention of IFPs overall. Although very few significant works in this area are acknowledged, this research intends to provide a more complete understanding of how religiosity effects consumers' purchase intention of different categories of IFPs.

Muslim's religiosity measurement instrument: A consistent and tested instrument is created to measure the influence that religion has on consumers' engagement in IFP purchase decisions. Constructs capturing the various forms of religiosity that Muslim consumers are committed to in their religion are conceptually defined, including religious belief, religious practice, religious knowledge, religious experience and consequences. Consumer buying attitude and purchase intention are also conceptually defined.

Interdisciplinary nature of the research: The research draws upon religiosity studies within psychological, sociological, and consumer marketing literature; the Theory of Reasoned Action (TRA) from consumption and social psychology-related studies; and the generational cohort theory within political, sociological, and marketing literature. These multiple lenses give a better picture of the 'Religiosity-Consumer Behaviour' model.

Value for practitioners: This research adds value for practitioners by justifying how the market can be segmented into degree of religiosity, different product types, and generational cohorts. Firstly, there are differences among Muslim people in terms of religious degree: some Muslims are more religious than others. Understanding religious differences as they relate to consumer behaviour can provide practitioners with a base for market segmentation at their strategic level. Secondly, product importance and Muslim consumers' preferences within IFP categories also affect their purchase intentions (Mukhtar \& Butt, 2012). IFPs are split into four categories and practitioners can segment their market on the basis of consumers' particular financial need for Islamic deposit products, credit products, capital market products and insurance products. Thirdly, generational cohort members experience the process of socialisation together and this socialisation influences and shapes the equivalent values, characteristics, attitudes, and preferences of members of the same cohort. Identifying the characteristics of each cohort may help practitioners to segment the consumer market and plan marketing activities (Schewe \& Noble, 2000). 
This research is one of the few studies that examine the association between Muslim consumer's religiosity and purchase intention towards IFPs. By incorporating mediation and moderating effects, the study analyses a complex 'Religiosity-Consumer Behaviour' model. The mixed findings in the literature regarding the relationship between Muslim consumers' religiosity and purchase intention towards Islamic finance (Khraim, 2010) may be because of the existence of mediators and moderators. This study advances the understanding of the religiosity and purchase intention relationship by explaining the mechanism of consumers' buying attitudes and the generational cohort through which religiosity influences consumers' purchase intention. Furthermore, it is valuable to discover the extent to which the degree of religiosity determines the preferences of different categories of IFPs among different generational cohorts. Accordingly, this study helps researchers and marketing practitioners to develop their knowledge of customers' purchase motives in terms of the degree of religious commitment.

\subsection{Research Methodology}

In order to achieve the specified objectives, a conceptual model was developed, tested and validated using instruments designed to measure religiosity, consumers' buying attitude and purchase intention. The study adopted a quantitative approach with a field survey instrument. A questionnaire was developed in order to proceed with the data collection phase of the study. Once the filed survey was completed, the study empirically tested the explanatory capabilities of the conceptual model across a number of different cohort groups within Bangladesh.

The results of the survey were analysed with Structural Equation Modelling (SEM), using AMOS to test the research hypotheses and answer the research questions. The results from the quantitative survey provide a comprehensive and rigorous analysis of Muslim consumers' religiosity and measure its impact on their buying behaviour. 


\subsection{Structure of the Thesis}

The thesis is organised into six chapters. A brief description of each chapter is provided below.

Chapter 2 provides a concept of Islamic finance and a background overview of the Islamic financial industry. In addition, it represents country profile, generational cohorts and the Islamic finance scenario in Bangladesh.

In Chapter 3, prior literature is reviewed to gain an understanding of previous studies' findings around the influence of religiosity on consumption behaviour. The conceptualisation of religiosity and its dimensions, and generational cohorts, are also a focus. Based on the literature review, the conceptual model is developed and the relationships between religiosity and consumers' buying behaviour are hypothesised.

Chapter 4 represents the research design of the study. The rationale for adopting a quantitative approach and its elements of the study are described. The statistical technique to test the hypotheses is also discussed.

Chapter 5 analyses the data from the field survey and presents the results of the hypotheses.

Finally, Chapter 6 discusses the key findings, and considers them in relation to the conceptual model and the hypotheses. It also specifies the key academic and theoretical contributions of the study, followed by implications for managerial practices. Additionally, the limitations of the study are acknowledged and areas for future research are suggested. 


\section{CHAPTER 2. An Overview of Islamic Financial Services and Bangladesh}

\subsection{Introduction}

The main objective of this chapter is to understand the outstanding growth of Islamic finance in the contemporary finance world. The chapter will firstly cover the concept of Islamic finance, followed by an overview of the global market scenario regarding Islamic financial services. The next section represents country profile, generation cohorts and Islamic financial advancement in Bangladesh.

\subsection{Islamic Finance: Principles and Products}

Financial products refer to the instruments that help save, invest, get insurance or borrowing facilities (Obaidullah, 2005). Islamic Financial Product (IFP) is defined as a financial service or product principally implemented to comply with the main tenets of Shariah or Islamic law on interest, non-Islamic investments, and speculation (Gait \& Worthington, 2008; Gait \& Worthington, 2009a). The participants in Islamic financial transactions are considered business partners who jointly bear the risks and profits.

\subsubsection{Principles of Islamic Finance}

The overall guiding principles of Islamic finance include the following (Iqbal, 1997; Khan \& Bashar, 2008; NBR, 2008):

- Any predetermined payment over and above the actual amount of principal is prohibited.

- The lender must share in the profits or losses arising out of the enterprise for which money was lent.

- Making money from money is not acceptable by Islamic law. Money is only a medium of exchange, and therefore should not be allowed to give rise to more money, via fixed interest payments, simply by being put in a bank or lent to someone else.

- Gharar (uncertainty, risk or speculation) is prohibited.

- Investments should only support practices or products that are not forbidden (or discouraged) by Islam. 
IFPs are significantly different from Conventional Financial Products (CFPs) in a number of ways (Iqbal, 1997; Khan \& Bashar, 2008; NBR, 2008). The Islamic finance system has its own peculiar merits, which are often lacking in the non-Islamic financial system. For instance, under the Islamic system, profit-sharing channels invest in projects with the highest expected profitability, as opposed to the interest-based system where funds go to the most creditworthy borrowers whose projects may not necessarily be the most profitable ones. This results in the allocation of goods and services that serve society's collective interests in the best possible manner. Profit-sharing also contributes more to economic growth because it increases the supply of risk capital for investment and provides better incentives for undertaking such risks due to expected profitability. Thus the Islamic system promotes an 'integrated' economic development, as it encourages the use of money for facilitating trade in goods and investment in a productive capacity, rather than creating money for the sake of money. This structure is likely to be more stable and less prone to financial collapse, which can be caused by speculative activities (Khan \& Bashar, 2008).

\subsubsection{Categories of Islamic Financial Products}

The reason for the existence of a financial system is to transfer funds from savings surplus units (SSU) to savings-deficit units (SDU) in the economy, which assists intermediation between savers and investors. This process involves the use of financial products and services that is created and provided by financial institutions (Obaidullah, 2005). Most of the service marketing literature endeavours to classify services using different criteria, such as how a service may be tailored to the customer or how the service is differentiated (Kasper, van Helsdingen, \& Gabbott, 2006). While attempting to categorise services, it becomes clear that financial services vary extremely. Financial services can be classified based on the nature of the service and to whom it is being supplied (Doyle, 2002). The issues that combine financial services is that they are often difficult to evaluate; they are offered through a range of delivery systems; there is opportunity for co-production and they are generally acquired as a means of achieving an end (Farquhar \& Meidan, 2010). Obaidullah (2005) has described various IFPs. These IFPs can be classified into four categories in terms of approaches of financing that satisfy the particular financial need of the customers: deposit products, credit products, capital market products and insurance products (see Figure 2.1). 
Figure 2.1: Categories of Islamic Financial Products

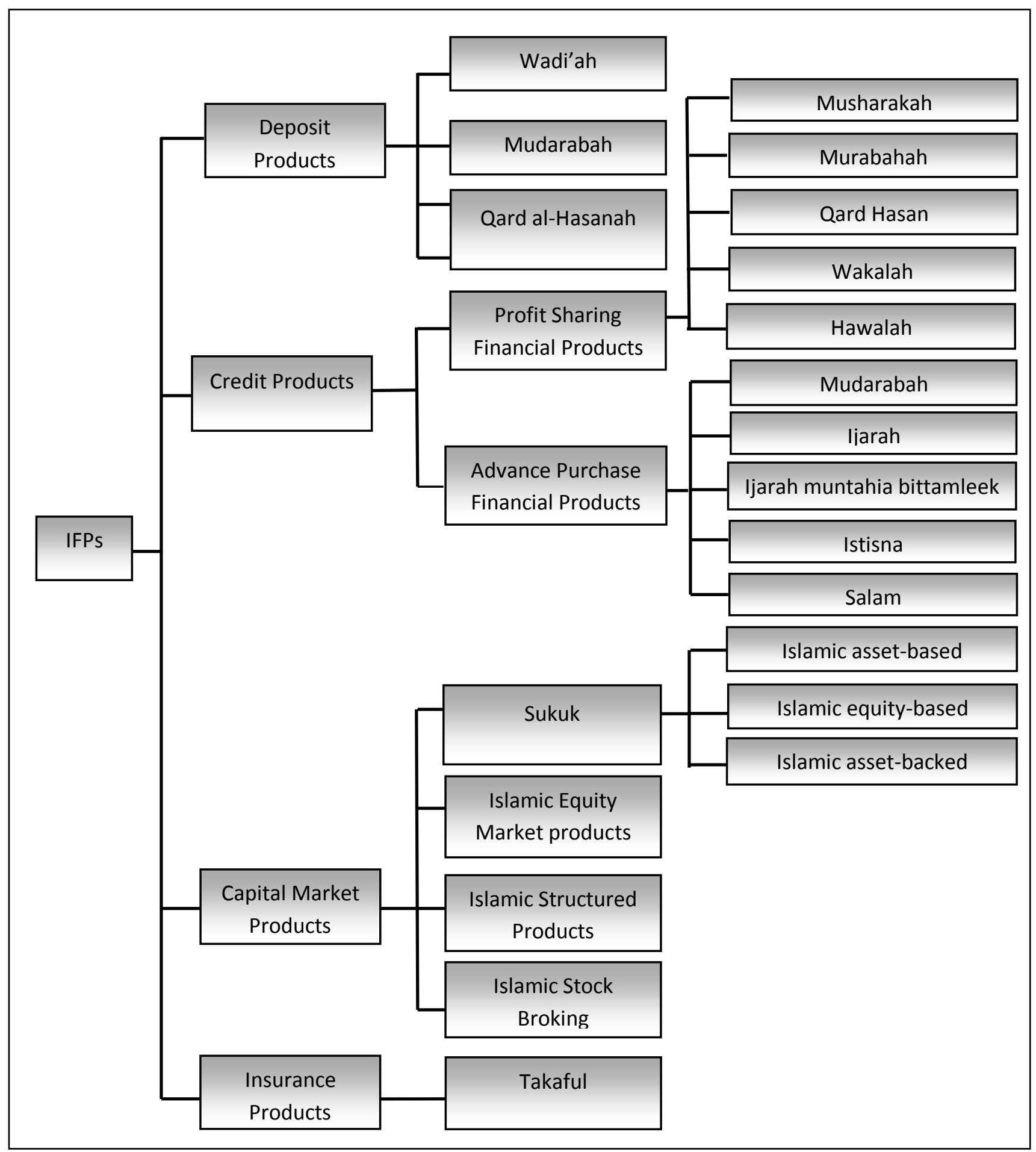




\subsubsection{Deposit Products}

Deposit products satisfy people's need of money during a crisis period, as customers can save money through such products (e.g. current accounts, savings accounts, term deposits and savings bonds). These products are based on revenue-sharing, which is usually calculated expost on a monthly basis. Islamic financial institutions are engaged in mobilising savings from groups of Muslim savers by offering Shariah-compliant products that also vary with respect to other dimensions in return, risk, liquidity, maturity, safety, stability and the like (Obaidullah, 2005). These Islamic deposit products allow no trade-off in the matter of Shariah-compliance.

Wadi'ah - deposits, including current accounts (giro wadi'ah).

Mudarabah - deposit products based on revenue-sharing between depositor and bank, including savings products that can be withdrawn any time and time deposit products. Qard al-Hasanah - unremunerated deposit products, usually for charitable purposes.

\subsubsection{Credit Products}

Credit products satisfy people's borrowing needs and are based on profit-sharing, either at a mutually agreed-upon ratio or at a mutually agreed-upon fixed rate. These products are backed by collateral, as collateral-free lending would normally be considered as containing a speculative element, or moral hazard. People can spend more money than they can earn through credit products (e.g. loans, hire purchase, leasing and mortgages). In this category IFPs can be categorised as 1) profit sharing financial products and 2) advance purchase financial products.

\section{(i) Profit sharing financial products}

Profits sharing products may include active partnership (Musharakah) or passive partnership (Mudaraba). In the case of Musharakah, capital is provided by the bank in return for a share in the realised profit (or the loss if a loss occurred). In diminishing musharaka, the bank is entitled to receive, in addition to its share in realised profits, an extra payment that is specifically assigned for the purpose of reducing its share in the company's capital until this is fully paid off by the partner. Mudarabah, on the other hand, is a contract between two parties; a capital-owner 
(who contributes capital) and an investment manager (who provides entrepreneurship). Profit is shared between parties on a pre-agreed ratio at the time of contract. These two modes provide an alternative banking system and, if implemented on a national level, are likely to result in much fairer distribution of wealth in society with a far reaching effect on the economy (Kahf \& Khan, 1993).

Other forms of credit products include Qard Hasan, Wakalah and Hawalah. Qard Hasan is a charitable loan free of interest and profit-sharing margins. The loan is repaid in instalments and a modest service charge is permissible. In the case of Wakalah, a bank is authorised to conduct business on behalf of customers. Hawalah, on the other hand, is an agreement by the bank to undertake some of the liabilities of the customer in return for a service fee. The customer pays back the bank when the liabilities mature (Obaidullah, 2005).

\section{(ii) Advance purchase financial products}

Advance purchase financial products include Murabahah, Ijara, Ijarah muntahia bittamleek, Istisna, and Salam. Murabahah is a spot sale contract where the client (the bank's customer) orders the purchase of a certain commodity that is available either in the domestic or the foreign market at a specified cash price, which includes a profit margin (mark-up) in favour of the bank. If the customer's creditability is satisfactory, the bank buys the commodity. The bank accepts payment for the commodity in instalments, which usually stretch over one year or more. When a Murabahah purchase is made by means of importation from foreign markets, letters of credit and foreign conventional banks are involved, and necessary Shariah precautions are taken to avoid payment of interest at any step (Gait \& Worthington, 2008; Gait \& Worthington, 2009a).

Ijarah is an Islamic alternative to leasing. Literally, Ijarah means to give something on rent. Therefore Ijarah is a leasing contract under which a bank buys and leases out equipment required by its clients for a rental fee. The bank (lessor) and the client (lessee) mutually agree on the leasing period, and terms of payment. Risk and rewards of ownership lie with the bank i.e. any loss to the asset beyond the control of the client (lessee) should be borne by the bank (lessor). Maintenance and insurance of the leased asset are the bank's responsibility, whereas the lessee has to bear the 
running costs as well as any repair costs in the case of misuse (Gait \& Worthington, 2007).

Ijarah muntahia bittamleek can be understood as a lease ending with ownership. It is a financing contract that implies a promise on the part of one party (the bank) to gift or to sell the leased asset at a nominal price at the end of the lease term to the client (lessee). As Shariah law does not allow for the combination of leasing and ownership in one single contract, this second transfer of ownership contract should be signed only after the termination of the lease term as promised by the bank (lessor).

Istisna is a manufacturing contract in which a party orders another to manufacture and provide a commodity; the description of which, delivery date, price and payment date are all set in the contract. For example, a household that wishes to build a house, or a firm that needs to construct a building, or to manufacture equipment with particular specifications, would approach the bank for this purpose. After assessing the economic viability of the operation and the creditability of the customer, an istisna contract is signed between the two parties. As this type of contract is of a binding nature, the customer submits a down payment and undertakes to pay the remaining part of the manufacturing price, as mutually agreed with the bank, in instalments over a given period of time. The Islamic bank would then sign a parallel istisna contract whereby it extends finance to a firm that agrees to manufacture the requested object according to specification and to deliver it at an agreed future date. Islamic banks in the Arab Gulf countries have used this type of contract successfully to finance big operations, particularly in the construction sector and infrequently in the industrial sector (Ahmad, 2010).

Salam is a contract to sell a prescribe commodity where the price is paid in advance at the time of contracting against delivery of the purchased goods or services at a specified future date. Salam is permissible in Shariah to meet the instant cash needs of a seller who undertakes the future delivery of the commodity. Thus, banking finance is extended to firms or individuals against their commitment to deliver commodities at future dates. To hedge the salam operation, banks also practice parallel salam. This involves making counter deals with other parties, whereby they obtain immediate cash payments against a commitment to deliver commodities of similar quantity and quality to those in the salam contracts at some future date. Islamic banks in Pakistan, 
Sudan, and in some Arab Gulf countries have practiced salam transactions (Ahmad, 2010).

\subsubsection{Capital Market Products}

Capital market products satisfy customers' investments needs with the expectation of earning a favourable return. These products are based on the same principles as credit products. The long-term funds are raised through capital market products, which are conducted by both financial institutions and governments (e.g. shares, securities, bonds, treasury etc.). Haider and Azhar (2010) have categorized Islamic capital market products as below:

\section{(i) Sukuk market products}

Sukuk are the most important and most prominent elements of the Islamic capital market. In Sukuk markets, financing is backed up by assets, equity, and asset-based securities. In Islamic economics, financing is based on the specific asset. In Islamic finance, money is considered to be just a medium of exchange or a mechanism to complete the transaction, while in non-Islamic finance this is not always the case and, most of the time, financing is currency-based. Equity-based financing in the Islamic model is based on the sharing of business risks, as well as rewards from the bank and its client. Both parties contribute to the basic ingredients of a business venture, such as capital, management, know-how, labour, and other related professional attributes. Profits are distributed based on an agreed profit distribution ratio, while losses are pro-rated to each party's capital participation. Equity financing is cemented by entering in either one of two contracts, namely a partnership contract and a trust financing contract. Shariah-compliant asset-backed securitisation (ABS) delivers a risk-return profile similar to a conventional structure. However, conventional securitisation was developed in non-Islamic economies and invariably involves interest-bearing debt.

(ii) Other capital market products.

Other Islamic capital market products include equity market products, structured products and stock broking. Islamic equity market operates on the basis of equity participation by the investor. It includes Islamic products such as Shariah-compliant 
stocks, Islamic unit trusts, Islamic REITs (real estate investment trusts) and Islamic index. Islamic structured investment products are customised products according to the needs of the specific investor, who can be a wealthy individual or group of investors. The risks and rewards of these products are designed to meet a specific objective. Generally, two types of Islamic structured products are used in an Islamic capital market: dual currency structured investment and equity-linked structured investment. In an Islamic capital market, stock broking is done according to Shariah principals. This part of an Islamic capital market deals with Shariah-compliant trading and Shariah-compliant margin financing.

\subsubsection{Insurance Products}

Insurance products allow individuals, businesses and other entities to protect themselves against significant potential losses and financial hardship. People who want to protect themselves or someone else against financial hardship consider insurance products (e.g. general and life insurance) (Gait \& Worthington, 2009a; Imady \& Seibel, 2006). Many insurance companies have been established to offer Muslim individuals and businesses insurance coverage. Islamic insurance is the mechanism through which the participants donate part or all of their contributions, which are used to pay claims for damages suffered by some of the participants (Mayasami \& Kwon, 1999). One key Islamic insurance product is:

Takaful - Islamic insurance with joint risk-sharing. Muslim jurists have agreed that Takaful schemes are accepted by Islamic Shariah because they encompass the elements of shared responsibility, joint indemnity, common interest and solidarity (Billah \& Patel, 2003).

\subsection{Global Market for Islamic Financial Products}

IFPs have been directly competing with CFPs in most of the Muslim countries. Islamic finance has established itself as an alternative method of investment (Ali, 2008). It is considered to be ethical finance i.e. not investing in unethical practices and industries (Maurer, 2001; Wilson, 1997). Significant developments have occurred in Islamic finance during the last 50 years (see Figure 2.2). 
Figure 2.2: Significant Developments in Islamic Finance

\begin{tabular}{|l|l|l|l|l|}
\hline \multicolumn{1}{|c|}{ Prior to 1970s $\rightarrow$} & \multicolumn{1}{|c|}{$1970 \mathrm{~s} \rightarrow$} & \multicolumn{1}{c|}{$1980 \mathrm{~s} \rightarrow$} & \multicolumn{1}{c|}{$1990 \mathrm{~s} \rightarrow$} & \multicolumn{1}{c|}{ Contemporary $\rightarrow$} \\
\hline $\begin{array}{l}\text { Primarily retail } \\
\text { banking }\end{array}$ & $\begin{array}{l}\text { Commercial } \\
\text { banking }\end{array}$ & $\begin{array}{l}\text { Property finance } \\
\text { and syndication }\end{array}$ & Equity funds & $\begin{array}{l}\text { Advanced treasury } \\
\text { services }\end{array}$ \\
& & $\begin{array}{l}\text { Islamic } \\
\text { insurance } \\
\text { (Takaful })\end{array}$ & $\begin{array}{l}\text { Leasing } \\
\text { Salamic } \\
\text { securitisation }\end{array}$ & $\begin{array}{l}\text { Innovative asset } \\
\text { management }\end{array}$ \\
\hline
\end{tabular}

Source: (IFSB, IDB, \& IRTI, 2010)

IFPs have evolved from a 'fringe industry' in the 1960s that provided for the specific banking requirements of the Muslim community, to a global industry incorporating banking, insurance and capital markets. The first Islamic finance applications and practices were offered in Egypt and Malaysia during the 1960s. Operational mechanisms for institutions offering Islamic financial services (IFS) were proposed during the ensuing years, and a number of books were published on Islamic banking. Islamic banks appeared during the 1970s, with the formation of Dubai Islamic Bank and the Islamic Development Bank (IDB). In addition, religious objections to conventional insurance became prominent, laying the groundwork for an alternative structure in 1975. The first takaful company started its operation in 1979. During the 1980s, more Islamic banks and academic institutions developed in a number of countries, and Islamic mutual funds and other non-banking financial institutions emerged towards the middle of the 1980s. In the 1990s, the Accounting and Auditing Organization for Islamic Financial Institutions (AAOIFI) was established and its first standards were issued. The advancement of Islamic banking products increased and reputable international conventional banks started operating Islamic windows. At the same time, the Dow Jones and Financial Times Islamic indexes were introduced. Systemic concerns, regulations, supervision and risk management issues together provided momentum for Islamic financial services. Commercial event organisers promoted Islamic banking and financial activities as a source of attractive business. As alternatives to conventional bonds, sovereign and corporate Sukuk have emerged and have increased rapidly in volume since 2000. International Islamic financial infrastructure institutions, as well as other commercial support institutions and the Liquidity Management Centre (LMC) have been established. The 
systemic importance of Islamic banks and financial institutions has been recognised by several national authorities (IFSB, et al., 2010).

\subsubsection{Growth Trends}

The rapid growth of Islamic finance indicates that the industry has increased threefold during the past five years. The total global assets of Islamic finance was US\$531 billion at the end of 2006 , whereas it was estimated to be US $\$ 700$ billion at the end of 2007 , with a combined revenue of US\$53 billion and profits totalling US\$15 billion, and was expected to more than double to US\$32 billion over the following five years (IFSB, et al., 2010; Novethic, 2008; OliverWyman., 2009). The total assets of Islamic finance increased from $\$ 531$ billion to $\$ 1,289$ billion (see Figure 2.3) with a compound annual growth rate of $19 \%$ between 2006 and 2011 (UKIFS, 2012). The rapid growth of Islamic finance indicates its ability to meet the changing pattern of demand by consumers and businesses, its competitiveness and its survival in the more challenging market. This trend has encouraged conventional financial institutions from developed economies to involve themselves in the Islamic financial market.

\section{Figure 2.3: Industry Growth over the Years}

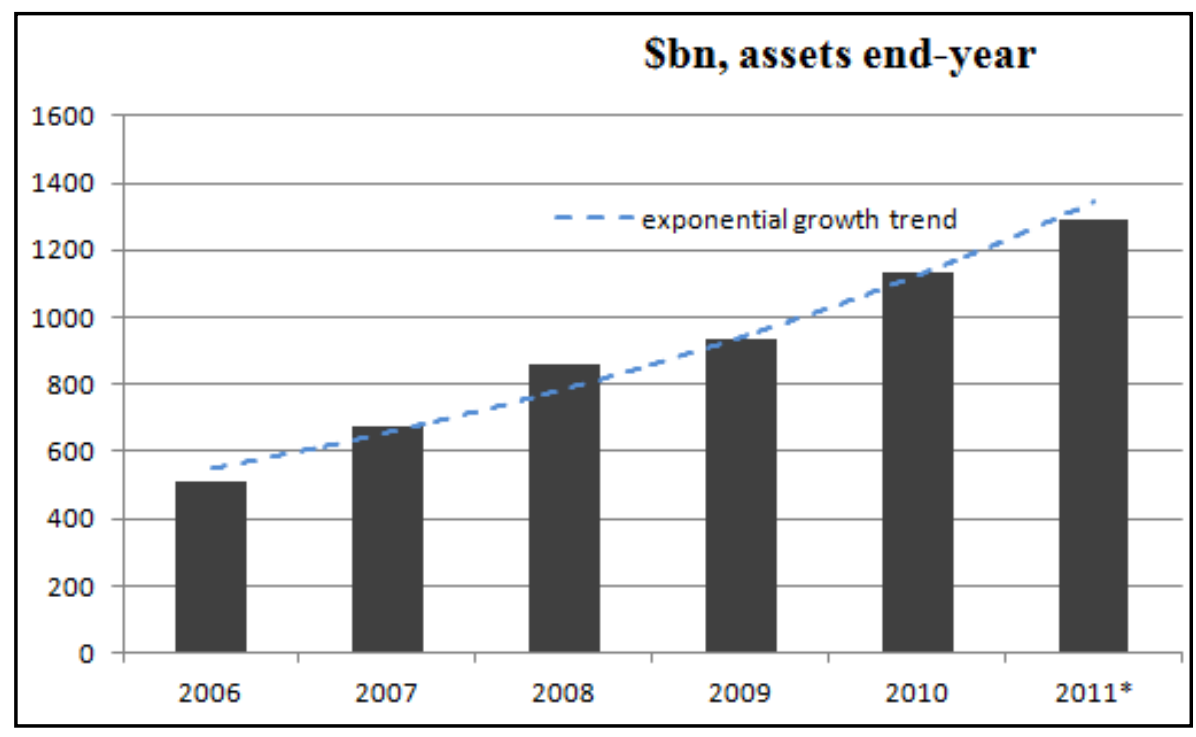

Source: UKIFS (2012)

The main reasons for the industry growth include: firstly, the strong demand from a large number of immigrant and non-immigrant Muslims for Shariah-compliant financial services and transactions; secondly, increasing oil wealth, with demand for suitable investments 
soaring in the Gulf region; and thirdly, the competitiveness of many of the products, attracting Muslim and non-Muslim investors (El-Qorchi, 2005). Moreover, a large number of key financial institutions worldwide have redesigned their conventional products as Shariahcompliant products in recognition of the growing importance of Islamic finance. The global financial crisis also sparked increased interest in Islamic finance as a form of financial intermediation that can perhaps promote financial stability. Islamic finance is viewed as fundamentally stable, since it avoids interest and interest-based assets, focuses on equity as opposed to debt, and restricts speculation. Islamic finance is also receiving increasing attention worldwide because of the role that conventional financial institutions played during the global financial crisis (Nasr, 2011).

\subsubsection{Industry Composition}

The Islamic financial services industry comprises an increasingly diverse range of institutions, including commercial and investment banks, mutual insurance (Takaful) and investment companies. Banks, however, remain the core of the financial services industry in many countries; and also offshore financial centres, since they are accountable to the bank for financial transactions and their soundness are of key concern for systematic liability (Sundararajan \& Errico, 2002). The assets of Islamic finance comprise these Islamic banks, Islamic investment firms, Sukuk issues, funds and Takaful institutions (Figure 2.4).

\section{Figure 2.4: Global Assets of Islamic Finance}

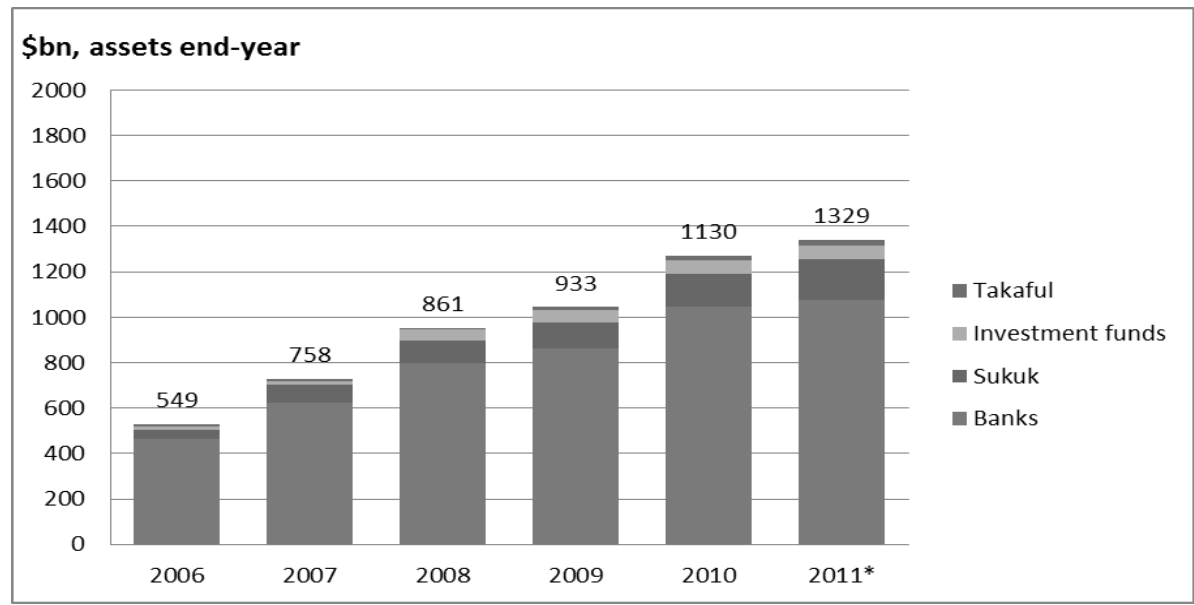

* UKIFS estimate

Source: The UK Islamic Finance Secretariat (UKIFS, 2012) 
Islamic banking assets represent a predominantly larger share, at $81 \%$, in the overall size of the global Islamic finance industry. On the other hand, Sukuk issues account for $13.4 \%$. As far as Islamic investment activity is concerned, it is observed that Islamic investment firm assets represent $4.5 \%$ of the industry's assets and the Takaful sector captures $1.1 \%$ of total Islamic finance assets. Total Islamic banking assets were US\$463 billion at the end of 2006 and US $\$ 660$ billion at the end of 2007, which indicates strong growth. Assets held by fully Shariah-compliant banks, including Islamic banking windows in conventional banks, rose by $21.4 \%$ to US\$1048 billion, from US\$863 billion in 2010 (The Banker, 2009). Islamic securities, or the Sukuk market, grew from US\$6 billion to US\$24 billion between 2004 and 2007, but registered a decline of about $30 \%$ in 2008 due to the uncertainty in global capital markets (Tayyebi, 2009). However, the sukuk market rebounded in the second half of 2009 and its potential is evident from the active participation of global players such as international investment banks, Islamic banks and securities firms that have participated in the issuance of sukuk. The total assets of Islamic funds were estimated at US\$58 billion in 2010, which rose by $7.4 \%$ from US\$54 billion in 2009. Takaful assets have increased from US\$13 billion in 2009 to over US\$21 billion in 2010. Takaful continues to record rapid growth in new and existing markets globally (IFSB, et al., 2010).

\subsubsection{Geographical Mandates}

Islamic financial operations are mainly concentrated in the Middle East and Southeast Asia, but are also appearing in Europe and the United States (El-Qorchi, 2005). The geographic mandates of IFPs are shown in Table 2.1. With 6\% of the global Muslim population, the Gulf Cooperation Council (GCC) region accounts for a $40 \%$ share of the US\$1.1 trillion global Islamic finance industry, with the majority of the growth in absolute terms. The growth of Islamic finance in the late 1970s concurred in the GCC with the two oil shocks of that decade, which created a huge amount of wealth (Hamzeh, 2009). In recent years, the development of the financial sector in the GCC has been unprecedented, with the growth of financial centres that have attracted global financial institutions (Ahmedji, 2011). The Middle East and North Africa (MENA) region is home to the majority of global Islamic finance assets, with a total share of $39 \%$ in 2011, comprising 22\% of the global Muslim population. Strong regulatory and political support promotes the growth of Islamic finance in the MENA region even more than demand by the society for Islamic finance (Ali, 2011). A range of Islamic financial products that was powered by the twin drivers of the resident Muslim 
populations in the region has been developed in Asia. Also banks in Southeast Asia are being pushed to offer an increasingly wide range of financial products, due to the arrival of Middle Eastern businesses (Venardos, 2006). Although the majority of Muslim people (41\% of the global Muslim population) live in Asia, the industry is represented inadequately with a relatively small share of $15 \%$, which in turn suggests a great potential for massive growth in the region. Conversely, Australia, Europe and America hold a collective share of 5\% in the global Islamic finance market as a large non-Muslim region. Consisting of $26 \%$ of the world's Muslim population, the Sub-Saharan African (SSA) countries, with $1 \%$ of global Islamic financial assets, face large funding gaps, particularly in the area of infrastructure, and are not getting the opportunity to tap into the Islamic finance market, which is expanding as a new source of funding for large infrastructure development projects (OIC, 2012).

Table 2.1: Breakdown of Islamic Assets by Institution and Region (2011*)

\begin{tabular}{|l|l|l|l|l|l|l|l|l|}
\hline Region & $\begin{array}{l}\text { Banking } \\
\text { Assets } \\
\text { USD } \\
\text { billion) }\end{array}$ & $\begin{array}{l}\text { Sukuk } \\
\text { Outstanding } \\
\text { (USD billion) }\end{array}$ & $\begin{array}{l}\text { Islamic } \\
\text { Fund } \\
\text { Assets } \\
\text { (USD } \\
\text { billion) }\end{array}$ & $\begin{array}{l}\text { Takaful } \\
\text { Assets } \\
\text { (USD } \\
\text { billion) }\end{array}$ & $\begin{array}{l}\text { Total } \\
\text { Islamic } \\
\text { Finance } \\
\text { Assets } \\
\text { (USD } \\
\text { billion) }\end{array}$ & $\begin{array}{l}\text { Market } \\
\text { Share }\end{array}$ & Population & $\begin{array}{l}\text { GDP } \\
\text { at PPP } \\
\text { USD }\end{array}$ \\
\hline Asia & 144.8 & 120.8 & 16.2 & 2.4 & 284.2 & $15 \%$ & $41 \%$ & 3,731 \\
\hline GCC & 411.1 & 55.6 & 2.1 & 6.4 & 500.3 & $40 \%$ & $6 \%$ & 10,944 \\
\hline $\begin{array}{l}\text { Mena (exc. } \\
\text { GCC) }\end{array}$ & 462.6 & .1 & .5 & 6.0 & 469.2 & $39 \%$ & $22 \%$ & \\
\hline $\begin{array}{l}\text { Sub- } \\
\text { Saharan } \\
\text { Africa }\end{array}$ & 14.5 & .2 & 1.5 & .4 & 16.6 & $1 \%$ & $26 \%$ & 2,075 \\
\hline Others & 42.9 & 1.5 & 14.6 & 0.0 & 59.1 & $5 \%$ & $5 \%$ & 6,528 \\
\hline Total & 1075.9 & 178.2 & 60 & 15.2 & 1329.3 & $100 \%$ & $100 \%$ & \\
\hline
\end{tabular}

Notes: Figures may not add up to the totals, due to rounding effect; others include Europe and North America, GCC: Qatar, Bahrain, Kuwait, UAE, Saudi Arabia, and Oman Source: Global Islamic Finance Forum (GIFF, 2012); (IDB, 2012)

It is clear from Table 2.1 that, at US\$462.6 billion, the MENA region has the highest number of Islamic banking assets, as the majority of Islamic banks are in the MENA region and are part of a private sector that exists along with the conventional financial institutions. Conversely, Asia captures a majority share of Sukuk and Islamic investment fund assets, at US $\$ 120.8$ billion and US $\$ 16.2$ billion respectively. This region is the most developed market 
for Sukuk in both primary and secondary markets, whilst Islamic funds are also performing very well in Asia and are set to grow further with the implementation of the various Shariahcompliant fund schemes that have been initiated (GIFF, 2012). The largest market of Takaful is GCC, with assets of US\$6.4 billion, whereas Asia remains the second largest region, with total Takaful assets of US\$6 billion. The industry has now achieved significant market share versus conventional insurance in most GCC countries, as well as South East Asian markets. There are a number of factors behind this growth, but the main reason that is becoming gradually important is regulatory support through proper changes in legislature to arrange for a level playing field with conventional insurance companies (Ernst \& Young, 2012).

Financial institutions have fully adopted Islamic banking in the Islamic Republic of Iran and Sudan. The development of full transformation of the financial system to become compliant with Islamic principles is also underway in Pakistan. Islamic financing operates along with conventional financing in some other countries, such as Malaysia, Indonesia, Bangladesh, Jordan, and Egypt through the opening of Islamic 'windows' in conventional institutions or by the establishment of separate banks, or branches and subsidiaries that specialise in Islamic financial products and services (Khan \& Bhatti, 2008; Sundararajan \& Errico, 2002).

At the country level, Table 2.2 indicates that Iran, in the MENA region, accounts for $35.7 \%$ in total Islamic financial assets. In the GCC region, Saudi Arabia accounts for $13.9 \%$, the United Arab Emirates (UAE) 8.7\%, Kuwait 7.3\%, Bahrain 5.3\%, and Qatar $4.8 \%$ of total Islamic financial assets. Additionally, Malaysia in Asia captures a share of $12.3 \%$. Islamic financial institutions operating in these countries are likely to foster the future growth of the industry and its expansion and development to new markets. The Islamic finance industry is developing very rapidly in other parts of the Middle East such as Turkey, Sudan, Egypt, Jordan and Syria. Nigeria is increasing its efforts to capitalise on the Islamic finance industry in the SSA region. With a combined largest indigenous Muslim population in Asia, Indonesia and Bangladesh each represent approximately $1 \%$ of the global Islamic finance industry. 
Table 2.2: Countries by Largest Shariah-compliant Assets, US\$ Billion, 2011

\begin{tabular}{|c|c|c|c|c|c|c|c|c|}
\hline Country & Total & Bank & Takaful & Funds & Others & $\begin{array}{c}\text { Market } \\
\text { share }(\%)\end{array}$ & $\begin{array}{c}\text { Muslim } \\
\text { population } \\
\text { (in millions) }\end{array}$ & $\begin{array}{c}\text { GDP per capita } \\
\text { PPP(current } \\
\text { intl. \$) }\end{array}$ \\
\hline Iran & 388 & 383.5 & .42 & .3 & --- & $35.7 \%$ & 75 & 11,508 \\
\hline S. Arabia & 151 & 147.8 & .32 & --- & 0.0 & $13.9 \%$ & 25 & 24,268 \\
\hline Malaysia & 133.4 & 120.4 & 9.9 & --- & 3.2 & $12.3 \%$ & 17 & 16,051 \\
\hline UAE & 94.1 & 92.5 & 1.5 & 0.0 & .1 & $8.7 \%$ & 5.18 & 47,893 \\
\hline Kuwait & 79.7 & 68.9 & .1 & 10.6 & 0.0 & $7.3 \%$ & 2.21 & 54,283 \\
\hline Bahrain & 57.9 & 56.2 & .4 & 1.3 & --- & $5.3 \%$ & .97 & 23,645 \\
\hline Qatar & 52.3 & 50.0 & .5 & 1.8 & .1 & $4.8 \%$ & 1.58 & 88,314 \\
\hline Turkey & 28.0 & 28.0 & --- & --- & --- & $2.6 \%$ & 75 & 17,110 \\
\hline UK & 19.0 & 19.0 & --- & --- & --- & $1.7 \%$ & 1.7 & 35,657 \\
\hline Sudan & 12.1 & 12.1 & --- & --- & --- & $1.1 \%$ & 31 & 2,325 \\
\hline Bangladesh & 11.7 & 11.4 & .3 & .1 & --- & $1.1 \%$ & 149 & 1,777 \\
\hline Indonesia & 10.5 & 10.0 & .5 & --- & --- & $1 \%$ & 205 & 4,636 \\
\hline Syria & 8.7 & 8.7 & --- & --- & --- & $.8 \%$ & 21 & 5,252 \\
\hline Egypt & 7.9 & 7.9 & --- & --- & --- & $.7 \%$ & 80 & 6,281 \\
\hline Switzerland & 6.6 & 6.6 & --- & --- & --- & $.6 \%$ & .34 & 51,262 \\
\hline Jordan & 5.9 & 5.7 & .1 & .1 & --- & $.5 \%$ & 5.96 & 5,966 \\
\hline Pakistan & 5.7 & 5.6 & --- & --- & .1 & $.5 \%$ & 178 & 2,745 \\
\hline Brunei & 3.8 & 3.8 & --- & --- & --- & $.3 \%$ & .26 & 51,760 \\
\hline $\begin{array}{l}\text { Other } \\
\text { Countries }\end{array}$ & 10.3 & 9.8 & .4 & .1 & 0.0 & $1.1 \%$ & --- & --- \\
\hline Total & 1086.5 & 1047.7 & 20.9 & 14.3 & 3.5 & $100 \%$ & --- & --- \\
\hline
\end{tabular}

*Includes only those firms submitting data to The Banker's survey

Source: UKIFS, 20012; OIC Outlook Series, 2012; World Bank Database, 2012

Table 2.2 indicates that Islamic banking assets have a predominantly higher share of the overall industry in almost all countries where Islamic financial services are available. In contrast, Takaful has a comparatively significant presence in countries such as Iran, Malaysia, Saudi Arabia and the UAE. On the other hand, in terms of Islamic investment activity, Islamic investment firm assets represent an important portion of the industry's assets in Kuwait (OIC, 2012). In 2011, the overall volume of Islamic finance assets was recorded at $\$ 388$ billion in Iran, followed by Saudi Arabia ( $\$ 151$ billion), Malaysia ( $\$ 133$ billion), UAE ( $\$ 94$ billion), Kuwait ( $\$ 80$ billion), Bahrain ( $\$ 58$ billion), Qatar ( $\$ 52$ billion), Turkey (\$28 billion), UK ( $\$ 19$ billion), Sudan ( $\$ 12$ billion) and Bangladesh ( $\$ 11.7$ billion).

\subsubsection{Islamic Finance Scenario in Bangladesh}

Bangladesh is the sleeping giant of the Islamic finance world, with three times the population of the Gulf region. A growing urban middle class, a dynamic microfinance sector, and strong 
support from regulators provide Islamic finance with a significant prospect of success in this country (Ethica, 2012). The global banking giants target Bangladesh as one of the potential markets for its Islamic financial products and services (Saha, 2012). At present, out of 47 banks, seven private commercial banks are operating as fully-fledged Islamic banks. In addition, 16 conventional banks are engaged in Islamic banking, according to the Bangladesh Bank's annual report for 2010-11. Bangladesh ranks $11^{\text {th }}$ among the top countries by largest Shariah-compliant assets.

Islamic banks in Bangladesh have performed better in the areas of loan recovery and various other financial measures, compared with the conventional banks (Ahmad \& Hassan, 2007; Ahmed, Rahman, \& Ahmed, 2006; Khan, Hassan, \& Shahid, 2007). Following such recognition of Islamic banks in Bangladesh, numbers of private commercial and international banks have launched various Islamic financial products/services for Bangladeshi customers (Hassan, 1999; Khan, et al., 2007).

The total net asset value of the seven full Islamic banks was US $\$ 11.67$ billion, around $16 \%$ of the industry, in June 2011. Whereas the conventional banks are currently suffering from a liquidity crisis, the surplus funds of the total Islamic banks of Bangladesh amount to about US\$0.65 billion (Shamsuzzaman, 2012). It is worth noting that the major part of the operational financial resources of Islamic banks in Bangladesh is derived from deposit products. Utilisation of funds within the Islamic framework has opened multifarious ways for making loans conforming to Shariah principles. Since Shariah-compliant banks cannot use interest-based lending, they have devised different types of interest-free financing modes based on profit-and-loss sharing (PLS) (NewHorizon, 2009). In 2011, Islamic banks disbursed the highest volume in soft loans to increase small investment in rural areas and reduce large investment in urban areas, with the aim of minimising a concentration of resources. Moreover, Islamic banks disbursed about 32\% to small and medium entrepreneurs within the SME sector alone (Shamsuzzaman, 2012). Financial resource mobilisation through the issue of Islamic bonds (Sukuk) is still at a growing stage. Only Bangladesh Central Bank is issuing Sukuk in Bangladesh and there are no other financial institutions to issue either bonds or any other financial instruments, such as debentures or mutual funds, in the primary or secondary markets (NewHorizon, 2009). The total net asset worth of the Islamic fund was US\$.1 billion in 2011 (UKIFS, 2012). The first takaful company in Bangladesh commenced in 2000 and the industry has grown. As with banking, the lack of takaful legislation has not 
provided too many obstacles for the formation of more Takaful companies. There are now six fully-fledged Takaful operators and 13 have windows in 62 insurance companies operating in Bangladesh (GIFR, 2011). As of 2010, total assets for takaful institutions were $\$ 0.3$ billion, which constituted 7\% of the total assets of the insurance sector (GIFR, 2011; UKIFS, 2012).

There is much potential in the Bangladeshi Islamic finance market, with a growing middle class sector and increased foreign participation in the investment arena. Therefore, a business environment scenario is required to explore this further. Based on a PEST analysis framework, the next section will summarise the business environment of Bangladesh. PEST stands for political, economic, sociological and technological environment, which influences the overall environment of a country. These factors will help to review a country's current environment and will provide knowledge to the policy makers and practitioners. This analysis will also assist Islamic issuers, investors, corporate and financial institutions to explore the opportunities within the country (Peng \& Nunes, 2007; Ward, 2005).

\subsection{Country Overview: Bangladesh}

Bangladesh is a South Asian country situated between India and Myanmar, with an area of 143,998 sq. km and a total population of 161 million as at 2012 (World Factbook, 2013). It is one of the most densely populated lands in the world, having more than 1142.29 persons per square kilometre (World Bank, 2012). Bangladesh is the world's third largest Muslim majority country, with Muslims making up more than 85 percent of the population (Mamun, 2011), behind Indonesia and Pakistan (UKIFS, 2012).

\subsubsection{Political History and Structures}

In the sixteenth century, Europeans began setting up trading placements in Bangladesh. The British came to rule the region and by the end of the century it had become part of British India. In 1947, both West Pakistan and East Bengal (Muslim majority) separated from India (largely Hindu) and together became the new country of Pakistan. East Bengal was named East Pakistan in 1955; however, the awkward arrangement of a two-part country with its territorial units separated by $1,600 \mathrm{~km}$ left the Bengalis marginalised and deprived (World Factbook, 2013). 
East Pakistan became independent from West Pakistan in 1971 and was born as a new country, Bangladesh. The Bangladesh Government positioned itself as one of the only democratically elected Muslim countries in the world and was governed by a multi-party parliamentary system. The first transition of Bangladesh towards a democratic state was short-lived. Bangladesh was under military rule during most of the period before 1991, apart from a short-lived period of democracy between 1979 and 1981 (Middlehurst \& Woodfield, 2004). In 1991, the military dictatorship was ended and a parliamentary form of government was restored (Mahiuddin, 2009).

\subsubsection{Economy of Bangladesh}

\subsubsection{Economic Reforms}

Bangladesh maintained a socialist economy by nationalising all industries after its independence, but growth in producing experienced entrepreneurs, managers, administrators, engineers, and technicians was slow (Moniruzzaman, 2012). Beginning in late 1975, Bangladeshi leaders began to turn their attention to developing new industrial capacity and regenerating the economy. Simultaneously, the government gradually began providing greater opportunity for the private sectors to participate in the economy (Lesser, 1988). As a result, many state-owned enterprises such as banking, telecommunications, aviation, media, and jute were privatised (BSCAA, 2013). But the ineffectiveness of the public sector, including infrastructure, caused a slowing down in economic growth. In the mid-1980s, the economic policies intended to encourage private enterprise and investment, privatise public industries, reinstate budgetary discipline, and liberalise the import regime were accelerated, and were positive indicators of development (Lesser, 1988). The government effectively implemented an enhanced structural adjustment facility (ESAF) with the International Monetary Fund (IMF). But it was unsuccessful in following through on restructures, in large part because of a preoccupation with its domestic political dilemmas between 1991 and 1993. There was a sudden drop in foreign direct investment; due to the government's entrenched economic policies in 2001 and 2002 (FDI net inflow was US\$0.078 billion in 2001 and US $\$ 0.052$ billion in 2002). A three-year US $\$ 490$ million project by the Poverty Reduction and Growth Facility (PRGF) was approved by IMF for Bangladesh in June 2003 to support the government's economic reform programme till 2006. Seventy million dollars was made available immediately. Consequently, the World Bank approved interest-free loans of 
US\$536 million and the Indian Government extended a line of credit worth US\$1 billion to counterbalance China's close relationship with Bangladesh in 2010 (BSCAA, 2013; Global Edge, 2012).

Bangladesh experienced a trade deficit, which was financed mainly through aid receipts and foreign remittances from workers overseas, and foreign reserves went down considerably in 2001 due to a higher absolute increase in imports than exports. However, foreign reserves became stable in 2007, supported by increased export earnings and a significant rise in remittance flows. According to the Central Bank of Bangladesh, reserves increased to US $\$ 3.74$ billion in 2007, US\$5.8 billion in 2008, and exceeded US\$10 billion in 2009. As of April 2011, they had exceeded US\$12 billion. Bangladesh has systematically managed to reduce imports and the aid-dependence it has experienced since the beginning of the 1990s (BSCAA, 2013).

\subsubsection{Economic Growth}

Economic growth in Bangladesh is composed of three main sectors: agriculture, industry and service. As a developing country, it has several production sectors that are playing an important role and have a significant impact on GDP. Agriculture's contribution to GDP was $20.29 \%$ for the fiscal year 2009-2010 (see Table 2.3). Industry was the second largest sector in the percentage contribution to GDP, which was $29.93 \%$ for the fiscal year 2009-2010. Service is the largest sector in the percentage contribution to GDP. The contribution to GDP by service organisations in Bangladesh was $49.78 \%$ for the fiscal year 2009-2010 (Bangladesh Economic Review, 2011). Although Bangladesh is an agricultural country and the agriculture sector has contributed greatly to GDP previously, the biggest contributor to GDP at present is the garments sector. Contribution by the agricultural sector to GDP was 48.3\% during 1973-1974 and in 2010-2011 it was estimated at about 19.95\%. In contrast, the industrial sector could not contribute as much as expected because of political instability and inconsistent economic and industrial policies. In 1973-1974 the contribution from the industrial sector was $11.1 \%$, and in 2010-2011 it was estimated to be $30.33 \%$. Meanwhile, there has been a significant increase in the service industry's contribution to national GDP, from $36 \%$ to $49.72 \%$ (Bangladesh Economic Review, 2011; BBS, 2012) . 
Table 2.3: Growth Trend of Main Sectors

\begin{tabular}{|c|c|c|c|}
\hline \multirow{2}{*}{ Year } & \multicolumn{3}{|c|}{ Sector-wise GDP Change in Percentage } \\
\cline { 2 - 4 } & Agriculture & Industry & Service \\
\hline 1990 & 30 & 21 & 48 \\
\hline 1995 & 26.4 & 24.3 & 49.1 \\
\hline 2000 & 25.5 & 25.3 & 49.2 \\
\hline 2005 & 20.1 & 27.2 & 52.6 \\
\hline 2010 & 18.7 & 28.5 & 53.0 \\
\hline 2011 & 18.6 & 28.2 & 53.5 \\
\hline
\end{tabular}

Source: World Bank (http://www.worldbank.org/)

The Gross Domestic Product (GDP) in Bangladesh extended 6.30\% in 2012 from the previous year. Previously, from 1994 to 2012, Bangladesh GDP Annual Growth Rate averaged 5.59\% and reached an all-time highest of 6.70\% in June of 2011 and a recorded low of 4.08\% in June of 1994 (Bangladesh Bank, 2012; Trading Economics, 2012). Table 2.4 shows the annual growth trend for Bangladesh GDP as well as other indicators.

Table 2.4: Bangladesh, selected indicators

\begin{tabular}{|l|l|l|l|l|l|l|l|}
\hline \multirow{2}{*}{ Indicator } & \multicolumn{7}{c|}{ Year } \\
\cline { 2 - 8 } & 1990 & 1995 & 2000 & 2005 & 2010 & 2011 & 2012 \\
\hline Total population (billion) & 0.11 & 0.12 & 0.13 & 0.14 & 0.151 & .152 & .16 \\
\hline Population growth (\%) & 2.48 & 2.09 & 1.85 & 1.40 & 1.12 & 1.1 & 1.2 \\
\hline GDP growth (\% annual) & 5.94 & 4.93 & 5.94 & 5.96 & 6.07 & 7.0 & 6.3 \\
\hline GDP (US\$ billion) & 30 & 38 & 47 & 60 & 100 & 111 & 116 \\
\hline GDP per capita (PPP US\$) & $\ldots$ & 322.9 & 363.6 & 428.8 & 674.9 & 731.9 & 752.2 \\
\hline FDI net inflow (US\$ billion) & 0.00 & 0.00 & 0.28 & 0.81 & 0.92 & 1.13 & 1.17 \\
\hline Foreign Exchange Reserves (US\$ billion) & .88 & 3.07 & 1.307 & 2.930 & 11.013 & 9.634 & 12.03 \\
\hline Balance of Payment (US\$ billion) & .517 & -.877 & -.226 & .365 & 2.108 & -.161 & 2.64 \\
\hline Average FX rate & 35.67 & 40.28 & 52.14 & 64.33 & 69.65 & 74.15 & 81.86 \\
\hline Inflation rate & 6.3 & 7.3 & 1.9 & 5.1 & 6.5 & 7.5 & 8.5 \\
\hline
\end{tabular}

Source: World Bank (Various years), Bangladesh Bank

\subsubsection{Inflation and Exchange Rates}

Subsequent to the independence of Bangladesh in 1972, the exchange rate continued nearly fixed until 1975. From 1972 to 1974 one US dollar cost only 7.8763 taka. During this period, 
inflation remained low and GDP growth remained remarkably high, due to the development policies of the government. Alongside the political change in 1975, the exchange rate changed and the taka was depreciated by $41.04 \%$, which meant one US dollar cost Tk15.054. Inflation could not be brought under control and persisted on average at over 10\% from 1976 to 1980 . The exchange rate policy appeared to begin a new trend with the political change in the early 1980s and the taka systematically depreciated year after year, beginning in 1981 when it fell to $19 \%$ of the US dollar. At the end of the military administration in 1990, one US dollar cost Tk35.6752, which indicates that in the 10 years from 1981 to 1990 the taka depreciated by $50.61 \%$. During this time, inflation increased strongly; on average more than $10.65 \%$ annually with the depreciation of the taka (Islam \& Biswas, 2009).

During the period of civil government from 1992 to 1996, the exchange rate of taka again remained almost fixed, with an annual average inflation rate of $4.24 \%$. After the democratic change in government from 1996 to 2001, the taka depreciated by almost $11 \%$ and the average annual inflation rate was $4.79 \%$ which had a positive impact on GDP growth. The GDP rose during this time, on average 3\% to 5.0\% annually. In 2003, the 'Free Floating Exchange Rate' policy of taka was introduced and the taka began to lose its value of $13 \%$ to the US dollar. Inflation increased and GDP tended to fall with the depreciation of the taka. After the tumultuous fall of the government in 2006, the new policy appeared to be fully effective, although it may have begun before the departure of the civil government. Between 2007 and 2009, inflation appeared to be uncontrollable (Islam \& Biswas, 2009).

In more recent times, the taka depreciated against the US dollar radically between July 2010 and January 2012, with a $23 \%$ fall down from Tk70 to Tk86. The continuous depreciation of the Bangladeshi taka is becoming a significant challenge for the government. The increasing trend of the trade deficit indicates the possibility of a short supply of foreign currency (i.e. US dollars) in the market (Fahmida, 2012).

\subsubsection{Constraints of Bangladesh Economic Development}

The main constraints on Bangladesh's economic growth include low levels of human capital, poor infrastructure, underdeveloped financial markets, low levels of trade, corruption, and cumbersome regulations (Rahman \& Yusuf, 2010). While FDI in Bangladesh has increased in the current decade, it remains small relative to GDP when compared with other similar economies. Furthermore, to benefit from the technological spill overs of FDI, the receiving 
country needs sufficient human capital - an area where Bangladesh lags behind. This would lend further credence to the view that further investment in education (and human capital, more broadly) is needed. Tertiary education and vocational studies have been largely neglected. The IT revolution that has benefited India and to a lesser extent Pakistan, has largely by passed Bangladesh (Rahman \& Yusuf, 2010; World Bank, 2012).

Infrastructure constraints are many, with energy inadequacy and transport inefficiencies being severe constraints to accelerating growth. There has been no increase in the capacity to generate power for several years, mainly due to governance-related problems. Bangladesh's main port, Chittagong, is among the most inefficient and cost-ineffective in the region (CUTS, 2003; World Bank, 2013).

Financial depth (measured as M2/GDP; where M2 is the measure of money supply) is quite low and the range of financial services are quite rudimentary. Many of the important contractual savings institutions are absent; while capital markets are extremely shallow. There is the problem of the 'missing middle' - those people who are covered neither by the micro finance institutions nor the formal banking sector. The public banking sector remains riddled with non-performing loans, despite recent improvements. Trade logistics performance is weak since the current cost of Bangladesh trade facilitation is very high, and this results in a reduction of trade competitiveness (World Bank, 2013).

Many central sides of governance are not strong and Bangladesh has ranked last in corruption ratings by Transparency International for last five years (World Bank, 2013). This reduces a significant price in terms of lost growth prospective. Indeed, to the extent that poor regulations and cumbersome bureaucracy breeds corruption. As such, tackling poor regulatory frameworks would appear to be a sensible priority for the country's policymakers in Bangladesh (Rahman \& Yusuf, 2010).

\subsubsection{Social Development}

The Bangladesh Government puts special emphasis on all major social sectors related to population, health and their development dynamics: gender development and education. Compared with other developing countries, Bangladesh emerges as a spirited fighter moving steadily to improve its status along the many dimensions of social development since 1990 (Ahluwalia \& Hussain, 2004). The improvements in infant and maternal mortality rates, 
immunisation, and female literacy ranked among the best achieved by any large-sized country in such a short period of time (Economist, 2012). Over the past 20 years, Bangladesh has made some of the most significant achievements in the basic conditions of people's lives ever seen anywhere (Choudhury, 2013). Life expectancy increased by 10 years, from 59 to 69 between 1990 and 2010 (Khasru, 2013). Infant mortality has more than halved, from 97 deaths per thousand live births in 1990 to 37 per thousand in 2010. Over the same period, child mortality fell by two-thirds and maternal mortality fell by three-quarters. It now stands at 194 deaths per 100,000 births. Bangladesh has also made massive improvements in education and gender equality (Chowdhury, 2013). In 2005, more than $90 \%$ of girls enrolled in primary school, which is slightly more than boys and twice the female enrolment rate in 2000. Over the years, there has been a remarkable improvement in the status of women in Bangladesh. As the readymade garment (RMG) sector has grown, women have increasingly come to work in the RMG factories and now they represent a large majority of the workforce in the industry. Though the wage rates of women are lower, the money they earn has given them an improved status both in the family and in society. This has facilitated the development of a new social phenomenon and paved the way for the gainful employment of women (UNDP, 2012). These progressions are not simply the result of increases in people's income. Bangladesh remains a poor country, with a GDP per head of $\$ 1,900$ at purchasingpower parity. Since 1990 its GDP has been rising at a more respectable 5\% a year, in real terms. That has helped reduce the percentage of people below the poverty line from $49 \%$ in 2000 to $32 \%$ in 2010 (Economist, 2012).

Bangladesh's per capita income moved up to US\$848 in the current fiscal year 2011-2012, from US $\$ 816$ of previous year, but is still considerably less than the US $\$ 1,006$ needed to pull the country up to the middle-income bracket. According to the government's perspective plan, the country aims to reach the middle income country category by 2021 . The required per capita income at that time would be US\$1,300, meaning a growth rate of $7.5 \%$ to $8 \%$ is needed every fiscal year (World Bank, 2012). Bangladesh managed a growth rate of $6.3 \%$ against a target of $7 \%$ this fiscal year, according to provisional data from the Bangladesh Bureau of Statistics (BBS). The previous year, the growth rate was $6.71 \%$, signifying the country went backwards with respect to its target of graduating to a middle income country status (Byron, 2012). However, continued growth since the 1990s speaks of the strength of the Bangladesh economy. 


\subsubsection{Technological Environment in Bangladesh}

Although Bangladesh has been lagging behind the developed world in the key fields of science and technology, the technological environment in Bangladesh is emerging fast (Mohammad, 2011). Information Communication Technology (ICT) has produced a social transformation in Bangladesh, from a grassroots to central level. ICT in rural areas began with innovative marketing strategies, and the adaptability of Bangladesh's poor to new technology has allayed fears that the poor might not gain access to this technology because of cost (UN, PRB, UNDESA, \& UNDP, 2012). The government is now using cell phones as a medium of information dissemination and advocacy on various national issues, such as vaccination, literacy, right to information etc. The total number of mobile and Public Switched Telephone Network (PSTN) subscribers was only 1.75 million in 2002, whereas it was close to 80 million in 2012. Therefore, the teledensity of the country has exceeded $50 \%$ in 2012, from a previous $1.25 \%$. Cyber cafes have appeared even in rural areas of the country, providing ICT support services for people over the last decade (UN, et al., 2012). In order to develop ICT, the government developed ICT Policy 2002, 2008 and so on (Mahmood, 2010). The government is preparing to arrange for high speed internet connections through fibre optic cables to the vast rural areas across all 64 districts by December 2013.

Bangladesh also needs to invest more in research and development (R\&D) if it wants to do well in a highly competitive global economic environment. However, R\&D has not been mentioned in the budgets of the industrial, science and ICT ministries. The Bangladesh Council of Scientific and Industrial Research (BCSIR), which is mandated to do research and provide scientific and technological solutions to industrial development, spent only Tk4.5 crore on R\&D in the current fiscal year. Exports are growing but scientific innovations are needed to accelerate the growth. Both public and private sectors care about R\&D, which can help increase the competitiveness of a product, boost innovations and diversify exports (Rahman, 2010).

\subsubsection{Generational Cohorts in Bangladesh}

During the second half of the $20^{\text {th }}$ century, several distinct and momentous events occurred in Bangladesh. Successive economic and political events in Bangladesh have evolved through three major phases: the pre-independence period, the post war and clientelistic military 
governance period and the democratic governance period (Khan, 2010). These momentous ideological events have resulted in three distinct generational cohorts among today's Bangladeshi people. This evolution reveals underlying features of the economy and society, which marketers must address in order to identify cohort members' characteristics and cohort differences (see table 2.5), to differentiate between consumers' values and their choice behaviours (Hung, Gu, \& Yim, 2007).

The pre-independence period people are known as the Traditionalist cohort. Members of this cohort are mostly older, mature and traditional in values. Traditionalists who came of age during economic hardship tend to assign more importance to savings, safety and security value (Schewe \& Meredith, 2004). Life experiences have also taught this cohort that life is really not supposed to be fun and conformity is good (Taylor, 2010). The members of this cohort were at a mature age before or around the independence of Bangladesh in 1971, and suffered economic hardship. Almost two thirds of the population was living below the poverty line. People were deprived of basic health care, education, shelter and other needs and were insecure about their lives in general (Khan, 2010).

The second-phase people are known as the Swing Generation, born between 1953 and 1972. The Swing cohort members 'swing' between the younger traditionalists and the older Generation Y in sharing some characteristics with each group (Mitchell, 2003). Economic ups and downs resulted in the members of this cohort being more frugal and adaptive than those in other cohorts (DeVaney \& Chiremba, 2005) and they also varied in terms of assigning importance to different values. The Swing Generation tends to emphasise the value of safety and security, pleasure and enjoyment of life, increased social status and prestige (Inglehart, 1997). The members of this cohort were maturing when Bangladesh's economy was slowly gaining some momentum during the middle of the post-war phase. But at the beginning of the post-war and clientelistic governance phase, and due to being in a newly independent country, the Swing cohort experienced a high level of unemployment and poverty. People were striving for their basic needs and work and were beginning to find their own ways of living (Khan, 2010), which characterised them as entrepreneurial as they were interested in taking risks in return for favourable earnings.

Generation Y (GenY) is known more appealingly as the Generation of the Millennium and is generally defined as those people who were born between the year 1973 and 1993 (Sheahan, 2005), during the democratic governance phase. The youngest members of the 
cohort matured between 1991 and 2011. Members of this cohort have been described as having grown up with modern technology, especially computers. They enjoy more educational and personal development prospects. They are familiar with Western popular culture through their experiences with foreign music, movies, television shows, magazines, the internet and other media programmes (Kaynak, Kucukemiroglu, \& Hyder, 2000). They are largely interested in self-indulgence and personal entertainment. Socio-economic development and democratisation have been found to be positively related to the importance of openness to change and self-enhancement values (Schwartz \& Sagie, 2000; Schwartz \& Ros, 1995). As GenY is enjoying an increase in security and prosperity during their comingof-age years, these changes imply that this younger group will give greater priority to personal pleasure and sensuous gratification, excitement and challenges in life, and the achievement of personal success (Inglehart, 1997; Schwartz, 2005). In the case of Bangladesh, the people of this generation came of age during a development phase that shows an acceleration in economic growth, a decline in the volatility of growth and a reduction in poverty in its multiple dimensions (Khan, 2010). 
Table 2.5: The Three Bangladeshi Cohorts

\begin{tabular}{|c|c|c|}
\hline A. Traditional Generation & B. Swing Generation & C. Generation Y \\
\hline Born between 1929-1953 & Born between 1954-1972 & Born between 1973-1993 \\
\hline Coming of age: 1947- 1971 & Coming of age: 1972- 1990 & Coming of age: 1991- 2011 \\
\hline Age in 2011: 82- 58 & Age in 2011: $57-40$ & Age in 2011: 39- 18 \\
\hline \multicolumn{3}{|c|}{ Historical events that shaped the generation } \\
\hline $\begin{array}{l}\text { Economic hardship, } \\
\text { independence war, } \\
\text { unemployment, poverty, } \\
\text { insecurity around life and } \\
\text { shelter, financial uncertainty. }\end{array}$ & $\begin{array}{l}\text { Famine, one-party parliament, } \\
\text { clientelistic government, privatisation } \\
\text { process began, received quotas under } \\
\text { the MFA and the acquisition of } \\
\text { garments technology. An } \\
\text { entrepreneurial society was slowly } \\
\text { building up at that time. }\end{array}$ & $\begin{array}{l}\text { Reinstitution of democracy, } \\
\text { acceleration of economic growth, } \\
\text { massive success in reducing } \\
\text { illiteracy, poverty and population } \\
\text { growth, expansion of micro credit } \\
\text { facilities, booming phase of ready- } \\
\text { made garments and other industrial } \\
\text { sectors, exposed to Western popular } \\
\text { culture, grown up with modern } \\
\text { technology, especially computers, } \\
\text { mobile phone and internet. }\end{array}$ \\
\hline \multicolumn{3}{|l|}{ Traits } \\
\hline $\begin{array}{l}\text { Conformity: Restraint of actions, } \\
\text { inclinations, and impulses likely to } \\
\text { upset or harm others and violate } \\
\text { social expectations or norms. }\end{array}$ & $\begin{array}{l}\text { Adaptive: Fit, change, or modify to } \\
\text { adjust oneself with different } \\
\text { conditions or new environment. }\end{array}$ & $\begin{array}{l}\text { Self-respect: People who endorse } \\
\text { self-respect as most important engage } \\
\text { in social identity purchasing and } \\
\text { display high levels of health } \\
\text { consciousness. } \\
\text { Sense of accomplishment: People } \\
\text { who endorse this value have made } \\
\text { significant accomplishments in their } \\
\text { lives and engage in reflecting social }\end{array}$ \\
\hline $\begin{array}{l}\text { Utilitarian: When people's basic } \\
\text { needs are difficult to satisfy, } \\
\text { therefore more likely to learn } \\
\text { utilitarian values. A utilitarian } \\
\text { might believe that it is worthwhile } \\
\text { to endure a certain amount of } \\
\text { suffering now, if it ensures a } \\
\text { greater amount of happiness later. } \\
\text { Strive for financial security: } \\
\text { Safety and security value endorsed } \\
\text { by Traditionalists who lack } \\
\text { economic and psychological } \\
\text { securitv. } \\
\text { Risk averse: Prefers a certain } \\
\text { outcome to a risky outcome with } \\
\text { the same expected return. } \\
\text { Sacrifice for the common good: } \\
\text { Preserving and enhancing the } \\
\text { welfare of group, society and } \\
\text { country. }\end{array}$ & $\begin{array}{l}\text { Entrepreneurial: Tends to } \\
\text { organise, manage, and assume the } \\
\text { risks of a business or enterprise. }\end{array}$ & $\begin{array}{l}\text { Self-fulfilment: People are } \\
\text { relatively fulfilled economically, } \\
\text { educationally, and emotionally. } \\
\text { Acceptance of change: Both of the } \\
\text { former emphasise independent } \\
\text { action, thought and feeling and } \\
\text { readiness for new experience. } \\
\text { Stimulation: Seeks excitement, } \\
\text { novelty, and challenges in life. } \\
\text { Pleasure-seeking: One who } \\
\text { specifies fun and enjoyment in life } \\
\text { might associate with this value. } \\
\text { Consumerism: An attitude that } \\
\text { values the acquisition of material } \\
\text { goods. } \\
\text { Technologically savvy: The first } \\
\text { generation to grow up with } \\
\text { computers, technology is woven in } \\
\text { their lives. This generation is } \\
\text { comfortable using cell phones, } \\
\text { mail, laptops and other technology. }\end{array}$ \\
\hline
\end{tabular}




\subsubsection{Role of Bangladesh Government in the Development of Islamic Finance}

There has been a change in the approach of the Bangladesh government and the central bank to Islamic finance in the country. Their initiatives in driving the industry forward cannot be overlooked, but the industry practitioners expect more to be done. They are certainly struggling to attain the legislative amendments needed to strengthen the industry. Conversely, the private sector has performed surprisingly well in a flourishing Islamic finance sector (GIFR, 2011).

Bangladesh Bank issued a licence for the establishment of the first Islamic bank in 1983. Right from the start, Bangladesh Bank approved preferential provisions to ensure the smooth development of Islamic banking in Bangladesh, taking into consideration the lack of Islamic financial markets and instruments in the country. Along with preferential provisions, Bangladesh Bank took the following steps (Ahmad \& Hassan, 2007; Sarker, 2000):

- Bangladesh Bank allowed Islamic banks to maintain their Statutory Liquidity Requirement (SLR) at $10 \%$ of the total deposit liabilities, although it is frequently fixed and re-fixed around $15 \%$ to $20 \%$ for the conventional banks. This provision assisted the Islamic banks to hold more liquid funds for more investment to generate more profit.

- Islamic banks were allowed to fix their profit-sharing ratios and mark-ups independently, appropriate to their own policy and banking environment under an indirect monetary policy regime. This openness in fixing PLS ratios and mark-up rates provided an opportunity for the Islamic banks to follow Shariah principles independently whilst realising the goals of Islamic Shariah.

- Islamic banks could pay back $10 \%$ of their proportionate administrative cost on part of their balances held with the Bangladesh Bank, which has given some opportunity for improvement of their profit base.

In the best interests of the government, Bangladesh Bank issued a Government Islamic Investment Bond as the first-ever Islamic financial instrument in Bangladesh to help the Islamic banks and financial institutions to invest their funds in 2004 (NewHorizon, 2009; Sarker, 2005). Overall, Bangladesh's government and financial regulators have been receptive to Shariah-compliant banking and finance activities. In 1990, a small Islamic economics unit was set up at the research department of Bangladesh Bank, to conduct analytical research on Islamic economics, banking and finance. Now this unit has expanded 
and upgraded, and is known as the internal and Islamic economics division (Ahmad, 2006; NewHorizon, 2009). Massive training of the inspectors and supervisors of Bangladesh Bank is being undertaken, both at home and abroad, so they can be equally familiar with the mechanisms of the different operational methods of the Islamic financial system. The Islamic Banks Consultative Forum (IBCF) was created by the industry players in response to Bangladesh Bank's call to assist in preparing the ground for the creation of a central Shariah board and also supports the government by issuing the Government Islamic Investment Bond (NewHorizon, 2009). A Focus Group on Islamic Banking has been formed in Bangladesh Bank to formulate the necessary guidelines for setting up an Islamic bank, Islamic bank subsidiary or branches in Bangladesh (Sarker, 2005). Moreover, another achievement is Bangladesh's membership of the Islamic Financial Services Board (IFSB), based in Malaysia, and founded to issue regulatory and supervisory standards for the Islamic banking and financial sectors (NewHorizon, 2009; Sarker, 2005). The present supervisory process and procedures are in plan to be restructured in order to consistent with the best international Islamic standards. The work of the IFSB will also act as a medium for the growth of a robust supervision framework in Bangladesh. Additionally, Competency Group on Islamic Banking has been formed at the Department of Banking Inspection (DBI) to create a 'Shariah Compliance Checklists' tool to assist Islamic banking supervisors (NewHorizon, 2009; Sarker, 2005). Bangladesh Bank has also started working on the Islamic Banking Act, with the financial support of the Central Bank Strengthening Project (CBSP), a division established under the patronage of Bangladesh Bank to plan and execute reforms in the country's financial sector (NewHorizon, 2009).

\subsection{Chapter Summary}

The significant opportunities for the growth and diversification of Islamic finance will be offered within next 10 to 15 years. The main reasons behind this potential are: firstly, Islamic financial institutions have, in the main, escaped significant damage in the global financial crisis; secondly, Islamic finance has much potential to diversify into new growth areas such as trade and infrastructure financing in Asia and the emerging markets; and thirdly, Islamic finance can also seek to meet the increased demand for simpler and more transparent products and 'back-to-basics' finance. Nevertheless, Islamic finance has to overcome some important challenges in order to increase its share in the global finance sector and contribute to cross-border finance (Shanmugaratnam, 2012). In the near future, Islamic finance could 
capture a large share of financial services in several countries by fulfilling the preferences of significant numbers of people, enhancing financial inclusion and intermediation, and contributing mostly to financial stability and development (Mohieldin, 2012).

Islamic finance has developed significantly in Bangladesh in last few decades because the demand for this type of financial service is present there. Although the Islamic banking market in Bangladesh began with a very limited resource base, it has shown a strong and positive growth to date. Its on-going progress indicates a high level of acceptance by the public in general. Collectively with the country's economic growth, the market share of Islamic financial institutions continues to increase in terms of assets, financing and deposits. Bangladesh still has a long way to go to achieve the same level of maturity in the industry as Malaysia and the Middle East. However, whatever developments are yet to be undertaken and whatever obstacles still need to be overcome, Bangladesh has shown it can attract the Shariah-based financiers in the world who are eager to invest in large infrastructure projects due to the positive economic outlook of the country (NewHorizon, 2009). 


\section{CHAPTER 3. Literature Review and Theoretical Framework}

\subsection{Introduction}

This chapter reviews the literature on religion and consumer behaviour that is pertinent to the study. First, it discusses the conceptualisation of religiosity and its dimensions, and the generational cohort theory. Presented next is a review of studies on the subject from the consumer behaviour literature that examines studies of religious influences on specific consumption behaviour focusing on main perspective, religiosity. The next section introduces the conceptual model based on the literature review, outlines the relationships between religiosity and consumers' buying behaviour, and hypotheses to be tested.

\subsection{Conceptualisation}

\subsubsection{Religiosity}

One of the most important aspects of a cultural phenomenon is religion, which has significant effect on people's values, habits and attitudes (Belzen, 1999; Mokhlis, 2009). It is a unified system of beliefs and practices relative to sacred or transcendent things and persuades an understanding of one's relationship and responsibility to others when living together in a community (Zimbardo \& Ruch, 1979). The centre of religion is religious commitment, often termed 'religiosity', and is defined as: "the degree to which a person uses or adheres to his or her religious values, beliefs and practices and uses them in daily living", (Worthington et al., 2003, p. 85). There is a possibility that a highly religious person will assess the world through religious guidelines and consequently will integrate his or her religion into much of his or her life (Worthington, et al., 2003, Jamaludin, 2013). Similarly, Johnson et al. (2001) describes religiosity as "the extent to which an individual is committed to the religion he or she professes and its teachings, such as the individual's attitudes and behaviours reflecting this commitment" (p. 25). Thus, religiosity is the religious commitment that refers to the participation in, or endorsement of, practices, beliefs, attitudes, or sentiments that are associated with an organised community of faith (Baetz, Larson, Marcoux, Bowen, \& Griffin, 2002). According to Geertz 'a religion is a system of symbols which acts to produce powerful, pervasive, and long-lasting moods and motivations in men by formulating conceptions of a general order of existence and clothing these conceptions with such an aura of factuality that the moods and motivations seem uniquely realistic' (Geertz, 1966; 1973, p. 
90). Most of the previous studies, adopted from Geertz's definition, highlighted the aspects of being committed to religion and the practice of being religious.

Religiosity is a multidimensional concept. The early study by Allport (1958), proposed two dimensions on the basis of interiorised and institutionalised religiosity, namely intrinsic and extrinsic religiosity. "Intrinsic religiousness is religion as a meaning-endowing framework, in terms of which all of life is understood. Extrinsic religiousness, in contrast, is the religion of comfort and social convention, a self-serving, instrumental approach shaped to suit oneself" (Donahue, 1985, p. 400). Lenski (1961) identified four dimensions as religious factors: associational frequency of religious involvement, communal preference and frequency of one's primary-type relations, doctrinal orthodoxy, and devotionalism communion with God. Fukuyama (1961) constructed an operational measurement for the four dimensions of religiosity: cognitive, cultic, creedal, and devotional, which are similar to those hypothesised by Lenski (1961) that used multi-dimensional features. King (1967) investigated the multidimensionality of religious involvement, basing on his studies on a new theoretical conceptualisation. The dimensions suggested are: assent to creedal propositions, religious knowledge, theological perspective, dogmatism vs. openness to growth and change, the extrinsic vs. intrinsic, worship, participation in organisational activities, involvement with friends in the social activities of the congregation, financial support and attitudes, loyalty to the institutional church, and attitudes toward moral questions (King \& Hunt, 1972).

Glock (1962) developed a model of religious dimensions based on different definitions of religiosity. Glock's earlier dimensions were elaborated with sub-dimensions and used to assess and compare religiosity further by Glock and Stark (1965) and Stark and Glock (1968). In their final form (Stark \& Glock, 1968), religious involvement can be understood on the basis of five dimensions designed to be comprehensive and broadly applicable. Individuals can be characterised in terms of: belief, experiential, religious practice, religious knowledge and consequences (religious effect), that is, the effects of the prior four in persons' day-to-day lives. According to Salleh (2012) (shown in Figure 3.1), Glock's dimensions have also been expanded by other works on religiosity such as Faulkner and DeJong (1966), Nudelman (1971), and O’Connell (1975).

Among all the authors, Verbit (1970) used the term 'components' instead of using the term 'dimensions'. Yet he used component simply as a term in which dimensions are embedded, as he believed that religion has several 'components', and an individual's behaviour vis-à-vis 
each one of these components has a number of dimensions (Salleh, 2012). Verbit (1970) has suggested a concordance of six components in an attempt to combine the extant research in this field: ritual, doctrine (belief), emotion (feelings), knowledge, ethics (consequences), and community.

Aside from these authors, others such as Fukuyama (1961) proposed four dimensions: cognitive, cultic, creedal, and devotional. Moberg (1971) suggested two main factors of religiosity: personal and institutional. In their study, the main focus was on spiritual wellbeing, which provides information for leaders concerned with the problems of older people. Himmelfarb (1975) also identified two elements of religiosity: doctrinal beliefs and ritual observance. Bergan and McConatha (2000) recommended a number of dimensions associated with religious beliefs and involvement. Ellison et al. (1989) looked at three dimensions of religiosity: private devotion, religious attendance, and denominational connection. Subsequently, Ellison (1991) extended in and observed four dimensions of religiosity, namely, denominational ties, social integration, personal sense of the divine and existential certainty (Holdcroft, 2006; Salleh, 2012).

Regardless of the terms, the core dimensions and components of the religiosity proposed by the above authors could be categorised into five main constructs: belief, knowledge, practice, experience and consequences. The higher these categories of dimensions and components are, the higher one's religiosity is (Salleh, 2012). 
Figure 3.1: Proposed Dimensions of the Conventional Measurement of Religiosity

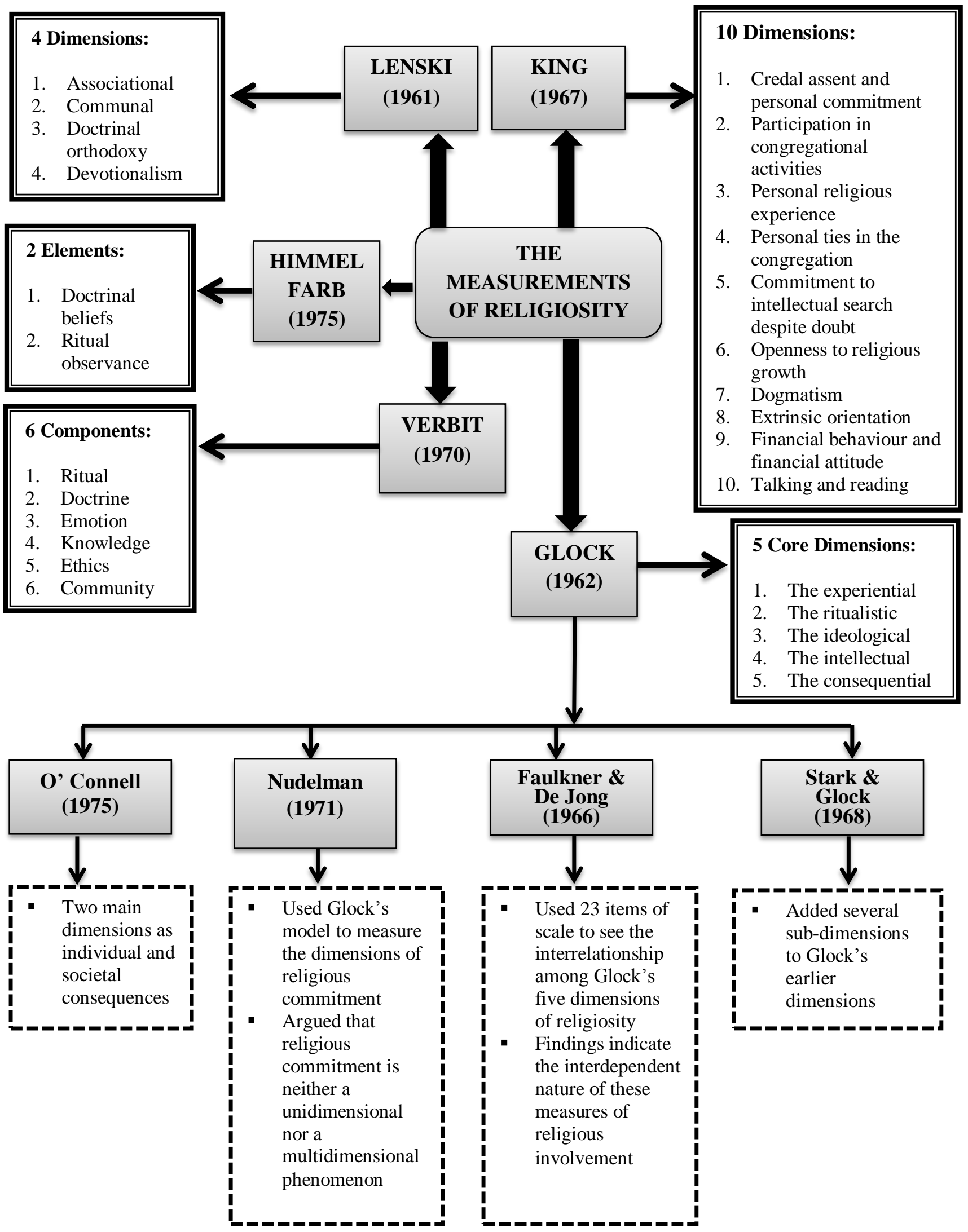

Source: Salleh (2012, p. 268) 


\subsubsection{Muslims' Religiosity}

Religion is the core of Muslim identity that applies to all Muslims all over the world. Thus, religiosity is both the evidence and expression of Muslim identity (Hassan, 2007; Ali, 2008). The Islamic concept of religion is basically different from Judeo-Christian traditions with regard to the meaning and scope of religion, the nature of the acts of worship and the dimensions of religious life (Ilyas, 1992; Krauss, et al., 2005). For Christians and Jews, religion is one hundred percent spiritual; completely separated from the material existence of man (Hashim, 1980). According to Ilyas (1992), while Islamic religion can be defined as the way of life based on the command of God; unlike other religions, Islam covers all aspects of human existence. It does not accept any separation between the material and spiritual aspects of life. In Judeo-Christian religion, worship means to develop in man the attitude of selfdenial, asceticism and isolation from life. On the other hand, these attitudes are not essential to devoutness in Islam. The content dimensions of religiosity are distinctly different from the Judeo-Christian religious tradition as regards the meaning, scope and the nature of the worship. As religion drives Muslim culture, it consequently affects Muslim consumers' behaviour (Lindridge, 2005). For academic researchers, consumer culture in the Muslim domain, or Muslims as a particular target group who take active part in a consumer market is a new area (ATKearney, 2007). Many Muslims believes that consumption has an important role in identity creation. The increasing cultural and religious self-awareness of Muslim people changes and diversifies markets and consumer behaviour.

Taqwa, the religiosity of Muslim people, is an Arabic word. It is defined in the Quran as "the whole pursuit of value and avoidance of disvalue in general" (Dar, 1963). Muslims with taqwa are self-controlled individuals who let the command of God to guide them. Taqwa be subject to, and is the consequence of, faith in God and adoration of him. The Quran has been shown to form the attitude of taqwa, or morality of people (Ilyas, 1992).

\subsubsection{Muslims' Religious Dimensions}

Muslims' religiosity can be represented by taqwa as a multidimensional concept based on Quran and Sunnah, and other Islamic studies (Ahmad, 1977; Ilyas, 1992; Maududi, 1960). The five dimensions of taqwa are identified as: belief (aqi'dah), practice ('amal), knowledge (ma'rifah), experience (ihsan) and consequence (natijah). Therefore, the proposed model operationalises Muslims' religiosity in accordance with those five dimensions. The belief 
(aqi'dah) dimension includes the overall beliefs associated with the religion, such as beliefs about God, the Prophet, fate, etc. Practice ('amal) includes the actions prescribed by religion such as: prayer, fasting, pilgrimage, etc. Knowledge (ma'rifah) refers to an individual's knowledge about religion. Consequence (natijah) refers to the importance of religion while experience (ihsan) describes the practicality of the religion (Ilyas, 1992; Rehman \& Shabbir, 2010).

There are general similarities between Glock and Ilyas's conceptions of religiosity as shown in table 3.1. The aqi'dah dimension seems to be similar in principle to Glock's ideological dimension: 'amal to ritualistic, ma'rifah to intellectual dimension, ihsan to experiential and natijah to consequential. The dimensions of religiosity recommended by Stark and Glock, without doubt, could also be used to measure the religiosity in Islam (Salleh, 2012). This study and analysis of Muslims' religiosity is guided by Stark and Glock's conceptualisation of religious commitment. Glock's five dimensions have evidenced broadly useful in research due to easy to measure of these dimensions and to differentiate one from another (Swatos, 1998). This conceptualisation has also been subjected to extended interviews with knowledgeable Muslim respondents and focus group discussions by Hassan (2007) in Australia, Pakistan and Indonesia to evaluate the dimensions of religiosity. These interviews and discussions have also supported the above five dimensions that are theoretical to express and indicate Muslim piety (Hassan, 2007).

Table 3.1: Comparison between Glock and Ilyas' Conception of Religiosity

\begin{tabular}{|c|c|c|}
\hline \multirow{2}{*}{$\begin{array}{c}\text { Religious dimensions of } \\
\text { Stark and Stark (1968) }\end{array}$} & \multicolumn{2}{|c|}{ Religious dimensions of Ilyas (1992) } \\
\cline { 2 - 3 } & Arabic Terms & General Terms \\
\hline Ideological & Aqi'dah & Religious Belief \\
\hline Ritualistic & 'Amal & Religious Practice \\
\hline Intellectual & Ma'rifah & Religious Knowledge \\
\hline Experiential & Ihsan & Religious Experience \\
\hline Consequential & Natijah & Consequence \\
\hline
\end{tabular}




\section{(i) Religious Belief}

This dimension constituted the religious beliefs a Muslim is expected and, in fact, required to hold and adhere to (Hanzaee \& Ramezani, 2011; Hassan, 2007). According to Hassan (2007), like other religions, the belief structure of Islam can be divided into three types: the first warrants the existence of the divine and defines its character; the second explains the divine purpose and defines the believer's role with regard to that purpose; and the third provides the ground for the ethical strictures of religion. In Islam, most importance is placed on purposive beliefs by avoiding the issue of their salience and function in the life of a believer. This study focuses on the doctrinally motivated main beliefs Muslim people hold that were acknowledged from the holy Islamic texts, and not on the meaning of these beliefs for them.

\section{(ii) Religious Practice}

Religious practices are a central part of a formal religion. This dimension includes the worship and devotion people do to express their religious commitment (Glock \& Stark, 1965). According to Islamic religion, Muslims are required to perform specific religious practices as a reflection of their faith. Exploring religious practices can be approached in two ways: firstly, distinguishing individuals in terms of the regularity with which they engage in religious activities; and secondly, considering the meaning of religious acts for the individuals who engage in them (Hassan, 2007). This study mainly focuses on the first approach as the frequency of observance of religious practices is a useful and meaningful indicator of an individual's religiousness or religiosity.

\section{(iii) Religious Knowledge}

This dimension refers to an individual's knowledge about the basic tenets of religion (Glock, 1972). In Islam, there are three types of knowledge: the knowledge of Tawhid deals with articles of faith; the knowledge of Fiqh deals with the rules and regulations in worship, daily social and economic dealings, and criminology; and the knowledge of Tasawuf deals with self-purification via the elimination of evil attributes and the creation of good attributes within one's inner self (Salleh, 2012). Knowledge of Fiqh is used in this study as God's rules and regulations (Shariah) act as guidelines to the realisation of one's dealings and may sometimes emerge in a physical form, which can be seen and is observable. 


\section{(iv) Religious Experience}

Religious experience is the psychological dimension of religiosity. It comprises all those feelings, perceptions and sensations generating from, or related to, some type of communication with, or experience of, final divine reality (Hassan, 2007). Such experiences are well-organised around perceptions of concern, cognition, trust, faith or fear (Glock \& Stark, 1965). These expectations exist in all religions. Particularly in Islam, Sufi traditions and several other traditions of 'folk' or 'popular' Islam, much importance is placed on personal religious experience or communication with the divine as an assertion of individual devoutness. Religious experience generally includes subjective feelings, impressions or visualizations that happen out of an individual's presumed contact with supernatural consciousness (Gellner, 1981; Hassan, 2007). In this study, experience is operationalised through the feeling of being in the presence of Allah.

\section{(v) Consequential Dimension}

Religious consequences specify attitudes of the believers and the religious effect on their daily lives. Some religions are more precise about these outcomes than others (Hassan, 2007). In Islam, consequences include those conditions or states of life that arise out of knowledge, belief and practice of Islam in the personal and social life of a Muslim. In this study, consequences will be considered as a qualitatively different measure of religious involvement and considered as a part of morality rather than a dependent measure (Ahmad, 1992).

\subsubsection{Generational Cohort Theory}

A Generational cohort is defined as a group of people who were born during the same time period and experience similar external events, which are described as "defining moments", during their late adolescence and early adulthood (Mannheim, 1952). Ryder (1965) also describes generational cohorts as individuals who are born around the same time and share social or historical events during critical developmental periods. Individuals in the same generation tend to think and act differently from those born in other time periods (Gursoy, Maier, \& Chi, 2008). As a result, it goes beyond age to reveal individuals' characteristics in the long term. 
Generational cohort theory was studied by Mannheim (1952) in his essay 'The Problem of Generations', which is considered as the most systematic and developed treatment of generations from a sociological viewpoint (Ting, de Run, \& Fam, 2012). The study attempted to understand how to interpret youth's attitude and behaviour toward political situations. In addition, Mannheim argued that generational cohort is not determined by biological choice, but by historical events. As these societal events have primacy, they define generational cohorts and give rise to new cohorts (Noble \& Schewe, 2003).

\subsubsection{Factors Influencing Generational Cohorts}

There are direct and indirect factors that can influence generational cohorts, both at macrolevel socialisation such as external events (historical, political, and social) and micro-level socialisation (e.g. religion).

\section{External Events as Macro-level Socialisation}

External events are essential elements to identify and segment generational cohorts. According to Mannheim (1952), individuals' values and behaviour will be formed based on historical events that they experience during their coming-of-age. Individuals' attitudes, beliefs, and behaviours are defined by external events (Ryder, 1965). Meanwhile, Kritz and Arsenault (2006) believe that external events experienced by individuals will shape their mind sets and provide the actual value of a generational cohort. Hence, it is necessary for marketers to identify generational cohorts' defining moments before they decide to implement marketing activities or strategies (Parment, 2013).

External events can occur at international, national, and local levels, such as historical events, political ideologies, social upheavals, economic changes, and technological innovations (Mannheim, 1952; Noble \& Schewe, 2003; Ryder, 1965; Schuman \& Scott, 1989). Meredith, Schewe, and Karlovich (2002, p. 13) pointed out that external events can create homogeneity in a generational cohort. They further argue that these events are inclined to influence generational cohort preferences, desires, attitudes, and buying behaviour and these elements remain for their entire lives. Schuman and Scott (1989) asserted that individuals often remember events that occurred during their coming of age and these events often influence them. They indicated that individuals born in the same period tend to have common 
memories. As a result, these memories and experiences from the external events unite individuals in the same cohort.

\section{Micro-level Socialisation}

Micro-level socialisation is important as a determinant of specific characteristics. Micro-level socialisation such as family, peers, religion, media, and ethnic groups (Noble \& Schewe, 2003; Rindfleisch, 1994) is seen as an agent that will provide the change in generational cohort effect. Schewe and Noble (2000) argued that the impact of external events alone on the individual is insufficient to create a distinctive generational cohort effect. They asserted that the micro-level should be taken into account in the determination of the cohort effect because it is has more impact on generational cohort creation.

\section{Coming of Age}

In generational cohort theory, the youth period is an extremely vital period for the formation of values and attitudes of a person. Mannheim (1952) pointed out that formative years are from late adolescence and early adulthood for each individual. This period, known as "coming of age" (Meredith \& Schewe, 1994), is the critical period for establishing generational cohort characteristics among cohort members. This period is considered to be a crucial time because individuals will develop their personal views and these will remain throughout their life.

This study considers an age period between 17 and 23 as coming of age, to identify consumer's defining moments (Schewe \& Meredith, 2004; Schewe \& Noble, 2000). Meredith et al. (2002, p. 6) argue that this is a period where consumers "likely fell in love for the first time, became economic beings, developed their own value systems, explored new ideas, and essentially became adults". They further added that the values formed during coming of age are tremendously powerful because these values will remain for the rest of a person's lifetime. Therefore, business organisations should identify historical events that occurred during coming of age because this is a crucial time for the formation of consumers' characteristics (Meredith \& Schewe, 1994). 


\subsubsection{Religiosity and Generational Cohorts}

Time and age has been shown to have a positive relationship with religiosity. As people age and pass through various life changes, religiosity also tends to change. In general, the religiosity of people increases as they get older, but in a non-linear fashion (Argue, et al., 1999). But it is not clear whether the relationship between age and religiosity is dependent on historical period or cohort membership. Several studies have stated that the Baby Boomer cohort (born between 1945 and 1964) witnessed, and was often a part of, social and political issues of the time, such as anti-war protests, the feminist movement, and the civil rights movement (Bass, 2000; Alwin, 1998; Williamson et al., 1997; Hill, 1997; Miller, 1994). These studies suggest that the religiosity of the Baby Boomer cohort was less than the cohort that preceded it (Gay \& Lynxwiler, 2013).

Generational cohort is a sociological theory and does not claim to be able to explain individuals' actions or to predict individuals' behaviour. But combined with personality profiles, such as religion, it can be a very useful additional step for the analysis of people's behavioural drivers (Codrington, 2011). For instance, Loroz's (2006) study found that religiosity plays an important role in identifying the consumption-related attitudes of different generational cohorts. Religious people exist in all cohorts and may also differ in terms of their degree of religiosity (Pew Research, 2010; Stipkova \& Vane, 2013). These indicate that generational cohorts can be identified as religious consumers or as a group (Loroz, 2006). Bangladesh is a Muslim-majority country, so this study has selected religion as a microsocialisation factor in an individual's socialisation process because differences in religiosity contributes to a range of characteristics and attitudes in individuals.

This study employed external events as a benchmark to identify generational cohorts in Bangladesh. Only external events that have a direct effect and significant impact on an individual's values, characteristics, attitudes and behaviours are selected for this study.

\subsubsection{Generational Cohorts as Consumers}

According to Inglehart (1977; 1997), two assumptions grounded generational cohort theory: a socialisation hypothesis and a scarcity hypothesis. The socialisation hypothesis suggests that adults' basic values reflect the socioeconomic conditions of childhood and adolescence. Even though societal conditions can change, the relative importance that a generation attributes to 
various personal values remains relatively stable (Inglehart, 1977; Inglehart, 1997; Egri \& Ralston, 2004). Whereas the scarcity hypothesis of generational cohort theory suggests that cohorts tend to place the most subjective value on the socioeconomic resources that were in short supply during their youth (Schewe \& Meredith, 2004; Ting, et al., 2012). As a result, generations who are growing up during periods of socioeconomic insecurity (e.g. social upheaval) learn survival values (e.g. economic determinism, rationality). Conversely, generations growing up during periods of socioeconomic security learn postmodernist values (Inglehart, 1977; 1997). Generation cohorts differ from country to country because of the differences in their life experiences and have differential value orientations and consumption behaviours, even though they are in similar life cycle stages (Hung, et al., 2007). Inglehart's work has been further extended by Rogler (2002) and highlights that disastrous historical events impose a stronger, longer-lasting value imprint on the coming-of-age group than on other age groups who live through the same historic period. In addition, reactions to these events will combine into stable orientations if the effects of the events are directed towards the young adult's experiences (Ting, et al., 2012). Therefore, the lifelong persistence of these orientations delineates historical generations. Rather than birth years, the late adolescent and early adulthood years are recognised as coming-of-age or formative years in other studies that distinguish one generational cohort from another. These assumptions are also supported by a number of studies conducted in other countries, for instance the Netherlands (Ester, Vinken, \& Diepstraten, 2000), England, Germany and Japan (Schuman, Akiyama, \& Knauper, 1998; Scott \& Zac, 1993), Brazil (Rubens \& Motta, 2005), the US (Holbrook \& Schindler, 1989; Holbrook \& Schindler, 1994; Schindler \& Holbrook, 1993), and China (Egri \& Ralston, 2004; Fong, 2004; Fam, et al., 2008).

A Generational cohort is a group of consumers who experience a similar socialisation period and external events (e.g. social, economic, politic etc.) when they are young adults, and these events affect their attitude, behaviour, characteristics, and values (Meredith \& Schewe, 1994; Petroulas, Brown, \& Sundin, 2010; Schewe \& Noble, 2000). Each cohort member shares similar characteristics, which are formed based on their experiences during their coming of age. Noble and Schewe (2003) believed that each cohort has values, attitudes, and beliefs that are different from other cohorts based on events that they encountered during their comingof-age period. External events that are believed to influence the consumers' values, attitudes, and beliefs can be used to distinguish one cohort from another (Reisenwitz \& Iyer, 2007). A few studies have connected the segmentation of generational cohorts to purchase behaviour 
and suggest that different generational cohorts vary in their product preferences (Dann, 2007). Generational cohorts were found to vary in their preferences for particular products and services, such as beverages (Rentz, Reynolds, \& Stout, 1983), motion pictures (Holbrook \& Schindler, 1989), automobiles (Braun-LaTour et al., 2007), formal and informal attire (Arsenault \& Patrick, 2008), and travel (Lehto, Jang, Achana, \& O'Leary, 2008). Therefore, it is essential for marketers to identify the events experienced by consumers during their formative years, in order to understand their values, characteristics, and preferences (Noble \& Schewe, 2003; Schuman \& Scott, 1989).

While segmenting by birth age, gender, education etc. has been a useful way to create groups, this does not aid understanding of segment motivations. However, environmental events experienced during one's coming of age create values that remain relatively unchanged throughout one's life. Segmenting by specific age at coming of age provides a richer segmentation approach than do the other demographic variables (Edris \& Meidan, 1989). In this study, consumers will be categorised as a group of people who are born in the same time period, live in the same location, and experience similar events during their late adolescence and early adulthood. These consumers have experienced the process of socialisation together. As a result, this socialisation will influence and shape the equivalent values, characteristics, attitudes, and preferences of members of the same cohort. Hence, marketers need to identify the features of each cohort in order to help them segment consumers and plan marketing activities (Schewe \& Noble, 2000; Williams \& Page, 2011).

\subsection{Overview of Religiosity and Buying Behaviour Literature}

The influence of religion on marketing, particularly global marketing, is well recognised in the literature (Mokhlis, 2006a; Mokhlis, 2006b). Religion, as one of the foundations of moral teachings in most civilisations (Bowen, 1998), defines and informs the kinds of problems faced in the market by consumers and marketers (Mittelstaedt, 2002). Most of the religious traditions forbid, discourage, encourage, or obligate the trading of certain products and services in the open market. They also impact on what can be marketed and how, when, and where marketing can occur. These fundamental market parameters (what, how, when, where) have an effect on the arrangement of pricing, distribution, product variety, and promotion decisions of marketing planners (Mittelstaedt, 2002; Boone, et al., 2012). Religion is evident in every aspect of a society and its effect on business organisations cannot be taking too lightly by marketers. Religious creeds form a stable and constant pillar in a society. When the 
fundamentals of a religion have been understood, the global marketer can be assured that these will not change frequently. Religion is a long-term phenomenon, not a trend that can be discarded by the marketer as a short-term modification. Global marketers need to allocate significant time and resources to understanding religion, specifically where Islam is the faith of the majority before entering a new market (Fam, Waller, \& Erdogan, 2004). Understanding the impact of religion on people's behaviours in a society and the effect of those behaviours on marketing must not be overlooked.

Religion is highly personal in nature and thus its influences on consumer behaviour depend on persons' degree of religiosity (Swimberghe, Sharma, \& Flurry, 2009; Mokhlis, 2009). Researchers are now more concerned with establishing the link between religiosity, which is the center of religion, and the behaviour of consumers (Mokhlis, 2006b). Religiousness, as an important value in individuals' cognitive structure, can effect consumer behaviour (Delener, 1994), and is now often used as an explanatory variable to justify the differences in the consumption habits of consumers in different parts of the globe (Moschis \& Ong, 2011). The concept of religiosity has been concerned partially with social science for over a century (Durkheim, 1912; Moschis \& Ong, 2011) as religion appears to influence individuals' behaviour. There is now also support for the idea that religion influences certain aspects of consumer behaviour (Delener, 1990b; Delener, 1994; Hirschman, 1981; McDaniel \& Burnett, 1990; Mokhlis, 2009; Wilkes et al., 1986).

Studies on religious influences have gained momentum since the 1980s and cover different marketing fields, particularly from the perspective of an Islamic influence on marketplace product offerings and Muslim consumer behaviours (Muhamad \& Mizerski, 2012; Muhamad \& Mizerski, 2013). Religion is one of the important aspects in Muslim culture (Kotler, 1994), and as a result affects Muslims' consumer behaviour (Lindridge, 2005). Islam guides Muslims in every aspect of life, not just in particular acts of worship but also in how and what to trade, how to interact with others and what can be consumed (Alam, et al., 2011). However, the degree of religiosity differs within the Muslim market and thus influences Muslims' consumer behaviour and purchasing decisions to varying extents (Essoo \& Dibb, 2004; Mokhlis, 2009; Taks \& Shreim, 2009). Muslim consumers show concerns about the Islamic-compliant attributes of a product when describing their intention to choose a product (Mukhtar \& Butt, 2012). Highly religious Muslims will follow the guiding principles of religious obligation more thoroughly than less religious Muslims (Taks \& Shreim, 2009). 
Islamic religion constantly issue rulings to adapt its 1,400-year-old principles and rulings to contemporary daily life. The two main bases of Islamic law are the Quran and the Sunnah (Muhamad \& Mizerski, 2012). Islam is a way of life that focuses on a balanced approach between material and spiritual values. Everything an individual undertakes, including business practices and marketing, is part of the worship of Allah in Islam (Fam, et al., 2004; Vitell, Paolillo, \& Singh, 2005). A number of countries with predominately Muslim populations have adopted Shariah law, which attempts to implement Islamic principles and ideals in everyday personal and business life. Islamic laws have a major impact on international business in general, and its functional areas in particular, such as finance, banking and marketing. These details can determine firms' profit, operational specifics, customer behaviour, and relationships between business-to-consumer and business-tobusiness practices. Shariah law impacts on economic activities and has extensive implications for marketing in many Islamic countries. Exceptionally significant religious differences may incite serious disputes for non-Muslim multinationals operating in Islamic countries (Marinov, 2007).

There is a strong relationship and a clear link between religiosity in Islamic countries and consumer behaviour (specifically, boycotting) that consecutively influences their purchase decisions (Al-Hyari, Alnsour, Al-Weshah, \& Haffar, 2012). Muslim consumers' concerns about the Shariah-compliant attributes of a product or service are expressed in their intention to choose a product or services (Mukhtar \& Butt, 2012). Muslim consumers are very alike to those in any other consumer segment, demanding products and services that must comply to Shariah requirements (Hanzaee \& Ramezani, 2011). Muslims living in multi-religious societies are considered more aware of the permissibility of products by Islam and the majority of Halal research in the non-financial sector has been conducted in multi-ethnic societies (Mukhtar \& Butt, 2012). Muslim consumers' religiosity has also an impact on new product adoption (NPA) by influencing their religious beliefs on how and what products they should accept (Rehman \& Shabbir, 2010; Baig \& Baig, 2013). Furthermore, religious Muslims consider Islam as their source of suggestion and they spend moderately. Religiosity performs as a full mediating factor in the association between relative and contextual variables, and the of Muslim consumers' purchase activities (Alam, et al., 2011).

Five religious influence factors have been recognised those may have impact towards consumer buying behaviour: commitment, motivation, affiliation, knowledge of a religion, 
and awareness of the social consequences of following a religion (Muhamad \& Mizerski, 2010). Islamic laws govern and rule financial services (Marinov, 2007) and it is noted that Muslim consumers ranked religious motivation topmost of their reasons for the use of Islamic finance (Gait, 2009). Particularly in a bank selection process, religious factors received the highest degree of importance (Erol \& El-Bdour, 1989; Gerrard \& Cunningham, 1997; Haron, Ahmad, \& Planisek, 1994; Khan, et al., 2007; Metawa \& Almossawi, 1998) and were conceptualised as a factor in patronising Islamic banks. Religiosity is considered an important factor and there is a strong relationship with attitudinal and subjective norm components, which increases the intention level of engaging with Islamic banking facilities (Jahya, 2004).

Religiosity is a driving factor that influences the choice of an Islamic, rather than conventional, loan and is observed in the emergence of Islamic finance in a number of countries from the Middle East and from Southeast Asia, as well as in Western countries (Weill \& Godlewski, 2012). Muslims living in Western countries are very willing to change their financial practices from the conventional system to the new Islamic financial system (Yusoff, Shamsuddin, Zaidin, \& Baharun, 2008).

Different consumer segments (traditionalist cohort, swing cohort and GenY cohort) can be identified within the Islamic financial services industry (IFSI), all of whom have a different relationship with IFS product/brand positioning. Based on the targeted segment, the services brand of IFS possibly can be positioned as Shariah-compliant, ethical, socially responsible and value for money (economic benefits) (Muhamad, Melewar, \& Alwi, 2012).

The next section discusses consumer behaviour, particularly from the perspective of purchase intention and consumers' buying attitude. Consumer behaviour is defined as "the decisionmaking process and physical activity involved in acquiring, evaluating, using and disposing of goods and services" (Bhagat, 2012; Khan, 2006). The behaviour of consumers can be predicted by their attitude towards products and services, and purchase intention is derived from attitude (De Mooij, 2010).

\subsubsection{Significance of the TRA}

Theory of Reasoned Action (TRA) has received extensive attention in the literature of consumer decision making process (Gait, 2009). According to TRA, consumers consider the significances of alternative behaviours before engaging in them and they decide to perform 
behaviours they associate with desired outcomes (Fishbein and Ajzen, 1975). Baker, Morrison, Carter and Vernon stated that (1996, p.531), “The TRA suggests an individual's intention to perform a specific behaviour is a linear function of his or her affective response to performing the behaviour (attitude) and perceived social norms about the behaviour". As TRA can be used to predict behaviour, measuring the intention of individuals to perform a particular behaviour could be a correct measure of the probability of the individuals' intention to perform the behaviour. Since individuals are in varying levels of willingness to perform the behaviour, TRA has important implication for this study for model development and to predict the potential use of IFPs by Bangladeshi consumers.

\subsubsection{Purchase Intention}

Purchase intention has been described as a consumer's intention to purchase a product or to patronise a service organisation (Shao, Baker, \& Wagner, 2004), or willingness to buy a particular product or service. Purchase intention provides a connection between consumers' reactions towards a product or service and their acquisition or use of products or services (Dodds, Monroe, \& Grewal, 1991; Gruber, 1970; Karim, Rahman, \& Ariffin, 2011). The intention to purchase is the main determining factor of actual buying behaviour (Van der Heijden, Verhagen, \& Creemers, 2003). Purchase intentions are widely used as proxy measures for purchase behaviour by academic researchers (Schlosser, 2003; Morwitz, Steckel, \& Gupta, 2007). Purchase intention data are also regularly assist marketing managers to make strategic decisions regarding both new and existing products and the marketing programmes that support them (Barber, Kuo, Bishop, \& Goodman Jr, 2012). Academic researchers and managers rely on purchase intentions and they expect and assume absolutely that these measures will be predictive of ensuing purchases. This concept is a basis of many theoretical models of consumer behaviour (Morwitz, et al., 2007).

The majority of formal consumer behaviour models explain intent as a key variable between attitude and choice behaviour by indicating that intentions outperform beliefs or other cognitive measures as behavioural factors (Warshaw, 1980). Whether or not an individual will perform a given behaviour can be confirmed in the simplest and possibly most effective way: asking the individual whether he/she intends to perform that behaviour (Fishbein \& Ajzen, 1975). On the other hand, intentions comprise a determined state of choice where one composes a self-implicated statement as to a future course of action (Bagozzi, 2003). 
Previous studies were concerned with investigating the link between religious variables and the buying attitude and buying intention of consumers. Those studies have been viewed from two standpoints: religious affiliation and religiosity (Mokhlis, 2006a). Religious affiliation influences consumers' purchase intention and serves as an important variable for consumer segmentation (Engel, 1976; McDaniel \& Burnett, 1991). Religious affiliation, by its rules and taboos, also promotes different choice behaviour and purchase intention in its followers (Nix \& Gibson, 1989). But "the heart of religion is commitment" (Stark \& Glock, 1968: p. 1) and because of their strong commitment of faith, highly religious individuals are often considered as close minded or rigid (Delener, 1994; Mokhlis, 2006a; Stark \& Glock, 1968). Several studies on the relationship between religiosity and consumer behaviour indicate that link exists between religiosity and consumers' purchase intention. Religious commitment covers beyond religion through to individuals showing commitment in many sides of their life, including consumption behaviour, such as choice behaviour and purchase intention (Mokhlis, 2006a; Wilkes, et al., 1986).

Religiosity may form an individual's shopping intention (also called purchase intention) (Sheth, 1983). Evidence provided by Sood and Nasu (1995) indicates that individuals with a high religious commitment differ when buying products and services (such as products on sale, or foreign products) from those who exhibit a low religious commitment. Less religious people follow trends and feel more imaginative than highly religious persons (Essoo \& Dibb, 2004). Consumer purchase intention can differ from one culture or country to another because of the impact of religion (Essoo \& Dibb, 2004; Sood \& Nasu, 1995). Sood \& Nasu (1995), in their study, focused on the relationship between the religiosity, nationality and purchase behaviour of American Protestant and Japanese consumers. They found that there were no significant differences between the purchase intention of the devout and the casually religious Japanese, but the devout American Protestants and casually religious Protestants exhibited considerably different purchase intention. Essoo \& Dibb (2004) stated that consumer purchase intention is influenced by religion, which is based on the proposition that being devoted to a particular religious faith significantly influences shopping behaviour. They examined the purchase of a high involvement product as the basis, contrasting the purchase intentions of Hindus, Muslims and Catholics. A comparative study for New Zealand and USA was conducted to find out the effects of religiosity on Sunday purchasing behaviour (Siguaw, Simpson, \& Joseph, 1995). Another similar study was conducted in five small towns in Ruston and Louisiana to find the effect of consumers' religiosity on their Sunday 
shopping behaviour (Siguaw \& Simpson, 1997). Both studies identified that the overall religiousness of a person has an impact on purchase intention.

Previously, few studies focused on religiosity and perceived risk and uncertainty (Delener, 1990b; Gentry, Tansuhaj, Manzer, \& John, 1988), whereas another area of research focused on the relationship between religiosity and consumer behaviour regarding purchasing and retail store patronage behaviour. Religiosity has an impact on the importance of various retail store attributes, as shown in store evaluative criteria given by consumers (McDaniel \& Burnett, 1990) and their repeat purchase intention (LaBarbera \& Stern, 1990). On the other hand, the effect of religiosity on purchase intention is positively related to age, which affects the quality sought in products, the social risk involved with a purchase and price sensitivity (Smith \& Frankenberger, 1991). The influence of religiosity on purchase behaviour differs among different socio-economic groups because of their purchasing patterns. For example, religiosity clearly influences the purchase behaviour of middle and lower socio-economic groups, whereas the effect of religiosity on an upper class group's purchase intention was not as clear, though they are considered to be the most religious group (Rodriguez, 1993).

Finally, religious values are generally believed to be the central point of the common beliefs people hold about desirable and undesirable modes of conduct and would determine, to some extent, people's attitudes and purchase intention (Fontaine, Duriez, Luyten, Corveleyn, \& Hutsebaut, 2005). Religion does not directly force for commitment but generally moralistically sets some values, beliefs, and practice requirements (Worthington, et al., 2003). Lindridge (2005) explores religiosity's effect on culture and consumption by comparing Indians living in Britain with Asian Indians and British Whites, explaining the role of religion's influence on culturally determined consumer purchase behaviour. The relationship between a consumer's religious affiliation and a number of consumption-related variables is significant, which specifies that a consumer's religious commitment significantly influences store loyalty and complaint intentions (Swimberghe, et al., 2009). According to Mokhlis (2009), religiosity also affects another aspect of consumer behaviour: shopping orientation. The shopping orientation factors, such as quality consciousness, impulsive shopping and price consciousness are related to religiosity and are potential elements of shopping orientations in consumer behaviour models.

Consumers' buying behaviour is influenced by religiosity before they intend to buy any particular product. For example, a consumer's religion affects their intentions to buy 
genetically modified food (GMF) (Ismail, Vivishna, Khurram, \& Jafri, 2012). There is a significant difference between the purchase intentions of Muslim and non-Muslim consumers towards GMF and suggests religion does affect the purchase intentions of Malaysian consumers regarding GMF (Ismail, et al., 2012). Religiosity also influences the purchase intention of counterfeit bag products through the mediation of consumers' lawfulness attitudes (Budiman, 2012). Malaysian Muslim consumers are hugely influenced by religiosity before they intend to purchase foreign-made consumer goods and services (Haque, Rahman, \& Yasmin, 2012). Muslim consumers' purchase intentions are also influenced by their religion when they purchase organic food that is directly related to Halal, a precondition where Muslims must consume certain permitted products that are consistent with Shariah requirements (Shaharudin, Pani, Mansor, Elias, \& Sadek, 2010).

Religiosity is the main factor for Muslims when purchasing Islamic financial products (Omer, 1992; Alam, Janor, Zanariah, \& Ahsan, 2012). In Islamic bank selection criteria, religiosity plays a key role in the banking behaviour of Islamic bank customers in Bahrain and Bangladesh (Khan, et al., 2007; Metawa \& Almossawi, 1998). Religiosity also has significant impact on the choice of Islamic home financing among Malaysian Muslim consumers (Alam, et al., 2012).

The number of previous studies documenting the influence of religiosity on consumers' purchase intentions of IFPs is very limited. Most of the research on IFP focuses primarily on Islamic banking services. This study aims to fill this gap in research by analysing the effect of religiosity on the buying behaviour of Muslim people when selecting overall IFPs and their different categories in Bangladesh. It is therefore valuable to take a closer look at the influence of religiosity on consumers' intentions to choose various types of Islamic financial products and to use this information to predict consumers' purchase intentions.

\subsubsection{Consumers' Attitudes}

Attitude can be defined as "an enduring organisation of motivational, emotional, perceptual and cognitive processes with respect to some aspect of our environment" (Hawkins, Best, \& Kenneth, 2001). More particularly, attitude refers to an "overall evaluation that expresses how much people like or dislike an object, issue, person or action" (Hoyer \& MacInnis, 2001; Petty, Unnava, \& Strathman, 1991; Pride \& Ferrell, 1991; Solomon, 2004). 
Attitude provides four key functions for people: the knowledge function, which organises beliefs around objects or activities such as brands and shopping; the value-expressive function, where attitudes are formed and serve to express an individual's central values and self-concept; the utilitarian function, when people tend to form positive attitudes towards rewarding products and negative attitudes towards other products; and the ego-defensive function, where people form attitudes to defend their egos and self-images against threats and shortcomings (Grewal, Mehta, \& Kardes, 2000; Katz, 1960). Attitudes are formed by all four of these influencers, but knowledge plays a more important role (Hawkins, Best, \& Coney, 2004). In this study, consumers' attitudes is operationalised as a knowledge function, in such a way that it is shaped by the way individuals organise their beliefs towards an organization and afterwards form their following purchasing behaviour (Carvalho, 2008). Consumers' attitudes can be also the outcome of the combination of attributes or characteristics that an object possesses (Asiegbu, Powei Daubry, \& Iruka, 2012). Attribute importance differs from consumer to consumer and this importance is the assessment of the significance of an attribute for a particular product (Kotler, Brown, Adam, \& Armstrong, 2004).

Religiosity influences consumers' attitude in different circumstances, which is reflected in the perception of consumers' behaviour (Light, Keller, \& Calhoun, 1989; Budiman, 2012). Religion as a key element has a good influence on people's attitudes and, in turn, impacts on consumers' choices in purchase intention (Essoo \& Dibb, 2004). By measuring altruism (attitude that emphasises social importance) and empathy, some researchers (Batson, Schoenrade, \& Ventis, 1993; Watson, Hood Jr, Morris, \& Hall, 1984) have established the relationship between religiosity and behaviour and concluded that religious values influence people's attitudes (Budiman, 2012). People with strongly religious characteristics are considered to have a high religious commitment (Beit-Hallahmi \& Argyle, 1997), upon which these consumers base their attitudes towards the attributes of products (Budiman, 2012).

People with different degrees of perceived religious commitment tend to differ in the degree to which they embrace certain attitudes and behaviour (Wilkes, et al., 1986). Religiosity plays an important role in determining consumers' attitudes concerning various doubtful consumer practices. It is a significant determinant of a consumer's personal moral philosophy (both idealism and relativism) and also a significant determinant of a consumer's ethical attitude and belief (Vitell \& Paolillo, 2003). On the other hand, based on specific philosophies, 
individuals form an attitude to a certain object and based on that they form an intention to behave with respect to that object (Van der Heijden, et al., 2003).

Religion and religiosity also influence attitudes towards the advertising of different products and services (Fam, et al., 2004). Religion can be an important factor in terms of predicting how an advertising message is perceived, consumption patterns, innovativeness, media usage, family decision making, purchase risk aversion and selected retail store patronage behaviour (Mokhlis, 2006b). For example, there is a negative relationship between religiosity and consumers' attitudes and recall scores of TV advertisements perceived to include contentious elements. Christian and Muslim people with higher levels of religious commitment had significantly less positive attitudes towards the contentious messages and conservative Muslims had much less recall scores than liberals (Michell \& Al-Mossawi, 1995; Michell \& Al-Mossawi, 1999; Shukor \& Jamal, 2013).

The study of consumers' attitudes has been linked with consumer purchasing behaviour research since the middle of 1970s. According to the model of attitude change and behaviour (Fishbein and Ajzen, 1975), consumer purchase intention is affected by attitude. Earlier research has shown that attitude towards online buying is a significant predictor of making online purchases (Yang, Lester, \& James, 2007) and purchasing behaviour (George, 2004; Moshrefjavadi, Dolatabadi, Nourbakhsh, Poursaeedi, \& Asadollahi, 2012; Yang, et al., 2007).

Studies of Islamic finance in the area of consumer behaviour are relatively new. Religious consumers have a more favourable attitude to Islamic banks because of their willingness to respect Islamic principles, and the claim that religious motivation is the main factor for Islamic banks' selection has been empirically supported by most of the previous studies (Hegazy, 1995; Metwally, 1996; Okumuş, 2005). On the other hand, previous studies on the patronisation behaviour of Islamic banks' customers have also indicated that religion does not necessarily predispose a customer to select an Islamic bank (Edris, 1997; Erol, Kaynak, \& Radi, 1990; Gerrard \& Cunningham, 1997; Selamat \& Abdul-Kadir, 2012). This may be for many reasons, but is largely because of, the extra charges applied by the Islamic banks, which are referred to as "the cost of being Muslim" (El-Gamal, 2007).

Erol and El-Bdour (1989) first studied individual customers' attitudes towards Islamic banks. The study of Jordanian customers found that religion was not such an important factor in bank selection as fast and efficient services, the bank's reputation and image and the 
confidentiality of the bank. Other studies also confirmed that religious motivations did not impact on the use of Islamic banks' products and services (Erol, et al., 1990; Selamat \& Abdul-Kadir, 2012). High profit and low service charges are the most important factors for influencing and attracting customers (Gerrard \& Cunningham, 1997). Religious motives are the second most persuading construct when customers choose Islamic banks (Zaher \& Hassan, 2001; Hasan, Akif, Subhani, Imtiaz, \& Osman, 2012). Jordanians live in a relatively secular society and identify themselves as liberals. This finding on Jordanian customers explained that bank customers do not differentiate between the services offered by conventional and Islamic banks. Therefore Islamic banks are not distinguishing themselves in terms of services they offer (Erol and El-Bdour, 1989).

Attitudes towards Islamic banks with Muslims consumers in Muslim majority countries like Kuwait, Saudi Arabia and Egypt have shown that religious factors are the main reason for choosing Islamic banks (Hegazy, 1995; Metwally, 1996). In Bahrain, Islamic bank customers' attitudes are also influenced by religion rather than profitability, which also indicate that Muslims select Islamic banks to comply with their Islamic religious beliefs (Metawa \& Almossawi, 1998). Jordanian Islamic bank customers indicate that a bank's reputation and religion were the most significant factors for bank selection and they are satisfied with their products and services (Naser, Jamal, \& Al-Khatib, 1999). There are differences in the perception of Islamic banking among Malaysian bank customers, but personal religious motivation has a significant impact on the use of Islamic banking services (Zainuddin, Jahyd, \& Ramayah, 2004; Nawi, Yazid, \& Mohammed, 2013).

Muslims in non-Muslim countries such as the UK are unaware of the Islamic method of finance but have strong preferences for Islamic products and services over conventional ones, in contrast to Muslim customers in Muslim countries such as Jordan (Omer, 1992). Customers in Kuwait use Islamic financial services as these services adhere to Islam (AlSultan, 1999). Conversely, the Malaysians' attitude towards the Islamic method of finance shows that they do not differentiate much between Islamic and conventional financial products and services, although the majority of them have adequate knowledge of Islamic financial products and services. When considering knowledge and perception of Islamic finance, Muslim students preferred Islamic financial products and services because of religious convictions in the United Arab Emirates (Bley \& Kuehn, 2004). Turkish Muslim consumers expressed religion as their primary motivation for the use of Islamic financial 
products and services, similar to the findings of the earlier studies (Okumuş, 2005). An awareness of Islamic financial products and services among Muslims in Australia indicates that the majority are interested in using the Islamic method of finance (Rammal \& Zurbruegg, 2007). In a non-Muslim country such as the UK, Muslims' attitudes towards the Islamic financial system are positive and they are willing to engage in the system and purchase the products (Yusoff, et al., 2008). Among Muslims in Malaysia, consumers' attitudes significantly influence the purchase intention of Islamic home financing, in particular (Alam, et al., 2012).

\subsection{Summary of Religiosity and Buying Behaviour}

Although there is relatively little literature on Muslim consumers' buying attitude and purchase intention towards Islamic finance, the above literature review covered many types of consumer behaviour from a religious perspective in Muslim and non-Muslim countries towards different products and services, and provided interesting results. Firstly, the results of the literature on religiosity and consumers' behaviour showed that religiosity is one of the major determinants of the characteristics that influence consumers' choice behaviour and buying decisions. Religious influences have taken drive particularly from the perspective of Islamic religion and Muslim consumer behaviours, as Islam guides Muslims in what they can consume. In general, the degree of religiosity differs among Muslim consumers and impacts Muslims' consumer buying and purchasing decisions to different extents (Essoo \& Dibb, 2004; Mokhlis, 2009). Secondly, the literature review also indicates a different result around consumers' attitude and purchase intention towards different types of Islamic financial products, whereas most of the studies focus on the banking behaviour of Islamic banking services. Finally, only a small amount of literature on the impact of religion on consumers' behaviour towards Islamic financial products provided any significant result. To sum up these results, religiosity is the major factor that motivates Muslim consumers to deal with Islamic finance, but the strength of this influence is not same for all categories of Islamic financial products. Though all categories of IFP principally comply with the main tenets of Islamic laws, there is still doubt amongst the broader Muslim community as to what constitutes an Islamic financial product.

In conclusion, the results of these studies shed light on the influence of religiosity on consumers' buying attitudes and purchase decisions towards Islamic financial products. 
These studies have inspired this thesis on similar aspects of religious influences on Bangladeshi Muslim consumers' buying attitudes and purchase intentions towards Islamic financial products, since global financial institutions target Bangladesh as one of the potential markets for its Islamic financial products and services.

\subsection{Conceptual Model and Hypotheses Development}

The main focus of the proposed 'Religiosity-Consumer Behaviour' model is that Muslims' religiosity plays a role in consumers' buying behaviour (Hamouri, 1991; Rehman \& Shabbir, 2010; Soesilowati, 2010). Although there are few empirical studies in the literature regarding religiosity and the effect on buying decisions and the consumption process, there is an implicit belief that religiosity should positively affect purchase intention and provide tangible results (Delener, 1990b; Delener, 1994; McDaniel \& Burnett, 1990; Mokhlis, 2006b; Wilkes, et al., 1986). A review of the extant religiosity and consumer behaviour literature and TRA led to the choice of the key measures of this study. Religiosity is associated with certain types of consumer behaviours that have been under-researched, especially among consumers in different cohort segments (Loroz, 2006). Measurement of the degree of religious commitment can provide a basis for a thorough and insightful prediction of consumers' buying behaviour.

Muslims' religiosity determine their intention to consume Shariah-compliant products (Soesilowati, 2010). This study argues that Muslims' religiosity influences purchase intention towards IFPs directly and indirectly by influencing their attitude towards IFPs. Religiosity, consumers' buying attitude and purchase intention relationships are moderated by cohort groups. Moreover, the relationships are likely to vary for different IFPs. The proposed conceptual model is shown in Figure 3.2 and discussed next. 
Figure 3.2: Religiosity-Consumer Behaviour: Conceptual Model

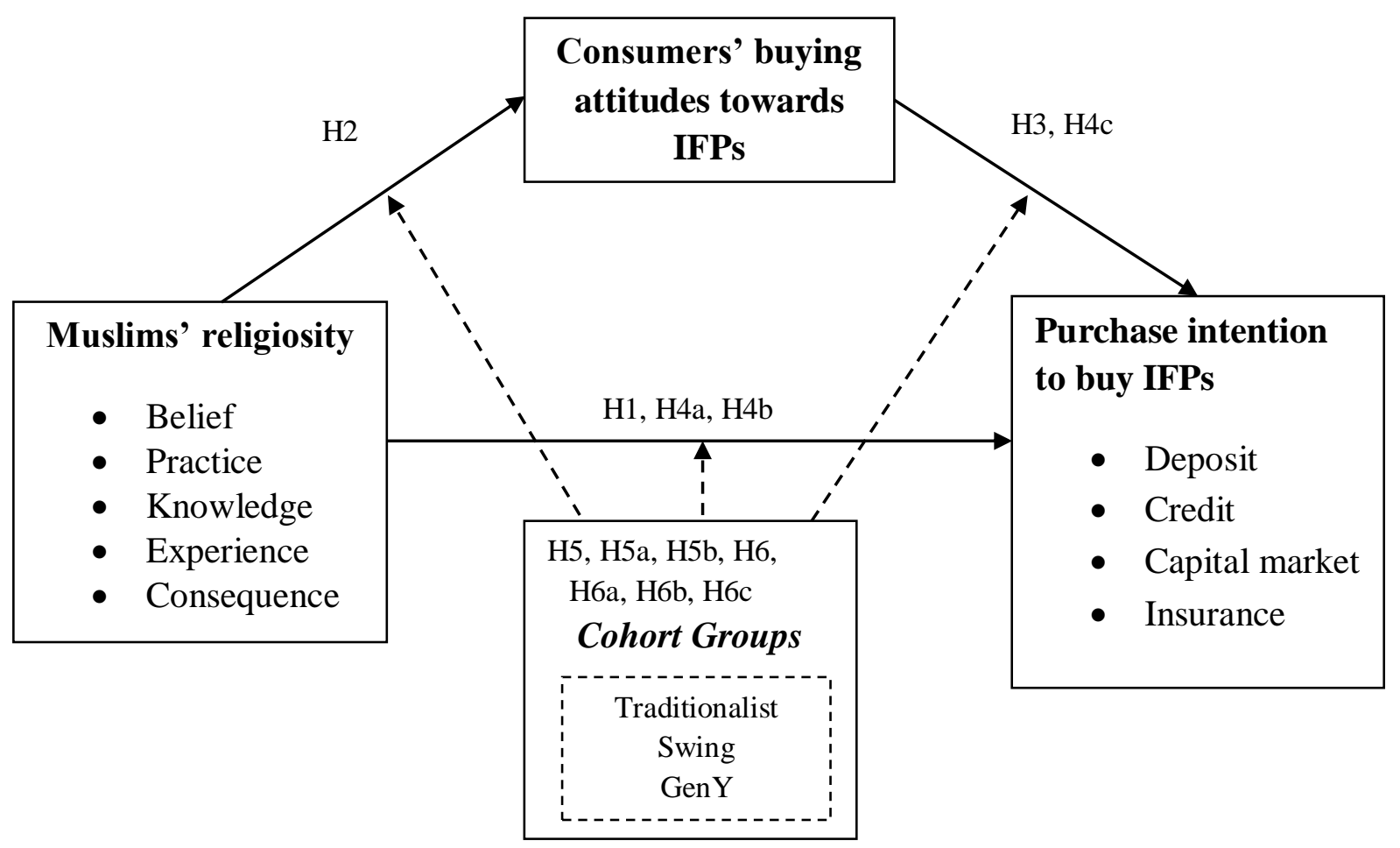

\subsubsection{Religiosity and Purchase Intention}

Religiosity is reflected through individual attitudes and behaviours, therefore the degree to which religion affects one's attitude and behaviour depends on the individual's level of religiosity and the importance one places on the religion itself (Sood \& Nasu, 1995). Highly religious individuals are likely to be more dogmatic and more conservative than less religious individuals (Delener, 1994). Thus, the more religious person is more likely to align their behaviour to their religious laws. Those who are strongly committed to religion are both attitudinally and behaviourally able to take decisions consistent with religion (Sood \& Nasu, 1995). Individual differences in religiosity are related to stable differences in perception that may guide the individual in the process of selecting solutions to a particular need (Gorsuch \& Smith, 1983).

Islamic society is affected by a distinct Islamic world view (three fundamental principles: unity, responsibility to the community, and justice) based on Shariah (Sulaiman, 2003). Therefore, religiosity impacts Muslim consumers' likes and dislikes (Rehman \& Shabbir, 2010) and they consider buying products if the products do not violate or contradict their 
sacred ideas (Yun, Verma, Pysarchik, Yu, \& Chowdhury, 2008). Religiosity is one of the prominent predictors of a better understanding of consumer intention to choose Shariahcompliant products (Mukhtar \& Butt, 2012). As Islamic financial institutions offer Islamic financial products and services that adhere to Islamic principles, values and goals (Amin, Rahman, Sondoh, \& Hwa, 2011), religious reasons are the principle motivations for Muslims who deal with Islamic financial institutions to choose these Islamic services (Omer, 1992). Previous studies have thoroughly documented the importance of religious factors affecting bank customers' attitudes and Islamic banking preferences (Amin, et al., 2011; Metawa \& Almossawi, 1998; Metwally, 1996). This leads to the following hypothesis:

H1: The greater the degree of religiosity, the greater the purchase intention of Muslim individuals towards IFPs.

\subsubsection{Religiosity and Buying Attitude}

Although religion mandates strict laws in terms of buying financial products or services, the extent to which its adherents follow those Shariah laws is likely to vary (Bonne, et al., 2007; Soesilowati, 2010; Youssef, et al., 2011) and this variation is affected by attitude (Ajzen, 1991). The extent to which Muslims will have a buying attitude towards IFPs depends on the degree to which an individual is religious (Soesilowati, 2010). Religion impacts devotees' beliefs and attitudes toward a particular element through its doctrines (Bailey \& Sood, 1993). Religiosity also plays an important role in measuring consumers' attitudes to various questionable consumer practices (Vitell \& Paolillo, 2003). Religion is one of the most important factors in shaping the attitude of Islamic banking customers (Hegazy, 1995; Metawa \& Almossawi, 1998; Metwally, 1996; Omer, 1992). Religion plays a key role in influencing retail consumers' attitudes towards Islamic finance (Gait \& Worthington, 2008). This also emphasises that Muslim consumers choose Islamic financial products to conform to their religious beliefs. Based on the theoretical and empirical support, the following hypothesis is proposed:

H2. The greater the degree of religiosity, the greater the Muslim individual's favourable attitude towards IFPs. 


\subsubsection{Buying Attitude and Purchase Intention}

A number of studies have shown the significant effect of attitude on intention (Davis, Bagozzi, \& Warshaw, 1989; Ing-Long \& Jian-Liang, 2005; Lu, Yu, Liu, \& Yao, 2003; Mathieson, 1991; Ramayah, Ling, Norazah, \& Ibrahim, 2005; Ramayah \& Mohd, 2006; Ramayah, Noor, Nasurdin, \& Hasan, 2003; Ramayah, Noor, Nasurdin, \& Sin, 2004; Rhodes \& Courneya, 2003; Shih \& Fang, 2004; Taylor \& Todd, 1995; Teo \& Pok, 2003) and that a behavioural intention reflects a person's decision to perform the behaviour (Ajzen, 1991). From a consumer behavioural respect, a consumer's intention to purchase a product or services is predicated on a positive attitude towards a particular product. Such a positive attitude towards a product appears also to be affected negatively by attitude towards other products in the choice set (Alba \& Hutchinson, 1987; Harlam \& Lodish, 1995; Laroche, Kim, \& Zhou, 1996). Previous studies in marketing literature observed that religion influences both peoples' attitudes and purchasing decisions (Essoo \& Dibb, 2004). Thus, the Islamic financial industry expects Muslims to view Islamic finance as relevant to the Muslim obligation (Loo, 2010). Previous studies also supported the premise that a consumer's attitude is one of the significant determinants in influencing the intention to use Islamic personal financing (Amin, Ghazali, \& Supinah, 2010; Amin, et al., 2011). It has also been observed that positive attitude or degree of favourableness towards Islamic financing is responsible for determining the intention to purchase Islamic personal financing products (Taib, Ramayah, \& Razak, 2008). Therefore, this study proposes the following hypothesis when considering the above discussion that buying attitude positively correlates with the purchase intention of IFPs.

H3: Muslim consumers with a more favourable attitude towards IFP have a higher purchase intention of IFPs.

\subsubsection{Mediation Effect of Consumers' Attitude}

Mediation effects occur when an independent variable influences the dependent variable through its effects on, or as a result of, a mediator variable (Baron \& Kenny, 1986). TRA (Fishbein and Ajzen, 1975), the planned-behaviour approach (Ajzen, 1991) and previous studies of consumers' attitudes and buying intentions towards Islamic-compliant products supports the influence of religiosity on purchase intention by influencing the attitudes of Muslim consumers (Soesilowati, 2010). Following these previous studies and based on the arguments that consumers' buying attitude influences consumers' purchase intention $(\mathrm{H} 2)$ 
and people's religiosity has an impact on their consumers' buying attitude (H3), it follows that the relationship between religiosity and purchase intention is mediated by consumers' buying attitude towards IFPs. Specifically, religiosity is the independent variable and buying attitude is the mediator variable (Soesilowati, 2010).

\subsubsection{Islamic Financial Product Categories and Purchase Intention}

In recent times, different categories of Islamic finance products and services (such as deposit products, credit products, capital market products and insurance products) have been offered in direct competition to the financial products and services offered by conventional financial institutions, even in Muslim countries (Mamun, 2011). All these categories of IFP are principally compliant with the main tenets of Shariah or Islamic law on interest, non-Islamic investments, and speculation (Gait \& Worthington, 2008; Gait \& Worthington, 2009). Despite a general recognition of the underlying Islamic principles, there is still doubt amongst the larger Muslim community as to what constitutes an IFP. Islamic finance still faces obstacles in its development and a lack of standard interpretations for each category of IFP (El-Gamal, 2006; Sadiq \& Black, 2012), which may affect whether customers choose to buy a particular product or not.

Islamic deposit and credit products offered by Islamic banks are very similar to the products offered by conventional banks, except that Islamic financing principles apply to the underlying bank assets and liabilities (Gait and Worthington, 2008). For Islamic deposit and credit products, no transaction that involves interest in any form can be undertaken, such as simple or compound, low or high, institutional or individual (Yusof, 2008). The most general statement regarding Islamic banks products is that they are exact reflections of Islamiccompatible design that the clients themselves respect and rely on in (Dusuki \& Abdullah, 2007). Customers are generally aware of various common Islamic deposit and credit products offered by banks (Khan, et al., 2007) and there is a strong demand and preference for interestfree banking services from a segment of people who have a strong desire to abide by the rules and principles set by Shariah (Mamun, 2011). Given these considerations, this is hypothesised:

H4a: The higher the religiosity, the higher the purchase intention in favour of Islamic deposit products and credit products. 
The significance of capital markets in the Islamic financial system also stems from the point that Islam forbids interest and inspires trade. Although capital market products comply with Shariah laws, consumers are less likely to invest in these products for two reasons (Ali, 2005). Firstly, capital market speculations are not accepted for economic and religious reasons (Warde, 2010). Secondly, even highly religious and knowledgeable people have less understanding and awareness of how money and investments are handled in Islam (Hassan and Mahlknecht, 2011). Currently, different individuals and financial entities, depending on their degree of awareness of Shariah-compliance, are voluntarily adopting or avoiding certain practices. Therefore, the investor base for Islamic capital market products is very small and sluggish (Ali, 2005).

Islamic insurance products are also complying with Islamic Shariah. But there are still doubts regarding these insurance products because the use of, and investment in, insurance companies is not permitted because 'safety' or 'insurance' is not itself viewed as an object of sale in classical Islamic jurisprudence. Thus, the insured-insurer relationship is regarded to be one affiliated to gambling, where the insured as buyer pays a periodic premium as price, but may or may not be given the object of sale (compensation in case of loss), conditional to chance. Another consideration that driven Islamic jurists to prohibit insurance is the fact that insurance companies tend to invest their assets in interest-based instruments, for instance government bonds and mortgage-backed securities (Ahmed, 2010). Considering the above issues, takaful schemes are specially developed to encompass the elements of shared responsibility, joint indemnity, common interest and solidarity, which are accepted by Islamic Shariah (Billah, 2007). Many Muslims around the world are till now not convinced of the complete and unquestionable acceptability of insurance, especially life insurance or family takaful schemes (Siddiqui \& Athemy, 2008). In reality, the growth of takaful gaps a far way behind its potential. The features, models and structures of takaful are not known much to people in general, whereas information regarding Islamic banking is increasingly being spread (Saaty \& Ansari, 2008). The above discussion leads to the following two hypotheses:

H4b: The higher the religiosity, the less the purchase intention in favour of Islamic capital market and insurance product.

Gait and Worthington (2009b) suggested that attitudes, perceptions and motivations towards Islamic methods of finance are the most important factors in determining the intention of purchasing Islamic methods of finance by retail consumers. Previous studies have identified 
Islamic principles as the key factors among Muslims for selecting Islamic financial products (Metawa \& Almossawi, 1998; Naser, et al., 1999; Osman, Ali, Zainuddin, Rashid, \& Jusoff, 2009). By strengthening Muslims' desire to follow Islamic tenets, Islamic financial institutions are encouraging them to financial transactions in a halal way (Loo, 2010). Hence

H4c: Muslim consumers with favourable attitudes towards IFPs will have a higher purchase intention of all categories of IFPs.

\subsubsection{Moderating Effect of Generational Cohort}

The strength of relationship plays a role in determining the relationships to be weak, moderate or strong (Cohen, 1988). Conversely, a moderator affects the strength of the relation between an independent and a dependent variable (Baron \& Kenny, 1986). According to generational cohort theory, significant intergenerational differences have been documented among different cohorts (Lu \& Alon, 2004; Yardley, 2003). A nation's historical events reveal the dissimilarities in values and attitudes among its generational cohorts (Conger, 1997; Rogler, 2002). Religiosity of different generational cohorts and their consumption-related attitude may also differ and can be identified as religious consumers as a cluster (Loroz, 2006). Hence generation cohort is included as a potential moderator of the relationship among religiosity, buying attitude and purchase intention of IFPs. The older and middle generations are more religious than the younger generation though a large number of people in all generations claimed themselves as religious (Markides \& Cole, 1984). A secularisation hypothesis argues that economic growth, industrialisation, increased literacy and decreasing fertility reduces religiosity (Akdede \& Hotunluoğlu, 2008). Thus, based on the secularisation theory and characteristics of each generational cohort, the Traditionalists are more conservative than the other two cohorts (Mitchell, 2003) and emphasise traditional and religious ethics, as well as place importance on loyalty and commitment (Billings \& Kowalski, 2004; Johnson \& Romanello, 2005). Compared with GenY, Swing individuals consider themselves to be conservative but GenY is more open to change than the other two cohorts (Mitchell, 2003). This implies that there are differences in personal values and attitudes between the members of the three generations in Bangladesh. Thus, this study expects that the strength of relationships between religiosity, buying attitude and purchase intention of IFPs is likely to be influenced by generation cohorts' differences, as a result of interaction. 
H5: Generation cohort moderates the relationships between customers' religiosity, buying attitude and purchase intention of IFPs.

H5a: Traditionalists will have stronger positive relationships between customers' religiosity, buying attitude and purchase intention of IFPs than the Swing cohort.

H5b: Swing cohort will have stronger positive relationships between customers' religiosity, buying attitude and purchase intention of IFPs than GenY.

A relatively high percentage of religious people in a particular segment don't mean that it is a religious segment. In each and every cohort, with slight variations, there are religious people in almost every layer of society (Gay \& Lynxwiler, 2013). Tremendously, and in every age group, numbers of people declare religion to be an vital part of their daily life (Markides \& Cole, 1984). However, cohort members' characteristics and cohort differences cause a dissimilarity in consumer values and choice behaviours (Hung, et al., 2007). Each cohort's needs and wants have been found to influence purchasing motives (Parment, 2013). Hence generation cohort also acts as a potential moderator of relationships between customers' religiosity, buying attitude and purchase intention in favour of a particular category of IFP. This leads to the following hypothesis:

H6: Generation cohort moderates the relationship among religiosity, buying attitude and purchase intention in favour of different product category of IFP.

Consumption-related values, their ties to religiosity and the connection between religiosity and preferences for purchasing different products among different generational cohorts, provide a complete range of religious consumers in each cohort as market segment (Loroz, 2006). Traditionalist cohort, the older generation of Bangladesh, have gone through significant violent events and economic suffering during their lives. They were deprived mainly of basic needs but sacrifice for the common good was widely accepted among these cohort members (Khan, 2010). Their experiences of living on the poverty line, insecure about their lives and shelter needs, and deprived of basic health care, education and other needs made them give priority to ensuring their basic needs were met, and value safety and security. It is also argued that early life experiences shape the saving, safety assurance and risk aversion characteristics of these cohort members (Schewe \& Noble, 2000). Therefore, these Traditionalist traits steer them to a preference for deposit products that save for long-term 
needs and insurance products that keep them safe from probable losses. As there are religious people in almost every segment of society (Gay \& Lynxwiler, 2013), it is argued that levels of religiosity and the financial needs of Traditional cohort consumers strongly influence purchases of Islamic deposit and insurance products. It is assumed that the more religious will be GenY, so the members of this cohort may have a more favourable attitude and preferences for Islamic credit and capital market products. Thus, the favourable attitude and preferences for Islamic credit and capital products may predispose them to having a greater intention to buy these products.

H6a: The greater the religiosity of traditionalist Muslim consumers, the greater the purchase intention for Islamic deposit and insurance products.

Swing generation, who are the middle generation, went through when the economy was slowly gaining some momentum (Littrell, Ma, \& Halepete, 2005). Swing generation's coming-of-age experience consisted of economic fall down and growth. During the first phase of post-war and the clientelistic government period, this cohort experienced unemployment, poverty, financial insecurity and food scarcity but, by the middle of the period, they experienced a time of remarkable growth of social security and safety. During this period, people were starting to find their own way for living. Overall, this cohort participated in the rise of the middle class and acquired a sense of security and stability (Khan, 2010). Experience of food shortages, being without jobs and financial crisis at some stage during the economic down period created a need in the Swing cohort for savings and security (Schewe \& Noble, 2000). Economic rises during the coming-of-age years rule the Swing cohort's need of investment. This need created people's interest in taking risks for favourable returns, in order to recover their own way of living and increase living standards. The religious people of this cohort will prefer the financial products that comply with Islamic Shariah. Therefore, it has been posited that the Swing generation's religiosity and financial needs influence preferences to purchase Islamic deposit, credit, capital market and insurance products.

H6b: The greater the religiosity of the Swing generation Muslim consumers, the greater the purchase intention of Islamic deposit, credit, capital market and insurance products.

GenY raised up during a relatively stable period of social and economic development (Wang $\& \mathrm{Wu}, 2002)$. Given that their formative years were spent in an era of accelerated economic 
growth and reduction in poverty, GenY enjoyed more educational and personal development opportunities and have been well-exposed to Western popular culture through their experience with foreign music, movies, television shows, magazines, internet and other media programmes. The members of this cohort group have a strong interest in selfindulgence and personal entertainment, and have a tendency to hold materialistic values (Dou, Wang, \& Zhou, 2006). They are individualistic and willing to try new things. With the rapid transformation taking place in the economy, along with increased income and consumers' habits, the behavioural patterns and tendencies of consumers have also changed for the betterment of life (Kaynak, et al., 2000). Due to the growing economy of Bangladesh today, GenY's desire for a diversion to relieve their stress and to enjoy themselves may be heightened. They have a tendency to earn favourable income, as well as to obtain consumer credit to buy products such as cell phones, laptops, cars etc. in order to maintain their lifestyle activities (Rahman, 2009). People in this generation should feel less need for protection and savings products. Thus, associating religiosity with the financial needs of GenY, religiosity influences preferences to purchase Islamic credit and capital market products.

H6c: The greater the religiosity of GenY Muslim consumers, the greater the purchase intention for Islamic credit and capital market products.

\subsection{Chapter Summary}

Religiosity is one of the most important contributors to consumption preference in an individual's perceptive structure. Peoples' religious differences are associated with their perception differences, and direct them in the process of choosing a specific product or services. Thus religiosity can form the basis of justifying how individuals make their purchase decisions when selecting products and services.

The empirical findings reviewed in this chapter provide some interesting evidence of a causal link between religiosity and buying behaviour, both in terms of consumers' attitude and purchase intention. Results indicate that intangible differences exist among individuals in terms of religiosity. Moreover, some contributions have been made regarding the influence of religiosity on certain aspects of consumer behaviour. Religiosity has an impact on consumption activities and consumer behaviour in different ways: firstly, religiosity influences the pattern of consumption; secondly, religiosity builds and conveys the meaning 
in products and services; and thirdly, religiosity effects how individuals make their purchase decisions.

The existing literature has based its religiosity measurements on a Western population comprised mainly of Jews, Catholics or Protestants. More recently, however, the influence of religiosity, specifically from an Islamic viewpoint, has gained momentum. Islam guides its followers in every aspect of life, including what they can consume. There are only a few studies that incorporate the relationship between Islamic religiosity and consumers purchase intention of IFPs, and most of previous findings of these studies were limited to only one product type, Islamic banking. Thus, there is a need to recognise whether religiosity influences the purchasing intention of other product categories of IFPs.

Relevant literature and previously proposed models of consumers' buying behaviour are reviewed to introduce a conceptual framework of this study. The requirement for a religiosity measure and constructs for operationalisation are discussed. Each of the three key model components is discussed, with respect to the linkages between each construct along with moderator, and thirteen hypotheses are proposed for testing. The study investigates the relationship between religiosity, buying attitude and purchase intention. The next chapter discusses the research methodology that is used to conduct the research, in order to answer the research question. 


\section{CHAPTER 4. Methods and Data}

\subsection{Introduction}

This chapter covers the research methodology and data collection procedures employed to test the conceptual model proposed in Chapter 3. The chapter begins with survey design and defines the explanatory and dependent variables in the study. The procedures adopted for sample selection and data collection are also discussed. The test of common method bias is explained next, followed by a description of the analytical techniques used for testing the hypotheses and answering the research questions.

\subsection{Research Design}

A number of factors should be considered when making a decision on whether to use qualitative or quantitative research. These factors include the researcher's own beliefs about the appropriate way to study human behaviour, the research questions, and the rigour of the research, which includes both the universality and verifiability of results. Other factors involve the degree of understanding of the problem provided by the method, the extent to which the results will generalise to other settings and persons, and the usefulness of the findings (Creswell, 1994; Maxwell, 1996; Patton, 1990).

This study adopted a quantitative research approach and the decision was guided by the purpose of the study, the nature of the research inquiry and the concepts to be investigated. The purpose of this study is to examine the possible relationship between religiosity and consumers' behaviour, which is explanatory in nature. Therefore, the quantitative approach is well-suited to addressing this research objective, where the main concern is establishing a causal relationship between two or more variables (Mokhlis, 2006b). Moreover, the quantitative approach is more suitable in this study for hypotheses testing and generalisation.

Previous studies have shown that there is a substantial body of existing consumer literature on religion which conceptualises the nature of the relationships between religious variables and certain aspects of consumer behaviour (Mokhlis, 2006b). Quantitative research is more suitable in mature research streams that emphasise testing rather than exploration. A quantitative research approach allowed this study to examine the complex relationships between religiosity and elements of consumers' buying behaviour towards IFPs. 
The quantitative research approach also provides the researcher with additional credibility in terms of interpretations and the confidence level of the findings. Statistical technique applications (such as bivariate and multivariate) have the advantage of allowing the researcher to measure and control variables (Edwards, 1998). These statistical techniques help to describe a relationship in a way that makes understanding easier (i.e. the modelling role) and to assess the strength and validity of any relationship defined (i.e. the testing role) (Cowan, 1990).

\subsubsection{Survey Design}

A questionnaire was developed comprising five sections: religious commitment, buying attitude, purchase intention, generation cohort and demographic (see Appendix A3). The first section elicited information on how religious belief, practice, knowledge, experience and consequence each contribute to the religiosity of Muslim people. The next two sections reflected peoples' attitudes to, and interest in, buying IFPs. The last two sections of the survey questionnaire provided information on generational cohorts and identified which cohort groups the respondent belonged to and their socio-economic background. Respondents were offered an executive summary of the research findings on completion of the thesis work.

The questionnaire was designed in such a way as to uncover specific information on how religious belief, practice, knowledge, experience and consequence influence the religiosity of Muslim people in Bangladesh. As individuals disclose more sensitive information under anonymous conditions (Hill, Dill, \& Davenport, 1988; Klein \& Cheuvront, 1990; Ong \& Weiss, 2000; Werch, 1990), this study's questionnaire did not try to obtain any information that was traceable to the respondents, so they could be assured that the information they provided would be treated as confidential at all times. The wording of the survey questionnaire was kept simple to ensure respondents' participation: it avoided jargon and included commonly used words to ensure a universal meaning and relevance for all Muslims participating in the study. The questionnaires were prepared in both Bengali and English to facilitate the effective collection of information (see appendix A3 and A6).

The respondents were asked to rate most of the questions in the questionnaire on a Likert scale. The literature suggests that the scales used most often are 3 to 7-point Likert scales. Past research on the number of response categories varies from a 3-point scale to a 25-point 
scale, but the general rule suggested is plus 7 or minus 2 categories. There is a reasonable level of reliability on all 3, 5, 7 and 9-point scale categories. A 7-point Likert scale is used in this study to measure the intensity of responses, where 1 meant 'strongly disagree' and 7 meant 'strongly agree'. A 7 point Likert scale has been found to be more reliable since it allows for a greater differentiation of responses compared with a 5-point scale, whereas not artificially increasing differentiation, as might be the case where more scale points are offered (Lietz, 2010; Munshi, 1990). Moreover, 7-point scales can easily be rescaled in order to facilitate comparisons.

\subsubsection{Measuring the Explanatory Variables}

The five dimensions of religiosity, namely religious belief, practice, knowledge, experience and consequence were included in the questionnaire to establish their impact on buying behaviour. For each of the explanatory variables, respondents were asked to rate a number of statements drawn from the literature. This was done to assess the influence of the identified variables on the religiosity of people. The explanatory variables are defined in chapter 3 and the details of the questionnaire items to measure these variables are listed in Appendix A3.

Religiosity has a general dimension (faith) and is sub-divided into a set of more specific dimensions - belief (aqi'dah), practice ('amal), knowledge (ma'rifah), experience (ihsan) and consequence (natijah) (Ilyas, 1992). It is assumed that each of the five dimensions contributes to the variance of faith (Hassan, 2007; Stark \& Glock, 1968). Therefore, religiosity is measured in accordance with these five dimensions. The measures of the five dimensions are primarily borrowed from Glock and Stark (1968). Questions regarding religious belief include the overall beliefs associated with the religion, such as beliefs about God, the Prophet, the Quran and Hadith. The practice ('amal) dimension includes questions regarding actions prescribed by religion such as: prayer, fasting, Duas', reading the Quran, and giving Zakat. The knowledge (ma'rifah) dimension asked questions about an individual's basic knowledge about religion; offering Sajjda at saints' graves; earning through haram means; avoiding minor and major sin; and following Islamic junctions in all matters of life. The experience (ihsan) dimension describes the practicality of the religion and the six questions used to measure it included the feeling of doing something against faith; being tempted by the devil, being afraid of Allah; being punished by Allah for doing something wrong; seeing others following Islamic teaching; and the importance religion places on answering questions about the meaning of life. The consequence (natijah) dimension refers to the importance of 
religion itself, which is measured by asking questions about respect for others and allowing them their rights according to Islamic injunctions; avoidance of activities which hurt others; helping those who need help; being honest and fair with others; and avoiding humiliating others.

With cohort analysis, whether or not respondents are in the right generational cohort and their value structures cannot always be easily determined (Schewe \& Meredith, 1994). In order to identify the traits of each generational cohort and to make generational value assessments, the respondents were asked to tick the one statement of three that best described them. The statements were a short summary of all the traits of a particular cohort. The first statement specified the Traditional cohort. The second and third statement indicated the Swing cohort and GenY, respectively. The statements describing the generational cohorts were developed based on Inglehart $(1977 ; 1997)$. This analysis helped to justify the traits and value of each generational cohort. In accordance with the self-report and coming of age year, it is found that there is high correlation. Therefore, the study mainly based the historical events and coming of age year to identify the generational cohorts. Therefore, traditionalist cohort is defined as individuals who are born between the years 1929-1953; swing cohort is defined as individuals who are born between the years 1954-1972; and GenY is defined as individuals who are born between the years 1973-1993.

Religiosity, buying behaviour and the importance of choice criteria varies between customers of different demographic profiles (Devlin, 2002a, 2002b). Previous research has suggested that consumers' attitude and selection of financial services and products might depend on demographic factors such as age, gender, household income, and educational attainment (Boyd, Leonard, \& White, 1994; Denton \& Chan, 1991; Joy, Kim, \& Laroche, 1991; Speed \& Smith, 1992; Tan \& Chua, 1986). Therefore, in this study, the model attempted to investigate the moderating impact of such demographic factors on the relationship between religiosity and buying behaviour as used in one or more of the previous studies. The demographic profiles comprising gender, occupation, educational attainment and monthly income were included in the questionnaire.

\subsubsection{Measuring the Dependent Variables}

Religiosity is a major construct in describing certain aspects of consumer buying attitude and purchase decision, therefore attitude and behaviour depends on the individual's level of 
religiosity and the importance they place on religion itself. Accordingly, the dependent variables chosen include consumers' buying attitude and purchase intention.

This study defines attitude as the degree of favourableness and unfavourableness of an individual's feeling towards a psychological object (Ajzen \& Fishbein, 2000). “Consumers' attitude is a function of their evaluation of product-specific attributes or features" (Kotler, et al., 2004). Therefore, attitude towards IFPs is measured through people's evaluations, feelings and tendencies towards Islamic finance. The measurement scale is designed in such a way as to elicit the relevant attributes of Islamic finance that could determine peoples' perception of IFPs. The scale items are adopted from Gait \& Worthington (2009b) and Amin et al. (2011). The questionnaire statements asked the respondent to rate the degree to which: Islamic finance operates in accordance with the principles of Islamic law and follows interest-free and profit-and-risk-sharing principles; speculation is prohibited in Islamic finance; capital has a social and ethical purpose beyond pure and unfettered return; Islamic finance is in harmony with religious values.

A behavioural intention reflects a person's decision to perform the behaviour. Purchase intention of IFPs is measured in terms of a person's plan to engage in some action within a specified period of time, and the probability that he or she will perform a buying behaviour. Five items are used to measure the purchase intention, and the measurements items are adapted from Amin et al. (2011). There is a slight change in the wording of the statements in respect to IFPs, so it will be better understood by the respondents. The respondents were asked to rate the statements, which involved their eagerness to learn more about this product relating to Islamic Shariah; their interest in using Islamic financial products and services; their interest in using Islamic financial products and services in the future or someday; and whether they would recommend Islamic personal financing to others.

An additional measurement item relating to information about the respondents' preferences for the different categories of IFPs (deposit products, borrowing products, capital market products and insurance products) is included in this study.

\subsubsection{Common Method Variance}

Common method bias is a main source of measurement error and may have a significant impact on observed relationships between the measured variables (Bagozzi \& Yi, 1991; 
Nunnally \& Bernstein, 1994). Research findings can be seriously affected by common method biases. There are several sources of common method bias, including context and item characteristics and the use of the same respondent for independent and dependent measures. The two main techniques to control for method biases are through designing the study's procedures and controlling statistics (Podsakoff, MacKenzie, Lee, \& Podsakoff, 2003). In order to control method variance through procedural remedies, it is necessary to identify what the measures of the predictor and criterion variables have in common and eliminate or minimise it through the design of the study. It is recommended that method biases can be reduced by allowing the respondents' answers to be anonymous. Anonymity can lessen social desirability bias, as people are more likely to agree with controversial or sensitive issues. Moreover, the respondents should be assured that there are no right or wrong answers and they should answer questions as honestly as possible. On the other hand, method biases can also be lessened through the cautious construction of the scale items. The questionnaire was designed to avoid confusing and unfamiliar words, vague concepts, double-barreled questions and complicated syntax. The questionnaire was kept simple, specific and concise to reduce method biases (Podsakoff, et al., 2003; Tourangeau, 2000).

Self-report studies have the propensity to introduce biases in the data collected. While responses to items that seek to measure behaviour (such as positive or negative attitude and purchase intention) should not be adversely affected, religiosity items could suffer from social desirability biases due to the sensitive nature of the subject (Mokhlis, 2006b). It can be challenging to ask questions about religious behaviour as some respondents (particularly religious Muslims) may consider it a sensitive issue (Khraim, Mohamad, \& Jantan, 1999). Data was collected for this study through an anonymous questionnaire, as this technique is most suitable for generating a high response rate with less bias.

This study uses Harman's single-factor test and common latent factor approach in order to check the potential existence of common method bias (Harman, 1976; Podsakoff, et al., 2003). When applying Harman's single-factor technique, all items from each construct in the study are put into an exploratory factor analysis and the unrotated factor solution is examined to determine whether the majority of the variance can be accounted for by one general factor (Podsakoff, et al., 2003). The basic assumption of this test is that if one single factor emerges, or one factor accounts for more than $50 \%$ of the variance of the items in the factor analysis, then this indicates the presence of common method bias (Harman, 1976). This test was 
performed for this study and the results exposed multiple factors, with the largest factor accounting for $24.16 \%$ of the variance of the items. This result demonstrates that common method bias appears not to be present, according to Harman's single-factor test.

The latent variable model has been used as an additional statistical remedy to examine the possibility of common method bias. The common latent factor (CLF) approach includes adding a first-order factor with all of the measures as indicators to the conceptual model of the study (Podsakoff et al., 2003). In order to test for this possibility, the delta in standardised regression weights has been compared in both the model with CLF and without CLF. This test shows that the standardised regression weights of all items are less than 0.2 (where 02 represents a moderate effect).

Based on the procedural remedies and statistical tests (Harman's and CLF), it can be confirmed that the findings do not suffer from common method bias ((Podsakoff et al., 2003).

\subsection{Data Collection Procedure}

\subsubsection{Sample Selection}

As this study is interested in investigating consumers' behaviour in the Muslim religious context, Bangladesh was chosen as the field for this research. Bangladesh is one of the largest Muslim countries in South East Asia, with $89.5 \%$ of the total population being Muslim. The data for the study was collected from five major metropolitan cities in Bangladesh, including Dhaka, Chittagong, Rajshahi, Khulna and Sylhet, so that the collected data represents the country.

It is important to decide the minimum sample size prior to data collection, in order to achieve the desired level of statistical power with a given model (Hoe, 2008; McQuitty, 2004). The sample size required depends on the normality of the data and estimation method that researchers use (Schreiber, Nora, Stage, Barlow, \& King, 2006). It is generally agreed that sample sizes should be greater than 10 times the number of every free estimated parameter (Byrne, 2010). There is little agreement on the recommended sample size for SEM (Sivo, Fan, Witta, \& Willse, 2006), but the proposed critical sample size is 200 (Garver \& Mentzer, 1999; Hoelter, 1983). As a rule of thumb, any number above 200 is understood to provide sufficient statistical power for data analysis (Hoe, 2008; Sharma \& Singh, 2012). 
The target participants were 18 years of age and over, male and female, and Muslim. Religiosity is one of the most important variables to be measured and there are three cohort groups in the study. As the minimum sample size for SEM is more than 200, the study aimed to have at least 900 respondents (300 times three cohort groups). In each city, the target respondents were from leading public universities (both BBA and MBA students), business organisations (both government and private) and associations of retired employees.

\subsubsection{Data Collection}

Data was collected through a survey questionnaire, using a pencil and paper method. In order to conduct the survey, both personal contacts and the researcher's social networks were used to obtain the respondents from the above targeted organisations. The 'in person' approach is more personal and convenient, since respondents for an online survey may be difficult to obtain (Case \& Yang, 2009). It is worth mentioning here that the cultural attributes of Bangladesh mean that, in the case of survey research, people still place more value on person-to-person contact than on any other method of communication. Questionnaires were distributed to the participants with an invitation to take part in the survey. This had been arranged with the cooperation of lecturers at universities, senior management in business organisations and secretaries of retired employee associations, who were also asked to encourage students and employees to participate. The respondents were advised that their participation in the survey would be completely voluntary and anonymous. The respondents were not coerced to participate in any way, and the university students were also advised that their participation in the survey would not have any effect on their grade or position as a student. At this data collection stage, the following additional steps were carried out:

- Called respective department heads or lecturers at the universities and personally met them to obtain permission to conduct the survey. The surveys were conducted at the lecture theatres of the universities, with the lecturer's permission. The students placed the completed survey questionnaires into a box file at the end of the session.

- Called the corporate offices and their branches to make an appointment. The researcher personally met the respective person to hand over the questionnaires, with the respective authorities' permission. They distributed those questionnaires among employees. The employees dropped their completed questionnaires into the box file, which was kept at reception or in the manager's office. Phone calls were made after 
one or two weeks, depending upon the completion of survey, to ensure that the questionnaires had been received. The phone calls acted as a reminder to complete the survey. The researcher personally collected the box files later on from the relevant person in each business organisation.

- Called the main office of the Retired Employee Association in Dhaka to establish the right person to contact for conducting the survey on retired employees. A reference letter and the phone numbers of the respective divisional offices were collected from the main office. Those contacted were predominantly the secretaries of the associations. In accordance with their suggestions, questionnaires were distributed personally to retired employees at various events such as annual picnics, annual sporting functions, and get-together programmes. These events were useful for contacting a number of people at a time. In order to obtain the target number of completed questionnaires, respondents were also selected from libraries, medical centres and recreation centres on a daily basis.

A comprehensive record was kept, in order to follow up with the organisations and respondents and remind them to participate in the survey. All responses were coded in an excel spread sheet for further analysis.

\subsection{Analytical Techniques}

The data coded in an Excel spread sheet was later summarised using SPSS, and structural equation modelling (SEM) was used to analyse the data, validate the measurement model and test the hypotheses.

\subsubsection{Structural Equation Modelling}

Structural equation modelling (SEM) is used extensively in a number of academic disciplines, including the marketing arena (Chau, 1997; Maruyama, 1998). SEM is described as a powerful, yet complex, second-generation multivariate analysis technique (Fornell \& Larcker, 1981; Shook, Ketchen, Hult, \& Kacmar, 2004) that can be used for analysing results having a number of variables, allowing the assessment of measurement properties and theoretical (structural) relationships, including unobservable latent variables with multiple relationships, at the same time within the same analysis (Chin, 2000; Chin, 1998). In a more general form, SEM consists of multiple regression, factor analysis and path analysis 
techniques to simultaneously estimate the measurement of, and the relationships between, a number of theoretically related constructs (latent variables) (Hoyle, 1995; Jöreskog, 1993; Kelloway, 1998; Kline, 2011; Maruyama, 1998; Richard, 2008; Schumacker \& Lomax, 2004; Shook, et al., 2004).

There are four general advantages of SEM procedures over other multivariate analysis techniques based on the general linear model (Quintana \& Maxwell, 1999). Firstly, SEM and path analysis allow for greater flexibility when representing relationships among theoretical constructs than is possible with other GLM procedures (Kenny, 1979). A second advantage is that SEM, like factor analysis, allows researchers to posit latent constructs that are presumed to be the underlying causes of observed manifest variables (Bollen, 1989; MacCallum, 1995). Thirdly, in most other statistical procedures based on the general linear model, constructs are assumed to be measured without error; measurement error that is present but unaccounted for can bias statistical results, such as regression coefficients (Bollen, 1989). In contrast, SEM procedures can be employed to calculate the reliability of measurement instruments, as well as estimated latent constructs (Kenny, 1979). Fourthly, SEM provides assessments for the general compatibility that is goodness of fit of the model for the data also to evaluating the strength of relationships among constructs (Hoyle, 1995).

SEM is based on two very important techniques: covariance-based and principal componentbased (Richard, 2008). Covariance-based SEM is mainly applied for model validation, whereas principal component-based SEM is used for score computation that can be applied to small sample sizes (Tenenhaus, 2008). Covariance-based SEM presupposes data to be multivariate normal; this approach enables the requirements of univariate normality, linearity, homoscedasticity, nonmulticollinearity, and scaled relative variance to be met, and requires a large sample size (the definition of large varies from one author to another: samples of 250 or more are often mentioned) (Hair, Black, Babin, Anderson, \& Tatham, 2006; Kline, 2011; Richard, 2008; Schumacker \& Lomax, 2004). Data distributions without these assumptions may not provide valid SEM results. Therefore, covariance-based SEM does not cope well with comparatively small sample sizes when examining large numbers of links, non-linear relationships between variables and constructs, multicollinearity and heteroscedasticity (Gefen, Straub, \& Boudreau, 2000). The covariance-based SEM approach must be applied properly with regard to: (a) data characteristics (b) reliability and validity (c) evaluating 
model fit (d) model respecification and (e) equivalent models (Shook, et al., 2004). Covariance-based technique is used in this study.

\subsubsection{Confirmatory Factor Analysis}

SEM has been referred to as a combination of exploratory factor analysis (EFA) and multiple regressions (Ullman, 2001; Kaur \& Medury, 2013), because SEM is more of a confirmatory technique that can also be used for exploratory purposes (Schreiber, et al., 2006). SEM relies on theory in order to specify a model for testing. In comparison with confirmatory factor analysis (CFA), SEM extends the possibility of relationships among the latent variables, and model specification includes two distinct components: (a) a measurement model (essentially CFA) and (b) a structural model (Hoyle, 1995; Kline, 2005; Schreiber et al., 2006). Within SEM analysis, CFA is a confirmatory technique that is theory driven and employed to validate the items (indicators), explicitly measuring the individual latent variables.

\subsubsection{Path Analysis}

Path analysis is an extension of multiple regressions (Streiner, 2005; p. 115). This analysis helps to observe more than one dependent variable at a time and allows for variables to be dependent, with respect to some variables, and independent with respect to others. During the last few years, path analysis has been replaced in many cases by the more sophisticated SEM technique. This technique extends path analysis by looking at latent variables (Norman \& Streiner, 2003).

Structural model describes the interrelations among latent constructs and observable variables in the proposed model as a succession of structural equations to be estimated and tested (Hoyle, 1995). Structural model also identifies the way by which specific latent variables directly or indirectly influence (i.e. "cause") changes in the values of certain other latent variables in the model (Byrne, 2010; p. 13).

\subsubsection{Multiple-group Analyses}

The basic structural model can be extended in multiple-group analysis and the inclusion of means. These analyses are particularly powerful when they are applied at the same time, as these offer an alternative to analysis of (co)variance for testing multiple groups for different 
means (Hox \& Bechger, 1998). It is possible to analyse more than one group simultaneously in SEM and examine whether a specific model fits equally well in various groups.

\subsubsection{Analysis of Moment Structures (AMOS)}

AMOS (Analysis of Moment Structures) or in other words, the analysis of mean and covariance structures, is an easy-to-use programme for SEM data analysis that is used in this study. One can quickly specify, view, and modify specified models graphically using simple drawing tools with AMOS. This helps to assess a model's fit, make any modifications, and print out a publication-quality graphic of the final model (Arbuckle, 2010).

LISREL, AMOS, and EQS are three popular statistical packages for undertaking SEM. The first two are distributed by SPSS. LISREL made SEM popular in sociology and the social sciences and is the package of reference till now in most articles regarding structural equation modelling. AMOS is a more recent package which, because of its user-friendly graphical interface, has become popular as an easier way of specifying structural models (Kline, 2011; Rodniam, 2007).

\subsection{Chapter Summary}

This chapter outlined the methodological approach that is followed in this study. The research strictly follows a quantitatively-oriented approach. A quantitative method is executed in this study as it provides accuracy, reliability and testability. Moreover, it suggests a high degree of generalisability of the findings from the sample of the population. This study intends to test hypotheses that have been developed from existing theory and research. A survey method was used to collect the primary data required in this study because it is scientifically based and the findings can be quantified. A structured questionnaire was designed to collect the data through a field survey. The development of the questionnaire was based on the conceptual model that helps to identify the required information and the relationship that needed to be investigated. This study distributed and collected survey questionnaires from five public universities, 20 business organisations and five associations of retired employees in Bangladesh.

Structural equation modelling (SEM) and data analysis techniques were subsequently discussed. Because of the complexity of the Religiosity-Consumer Behaviour model, with 
latent variables taking on both dependent and independent roles, and a large sample size, an Analysis of Moment Structures (AMOS) programme was used to test the research hypotheses. The next chapter discusses the analytical procedures of data analysis, indicating the reason for their use, the technical approach followed and the assumptions of each technique applied. 


\section{CHAPTER 5. Data Analysis and Results}

\subsection{Introduction}

The purpose of this chapter is to present an analysis of the relevant data collected from the field survey conducted in Bangladesh. The chapter presents the results from the questionnaire survey, including the multigroup analysis techniques undertaken, and the results of the hypotheses testing.

\subsection{Survey Response Analysis}

\subsubsection{Response Rate}

In order to conduct research, scholars have to depend on the willingness of people to respond to questionnaires. A maximum response is not expected in studies where participation in a survey is voluntary (DeMaio, 1980). Survey methods using questionnaires should aim for the maximum response rate possible. Higher response rates lead to larger data samples and statistical power, as well as findings that have higher credibility among key stakeholders (Baruch \& Holtom, 2008; Rogelberg \& Stanton, 2007). The average aggregate response rate has settled at about 50\% as a benchmark at individual level (Baruch \& Holtom, 2008).

This study intended to collect data from a target sample size of 900. For purposes of multigroup analysis, this sample was split into three: a sample size of 300 for each sample group (Traditionalist, Swing and GenY cohorts). The minimum requirement of sample size depends on the function of the ratio of indicator variables to latent variables. According to Westland (2010), the rule of thumb requires choosing 10 observations per indicator in setting a minimum number of sample sizes. Several studies have concluded that 'the rule of 10 ' is a poor guide to the fit and explanatory power of the model or the adequacy of the sample size. On the other hand, minimum sample size also depends on the function of minimum effect, power and significance level. This is required to confirm or reject the existence of the smallest correlation between latent variables in an SEM model at given significance and power levels. While testing various hypotheses for model fit, it is important to have adequate power to identify when a hypothesis about model fit is false (MacCallum, Browne, \& Sugawara, 1996). Structural equation modelling (SEM) was used to analyse the data and the recommended sample size for SEM proposed a sample size above 200 for statistical power 
for data analysis (Hoe, 2008; Hoelter, 1983; Sharma \& Singh, 2012). Therefore, this study targeted 300 respondents from each cohort group in order to obtain responses from more than 200 people. A total of 1,800 questionnaires were distributed personally to public universities, business organisations (both public and private sector), and the retired employee associations of five major cities (Dhaka, Chittagong, Rajshahi, Khulna and Sylhet) in Bangladesh. Survey questionnaires totalling 1385 were returned, which corresponds to a total response rate of $76.94 \%$. Ninety-three of the questionnaires received were missing data, resulting in a usable response rate of $71.77 \%$ (1292 respondents).

Though large samples have many advantages, they may create potential problems when interpreting statistical significance. Researchers using statistical implication should be aware of the p-value problem related to large samples. P-values can quickly reach zero when a very large sample is used (Lin, Lucas, \& Shmueli, 2013). There is no commonly accepted definition of large (Pedhazur \& Schmelkin, 1991) but, in general, samples sizes of 50 as viewed as very poor, 100 as poor, 200 as fair, 300 as good, 500 as very good and 1000 as excellent (Comrey \& Lee, 1992; Nabatchi, 2007). The sample size of 1292 was larger than the intended sample size, which was useful for undertaking statistical analyses and modelling in this study.

\subsubsection{Respondent and Demographic Profiles}

Before analysing the data provided by the samples, it is important to obtain some insights into the characteristics of respondents who took part in this study, with respect to their demographic and socioeconomic profiles. This is a standard practice that provides a background for the analysis that follows. The characteristics that are discussed here include coming of age year, gender, marital status, occupation, education and household income, which are expected to be significant in the interpretation of the results (see Table 5.1).

The participating respondent profiles are presented in Table 5.1. For any sampling method, it is important that the sampled population is representative of the target population, at least with respect to the characteristics of interest to the survey (Statistics Canada, 2003). About $23 \%$ of Bangladesh's population has access to basic banking services. Basically all banking services are concentrated in urban areas (Bangladesh Bank, 2013). The sample used in this study covers five large metropolitan cities (Dhaka, Chittagong, Rajshahi, Khulna and Sylhet) and is broadly representative of the population of Bangladesh (UNPD, 2008). 
The respondents from the Traditionalist cohort are represented with 37.38\%. The sample representation of the Swing cohort is $34.52 \%$, and the GenY cohort is $28.32 \%$. This representation indicates a fairly evenly distributed sample from three different cohort groups. The majority of respondents described their characteristics in the same way as the characteristics have been defined in the generation cohort theory.

Males comprised $85.84 \%$ and females $14.16 \%$ of the total participants. The majority of the participants are male due to the context. Bangladesh is a moderate Muslim country. Traditionally, because of religious attitudes in this male-dominated society, males performed all financial activities, including banking. Therefore, female dominance has been irregular (Joshi, 2004).

The analysis of marital status revealed that more than half of the total sample, or $60 \%$ of the 1,292 respondents included were married, while $35.76 \%$ were single and $4.2 \%$ were categorised as divorced or widowed.

Occupational statistics showed that a large proportion of the respondents $(25.07 \%)$ were employees working in the private sector, while $16.57 \%$ of the respondents were government employees. Students and retired employees comprised $30.96 \%$ and $27.4 \%$ of the total sample respectively.

Educational statistics showed that $13 \%$ of the respondents possessed a higher secondary education. The largest percentage of respondents $(52.32 \%)$ had attained an honours degree or diploma, and $34.52 \%$ respondents had earned a postgraduate degree or above. The high proportion of respondents having a high education level is due to the urban nature of the sample.

The income frequency count showed that the majority of the respondents $(29.56 \%)$ mentioned their income level as 'not applicable'. The reason behind this is that same proportion of respondents in the sample was students, who identified their income level as not appropriate. $20 \%$ of respondents reported an income level less than BDT15,000, while $15.24 \%$ indicated income between BDT15,001 and BDT25,000. In addition, $14.55 \%$ of the respondents revealed income between BDT25,001 and BDT35,000, 15.32\% had income between BDT35,000 and BDT45,000, while 4.1\% respondents had income between 
BDT45,001 and BDT55,000. The remaining 1.24\% of the respondents reported total income between BDT55,001 and BDT65,000, or above.

Table 5.1: Respondent Profiles $(n=1,292)$

\begin{tabular}{|c|c|c|c|}
\hline Characteristics & Category & No. respondents & Total Sample \% \\
\hline \multirow[t]{5}{*}{ City } & Dhaka & 309 & 23.91 \\
\hline & Sylhet & 229 & 17.72 \\
\hline & Chittagong & 227 & 17.57 \\
\hline & Rajshahi & 288 & 22.30 \\
\hline & Khulna & 239 & 18.50 \\
\hline \multirow[t]{3}{*}{ 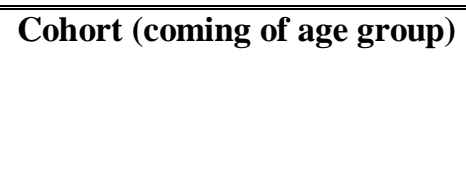 } & Traditionalist (aged between 58-82) & 483 & 37.38 \\
\hline & Swing (aged between 40-57) & 446 & 34.52 \\
\hline & GenY (aged between 18-39) & 366 & 28.32 \\
\hline \multirow[t]{2}{*}{ 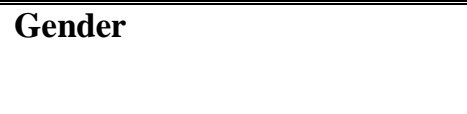 } & Male & 1109 & $85.84 \%$ \\
\hline & Female & 173 & $14.16 \%$ \\
\hline \multirow[t]{3}{*}{ Marital Status } & Single & 462 & $60 \%$ \\
\hline & Married & 774 & $35.76 \%$ \\
\hline & Divorced/widowed & 56 & $4.2 \%$ \\
\hline \multirow[t]{4}{*}{ Occupation } & Government employee & 214 & $16.57 \%$ \\
\hline & Private sector employee & 324 & $25.07 \%$ \\
\hline & Housewife/retired/unemployed & 354 & $27.4 \%$ \\
\hline & Student & 400 & $30.96 \%$ \\
\hline \multirow[t]{3}{*}{ Education } & "Higher Secondary School & 168 & $13 \%$ \\
\hline & Honours/Diploma & 676 & $52.32 \%$ \\
\hline & Master degree and above & 446 & $34.52 \%$ \\
\hline \multirow[t]{8}{*}{ Income } & Not appropriate & 382 & $29.56 \%$ \\
\hline & Less than Tk. 15,000 & 258 & $20 \%$ \\
\hline & Tk. $15,001-$ Tk. 25,000 & 197 & $15.24 \%$ \\
\hline & Tk. $25,001-$ Tk. 35,000 & 188 & $14.55 \%$ \\
\hline & Tk. 35,001 - Tk. 45,000 & 198 & $15.32 \%$ \\
\hline & Tk. 45,501 - Tk. 55,000 & 53 & $4.1 \%$ \\
\hline & Tk. 55,001 - Tk. 65,000 & 12 & $.92 \%$ \\
\hline & Tk. 65,001 and above & 04 & $.3 \%$ \\
\hline
\end{tabular}




\subsection{Measurement Refinement and Initial Analysis}

The literature of SEM and related studies recommends a two-step model building approach (Anderson \& Gerbing, 1988; Hair, et al., 2006; Schumacker \& Lomax, 2004). First step involved EFA, for untested new scales, and a confirmatory factor analysis (CFA), for preexisting validated scales, to purify and validate the measures. The second step involved building and testing the structural model. Since the study used existing scale to measure different constructs, CFA was used to confirm and reduce the number of items from the constructs (religious belief, practice, knowledge, experience, consequence, buying attitude and purchase intention). AMOS software was used to conduct the CFA and testing the model (Byrne, 2010).

\subsection{Confirmatory Factor Analysis and Measurement Model}

This study constructs two standard CFA models, the first-order CFA and second-order CFA. In creating two CFA models, the first step needed to include the scale items as the 'measured variables' and the item groups as the 'latent variables'. If there is adequate fit, then the next step proceeds to create the second model, in which the item groups are the 'measured variables' and the sub-scales are the 'latent variables'.

A confirmatory factor analysis (CFA) approach was used to test the factorial validity of the hypothesised measurement model before evaluating the structural (theoretical) model (Anderson \& Gerbing, 1988; Arbuckle, 2010; Bagozzi, 1994; Falk \& Miller, 1992; Fornell \& Yi, 1992; Jöreskog, 1993). Figure 5.1 shows the original measurement model, including all items related to each construct. The full-scale model, including all 36 items divided into the seven subscales, was tested in the whole sample. Based on examination of the fit of this model by inspecting standardised residuals and the modification indices (MI), the study respecified the model by removing items with cross-loadings on more than one factor, and reestimated the fit. Secondly, a multi-group CFA was used to test the invariance of the sevenfactor structure and the various respecified models across the three generational cohorts. Because multi-group analysis only provides overall fit indices, the study also conducted the same series of confirmatory factor analyses for each cohort group separately. Thirdly, through a multi-group CFA, this study estimated whether each subsample had equivalent factor loadings, factor variances and covariances (Byrne, 2001; Jöreskog \& Sörbom, 1997). 
A maximum-likelihood method has been used to examine the covariance matrix of the items. In large samples, the chi-square statistic, used as an overall index of model fit, is very powerful and may produce significant differences, even when the model fit is quite good (Byrne, 2001). Therefore, other fit indices which are not substantially affected by sample size are also used in the analyses i.e. the root mean square error of approximation (RMSEA), the Tucker-Lewis index (TLI), the comparative fit index (CFI), as well as Aikaike's information criterion (AIC). In general, models with fit indices $\geq .90$, an RMSEA $<.06$, and AIC with smaller values indicate a good fit (Byrne, 2001).

The results of the CFA are presented in Table 5.5. The original measurement model (Model 1) used for confirmatory factor analysis did not provide a reasonable fit to the data with $X^{2} / \mathrm{df}$ $=7.126, \mathrm{p}<0.000$, comparative fit index $(\mathrm{CFI})=0.816$, root-mean-squared error of approximation $(\mathrm{RMSEA})=0.069$. Factor loadings greater than \pm .50 are considered necessary for practical significance (Hair, Anderson, Tatham, \& Black, 1998) and the items that loaded less than .5 (Prac4, Prac5, Know1, Know2, Exp1, BAPrin4 and PurIntan4) have been removed from the model. As a way of improving the model fit, one of the suggestions made by the modification indices was adopted, connecting the error terms of PurIntan1 \& PurIntan3 (Kim, LaRose, \& Peng, 2009). However, upon inspection of MI values of error covariances, the study found that err21 and err16 are covarying extremely high with the other errors of the items within the same factor. Therefore these two items (Conq1 and Exp2) have been removed from the model. Afterwards, the residuals have been checked to establish the discrepencies between the proposed and estimated measurement models and look for patterns of larger residuals. Values $>2.58$ are considered large (Jöreskog \& Sörbom, 1988). These are indicative of possible fit problems in the model. Note that along with regular residuals, the study obtained standardised residuals. These are residuals divided by their standard error. These are, therefore, analogous to z-scores (Byrne, 2010). After examination, the residuals Exp3, Conq3, Conq4, BAPrin5 and BAPrin6 were removed from the model as their residuals value was more than 2.58 and was problematic for the model fit. Finally the study tested the fit of measurement model with 14 items removed. The final measurement model (Model 2) represents the measurement model with 14 items removed. Model 2 (Figure 5.2) provided the superior fit for the total sample, with CMIN/DF 4.798, CFI .938, TLI .924, NFI .923 and RMSEA value of .054. 
Figure 5.1: Original measurement model used for confirmatory factor analysis (Model 1)

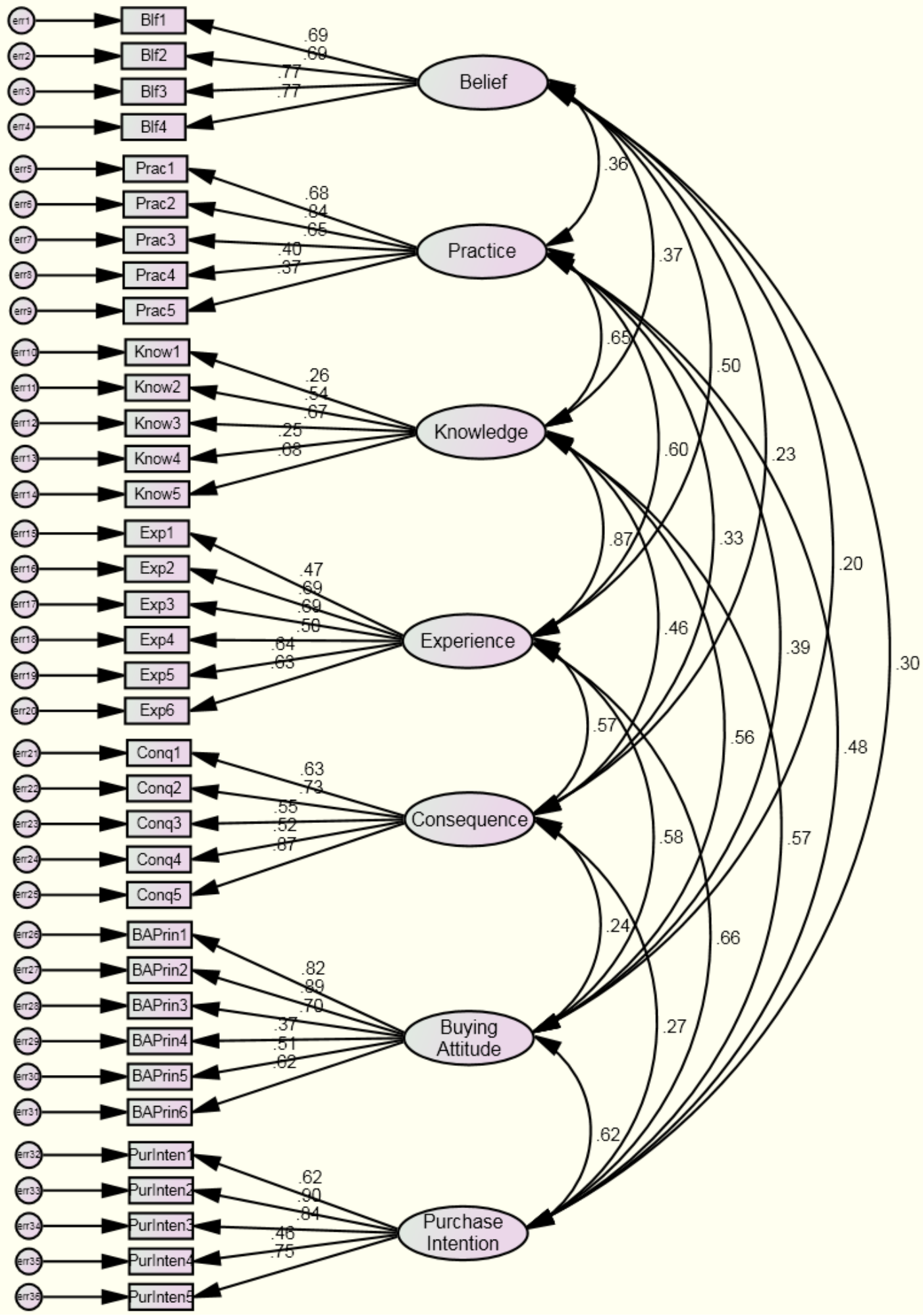


Figure 5.2: Final Measurement Model (Model 2):

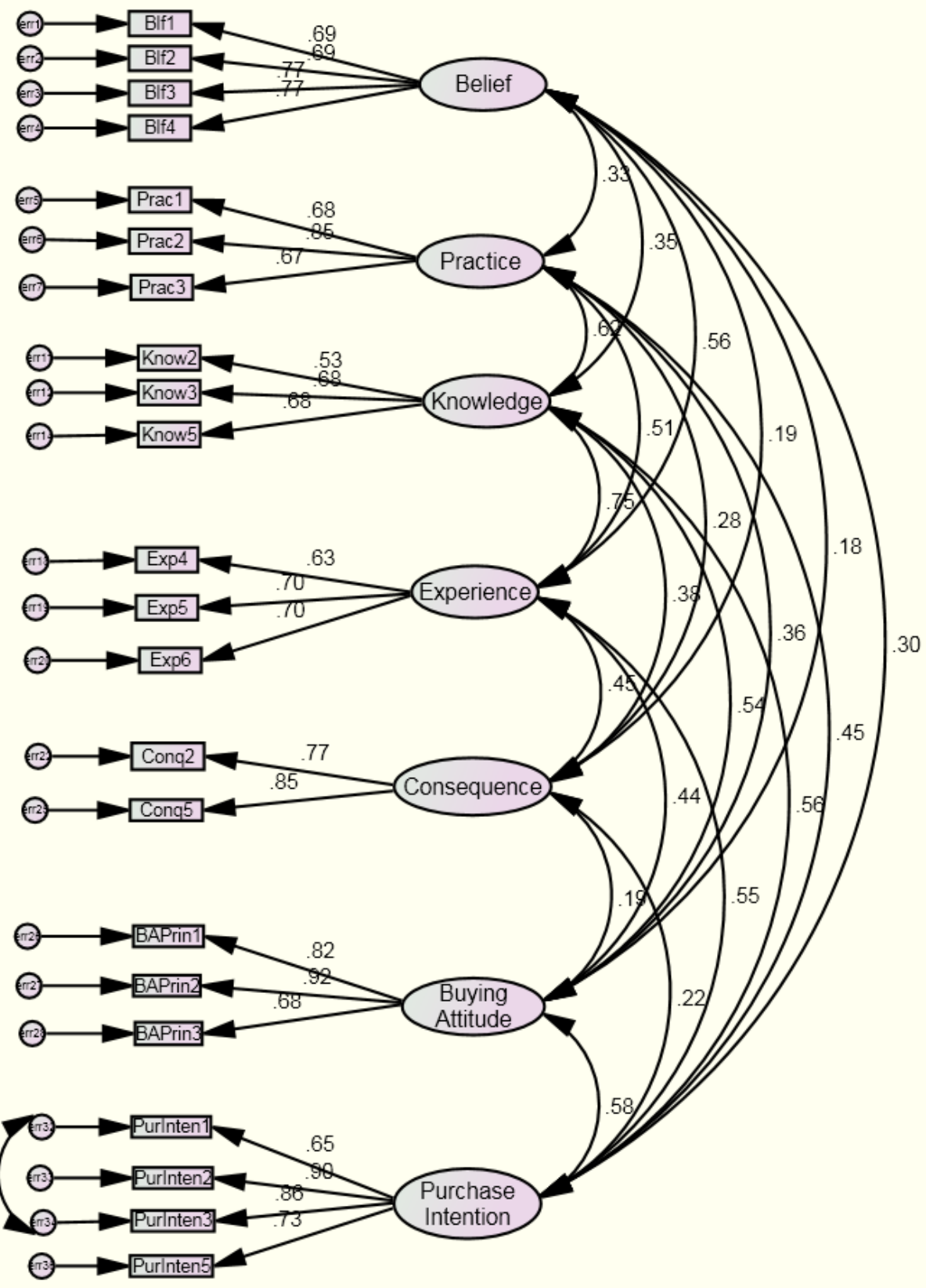




\subsubsection{Reliability and Validity Test}

It is essential to test reliability and validity to standardise the measurement scales, and to establish whether they truly measure what they are supposed to measure. In structural equation modelling (SEM), some statistical outputs can be used to measure the construct validity and reliability (Al-Hawari, Hartley, \& Ward, 2005). Both validity and reliability tests were conducted using CFA (Confirmatory Factor Analysis). In construct validity, four categories of validity have been used i.e. Convergent Validity, Variance Extracted, Construct Reliability, and Discriminant Validity (Arbuckle, 2010; Dimitrov, 2003; Hair, et al., 1998; Hwang, Chang, \& dan Chen, 2004; Lawson-Body, Willoughby, \& Logossah, 2010).

\subsubsection{Convergent Validity}

Convergent Validity refers to how much an indicator converges or shares in a single construct. An indicator is said to converge if it has a standardised factor loading value estimate greater than 0.5 and significant. As shown in Table 5.5, the standardised loadings for all the items are above 0.6.

In the next step, reliability and validity of the measures were tested calculating the composite reliability (CR) of the constructs and the average variance extracted (AVE) (Fornell \& Larcker, 1981). The construct validity is determined by the average value AVE (Average Variance Extracted). The AVE by a construct is a measure that reflects the overall amount of variance in the indicators accounted for by the latent construct (Hair et. al., 1998, p. 612). Guidelines suggest that the AVE value should exceed .50 for a construct. The average variance extracted for the different measures used in this study are greater than 0.5 for most constructs, except 0.4 and 0.46 for Knowledge and Experience, respectively (see Table 5.2). Although the Variance Extracted statistic for these two constructs falls slightly short of the .50 benchmark, the other test (such as convergent validity, construct reliability and discriminant validity) presented provide enough evidence to suggest that this questionnaire exhibits adequate reliability. AVE values got hold of the formula:

$$
\mathrm{AVE}=\quad \begin{aligned}
& \text { Sum of standardized Loading Square } \\
& -
\end{aligned} \text { Sum of Standardized Loading Square + Measurement error }
$$

Where, Measurement error $=1-(\text { Standardized Loading })^{2}$ 
Construct Reliability (CR) is intended to determine the consistency of the construct validity indicator. Construct reliability (shown in Table 5.2), being above or close to the generally used threshold of .6 (Matzler \& Waiguny, 2005), is satisfactory. Construct Reliability was calculated by the formula:

$\mathrm{CR}=\quad \begin{aligned} & \text { Square of Total Standardized Loading } \\ & - \text { Square of Total Standardized Loading }+ \text { Measurement error }\end{aligned}$

Table 5.2: AVE and Construct Reliability

\begin{tabular}{|l|c|c|}
\hline Constructs & Variance Extracted (AVE) & Construct Reliability (a) \\
\hline Belief & 0.53 & 0.82 \\
\hline Practice & 0.54 & 0.78 \\
\hline Knowledge & 0.4 & 0.67 \\
\hline Experience & 0.46 & 0.72 \\
\hline Consequence & 0.63 & 0.78 \\
\hline Buying Attitude & 0.66 & 0.85 \\
\hline Purchase Intention & 0.63 & 0.87 \\
\hline
\end{tabular}

\subsubsection{Discriminant Validity}

To assess discriminant validity, AVE and shared variance estimates should be compared (Fornell \& Larcker, 1981). Discriminant validity information should be reported to show that constructs adequately discriminate from each other. According to Fornell and Larcker (1981), average variance extracted (AVE) should be more than the correlation squared of two constructs to support discriminant validity (compare Table 5.3). All variance extracted (AVE) estimates in Table 5.3 are larger than the corresponding squared interconstruct correlation estimates (SIC) except two constructs: knowledge and experience. Therefore, the five constructs in the CFA model demonstrate discriminant validity. The other two constructs religious knowledge and experience - do not discriminate from each other, which mean the indicators have more in common with the construct they are associated with than they do with other constructs.

In some cases, these two dimensions are unable to detect unique differences (Furseth \& Repstad, 2006) since religious knowledge is obtained through religious experiences. But 
religious knowledge is not the same as religious experience and just knowing about something is not the same thing as experiencing it (Otterson, 2010).

Table 5.3: Discriminant Validity

\begin{tabular}{|c|c|c|c|c|c|c|c|}
\hline & Belief & Practice & Knowledge & Experience & Consequence & $\begin{array}{l}\text { Buying } \\
\text { Attitude }\end{array}$ & $\begin{array}{l}\text { Purchase } \\
\text { Intention }\end{array}$ \\
\hline Belief & & 0.11 & 0.122 & 0.315 & 0.038 & 0.033 & 0.087 \\
\hline Practice & & & 0.38 & 0.26 & 0.079 & 0.126 & 0.203 \\
\hline Knowledge & & & & 0.56 & 0.15 & 0.29 & 0.318 \\
\hline Experience & & & & & 0.205 & 0.198 & 0.298 \\
\hline Consequence & & & & & & 0.037 & 0.048 \\
\hline Buying Attitude & & & & & & & 0.338 \\
\hline Purchase Intention & & & & & & & \\
\hline
\end{tabular}

The discriminant validity test compares the average variance extracted (AVE) estimates for each factor with the squared interconstruct correlations (SIC) associated with that factor, as shown in Table 5.3. It has been noted that the interconstruct correlation (IC) between Knowledge and Experience is .75 and the squared interconstruct correlations (SIC) of this is .56. These two constructs are so strongly correlated that it is reasonable to question whether the study is really measuring two different constructs at all. To assess the discriminant validity between these two constructs, it is necessary to follow the chi square difference test (Segars, 1997). This test assesses the discriminant validity of two constructs by estimating the standard measurement model in which all factors are allowed to covary, creating a new measurement model identical to the previous one, except that the correlation between the two factors of interest is fixed at 1 and computing the chi-square statistics for the two models. For a discriminant validity test of Knowledge and Experience, the study modified the measurement model so that the covariance between the two factors is fixed at 1 . The model created as a result of this modification is called a unidimensional model and the model in which correlation between Knowledge and Experience is a free parameter that is estimated, referred to as the standard measurement model. When estimated, the unidimensional model displayed a model chi-square 1321.536 with $188 d f$. The standard measurement model showed that the chi-square for that model was 906.187 with $187 d f$, so the difference of chisquare was 415.349 (see table 5.4). To determine whether this value is statistically significant, the study must find the critical value of the chi-square for the degrees of freedom 
associated with the test. The $d f$ for the test is found for the two models 1 (188-187). The observed chi-square difference, the difference between the two models, was clearly significant at $\mathrm{p}=0.000$. On the other words, the standard measurement model in which the factors were viewed as distinct but correlated constructs provided a fit that was significantly better than the fit provided by the unidimensional model. In short, this test supports the discriminant validity of Knowledge and Experience.

Discriminant validity is confirmed if chi-square is significantly lower for the first model, as this recommends that that the better model was the one in which the two constructs were viewed as distinct (but correlated) factors (Anderson \& Gerbing, 1988; Bagozzi \& Phillips, 1982).

Table 5.4: Chi- square Difference Test

\begin{tabular}{|l|l|}
\hline Model 1 & Model 2 \\
\hline Chi-square $=906.187$ & Chi-square $=1321.536$ \\
Degrees of freedom $=187$ & Degrees of freedom $=188$ \\
Probability level $=0.000$ & Probability level $=0.000$ \\
\hline Chi-square difference $=415.349$ & \\
\hline$D f$ differences $=1$ & \\
\hline
\end{tabular}

\subsubsection{Second- order CFA Model}

In contrast to the previous application which focused on CFA first-order models, the next step examines a CFA model that comprises a second-order factor (see figure 5.3). The religiosity scale is that which measures degree of commitment related to the religious belief, practice, knowledge, experience and consequences components of Muslims' religiosity. CFA of a measuring instrument is most appropriately conducted with fully developed assessment measures that have demonstrated satisfactory factorial validity. Justification for CFA procedures in this study is based on theory and the religiosity score data is most adequately represented by a hierarchical factorial structure. The first-order factors are explained by a higher-order structure which, in the case of this study, is a single second-order factor of 
religiosity. In this study the CFA model tested hypothesises a priori that responses to the degree of religiosity can be explained by the five first-order factors (belief, practice, knowledge, experience and consequence) and one second-order factor (religiosity). In reviewing the goodness of fit statistics, it has been shown that the hypothesised model fits the data very well, as evidenced by the CFI of .933, TLI .923, NFI .928 and RMSEA of .056. It becomes interesting when it is compared with the AIC of a series of models specified a priori - the model with the lowest AIC being the best model among all models specified for the data at hand (Burnham \& Anderson, 2004). For this study, the AIC of the first order model is 1082.187; for second order model it is 550 (value of the AIC for a given data set has no meaning, but the smaller the better). In terms of very good fit of the model, together with the trivial nature of the MIs, it has been suggested that the second-order model is the optimal representation of Muslims' religiosity structure for Bangladeshi Muslims. 
Figure 5.3: Second Order CFA Model

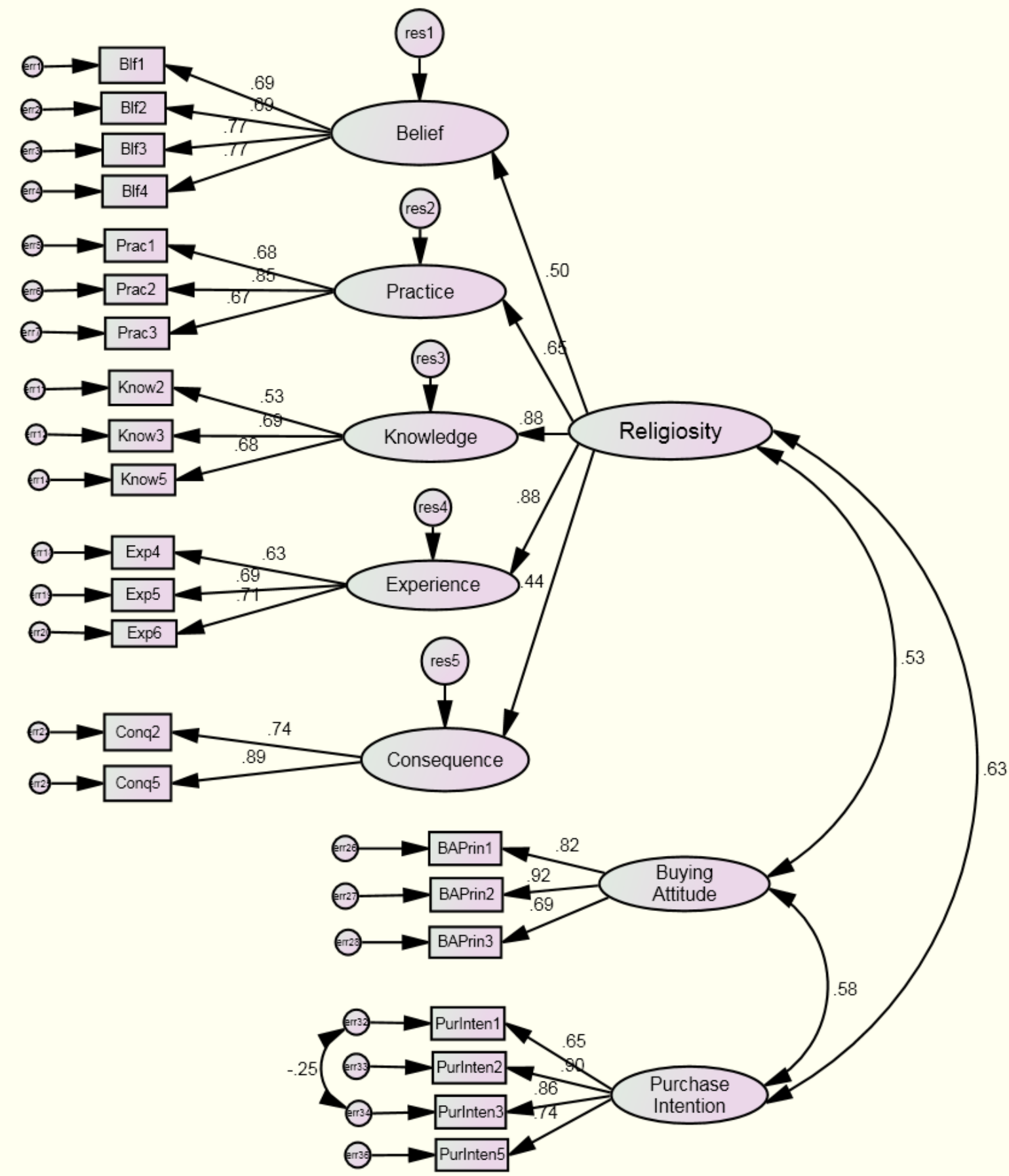

\subsubsection{Final Measurement Model}

The loadings for the fully assessed measurement model are shown in Table 5.5. All item loadings are greater than 0.50 (with the majority of items exceeding 0.70 ), are significant at 
the $\mathrm{p}<.001$ level, and demonstrate adequate convergent and discriminant validity. This measurement model has been assessed to move into the structural model (theoretical) and test the research hypotheses.

Table 5.5: Final Measurement Model Items, Loadings and Significance Values

\begin{tabular}{|c|c|c|c|c|c|}
\hline \multicolumn{2}{|c|}{ Factor/Construct } & Item & Label & Loadings & Significance \\
\hline \multirow{15}{*}{ Religiosity } & \multirow{4}{*}{ Belief } & Blf1 & $\begin{array}{l}\text { believe that there is no other God but Allah and } \\
\text { Mohammad (SWS) is His prophet }\end{array}$ & 0.69 & $\mathrm{p}<0.001$ \\
\hline & & Blf2 & $\begin{array}{l}\text { believe that there will be the end of time when } \\
\text { people will be judged according to how they } \\
\text { live their life in this world }\end{array}$ & 0.69 & $\mathrm{p}<0.001$ \\
\hline & & Blf3 & $\begin{array}{l}\text { believe that the Qur'an is the word of Allah, } \\
\text { thus its authority is justified }\end{array}$ & 0.77 & $\mathrm{p}<0.001$ \\
\hline & & Blf4 & $\begin{array}{l}\text { believe Hadith is the word of Prophet } \\
\text { Mohammad (SWS) and should live life } \\
\text { according to this }\end{array}$ & 0.77 & $\mathrm{p}<0.001$ \\
\hline & \multirow{3}{*}{ Practice } & Prac1 & engage in Dua'a & 0.68 & $\mathrm{p}<0.001$ \\
\hline & & Prac2 & pray five times a day & 0.85 & $\mathrm{p}<0.001$ \\
\hline & & Prac3 & read the Qur'an & 0.67 & $\mathrm{p}<0.001$ \\
\hline & \multirow{3}{*}{ Knowledge } & Know1 & $\begin{array}{l}\text { know the basic and necessary knowledge about } \\
\text { my religion }\end{array}$ & 0.53 & $\mathrm{p}<0.001$ \\
\hline & & Know3 & $\begin{array}{l}\text { always keep myself away from earning through } \\
\text { haram (prohibited) means }\end{array}$ & 0.68 & $\mathrm{p}<0.001$ \\
\hline & & Know5 & $\begin{array}{l}\text { always try to follow Islamic junctions in all } \\
\text { matters of my life }\end{array}$ & 0.68 & $\mathrm{p}<0.001$ \\
\hline & \multirow{3}{*}{ Experience } & Exp4 & $\begin{array}{l}\text { have the feeling of being punished by Allah for } \\
\text { doing something wrong }\end{array}$ & 0.63 & $\mathrm{p}<0.001$ \\
\hline & & Exp5 & $\begin{array}{l}\text { feel pleasure by seeing others following Islamic } \\
\text { teaching }\end{array}$ & 0.70 & $\mathrm{p}<0.001$ \\
\hline & & Exp6 & $\begin{array}{l}\text { religion is especially important because it } \\
\text { answers many questions about the meaning of } \\
\text { life }\end{array}$ & 0.70 & $\mathrm{p}<0.001$ \\
\hline & \multirow[b]{2}{*}{ Consequence } & Conq2 & try to avoid any activity that hurts others & 0.74 & $\mathrm{p}<0.001$ \\
\hline & & Conq5 & always avoid humiliating others & 0.85 & $\mathrm{p}<0.001$ \\
\hline \multirow{3}{*}{\multicolumn{2}{|c|}{ Buying Attitude }} & BAPrin 1 & $\begin{array}{l}\text { Islamic finance operates in accordance with the } \\
\text { principles of Islamic law (or Shariah) }\end{array}$ & 0.82 & $\mathrm{p}<0.001$ \\
\hline & & BAPrin2 & Islamic finance follows interest-free principle & 0.92 & $\mathrm{p}<0.001$ \\
\hline & & BAPrin 3 & $\begin{array}{l}\text { Islamic finance follows profit and risk sharing } \\
\text { principle }\end{array}$ & 0.68 & $\mathrm{p}<0.001$ \\
\hline \multirow{4}{*}{\multicolumn{2}{|c|}{ Purchase Intention }} & PurInten 1 & $\begin{array}{l}\text { eager to learn more about this product related to } \\
\text { Islamic Shariah }\end{array}$ & 0.65 & $\mathrm{p}<0.001$ \\
\hline & & PurInten2 & $\begin{array}{l}\text { interested in using Islamic financial products } \\
\text { and services }\end{array}$ & 0.9 & $\mathrm{p}<0.001$ \\
\hline & & PurInten3 & $\begin{array}{l}\text { interested in using Islamic financial products } \\
\text { and services in the future }\end{array}$ & 0.86 & $\mathrm{p}<0.001$ \\
\hline & & PurInten5 & $\begin{array}{l}\text { definitely recommend Islamic personal } \\
\text { financing to others }\end{array}$ & 0.73 & $\mathrm{p}<0.001$ \\
\hline
\end{tabular}




\subsection{Model Construction and Evaluation}

\subsubsection{Structural Model}

The structural model evaluation may begin once an acceptable measurement model is available. The initial Religiosity-Buying Behaviour structural model was constructed based on the extant literature, conceptualisation and theory. Each linked path between the constructs represents a specific research hypothesis to be tested. In this case there are 13 hypotheses to be examined. In the structural model presented in Figure 5.4, religiosity is treated as the exogenous variables, and the endogenous variables include buying attitude and purchase intention. The terms 'exogenous variables' and 'endogenous variables' are synonymous with independent and dependent variables, respectively.

The exogenous variable is located on the left side of Figure 5.4. Structural equation parameters represent paths from exogenous to endogenous variables (Koufteros, 1999). The initial structural model including path coefficients, $\mathrm{p}$-values, and variance explained $\left(\mathrm{R}^{2}\right)$ for each endogenous (dependent variable) construct is shown in Figure 5.4.

The results of fitting the structural model to the data indicate that the model with $\chi 2 / \mathrm{df}=5.05$ had a good fit as indicated by CFI 0.933, NFI 0.918, TLI .923 and RMSEA .056.

Figure 5.4 displays the results of the analysis. Three paths show a significant relationship between the constructs. Religiosity explains $28 \%$ of the variance of buying attitude and $48 \%$ of the variance of purchase intention is explained by religiosity and buying attitude.

The causal paths can be estimated in terms of statistical significance and strength using a standardised path coefficient that ranges between -1 and +1 (Hoe, 2008). Cohen (1988) provided rules of thumb for interpreting the effect sizes, suggesting that a correlation of $|.1|$ represents a 'small' effect size, $|.3|$ represents a 'medium' effect size and $|.5|$ represents a 'large' effect size. Religiosity has a strong positive impact on purchase intention $(\beta=.45, \mathrm{p}<.001)$ as well as on buying attitude $(\beta=.53, \mathrm{p}<.001)$. On the other hand, buying attitude has a medium positive impact on purchase intension $(\beta=.34, \mathrm{p}<.001)$. 
Figure 5.4: Second-order Structural Model

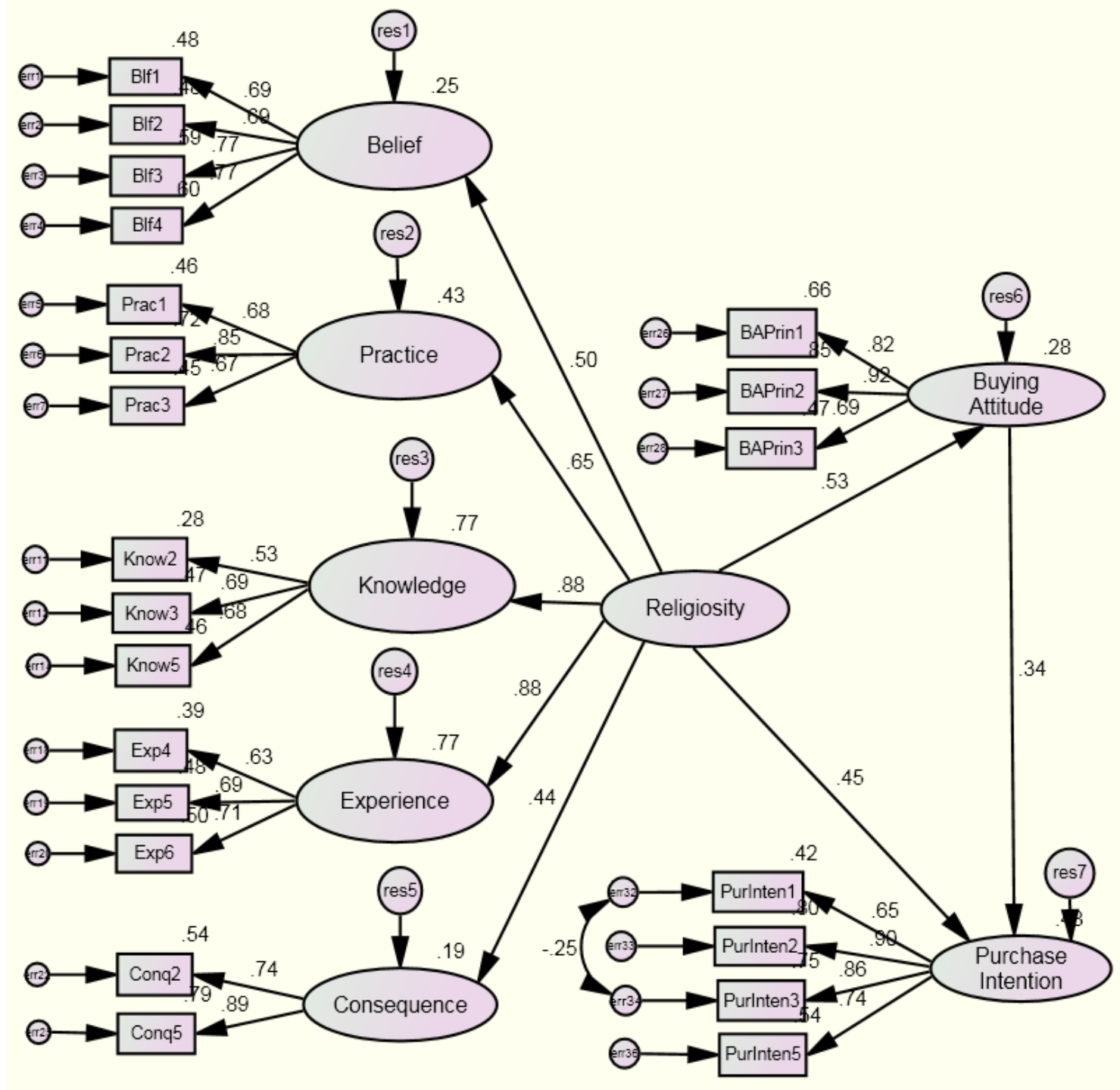


Table 5.6: Structural Model Path Coefficients and Significance Level

\begin{tabular}{|l|l|l|}
\hline & Path Coefficient & P value \\
\hline Religiosity $\rightarrow$ Purchase Intention & .45 & $\mathrm{p}<.001$ \\
\hline Religiosity $\rightarrow$ Buying Attitude & .53 & $\mathrm{p}<.001$ \\
\hline Buying attitude $\rightarrow$ Purchase Intention & .34 & $\mathrm{p}<.001$ \\
\hline
\end{tabular}

\subsubsection{Direct Effects}

In the structural model, all three of the hypothesised paths Religiosity $\rightarrow$ Purchase Intention $(\beta=.45)$, Religiosity $\rightarrow$ Buying Attitude $(\beta=.53)$, and Buying attitude $\rightarrow$ Purchase Intention $(\beta=.34)$, are significant at the $99.9 \%$ CI level. The model (refer to Table 5.6 and Figure 5.4) demonstrates that Muslim people's religiosity significantly and positively influences their purchase intention and buying attitude towards IFPs. It also demonstrated that buying attitude towards IFPs significantly and positively influences their intention to purchase IFPs. This finding is consistent with the underlying theory and conceptualisation of the original model. The original model hypothesised that religiosity contributed positively to the relationship between buying attitude and purchase intention. The result of the specified model provides empirical evidence that religiosity contributes to buying attitude and, as discussed below, indirectly to purchase intention.

\subsubsection{Total Effects}

The total effects consider not only the direct relations among the constructs, but also the indirect effects on the dependent (endogenous) variables (Cool, Dierickx, \& Jemison, 1989). Indirect effect is manifest in the model and relevant in the evaluation, interpretation and understanding of the total impact of one construct on another within the Religiosity-Buying Behaviour model. For example, from Table 5.7, even though religiosity has a direct effect on purchase intention, religiosity does have a positive and significant effect on purchase intention through buying attitude. Consider the effect of religiosity on purchase intention towards IFPs. The direct effect is .449 (the path coefficient from religiosity to purchase intention). The indirect effect, through buying attitude, is computed as the product of the path coefficient from religiosity to buying attitude and the path coefficient from buying attitude to purchase intention, $(.533)(.342)=.182$. The total effect is the sum of direct and indirect effects, $(.449+.182)=.631($ Kline, 2011) . 
The results of the total effects analysis demonstrate that religiosity positively and significantly influences customer relationship performance, through people's buying attitude. The results also show that the total effect of religiosity on purchase intention is much stronger than the direct effect of religiosity on purchase intention. The approximate criterion for strength of relationship is 0 for no effect, .1 for a small effect, .3 for a medium effect, and .5 for a large effect (Cohen, 1988).

Table 5.7: Direct, Indirect and Total Effects of Religiosity on Buying Attitude and Purchase Intention

\begin{tabular}{|l|c|c|c|}
\hline \multicolumn{1}{|c|}{ Paths } & Direct & Indirect & Total \\
\hline Religiosity $\rightarrow$ Purchase Intention & .449 & .182 & .631 \\
\hline Religiosity $\rightarrow$ Buying Attitude & .533 & --- & .533 \\
\hline Buying attitude $\rightarrow$ Purchase Intention & .342 & --- & .342 \\
\hline
\end{tabular}

\subsection{Multigroup Analysis}

\subsubsection{Measurement Model Invariance Across group}

Researchers are often interested in investigating the differences in the constructs of interest across groups by gender, age, socioeconomic status, ethnicity, and other grouping variables (Byrne, 2010; Dimitrov, 2010). A central question to be addressed prior to comparing groups on a construct is whether the construct has the same meaning for each group. In other words, is the measurement model group-invariant? Typically, this question is addressed through testing for factorial invariance of targeted constructs across groups. The invariance of a factor model over different groups is called factorial invariance (or multiple-group invariance). Although there are approaches to testing multiple-group invariance in the framework of EFA (Cliff, 1966; Meredith, 1993; Zumbo, Sireci, \& Hambleton, 2003), they focus only on similarity of factor patterns across groups. The literature suggests that configural, metric and scalar invariance should be established before comparisons across groups can be meaningful 
(Hong, Malik, \& Lee, 2003; Meredith, 1993; Steenkamp \& Baumgartner, 1998; Vandenberg \& Lance, 2000; Teo, Lee, Chai, \& Wong, 2009).

\section{Box 1: Testing for measurement invariance: a summary of recommended steps}

Step 0: Testing for the configural (CFA) model for each group separately. Ideally, the model should be the same for all groups or contain minor variations. The fit indices should be above the rules of thumb. The number and pattern of factor loadings should be the same and significant [substantive and statistical; usually above 0.40; (Brown, 2006): 130].

Step 1: Testing for the configural model for all groups together (multigroup model). If the fit indices are above the rules of thumb the model has a similar factor structure, but it is not necessarily equivalent across groups.

Step 2: Testing for metric invariance. Constrain the factor loadings to be equal across groups and check the fit of the metric model. If the fit difference between configural and metric models is above the rules of thumb, look for the source of misfit and free some factor loadings (partial metric invariance) or eliminate some groups from analysis.

Step 3: Testing for scalar invariance. Constrain the intercepts to be equal across groups and check the fit of the scalar model. If the fit difference between metric and scalar models is above the rules of thumb, look for the source of misfit and free some intercepts (partial scalar invariance) or eliminate some groups from analysis.

Step 4: Chose a reference group and set its mean to zero. Compute and compare the mean of latent variable across groups.

Source: (Comşa, 2010, p. 647)

\subsubsection{Configural Invariance}

Invariance of the model configuration (the pattern of free and fixed model parameters) across groups is referred to as configural invariance; the term form invariance is also used in the literature (Teo, et al., 2009). All tests for invariance begin with the configural model, for which interest focuses on the extent to which the same number of factors best represents the data for all the groups. As such, no equality constraints are imposed and judgment is based on the adequacy of the goodness-of-fit statistics only (Byrne, 2010; p. 239). In this regard, the 
configural model was found to be well fitting in its representation of the multigroup student data $(\chi 2 / \mathrm{df}=3.130 ; \mathrm{CFI}=.90 ; \mathrm{RMSEA}=.041)$. This finding allows this study to proceed to the next step while keeping in mind that configural invariance is a pre-condition for metric invariance (Comşa, 2010).

\subsubsection{Metric Invariance}

Metric invariance test confirms that different groups respond to the items in the same manner, so that researchers may compare ratings obtained from different groups in a significant way (Hair et al., 2006; Steenkamp \& Baumgartner, 1998). According to Teo, et al. (2009), metric invariance allows researchers basically to compare the strength of connections between constructs among different groups. At this stage, the model with metric invariance is more restrictive than the baseline model. Metric invariance test is directed by constraining the factor pattern coefficients (loadings) to be equal across groups since the pattern coefficients carry the information about the relationship between latent scores and observed scores. When metric invariance is established, the different scores on the item can be meaningfully compared across groups, that is, observed item differences indicate group differences in the underlying latent construct (Steenkamp \&Baumgartner, 1998).

In this stage, the model has tested for metric invariance by imposing constraints on particular parameters (Bentler, 2004; Jöreskog \& Sörbom, 1997; Comşa, 2010). Testing for metric invariance means that the factor loadings between the indicators and their corresponding factor were constrained to be the same in each cohort group. These constraints appear in Model 1. The fit indices suggest that the metric invariance model should not be rejected $(\chi 2 / \mathrm{df}=3.475, \mathrm{RMSEA}=.044$, Pclose $=1.000$.

Even though the fit indexes for the metric model look fine, they are not as good as those associated with the configural model ( $\chi 2 / \mathrm{df}$ drops .317 and CFI .02). Usually, for model comparison and assessing multi-sample model invariance, instead of $\chi^{2}$ difference test $\left(\Delta \chi^{2}\right.$ test), a difference in CFI $(\triangle \mathrm{CFI})$ and RMSEA ( $\triangle \mathrm{RMSEA})$ can be the basis of an invariance decision (Chen, 2007; Cheung \& Rensvold, 2002).

Chen (2007) suggested that a more parsimonious model is supported if the change in the CFI is less than .01 or if the change in the RMSEA is less than .015 ( $\triangle$ CFIs $\leq .01, \Delta$ RMSEAs $\leq$ .015).).The results from the generation cohort-based tests of measurement invariance for the 
first-order structure revealed that the first steps of invariance testing resulted in significant $\chi^{2}$ and CFI ( $\triangle$ CFI .02) but a non-significant RMSEA ( $\triangle$ RMSEA .003). Using the RMSEA difference test as the criterion upon which to determine evidence of invariance, the factor loadings were concluded to be operating similarly across Traditionalist, Swing and GenY cohorts.

\subsubsection{Scalar invariance}

The third step includes the scalar invariance test. When testing scalar invariance, the item intercepts are equated across the samples. If the model fit does not prove to be significantly worse in comparison with the metric invariance model, this means that scalar invariance is given. Scalar invariance guarantees the comparability of values measurements and allows the comparison of latent means (Meredith 1993; Steenkamp and Baumgartner 1998). Comparisons of latent means between the groups are important under such conditions as they assure that dissimilarities or similarities in factor means are a result of differences in the scores of the value questions and not due to differences in intercepts or factor loadings (Davidov \& Depner, 2011).

This step in the process involved constraining the intercepts for each observed variable to be equal across groups (constrained model $\chi 2 / \mathrm{df}=3.739$; $\mathrm{RMSEA}=0.046$; Pclose $=1.000$ ). Again, the chi-square difference test was significant $\left(\Delta \chi^{2}(14)=320.21, \mathrm{p}=.000\right)$, and also the difference between the CFI values did not meet the recommended cut-off criterion of .01 $(\Delta \mathrm{CFI}=.022)$. On the other hand, RMSEA value increased to .002 and met the threshold. According to Chen's criteria (2007), one of the global fit measures decreased in fit beyond the critical recommended values. As per the result, we cannot reject the scalar invariance model (Hu \& Bentler, 1999; Marsh, Hau, \& Wen, 2004).

The above results of the metric and scalar invariance tests allowed accepting the hypothesis of equal intercepts and equal regression weights in the measurement model. It was important to establish the credibility of this hypothesis because without equal intercepts and equal regression weights it would be unclear whether the factors have the same meaning for Traditionalist and Swing as they do for GenY, and so it would not be of interest to compare their means (Arbuckle, 2010). As the scalar invariance was supported, the mean comparisons were carried out with confidence. 
Group differences among the Traditionalist, Swing and GenY factor means can be determined from the following estimates of latent mean differences in the Measurement intercepts model.

\subsubsection{Latent Mean Differences}

As the scalar invariance was guaranteed, it was considered interesting to test whether value means differed across the samples. As configural, metric, and scalar invariance had been confirmed, the comparison of latent mean values between the survey samples was allowed. The latent means were then compared across the samples. The means in one group were restricted to zero and in the other group they were freely estimated. It was not possible to estimate all means for three groups at once, but the difference between the mean of Traditionalist, Swing, and Generational cohorts would be the same, no matter which (group's) mean is fixed and no matter what value (zero, 1, 2, 3...) is fixed for it. If estimated means in the freely estimated group differed significantly from zero, the conclusion was drawn that means in both groups differed significantly from each other. Table 5.8 displays the latent mean differences for the seven constructs among the three generational cohorts.

Firstly, the mean values were set to zero in the Swing cohort (known as the reference group) and were freely estimated for the Traditionalist and GenY sample. Results show significant mean differences for the constructs belief, practice, knowledge, experience, consequence, buying attitude and purchase intention between Traditionalist and both Swing and GenY cohorts. Given that the latent mean parameters were estimated for the Traditionalist cohort with Swing and GenY, and that they represented positive values, we interpret these findings as indicating that Traditionalists appear to have significantly higher religiosity than Swing and GenY cohorts with respect to practice, knowledge and experiences, but little difference in the belief and consequence aspects. On the other hand, when it comes to buying attitude and purchase intention of IFPs, the Traditionalist cohort has a more positive attitude and purchase intention than the GenY and Swing cohorts.

Next, the GenY group was designated as the reference group and thus their factor means were fixed to zero and were freely estimated for the Swing cohort. The values reported in Table 5.8 represent latent mean differences between the GenY and Swing groups. Reviewing these values, we see that whereas the latent factor means related to the more specific facets of religious knowledge and buying attitude towards IFPs were statistically significant (as 
indicated by the critical ratio values $>1.96$ ), this was not the case for religious belief, practice, experience, consequences and purchase intention towards IFPs (as indicated by the critical ratio values $<1.96$ ). We can interpret these findings as representing that GenY has significantly lower religious knowledge and buying attitude towards IFPs than Swing.

Table 5.8: Latent Means Differences of the Constructs

\begin{tabular}{|c|c|c|c|c|c|c|c|c|c|}
\hline \multirow[t]{2}{*}{ Constructs } & \multicolumn{3}{|c|}{ Traditionalist and Swing } & \multicolumn{3}{|c|}{ Traditionalist and GenY } & \multicolumn{3}{|c|}{ GenY and Swing } \\
\hline & Estimates & C.R. & $\mathrm{P}$ & Estimates & C.R. & $\mathrm{P}$ & Estimates & C.R. & $\mathrm{P}$ \\
\hline Belief & .072 & 2.804 & .005 & .073 & 2.563 & .010 & .002 & .069 & .945 \\
\hline Practice & .347 & 7.407 & $* * *$ & .373 & 7.885 & $* * *$ & -.055 & -.995 & .320 \\
\hline Knowledge & .171 & 4.163 & $* * *$ & .453 & 7.808 & $* * *$ & -.246 & -4.206 & $* * *$ \\
\hline Experience & .203 & 4.971 & $* * *$ & .177 & 3.723 & $* * *$ & .005 & .100 & .921 \\
\hline Consequence & .098 & 3.067 & .002 & .098 & 2.894 & .004 & -.001 & -.034 & .973 \\
\hline $\begin{array}{l}\text { Purchase } \\
\text { Intention }\end{array}$ & .119 & 3.236 & .001 & .240 & 4.547 & $* * *$ & -.092 & -1.680 & .093 \\
\hline $\begin{array}{l}\text { Buying } \\
\text { Attitude }\end{array}$ & .148 & 2.249 & .025 & .393 & 4.696 & $* * *$ & -.252 & -2.708 & .007 \\
\hline
\end{tabular}

\subsubsection{Group Comparison}

The hypothesised model with multigroup analysis shows a good fit with the data encompassing Traditionalist, Swing, and GenY groups: $X^{2}=1939.749$, df $=600, p<0.001$, comparative fit index $(\mathrm{CFI})=0.89$, root-mean-squared error of approximation $(\mathrm{RMSEA})=$ 0.042 .

A multigroup analysis was performed to test H5. The multigroup analysis can be used for checking whether the same path model can be applied across different sets of data. In other words, if there is any significantly different causal path among three different cohort groups, it means that certain causal relationships in the hypothesised model might be stronger (or weaker) for certain activity than those of the remaining activities. The main focus of the comparison across the three cohort groups was to establish whether any causal path in the hypothesised model differed significantly between the three cohorts. Thus, each of the three causal paths was constrained to an equal value across the three cohort groups one at a time and contrasted against the model without any constraint. The $\mathrm{X}^{2}$ of each model with one path constrained to equality was contrasted against that of the unconstrained model. If any of the $\mathrm{X}^{2}$ of the model with one constrained path became significantly worse than that of the 
unconstrained model, it can be concluded that the constrained path coefficient is significantly stronger or weaker for certain groups compared with the others. In the first multigroup analysis, all the paths (i.e. religiosity $\rightarrow$ purchase intention; religiosity $\rightarrow$ buying attitude; and buying attitude $\rightarrow$ purchase intention) are significantly positive for each of these three cohorts. As shown in table 5.9, the path differences along these three paths are not significantly different across cohorts except the path from religiosity $\rightarrow$ buying attitude, where GenY differs from both Traditionalist and Swing cohorts.

Table 5.9: Group Comparison on the Basis of Cohort (Standard Coefficients for each Path of Traditionalist, Swing and GenY)

\begin{tabular}{|l|l|l|l|l|l|l|}
\hline & \multicolumn{2}{|l|}{ Traditionalist } & \multicolumn{2}{l|}{ Swing } & \multicolumn{2}{l|}{} \\
\hline Paths & $\begin{array}{l}\text { Standard } \\
\text { coefficients }\end{array}$ & P-value & $\begin{array}{l}\text { Standard } \\
\text { coefficients }\end{array}$ & $\begin{array}{l}\text { P- } \\
\text { value }\end{array}$ & $\begin{array}{l}\text { Standard } \\
\text { coefficients }\end{array}$ & $\begin{array}{l}\text { P- } \\
\text { value }\end{array}$ \\
\hline $\begin{array}{l}\text { Religiosity } \rightarrow \\
\text { Purchase Intention }\end{array}$ & .38 & 0.001 & .51 & 0.001 & .40 & 0.001 \\
\hline $\begin{array}{l}\text { Religiosity } \rightarrow \text { Buying } \\
\text { Attitude }\end{array}$ & $.30^{c}$ & 0.001 & $.46^{c}$ & 0.001 & $.67^{\text {ab }}$ & 0.001 \\
\hline $\begin{array}{l}\text { Buying attitude } \rightarrow \\
\text { Purchase Intention }\end{array}$ & .40 & 0.001 & .32 & 0.001 & .35 & 0.001 \\
\hline
\end{tabular}

Note: ${ }^{a}$ significantly different from the Traditionalist sample ${ }^{b}$ significantly different from the Swing sample csignificantly different from the GenY sample

\subsubsection{Product Preferences Across group}

In the next step, another multigroup analysis was performed to test Hypothesis 6. The main focus of this multigroup analysis was to examine whether or not the paths differed significantly between three different cohort groups across four preferable IFP categories (i.e. deposit products, credit products, capital market products and insurance products).

The first hypothesised model with deposit products (Product Category 1) shows a good fit with the Traditionalist, Swing, and GenY multigroup: $X^{2}=1385.774$, df $=435$, $p<0.001$, comparative fit index $(\mathrm{CFI})=0.90$, root-mean-squared error of approximation $(\mathrm{RMSEA})=$ 0.041. The second hypothesised model with credit products (Product Category 2) also shows 
a good fit with the data: $\mathrm{X}^{2}=1317.123, \mathrm{df}=435, \mathrm{p}<0.001$, comparative fit index $(\mathrm{CFI})=$ 0.904, root-mean-squared error of approximation $($ RMSEA) $=0.040$. With capital market products (Product Category 3), the third hypothesised model also exemplifies a good model fit with $\mathrm{X}^{2}=1331.172, \mathrm{df}=435, \mathrm{p}<0.001$, comparative fit index $(\mathrm{CFI})=0.903$, root-meansquared error of approximation $($ RMSEA $)=0.040$. Finally, a good model fit is also exposed by the fourth hypothesised model with insurance products (Product Category 4) where $\mathrm{X}^{2}$ $=1309.978, \mathrm{df}=435, \mathrm{p}<0.001$, comparative fit index $(\mathrm{CFI})=0.903$ and root-mean-squared error of approximation $($ RMSEA $)=.039$.

The influences of religiosity on buying attitude and purchase intention, and the impact of buying attitude on purchase intention towards different product categories are analysed and presented in the following Table 5.10. The deposit products model shows that religiosity has positive effects on both buying attitude and purchase intention for all the generation cohorts, except GenY cohort's religiosity has no significant direct effect on its willingness to buy deposit products. But religiosity has a positive indirect effect through buying attitude. Religiosity has a positive effect on consumers' buying attitude and purchase intention, and buying attitude also has a positive impact on purchase intention for the Generation cohort in the credit products model. The Traditionalist cohort's religiosity has no significant direct effect on consumers' willingness to buy credit products, but has an indirect effect through buying attitude. The capital market products model shows the positive direct effect of religiosity on buying attitude, and buying attitude on purchase intention for all cohort groups. But there is no direct effect of religiosity on purchase intention of capital market products for Traditionalist and GenY groups, with the exception of the Swing cohort. Moreover, religiosity has an indirect effect on purchase intention through buying attitude for Traditionalist and GenY groups. The insurance products model shows that religiosity positively influences the buying attitude of all cohorts. But both religiosity and buying attitude do not have any significant effect on purchase intention for all the cohorts. But there is only a small positive direct effect of buying attitude on purchase intention of insurance products for the Swing cohort, this adds to the positive indirect effect of religiosity on purchase intention through buying attitude. 
Table 5.10: Comparison of Traditionalist, Swing and GenY Cohorts for Path Parameters across Product Categories

\begin{tabular}{|c|c|c|c|c|c|c|c|c|c|}
\hline $\begin{array}{l}\text { Product } \\
\text { category }\end{array}$ & Path & $\begin{array}{l}\text { Overall } \\
\text { Sample }\end{array}$ & $\mathbf{P}$ & Traditionalist & $\mathbf{P}$ & Swing & $\mathbf{P}$ & GenY & $\mathbf{p}$ \\
\hline \multirow{3}{*}{$\begin{array}{l}\text { Islamic } \\
\text { deposit } \\
\text { products }\end{array}$} & $\begin{array}{l}\text { Religiosity } \rightarrow \\
\text { Purchase Intention }\end{array}$ & .31 & $* * *$ & .20 & $* * *$ & .39 & $* * *$ & .16 & NS \\
\hline & $\begin{array}{l}\text { Religiosity } \rightarrow \text { Buying } \\
\text { Attitude }\end{array}$ & .53 & $* * *$ & $.31^{\mathrm{c}}$ & $* * *$ & $.46^{\mathrm{c}}$ & $* * *$ & $.67^{\mathrm{ab}}$ & $* * *$ \\
\hline & $\begin{array}{l}\text { Buying attitude } \rightarrow \\
\text { Purchase Intention }\end{array}$ & .40 & $* * *$ & .35 & $* * *$ & .42 & $* * *$ & .47 & $* * *$ \\
\hline \multirow{3}{*}{$\begin{array}{l}\text { Islamic } \\
\text { credit } \\
\text { products }\end{array}$} & $\begin{array}{l}\text { Religiosity } \rightarrow \\
\text { Purchase Intention }\end{array}$ & .11 & $* *$ & $.01^{\mathrm{b}}$ & NS & $.32^{\mathrm{a}}$ & $* * *$ & .24 & $* *$ \\
\hline & $\begin{array}{l}\text { Religiosity } \rightarrow \text { Buying } \\
\text { Attitude }\end{array}$ & .53 & $* * *$ & $.30^{\mathrm{c}}$ & $* * *$ & $.46^{\mathrm{c}}$ & $* * *$ & $.67^{\mathrm{ab}}$ & $* * *$ \\
\hline & $\begin{array}{l}\text { Buying Attitude } \rightarrow \\
\text { Purchase Intention }\end{array}$ & .37 & $* * *$ & $.42^{\mathrm{bc}}$ & $* * *$ & $.33^{\mathrm{a}}$ & $* * *$ & $.27^{\mathrm{a}}$ & $* * *$ \\
\hline \multirow{3}{*}{$\begin{array}{l}\text { Islamic } \\
\text { capital } \\
\text { market } \\
\text { products }\end{array}$} & $\begin{array}{l}\text { Religiosity } \rightarrow \\
\text { Purchase Intention }\end{array}$ & .17 & $* * *$ & .08 & NS & .41 & $* * *$ & .17 & NS \\
\hline & $\begin{array}{l}\text { Religiosity } \rightarrow \text { Buying } \\
\text { Attitude }\end{array}$ & .53 & *** & $.30^{\mathrm{c}}$ & $* * *$ & $.45^{\mathrm{c}}$ & $* * *$ & $.67^{\mathrm{ab}}$ & $* * *$ \\
\hline & $\begin{array}{l}\text { Buying Attitude } \rightarrow \\
\text { Purchase Intention }\end{array}$ & .31 & $* * *$ & $.36^{\mathrm{b}}$ & $* * *$ & $.26^{\mathrm{a}}$ & $* * *$ & .26 & $* *$ \\
\hline \multirow{3}{*}{$\begin{array}{l}\text { Islamic } \\
\text { insurance } \\
\text { products }\end{array}$} & $\begin{array}{l}\text { Religiosity } \rightarrow \\
\text { Purchase Intention }\end{array}$ & .04 & $\mathrm{NS}$ & .12 & NS & -.04 & NS & .11 & $\mathrm{NS}$ \\
\hline & $\begin{array}{l}\text { Religiosity } \rightarrow \text { Buying } \\
\text { Attitude }\end{array}$ & .53 & *** & $.29^{\mathrm{c}}$ & $* * *$ & $.45^{\mathrm{c}}$ & *** & $.67^{\mathrm{ab}}$ & $* * *$ \\
\hline & $\begin{array}{l}\text { Buying Attitude } \rightarrow \\
\text { Purchase Intention }\end{array}$ & .13 & $* * *$ & .08 & NS & .22 & .007 & .05 & NS \\
\hline
\end{tabular}

Note: ${ }^{\text {a }}$ significantly different from the Traditionalist sample bsignificantly different from the Swing sample csignificantly different from the GenY sample NS: Not Significant

The comparison of parameter estimations for product categories among Traditionalist, Swing and GenY groups is presented in Table 5.10. According to the comparison results, the tests 
show that there are no significant differences in the relationships between religiosity and purchase intention, as well as the relationship between buying attitude and purchase intention towards Islamic deposit products between the Traditionalist, Swing and GenY groups. The study suggests that the path between buying attitude and purchase intention for Traditionalists differ from Swing and GenY cohorts for Islamic credit products, but there is no significant path difference between Swing and GenY. On the other hand, the impact of religiosity on purchase intention of Islamic credit products differs significantly between Traditionalist and Swing groups, while GenY along with this relationship, does not significantly differ from Traditionalist and Swing cohorts. For capital market products, the relationship between buying attitude and purchase intention significantly differs between Traditionalist and Swing cohorts and there is no significant difference for GenY with Traditionalist and Swing. There are no significant differences among the three cohorts in the relationship between religiosity and purchase intention of capital market products. However, the impact of religiosity and buying attitude on purchase intention of insurance products is also not significantly different between the Traditionalist, Swing and GenY cohorts.

Noticeably, GenY is significantly different, in terms of the relationship between religiosity and buying attitude towards all categories of IFPs from Traditionalist and Swing cohorts.

\subsection{Hypothesis Testing Summary}

Hypothesis testing is appropriate when the purpose is to test the probability of assumption about population parameters based on samples from such populations. Hypotheses cannot be proved precisely, but statistically can be accepted or rejected based on levels of significance and confidence intervals. Therefore, to 'accept' or 'reject' the hypothesis represents that there is enough statistical evidence to actually accept or reject the hypotheses.

The hypotheses in this study focus on the relationship between religiosity (independent variable) and consumers' buying behaviour. In the model, consumer purchase intention is dependent variable and consumers' buying attitude is mediator. All these variables were measured by the Muslim consumers' responses. Each structural path in the model represents a possible relationship between the two variables and can be analysed for significance. The path coefficient may be considered equivalent to a regression coefficient $(\beta)$ and measures the unidirectional relationship between two constructs (Fornell, 1982; Pedhazur, 1982). 
As shown in Table 5.11, Hypotheses 1, 2 and 3 are accepted: religiosity positively influences both buying attitude and purchase intention towards IFPs. The result also shows the significant positive effect of consumers' buying attitude on purchase intention, as stated in Hypothesis 3. Not unexpectedly, these results show that consumers' buying attitude performs as a partial mediator in the relationship between religiosity and consumers' purchase intention towards IFPs.

In terms of product categories of IFPs, religiosity has a significant and positive influence on the purchase intention of Islamic deposit, credit and capital market products. But there is no significant influence of religiosity on the purchase intention of Islamic insurance products. Considering the relationship between religiosity and purchase intention in terms of different product categories, Hypothesis $4 \mathrm{a}$ is accepted and Hypothesis $4 \mathrm{~b}$ is rejected. There is a positive relationship between buying attitude and purchase intention for all categories of IFPs, which is significant. Hence, Hypothesis $\mathrm{H} 4 \mathrm{c}$ is accepted. Considering the positive influence of religiosity on the buying attitude towards IFPs, it is surprising that consumers' buying attitude fully mediates the relationship between religiosity and purchase intention towards Islamic insurance products. Whereas, consumers' buying attitude partially mediates this relationship for Islamic deposit, credit and capital market products.

Interestingly, there is empirical evidence from this data that generational cohort moderates the effect of religiosity on consumers' buying attitude; and effect of religiosity on purchase intention towards IFPs at a significant level. But the result found no moderating effect of generational cohort on the relationship between buying attitude and purchase intention. Each structural path was tested and the standardised path coefficients $(\beta)$, however, indicate that the Swing cohort has the greater influence on the relationship between religiosity and purchase intention towards IFPs $(\beta$ : Traditionalist=.38; Swing=.51; GenY=.40). The Traditionalist cohort has more influence on the relationship between buying attitude and purchase intention for IFPs, but the effect is medium for all three cohorts ( $\beta$ : Traditionalist=.40; Swing=.32; GenY=.35). Moreover, the relationship between religiosity and buying attitude is more highly influenced by GenY than the Traditionalist and Swing cohorts ( $\beta$ : Traditionalist=.30; Swing=.46; GenY=.67). Therefore, H5 is accepted partially. As shown in Table 5.12, Hypotheses $5 \mathrm{a}$ and $5 \mathrm{~b}$ are partially accepted: the positive influence of religiosity on purchase intention and buying attitude towards IFPs for the Traditionalist cohort is less strong than for the Swing cohort, but relationship strength between buying 
attitude and purchase intention for IFPs is greater. At the same time, the impact of religiosity on purchase intention of IFPs is stronger for the Swing cohort than for GenY, but the influence of religiosity on buying attitude and the impact of buying attitude towards purchase intention for IFPs is less for the Swing cohort than for GenY.

To examine whether relationships between religiosity, buying attitude and purchase intentions towards different categories of IFP are moderated, it is of interest to investigate whether the effects (religiosity to buying attitude and purchase intention; and buying attitude to purchase intention) differs across generational cohorts, the moderator. There are differences in IFP category purchase preferences between the Traditionalist, Swing and GenY cohorts. The impact of religiosity on purchase intention of Islamic credit products differs significantly only between the Traditionalist and Swing cohorts (effect is medium for Swing cohort; no effect for Traditionalist). Conversely, the effect of buying attitude on purchase intention of Islamic credit products differs between the Traditionalist, Swing and GenY cohorts (medium effect for Traditionalist and Swing; small effect for GenY). For Islamic capital market products, the effect of religiosity on purchase intention does not significantly differ among three cohorts but the impact of buying attitude on purchase intention differs significantly between the Traditionalist and Swing cohorts (medium effect for Traditionalist; small effect for Swing). There is no evidence of difference in the relationship between religiosity and purchase intention of Islamic deposit and insurance product categories between the three groups. As a result, Hypothesis 6 is partially accepted.

The religiosity of traditionalist Muslim consumers has a small but positive direct effect on the purchase intention of deposit and insurance products. On the other hand, the buying attitude of traditionalist Muslim consumers has medium effect on the purchase intention of deposit products, but there is no significant influence on purchase intention of Islamic insurance products. On the other hand, it is evident that religiosity has a medium total effect on purchase intention for deposit products. Consequently, Hypothesis 6a is partially accepted (supports for deposit product).

Swing Muslim consumers' religiosity has a positive medium direct effect on the purchase intention of Islamic deposit, credit and capital market product categories, except for Islamic insurance products, which shows no significant effect. The relationship strength between buying attitude and purchase intention towards deposit and credit product is medium, whereas it is small for capital market and insurance products. But as there is significant 
indirect effect through buying attitude, the total effect of religiosity is high on purchase intention of deposit and capital market products, medium for capital market and nil for insurance products. Hypothesis $6 \mathrm{~b}$ stated that preferences for deposit, credit and capital market products by the Swing cohort is significant except for insurance products, thus the evidence supports partially accepting this hypothesis.

The religiosity of GenY Muslim consumers has a positive but small direct effect on purchase intention of Islamic credit and capital market products. There is also evidence that buying attitude has a positive small effect on purchase intention. The total effect of religiosity with indirect effect through buying attitude evidences a small purchase intention of Islamic credit and capital market products. Therefore, Hypothesis $6 \mathrm{c}$ is accepted. 
Table 5.11: Summary of Hypotheses Testing

\begin{tabular}{|c|c|}
\hline Hypothesis & Accepted \\
\hline $\begin{array}{l}\text { H1. The greater the degree of religiosity, the greater the purchase intention of } \\
\text { Muslim individuals towards IFPs }\end{array}$ & Yes \\
\hline $\begin{array}{l}\text { H2. The greater the degree of religiosity, the greater the Muslim individual's } \\
\text { favourable attitude towards IFPs }\end{array}$ & Yes \\
\hline $\begin{array}{l}\text { H3: Muslim consumers with a more favourable attitude towards IFP have a higher } \\
\text { purchase intention of IFPs }\end{array}$ & Yes \\
\hline $\begin{array}{l}\text { H4a: The higher the religiosity, the higher the purchase intention in favour of Islamic } \\
\text { deposit products and credit products }\end{array}$ & Yes \\
\hline $\begin{array}{l}\text { H4b: The higher the religiosity, the less the purchase intention in favour of Islamic } \\
\text { capital market and insurance product }\end{array}$ & No \\
\hline $\begin{array}{l}\text { H4c: Muslim consumers with favorable attitudes towards IFPs will have a higher } \\
\text { purchase intention of all categories of IFPs }\end{array}$ & Yes \\
\hline $\begin{array}{l}\text { H5: Generation cohort moderates the relationships between customers' religiosity, } \\
\text { buying attitude and purchase intention of IFPs. }\end{array}$ & $\begin{array}{l}\text { Partially } \\
\text { supported }\end{array}$ \\
\hline $\begin{array}{l}\text { H5a: Traditionalists will have stronger positive relationships between customers' } \\
\text { religiosity, buying attitude and purchase intention of IFPs than the Swing cohort }\end{array}$ & $\begin{array}{l}\text { Partially } \\
\text { supported }\end{array}$ \\
\hline $\begin{array}{l}\text { H5b: Swing cohort will have stronger positive relationships between customers' } \\
\text { religiosity, buying attitude and purchase intention of IFPs than GenY }\end{array}$ & $\begin{array}{l}\text { Partially } \\
\text { supported }\end{array}$ \\
\hline $\begin{array}{l}\text { H6: Generation cohort moderates the relationship among religiosity, buying attitude } \\
\text { and purchase intention in favour of different product category of IFP }\end{array}$ & Yes \\
\hline $\begin{array}{l}\text { H6a: The greater the religiosity of traditionalist Muslim consumers, the greater the } \\
\text { purchase intention for Islamic deposit and insurance products }\end{array}$ & $\begin{array}{l}\text { Partially } \\
\text { (Supports for } \\
\text { deposit product) }\end{array}$ \\
\hline $\begin{array}{l}\text { H6b: The greater the religiosity of the Swing generation Muslim consumers, the } \\
\text { greater the purchase intention of Islamic deposit, credit, capital market and } \\
\text { insurance products }\end{array}$ & $\begin{array}{l}\text { Partially (except } \\
\text { Islamic } \\
\text { insurance } \\
\text { products) }\end{array}$ \\
\hline $\begin{array}{l}\text { H6c: The greater the religiosity of GenY Muslim consumers, the greater the purchase } \\
\text { intention for Islamic credit and capital market products }\end{array}$ & Yes \\
\hline
\end{tabular}




\subsection{Additional Research Findings}

Buying behaviour and the importance of choice criteria varies among customers of different demographic profiles (Devlin, 2002a, 2002b). Previous research suggested that consumers' attitude and selection of financial services and products might vary by demographic factors such as age, gender, household income, and educational attainment (Boyd, et al., 1994; Denton \& Chan, 1991; Joy, et al., 1991; Speed \& Smith, 1992; Tan \& Chua, 1986). Therefore, in this study, the model additionally attempts to examine the moderating effect of demographic factors between the relationship of religiosity, consumers' buying attitude and purchase intention that have been used in one or more of the previous studies. Demographic variables such as gender, marital status, income level, education and occupation are often used as market segmentation determinants (Pol, 1991). As a result, they have also been incorporated into the survey instruments of this study (see Appendix A3). The results of the moderating effect of demographic variables are summarised in Table 5.12. Gender and marital status moderates the relationship between religiosity and consumer buying attitude and purchase intention. On the other hand, no moderating effect of gender and marital status was found on the relationship between consumer buying attitude and purchase intention. The strength of the relationship between religiosity and purchase intention; and the relationship between religiosity and buying attitude, is greater for female participants than for male $(p<0.01)$ and less for married participants than single $(p<0.01)$. Previous studies have constantly revealed that females tend to be more religious than males (Miller \& Hoffmann, 1995). The result of gender effect suggests that religiosity of female respondents' tend to have more favourable buying attitude and buying motive towards IFPs than their male counterparts. On the other hand, moderating effect of marital status display that single respondents' religiosity have greater impact on buying attitude and purchase motivation towards IFPs than married people. Though married people are like to be more religious and more conservative $(\mathrm{Hu}, 2012)$, but the result of this study shows that single respondent remains more committed in religious philosophies and performances (Pew Research, 2010).

Educational attainment moderates the relationship between religiosity, consumer buying attitude and purchase intention. Better-educated people differ, in terms of the relationship between religiosity and purchase intention, from highly educated $((p<0.1))$ and less-educated $(p<0.01)$ people. For better-educated people, the relationship strength between religiosity and purchase intention towards IFPs is greater than it is for highly educated and less-educated 
people. In addition, the strength of the relationship between religiosity and purchase intention of IFPs is greater for less-educated people than it is for highly educated people and differs between the two groups $(p<0.05)$. The strength of the relationship between religiosity and consumer buying attitude, however, is considerable for highly and better-educated people, and moderate for less-educated people. Less-educated people differ from highly and bettereducated people in terms of the relationship between religiosity and consumer buying attitude $(p<0.01)$. The relationship between consumer buying attitude and purchase intention is strong for less-educated people and minimal for highly and better-educated people. In this relationship, less-educated people differ from highly $(p<0.1)$ and better-educated people $(p<0.01)$. Modernization theory suggests that religiosity will decrease as people become more educated (Backer \& Vink, 1994; Peters, 1993). So it can be said that higher education has a negative influence on religiosity, but this view is not accepted by all previous studies (Albrecht \& Heaton, 1984). One does not reject religion as a higher level of educational attainment, rather on may try to find out more logical pursuits as a consequence of already having rejected one's religious faith. The result of this study suggests that education level of people have impact on giving less or more importance to their religiosity which reflects one's buying attitude and purchase intention towards IFPs.

Occupation is also often linked to consumer behaviour. The relationship strength between religiosity and purchase intention towards IFPs is medium for government, private and retired employees, and strong for students. Government employees $(p<0.01)$ and students $(p<0.05)$ differ, in terms of this relationship, from private and retired employees. On the other hand, the relationship strength between religiosity and buying attitude is strong for government employees and students; medium for private employees, and non-significant for retired employees. Government employees, private employees and students differ with regard to this relationship $(p<0.01)$. The effect of buying attitude on purchase intention is medium for government, private and retired employees, but small for students. Government employees differ, in terms of the relationship between buying attitude and purchase intention, from private employees $(p<0.05)$, retired employees $((p<0.01)$ and students $(p<0.01)$. Private and retired employees also differ from each other $(p<0.01)$ in this regard, and there is no difference between retired employees and students. The findings of this study suggest that occupational category is significantly associated with the relationship between religiosity, buying attitude and purchase intention of IFPs and act as a moderator. 
Table 5.12: Effect of Demographic Variables on the Relationship between Religiosity, Consumer Buying Attitude and Purchase Intention

\begin{tabular}{|c|c|c|c|c|}
\hline \multirow[t]{2}{*}{ Relationship } & \multicolumn{2}{|c|}{ Gender } & \multicolumn{2}{|c|}{ Marital Status } \\
\hline & Male & Female & Single & Married \\
\hline $\begin{array}{l}\text { Religiosity } \rightarrow \text { Purchase } \\
\text { Intention }\end{array}$ & $.42^{b}$ & $.61^{\mathrm{a}}$ & $.43^{\mathrm{b}}$ & $.39^{\mathrm{a}}$ \\
\hline $\begin{array}{l}\text { Religiosity } \rightarrow \text { Buying } \\
\text { Attitude }\end{array}$ & $.53^{b}$ & $.59^{\mathrm{a}}$ & $.62^{b}$ & $.40^{\mathrm{a}}$ \\
\hline \multirow{4}{*}{$\begin{array}{l}\text { Buying Attitude } \rightarrow \\
\text { Purchase Intention }\end{array}$} & .36 & .21 & .36 & .35 \\
\hline & \multicolumn{2}{|c|}{$\begin{array}{l}\text { a significantly different from the male } \\
\text { sample } \\
\text { bsignificantly different from the } \\
\text { female sample }\end{array}$} & \multicolumn{2}{|c|}{$\begin{array}{l}\text { a significantly different from the single } \\
\text { sample } \\
\text { bsignificantly different from the marriec } \\
\text { sample }\end{array}$} \\
\hline & \multicolumn{4}{|c|}{ Education } \\
\hline & Higher School & Graduate & Post Graduate & \\
\hline $\begin{array}{l}\text { Religiosity } \rightarrow \text { Purchase } \\
\text { Intention }\end{array}$ & $.40^{\mathrm{bc}}$ & $.56^{\mathrm{ac}}$ & $.29^{\mathrm{ab}}$ & \\
\hline $\begin{array}{l}\text { Religiosity } \rightarrow \text { Buying } \\
\text { Attitude }\end{array}$ & $.38^{\mathrm{bc}}$ & $.50^{\mathrm{a}}$ & $.58^{\mathrm{a}}$ & \\
\hline \multirow{4}{*}{$\begin{array}{l}\text { Buying Attitude } \rightarrow \\
\text { Purchase Intention }\end{array}$} & $.56^{\mathrm{bc}}$ & $.28^{\mathrm{a}}$ & $.38^{\mathrm{a}}$ & \\
\hline & \multicolumn{4}{|c|}{$\begin{array}{l}{ }^{\mathrm{a}} \text { significantly different from the higher school pass sample } \\
{ }^{\mathrm{b}} \text { significantly different from the graduate sample } \\
{ }^{\mathrm{c}} \text { significantly different from the post graduate sample }\end{array}$} \\
\hline & \multicolumn{4}{|c|}{ Occupation } \\
\hline & Govt. Job & Private Job & Retired & Student \\
\hline $\begin{array}{l}\text { Religiosity } \rightarrow \text { Purchase } \\
\text { Intention }\end{array}$ & $.36^{\mathrm{bc}}$ & $.38^{\mathrm{ad}}$ & $.40^{\mathrm{ad}}$ & $.54^{\mathrm{bc}}$ \\
\hline $\begin{array}{l}\text { Religiosity } \rightarrow \text { Buying } \\
\text { Attitude }\end{array}$ & $.52^{\mathrm{bd}}$ & $.47^{\mathrm{ad}}$ & $.01^{\mathrm{ns}}$ & $.64^{\mathrm{ab}}$ \\
\hline \multirow[t]{2}{*}{$\begin{array}{l}\text { Buying Attitude } \rightarrow \\
\text { Purchase Intention }\end{array}$} & $.38^{\mathrm{bcd}}$ & $.49^{\mathrm{acd}}$ & $.36^{\mathrm{ab}}$ & $.23^{\mathrm{ab}}$ \\
\hline & \multicolumn{4}{|c|}{$\begin{array}{l}\text { asignificantly different from the govt. job holder sample } \\
\text { bsignificantly different from the private job holder sample } \\
\text { csignificantly different from the retired employee sample } \\
{ }^{d} \text { significantly different from the student sample }\end{array}$} \\
\hline
\end{tabular}




\subsection{Chapter Summary}

This chapter outlines the survey response analysis, confirmatory factor analysis, the process of measurement refinement, establishes measurement validity and reliability, and presents AMOS analysis and hypotheses testing. Most of the hypotheses are accepted as significant, while a few are partially accepted and one hypothesis is not significant. The important finding is that religiosity positively and directly influences consumers' purchase intention and buying attitude. In addition, there is empirical support that consumers' buying attitude partially mediates the relationship between religiosity and purchase intention towards Islamic financial products (IFPs).

The results also show the relationship between religiosity and purchase intention in terms of Islamic deposit, credit and capital market products are significantly positive, whereas it is non-significant for Islamic insurance products. But there are significant indirect effects of religiosity through buying attitude on purchase intention in all categories of products. These outcomes provide evidence of partial mediation of buying attitude on the relationship between religiosity and purchase intention towards deposit, credit and capital market products, and full mediation for Islamic insurance products. This means that the effect of religiosity on purchase intention of some particular categories of IFPs has been difficult to establish directly, whereas consumers' buying attitude may provide an appropriate medium from which consumers' purchase intention can be changed.

The outcomes of the results also confirm that generation cohort to some extent moderates the relationships between customers' religiosity, buying attitude and purchase intention of IFPs. The positive influence of religiosity on purchase intention and buying attitude towards IFPs for the Traditionalist cohort is less strong than for the Swing cohort but the relationship strength between buying attitude and purchase intention for IFPs is greater. At the same time, the impact of religiosity on purchase intention of IFPs is stronger for the Swing cohort than for GenY. But the influence of religiosity on buying attitude and impact of buying attitude towards purchase intention for IFPs is less for the Swing cohort than for GenY. Generation cohort also moderates the effect of religiosity on buying attitude and purchase intention; and buying attitude towards purchase intention across different categories of IFP. But some of the relationships between religiosity, consumers' buying attitude and purchase intention for some categories of IFP do not moderated. 
Finally, the analysis show the results of tying religiosity and consumption-related values of different generational cohorts and their impact on preferences for purchasing different categories of IFPs. For Traditionalist Muslim consumers, religiosity has a significant positive effect on purchase intention of deposit products, but no significant impact towards Islamic insurance products. For Swing Muslim consumers, religiosity has a significant positive effect for deposit, credit and capital market products but no significant effect for insurance products. On the other hand, religiosity of GenY Muslim consumers has a positive effect on purchase intention of Islamic credit and capital market products. Next, Chapter 6 will discuss the implications of the results for practitioners and academics, as well as contribution to marketing literature. 


\section{CHAPTER 6. Discussion and Conclusions}

\subsection{Introduction}

The main focus of the study is to determine the effect of religiosity on the buying behaviour of Muslim consumers. It investigates the impact of religiosity on buying behaviour and preferences towards IFPs of different generational cohorts. In this context, an initial research model is conceptualised and tested using a questionnaire survey of Muslim people in Bangladesh. Data was collected from five major metro cities across a number of universities, business organisations and retired employee associations. The results of the nationwide survey were analysed using structural equation modelling (SEM).

This chapter discusses the results of the study with reference to the extant relevant literature. It also provides implications, limitations, future research areas and conclusions. The study seeks to extend the marketing and consumer behaviour literature by investigating the impact of religiosity on buying attitude and purchase intention of IFPs. The main findings suggest that religiosity influences and predicts consumer buying attitude and purchase intention towards IFPs. This finding also shows that consumer buying attitude has a partial mediating effect on the relationship between religiosity and consumer purchase intention towards IFPs. Additionally, the results show the partial moderation effect of generational cohort on the impact of religiosity on consumer buying attitude and purchase intention of overall IFPs and across different product categories.

\subsection{Effects of Religiosity on Consumer Buying Behaviour}

\subsubsection{Religiosity and Purchase Intention}

The findings indicate significant differences in purchase intention among consumers with different levels of religiosity. In particular, purchase intention is influenced by the degree of religiosity in a positive direction; consumers with a high degree of religiosity tend to be more interested in buying IFPs. As Islamic financial products and services adhere to Islamic principles, values and goals, this represents significant motivation for Muslims to choose these Islamic financial services (Omer, 1992). The literature on religiosity and purchase intention has provided mixed evidence of the impact of religiosity on consumers' purchase intentions towards Islamic finance. Some researchers have found evidence that religiosity is 
the main reason for Muslims to purchase Islamic financial products (Omer, 1992; Metawa and Almossawi, 1998; Khan, et al., 2007; Alam, et al., 2012). However, other studies have shown that religiosity is not an important factor for selecting Islamic finance (Dusuki \& Abdullah, 2007; Erol \& El-Bdour, 1989; Erol, et al., 1990; Gerrard \& Cunningham, 1997; Haque, Osman, \& Ismail, 2009). The findings of this research align with the former research stream and reveal that religiosity plays a major role in determining purchase intention of IFPs. The study finds that consumers' buying attitude is the mechanism through which religiosity enhances purchase intention towards IFPs. In other words, religiosity influences buying attitude and thus purchase intention of Muslim consumers. Existence of mediation effect is one of the reasons in explaining mixed findings in the past research. The finding suggests that Muslims in Bangladesh consider purchasing IFPs because these products do not violate or contradict their religious values and comply with their financial requirements (Yun, et al., 2008).

\subsubsection{Religiosity and Consumers' Buying Attitude}

The result confirms that Muslim consumers' buying attitudes are positively influenced by their religiosity. That is, devout consumers place greater importance than casually religious consumers on Shariah-compliant financial products. This present finding can be corroborated by previous studies, which found that religiosity is a significant factor influencing consumers' attitudes towards IFPs (Omer, 1992; Metwally, 1996; Metawa and Almossawi, 1998, Okumus, 2005; Worthington, 2009). This finding also shows that individuals who are highly committed to their religion place considerable emphasis on product attributes when purchasing financial products or services. This result is similar to the results of Budiman (2012), who stated that high religiosity inspires a consumer to find out more about the surrounding attributes of products. This means that, alongside religious values, religiosity influences peoples' lawful attitudes. For Muslim consumers, religiosity relates significantly with their view of Islamic laws and reflects lawful attitudes towards Shariah-compliant financial products. This result clearly contrasts with those of previous studies, which established that religious drivers have little impetus for the use of Islamic finance; rather, consumers placed more importance on the high profits and low service charges offered by conventional finance (Erol, et al., 1990; Gerrard and Cunningham, 1997; Zaher \& Hassan, 2001; Selamat \& Abdul-Kadir, 2012). However, this study clearly indicates that religiosity represents the primary predictor for increasing the probability of favourable attitudes towards 
IFPs in Bangladesh for Muslims, rather than other features of the financial services, such as location and profit.

\subsubsection{Consumer Buying Attitude and Purchase Intention}

The results of this study indicate that buying attitude significantly and positively impacts consumer buying intention towards IFPs. This result supports the view that religious people with favourable attitude are more interested to buy IFPs. Buying attitude forms as (a) belief and evaluations of attributes or characteristics, and (b) emotional feelings such as like or dislike, for IFPs (Kotler, et al., 2004). The finding underscores the importance of buying attitude as a key factor in convincing people to purchase IFPs. This result is similar to those previous findings, which concurred that consumer attitude is an important element in manipulating the intention to use Islamic finance (Amin, et al., 2010; Amin, et al., 2011). According to the Theory of Reasoned Action (TRA), a person's favourable buying attitude can add value to purchase intention and, through the correct influence of buying attitude, purchase intention can be enhanced. The consideration of customers' attitudes towards products has become more significant due to the influence of religiosity on consumers' buying attitudes. Therefore, IFP providers must not rely only on religious factors as a strategy to secure customers' loyalties (Khan et al., 2007). Muslims who have a sound basic knowledge of Islam are familiar with the term 'Shariah'. Thus, this research indicates that by creating awareness of Shariah principles in Bangladesh, IFPs that satisfy the needs and preferences of Muslims will ensue, providing them with spiritual harmony while they consume the products.

\subsubsection{Mediating Effects}

Perfect, complete or full mediation happens when there is a significant indirect effect of the independent variable on a dependent variable, but no significant direct effect of the independent variable on a dependent variable. In contrast, if there is a significant direct effect of the independent variable on a dependent variable after controlling, the mediator is called partial mediation (Rucker, Preacher, Tormala, \& Petty, 2011). The results of this study clearly show a significant direct and indirect effect of religiosity on purchase intention of IFPs. This finding indicates that consumer buying attitude has a partial mediating effect on the association between religiosity and consumer purchase intention towards IFPs. The results of this study also indicate that between the two dependent variables - buying attitude 
and purchase intention - religiosity has a stronger effect on buying attitude $(\beta=.53)$ than purchase intention $(\beta=.45)$. The total effect of religiosity towards purchase intention of IFPs is .63 and this finding provides empirical evidence for consumer behaviour literature, where religiosity has been conceptualised as a factor contributing to an understanding of consumer perception (Fam, et al., 2004; Foxall, Goldsmith, \& Brown, 1998; Mukhtar \& Butt, 2012).

Religiosity has not always demonstrated positive results or a strong effect on purchase intention (Soesilowati, 2010) and has not been uniformly viewed as a valuable predictor of purchase decision (Dusuki \& Abdullah, 2007). But the partial mediating effect of buying attitude evidenced in this study indicates that religiosity can more successfully influence purchase intention of IFPs in the presence of favourable consumer buying attitude. The implication is that neither religiosity nor consumer buying attitude is sufficient alone to persuade people to purchase IFPs; rather, the two working in tandem provide the greatest potential value in the buying decision process.

\subsubsection{Product Category Preferences}

This study finds a significant direct and indirect positive influence of religiosity on purchase intention of Islamic deposit and credit products. The reasons religious Muslims prefer to be associated with the Islamic banking system is that Islamic banks are committed to the principle of Shariah and prohibit the receipt and payment of interest in any of their operations. Therefore, the demand for Islamic banking products is enormous (Yusoff \& Shamsuddin, 2003; Yusoff, et al., 2008). An interpretation of this result is that profit-and-loss sharing (PLS) arrangements distinguish Islamic banks from conventional banks, which reflects Islamic ideals in financial affairs, risk and equity in welfare distribution and that those who have a certain level of religious faith prefer to use Islamic banking services, such as Islamic deposit and credit products (Yap, 2011). Prohibited dealings with interest or PLS arrangements encourage Muslim consumers to give up the certainty of investment returns in order to fulfil their religious commitments.

Product importance has been supposed to effect consumer decision making processes (Howard \& Sheth, 1969; Bloch \& Richins, 1983) and Muslim consumers' preferences for IFP categories also affected their purchase intentions (Mukhtar \& Butt, 2012). It is not completely surprising that religiosity has both a direct and indirect positive influence on purchase intention of Islamic capital market products. Islamic capital products are treated as highly 
useful alternative investments for the diversification of portfolios, since these products are created according to Islamic principles (with special focus on social justice, ecology and kindness, to create investment products and financial markets that are both ethical and sustainable). This result supports the previous findings that Islamic capital market products have become increasingly popular with both Muslims in secular and democratic countries and non-Muslim investors (Hassan \& Mahlknecht, 2011). The current results indicate that customers have become more aware of investment products over time, depending upon their need for large investments (Khan, et al., 2007).

On the other hand, the study does not find any direct significant relationship between religiosity and purchase intention of Islamic insurance products. But there is an indirect effect of religiosity, through full mediation of buying attitude on purchase intention towards insurance products. Shariah does not allow Muslims to purchase insurance products, particularly life insurance. According to the Islamic faith, life is given or taken away by God, and anyone buying an insurance policy is, in fact, going against God's will. There are Islamic insurance products available, but this phenomenon is restricted to some Muslim countries and insurance companies have largely stayed away from Islamic products to those countries (Roy \& Banerjee, 2007). Previous studies focused mainly on macroeconomics as a factor influencing the consumption of family takaful (Redzuan, Rahman, \& Aidid, 2009). It was found that subjective norms, such as religious organisation, have significant influence on an individual's perception and acceptance of Islamic insurance. However, research on consumer acceptance of Islamic insurance has been overlooked (Rahim \& Amin, 2011). Many Muslims around the world are still not convinced of the complete and unquestionable permissibility of life insurance or family takaful schemes.

Conversely, the impact of buying attitude towards purchase intention for all categories of IFPs is medium for Muslim consumers and this interprets as no variability in the purchase intention of different product categories. Islamic financial companies have developed these different product categories to meet customer needs and provide Shariah-compliant alternatives to widely available conventional options. This result may help the marketing of such products, which may pose significant challenges in light of competition from conventional financial institutions, and identify customer preferences for different products. If it is possible to convince Muslim consumers, then undoubtedly this industry can look forward to seeing huge growth. 


\subsubsection{Moderating Effects of Generational Cohort}

The findings of the study indicate the partial moderating effects of generational cohort in the relationships between religiosity, buying attitude and purchase intention. Generational cohort has an impact on the relationship between religiosity and purchase intention of IFPs, as well as on the relationship between religiosity and buying attitude. The relationship strength between religiosity and purchase intention is strong for the Swing cohort and medium for the Traditionalist and GenY cohorts. On the other hand, the relationship strength between religiosity and buying attitude is very strong for GenY, but medium for the Traditionalist and Swing cohorts. The strength of the relationship between buying attitude and purchase intention is medium for all cohort groups. This implies that generation moderates the relationship between religiosity and purchase intention, as well the relationship between religiosity and buying attitude, whereas cohort does not moderate the relationship between buying attitude and purchase intention. This finding is the partial evidence of the moderating effect of generational cohort for the hypothesis. The result supports the previous research findings that generation is likely to have various moderating effects on behavioural measures, as well as on consumers' consumption patterns (Harris \& Blisard, 2001; Park \& Gursoy, 2012).

The findings of the study are not fully consistent with generational cohort theory, which highlighted substantial intergenerational differences in values and attitudes among different cohorts (Lu \& Alon, 2004; Yardley, 2003). This study found differences only in terms of religiosity and its' relationship with buying attitude, where GenY differs from both Traditionalist and Swing cohorts. Among previous limited studies comparing generational cohorts, it has been found that there are distinct generational differences among the cohorts in product preferences that reflect larger value differences among the cohorts (Littrell, et al., 2005; Noble \& Schewe, 2003). However, this study suggests that religiosity has a strong effect on the buying attitude of GenY, compared with the other two cohorts. It interprets that GenY remains fairly traditional in religious beliefs and practices (Pew Research, 2010), which is reflected in a favourable attitude towards IFPs. Hence, religiosity is an important prerequisite for enhancing the favourable attitude of GenY towards IFPs, but may not necessarily result in purchase intention. Based on the concept of TRA (Ajzen \& Fishbein, 1980) and previous studies on consumers' attitude and buying intention towards different 
Islamic financial products (Gait, 2009), it can be stated that the religiosity of GenY in Bangladesh strongly influences their purchase intention towards IFPs.

\subsubsection{Product Preferences across Groups}

Generational cohort also partially moderates the relationship between religiosity, buying attitude and purchase intention, in terms of different product categories of IFP. This result supports the previous finding that there are various groups of consumers with differing purchasing motives (Muhamad, et al., 2012). The study finds that relationship strength between religiosity and purchase intention for Islamic deposit products is small for Traditionalist and GenY, and medium for the Swing cohort. The relationship strength between buying attitude and purchase intention towards Islamic deposit products is medium for all cohort groups and the moderating effect of cohort group was found to be nonsignificant. The strength of the relationship between religiosity and purchase intention for Islamic credit products was found to be very weak, which is non-significant for Traditionalist, medium for Swing, and small for GenY. The relationship strength between buying attitude and purchase intention towards Islamic credit products is medium for Traditionalist and Swing cohorts, and small for GenY. In terms of Islamic capital market products, there is no significant relationship between religiosity and purchase intention for Traditionalist and GenY, but a weak relationship exists for the Swing cohort. But the relationship that exists between buying attitude and purchase intention is medium for Traditionalist and weak for Swing and GenY cohorts. In relation to Islamic insurance products, there is no significant relationship between religiosity and purchase intention for any of the cohort groups. However, there is a weak relationship between buying attitude and purchase intention for the Swing cohort, but no relationship exists for Traditionalist and GenY. The findings suggest that generational cohort does have some impact on the relationship between religiosity, buying attitude and purchase intention of different categories of IFPs. This provides an insight when comparing the moderating effect of generational cohort between different product categories and contrasting this result with the moderation effects towards IFPs in general. This indicates that, although all IFPs follow the main Islamic principles, when comparing Islamic finance in terms of individual products, all products are still not fully accepted by customers (Ahmad \& Haron, 2002). Lack of knowledge and misconceptions of different categories of IFPs are the main reasons that some consumers remain unconvinced. 
It has been argued that the characteristics of generational cohort reflects what consumers in different age group wants, prefer and what are the passions surrounded by (Schewe \& Meredith, 2004; Ting, et al., 2012). The result of this study demonstrates that the generational cohorts are different in terms of the psychographic factors that help to explain their behaviour towards different IFP categories. The differences between groups of consumers have long been recognised as opportunities in the market by marketing researchers (Van Raaij \& Verhallen, 1994). Although individuals make purchasing decisions, they do so based on events experienced while coming of age and these events influence their attitudes, preferences and buying behaviours (Bidwell, 2009). The ability to understand the specific requirements of different segments of consumers would enable companies to achieve a competitive edge within the existing conditions of the market, whereas failure to do so could lead to the loss of market position (Smith, 1956). The findings of this study stated that religiosity and the buying attitudes of Traditionalist Muslim consumers have a positive effect on purchase intention for deposit products but no significant effect for insurance products. These results indicate that the religiosity of those in the Traditionalist cohort persuades or guides them to prefer deposit products (saving for long term needs) over insurance products (protection from possible losses). The Traditionalist cohort is more religious and believes that purchasing an insurance product is against Shariah (Markides \& Cole, 1984; Roy \& Banerjee, 2007). This belief has shaped a psychological block against insurance among the Traditionalist Muslims in Bangladesh (Siddiqui \& Athemy, 2008).

Similarly, the findings of the study indicate that, in terms of the product preferences of the Swing cohort, based on coming-of-age experiences, religiosity has an impact on purchase intention for deposit, credit and capital market products, but not for insurance products. Consistent with previous studies, this result provides support for the premise that Swing's coming-of-age experiences of economic failure and growth created saving, borrowing and investment needs (Schewe \& Noble, 2000). Interestingly, this study does not support the security needs of this cohort to buy insurance products. There is a common misconception that insurance or risk mitigation is not allowed under Islam, as Muslims believe that only God knows one's future and faith (Jaffer, Ismail, Noor, \& Unwin, 2010). Although Islamic and conventional insurance products differ, there is disagreement over whether they are, in fact, essentially the same (Amin, 2012). These misconceptions have produced a negative image of Islamic insurance, which in turn could deter consumers from purchasing Islamic insurance products (Amin, 2012; Swartz \& Coetzer, 2010). 
A significant direct relationship was found between religiosity and buying attitude with purchase intention of Islamic credit and capital market products among GenY respondents. Based on existing literature, GenY are generally optimistic about the future, tend to use credit facilities and invest, rather than save, and are risk-averse (Rahman, 2009). The materialistic values of the members of GenY have created a strong interest in buying these types of financial products; associating religiosity with these values has resulted in favourable intention to purchase Islamic credit and capital market products in this cohort. During the last few years, the capital market in Bangladesh has experienced both heightened growth and uncontrollable collapse, indicating a highly risky and unstable capital market. Many unwise investors, such as students and unemployed youth, have invested their savings in the capital market with expectations of profit (Jahan, Dhar, \& Ahmed, 2012). The results of this study indicate that religious GenY members are interested to purchase Islamic credit and capital market products. This intent may be due to gain an additional source of income to satisfy their materialistic needs, but also to increase their living standards in accordance with Shariah principles. In doing so, they avoid having to deal with the high interest and speculation of conventional credit and capital market products.

The above discussion demonstrates that the generational cohorts are different in terms of the psychographic factors that help to explain their behaviour towards different IFP categories.

\subsection{Research Contributions and Implications}

The results of the research provide several contributions to theory, research and practice. The academic and theoretical contributions are discussed and followed by implications for managerial practice.

\subsubsection{Contributions to Theory}

The development and empirical testing of the 'Religiosity-Consumer Behaviour' model bringing religion as a subcultural construct and marketing research area together - is a key contribution of this study. The 'Religiosity-Consumer Behaviour' model establishes clear links between (a) the degree of religiosity and consumer purchase intention, (b) consumer attitude and purchase intention, and (c) the mediating effect of buying attitude in the relationship between religiosity and consumer purchase intention. 
The construct of culture and subculture have become more significant in consumer behaviour literature. A considerable body of existing literature focuses on culture and its influence on various aspects of consumer behaviour, although there is limited research incorporating the role of religion, as an element of culture, with consumer behaviour. Researchers have mostly emphasised other subcultural factors as important predictors of certain consumer behaviour: for instance, ethnicity (Herbig \& Yelkur, 1998; Kim \& Kang, 2001; Lee, Fairhurst, \& Dillard, 2002; Rajagopalan \& Heitmeyer, 2005), nationality (Moss \& Vinten, 2001) and values (Gregory, Munch, \& Peterson, 2002; Grunert \& Juhl, 1995; Mokhlis, 2006b; Slowikowski \& Jarratt, 1997).

Religion plays a vital role in influencing many other aspects of everyday life, including that which is permissible or forbidden for consumption. The impact of religion on consumptionrelated behaviour has been studied only minimally in marketing literature, although people's behaviours and attitudes are directly influenced by the religious-based cultural aspects of their living environments. Although scant and impartially theoretical in nature, the existing literature submits evidence, however, that people's religious background is an important construct in the study of consumer behaviour. The effect of religion on consumer behaviour depends on the religion itself, and on the level to which individuals are committed to their religion, that is, religiosity. Yet the role of religion as a variable in consumer behaviour models is still not well-established. Only limited consumer research on religion has pointed to the significant effects of religious variables - mainly, religious affiliation and religiosity - on some aspects of consumer behaviour, such as purchasing pattern, store selection and selected aspects of retail store patronage (Choi, 2010; Essoo \& Dibb, 2004; Mokhlis, 2006a; Mokhlis, 2006b; Sood \& Nasu, 1995). In the context of Muslim communities, these effects are even more prominent. The scarcity of studies on both Islam and the relationship between religiosity and consumer purchase intention increases this study's potential contribution to the literature. The present study was undertaken with the intent to contribute to the current literature on consumer behaviour by investigating the effects of religiosity as a religious variable on Muslim consumers' purchase intentions. Most of the primary results reported here support the common nature of already established understanding and perception of the religion-consumer behaviour relationship. Furthermore, these findings potentially provide some important theoretical contributions to the accumulating theories on consumer behaviour. 
This study was intended, in part, to contribute to the process of model building in consumer behaviour research. A model of religiosity-consumer behaviour was developed, based on the literature review relevant to consumer behaviour, and tested with data collected through the survey. All the possible causal linkages of the proposed model were empirically tested and the results were mostly supportive of the study's hypothesis: that consumer's religiosity significantly affects their purchase intentions. The proposed model can be used as a foundation for further research to develop a better understanding of the linkages among important constructs, and may be employed as a conceptual background to study the impact of religiosity on purchase intention.

The results of this study reveal the links between religiosity and some important aspects of consumer behaviour, in terms of consumer buying attitude and purchase intention (see Figure 3.2 for the conceptual model). In consumer behaviour literature, it has been established that consumers' buying decision activities are influenced by a variety of personal characteristics and demographic factors, including personal values, occupation, social class, gender, educational attainment, marital status, age and income (Boyd, Walker, Mullins, \& Larre' che', 2002; Czinkota \& Kotabe, 2001; Darden, 1980; Dibb, Simkin, Pride, \& Ferrell, 2001; Harrell \& Frazier, 1999; Jobber, 2001; Shim \& Kotsiopulos, 1992; Solomon \& Stuart, 2003). Although religiosity has been accepted as a subset of consumers' personalities, it has received comparatively limited attention within consumer behaviour research (Sheth, 1983). Subsequently, very little is known about how this subcultural variable may impact on consumer buying attitude and purchase intention in a Muslim cultural context. This study has some fundamental theoretical worth that enhances the understanding of the role of religiosity, which is that religion is core as a cultural-based predictor of Muslim consumer behaviour. There is widespread empirical support for the Theory of Reasoned Action (TRA: Ajzen and Fishbein, 1980) by many studies in the banking and finance discipline, but exploration based on applying this theory to investigating the purchase intention of Islamic financial products appears to be very scant. In particular, this study gives empirical support to the Theory of Reasoned Action. Understanding religious-driven behaviours, as manifested or as influenced by religious commitment, can support researchers in developing religiously appropriate instruments to better understand the theoretical premise of religious consumer behaviour.

The current study has uncovered new evidence that adds to the currently limited knowledge of the influence of religiosity on consumers' purchase intentions. But there is little agreement 
on which measure most efficiently explains the variation in aspects of consumer behaviour. This study supports including the religious variable as a reliable and valid predictor in consumer research. This is one of the main contributions of this study, and up to now the only existing literature on this subject. It appears that religiosity generates many differences in consumer behaviour. This implies that religiosity may serve as a potentially powerful predictor and determinant of major consumer behaviours in such areas as information source, consumer buying attitude and purchase intention. Thus, researchers should give more attention to consumer religiosity when studying consumers' buying decisions and perhaps other areas of consumer behaviour.

Though there is no agreement in the previous literature on the actual number of religious dimensions, most academics agree that religiosity is a multidimensional construct. In accordance with the restriction of measuring religiosity in a multidimensional method, the study employed a multi-item scale covering belief, practice, knowledge, experience and consequential dimensions of religiosity, in order to obtain a clear picture of religiosity levels. This study predominantly sheds light on measuring religiosity from an Islamic perspective. The most appropriate combinations of dimensions were assessed to give the best results. The religious dimensions found in this study advance support for Glock and Stark's (1972) conceptualisation. The analytical approach followed in the analysis of Muslims' religiosity in this study was based largely on the work of Charles Y. Glock and Rodney Stark, who have made seminal contributions to the sociology of religion. Based on the literature review, this study observes that these five religious dimensions are particularly important in Muslim consumer research since they are based on Quran and Sunnah, and other Islamic studies (Ahmad, 1977; Ilyas, 1992; Maududi, 1960). The findings of the current study further demonstrated that each of the five dimensions contributes to the variance of faith of Muslim consumers. These variations of religiosity have differential effects on certain aspects of consumer behaviour. For instance, consumers' preferences for particular categories of IFPs and their intention to purchase those categories were influenced by religiosity, while generational cohort moderates the relationship between religiosity and consumers' preferences of different categories of IFPs and their purchase intention.

In addition, this thesis is unique because of the relative originality of the Muslim religiosity measures utilised by the study. Very little research thus far has adapted Glock and Stark's (1968) religious dimensions as a measurement device for the religiosity construct. The use of 
Glock and Stark's multidimensional scale in the current research has proved to be a reliable measure. The reliability tests performed on the five components of the scale, religious belief, religious practice, religious knowledge, religious experience and consequences, showed a high degree of internal consistency with alpha coefficients of $0.82,0.78,0.67,0.72$ and .78 respectively. The high alpha values for scales confirmed the prior reliability tests of the scale (Hassan, 2007). Although a higher alpha level would be preferred for religious experience, the researcher believes that the scale is generally acceptable for an initial research work. In the current study, this scale was used to measure the degree of religiosity of Muslim people from three different cohort groups, which had not previously been measured using this scale. Thus, experience gained from this study would indicate that those seeking a Muslim religiosity scale for use in survey research should probably consider the five dimensions that have been purported to express and signify Muslim religiousness.

The study utilised the generational theory to identify generational cohorts in Bangladesh. The generational cohort study has gained significance in the marketing discipline (Ting, et al., 2012). But there is a noticeable lack of research comparing generational cohorts (Pentecost \& Andrews, 2010). This study is the first attempt to this end and contributes to laying the groundwork for further analyses on cohort characteristics in Bangladesh. Descriptions of three cohorts such as Traditionalist, Swing and GenY can be utilised to help understand cohorts' differences in terms of consumer behaviour.

Another significant contribution of this study lies in its focus on the Islamic financial industry and on purchase intention of different categories of Islamic financial products. As noted earlier, past studies on the relationship between religiosity and consumer behaviour have been limited only to Islamic financial products such as Islamic banking (Pepinsky, 2013). There are misconceptions among consumers around Islamic financial products, as well as around specific categories of IFPs, making them attractive only to certain consumers. This study differs from previous studies in that purchase intention of Islamic financial products and its different categories was used as a purchase planning scenario when examining religious influences on consumer buying behaviour. The results add an additional aspect to the current body of knowledge by providing evidence that the impact of religiosity on consumer behavioural directions is not restricted only to the purchase of banking products, but also to capital market and insurance product categories. The suggestion is that, even with a purchasing decision of this type of financial product, consumers' levels of religious 
commitment apparently influence their buying behaviour. Such variations existing within IFPs appear to suggest that there may be the same or even more marked differences for other non-financial Islamic products. This outcome is important for theory building in religiosityconsumer behaviour aspects and in other marketing and consumer contexts.

Finally, the findings of this thesis provide empirical evidence of religiosity's influence on consumer behaviour in a non-Western culture. A review of relevant literature showed that most of the past studies focusing on the association between these two constructs have been typically conducted in Western Judeo-Christian cultures where Jews, Protestants and Catholics are predominant in society. Other countries with different socio-cultural backgrounds are less predominant in research investigating this issue of religiosity and consumer behaviour. As such, these studies provide incomplete evidence of the general conclusion of the research findings. This study contributes to the current literature as the first step of an empirical effort to probe the relationship between religion and consumer behaviour in a totally different cultural aspect - Bangladesh, a Muslim-dominant democratic country.

To the best knowledge of the researcher, there has been no evidence until now of any empirical study revealing the influence of religion on consumer behaviour, in the context of Bangladeshi Muslim culture. The present research may lead international consumer researchers to a better understanding of the relevance of degree of religiosity to consumer behaviour in a Muslim cultural setting - particularly in Bangladesh. With 149 million of Muslim population, Bangladesh holds over $1.1 \%$ of the global market share of Islamic finance industry. This represents a good potential for the IFPs market in the future.

To conclude, the key contributions of the thesis are as follows:

- Development and testing of the integrated 'Religiosity-Consumer Behaviour' model for Muslim consumers

- Provision of empirical support to the Theory of Reasoned Action (TRA) to understand religious-driven behaviours influenced by religious commitment

- Identification of important religious dimensions and advancement of measuring religiosity from an Islamic perspective 
- Definition of generational cohort in a Bangladeshi context and extension of the current research by examination of its moderation effect on the relationship between religiosity and consumer behaviour

- Focus on the Islamic financial industry and purchase intentions of Muslim consumers towards the overall and different categories of Islamic financial products (IFPs)

- Investigation of the relationship between religion and consumer behaviour in an entirely different cultural context - a Muslim-dominant democratic country, such as Bangladesh.

\subsubsection{Managerial Implications}

The findings of this study have some practical implications, as well as a theoretical contribution. It is important for companies to understand consumer behaviour in the local market as they grow and compete globally. Many marketers face the fundamental problem while operating within a Muslim consumer society of how to efficiently target and meet the needs of Muslim-religious target markets, such as Bangladesh. Because the market is comprised of a very high number of Muslim consumers, it cannot be deemed to be the same as other Muslim countries and marketers naturally have to find ways of approaching these consumers. Although marketers can use a standardised marketing approach that focuses on the common characteristics of Muslim consumers, this approach appears to misinterpret the reflective influence of religiosity level variations among consumers that lead to variations in their purchasing behaviours. This finding recommends that international marketers adopt strategies to attract consumers from different countries around the world.

This study examined a case where religiosity may be a useful conceptual element for interpreting consumer behaviour. The majority of believers and worshippers have doubts and therefore they differ in their degrees of religiosity. This would clarify why there might be differences in religiosity measures within the same religious group (Beit-Hallahmi \& Argyle, 1997). There are also variations among Muslim people in terms of religious degrees, where some Muslims are adhering to all Islamic rules, while others are more secular (Sedgwick, 2006). The findings of this study, which is consistent with the previous research (Hirschman, 1981; Wilkes et al., 1986; Delener, 1990a, 1994; McDaniel and Burnett, 1990; Sood and Nasu 1995; Essoo and Dibb, 2004; Mokhlis, 2009) suggest that consumers' behaviour varies 
significantly depending on their degree of religiosity. Thus marketing strategists who wish to understand Muslim consumers in a more predictive and comprehensive manner might benefit from considering religiosity as a predictor of consumer behaviour, rather than simply as correlates of product purchasing. A number of practical implications of probable significance for marketers are argued below.

The insights of religious differences in consumer behaviour can provide companies with a means for developing market segmentation approaches at their strategic level. The most obvious consideration is the selection of a segmentation basis by using religiosity. The findings of this study indicate that the extent to which people are committed to their religion impacts on their consumption behaviour. Therefore, religiosity can be considered helpful to the effectiveness of marketing strategies.

As differences based on religiosity, such as consumer buying attitude and purchase intention, were found to be significant in predicting consumer behaviour, it follows that knowledge of the religiosity of consumers can provide marketers with a very practical tool for market segmentation. When the markets are segmented on the basis of religiosity, marketing strategies that reflect and are better suited to the individualities of consumer behaviour may then be considered (Essoo and Dibb 2004). The study found that traditionalists prefer Islamic deposit products, swing cohort prefers Islamic deposit, credit and capital market products and GenY prefers Islamic credit and capital market products. By identifying the characteristics of each generational cohort and their product category preferences can also provide a base for the segmentation approach in the marketplace.

Marketers should include the aspect of religiosity as a tool for achieving greater effectiveness in their advertising and promotional strategies for Bangladeshi consumers, in order to improve their intentions to buy IFPs. Consumers with different degrees of religiosity were found to attach different levels of importance to IFP attributes. These results would identify distinct differences in the pricing, placing, promotion and communication elements of the marketing activities for both the devout and the informally religious target markets. Moreover, marketers should take into account these differences to help them adjust or change their existing marketing programmes.

By exploring consumers with different levels of perceived religiosity, alongside their varying evaluations of certain IFP attributes, marketers could determine the appropriate image for 
IFPs and design an overall marketing strategy based on that image. Consequently, marketers need to measure the religiosity of their local market, giving them an advantage over other competitors. For example, the higher the religiosity of the target market area, the more likely the community is to have a stronger preference for IFPs.

The finding that IFP attributes are considered more important by Muslim religious consumers indicates an opportunity for marketers to attract their target market segments. Highly religious consumers can be characterised as conservative and are found to attach greater importance to the Shariah-compliant attributes of IFPs. To attract this segment, marketers should highlight Islamic principles in their advertising and promotional strategies, combined with offering attributes valued by religious consumers.

Marketing communications could be significantly impacted by religiosity. Through predicting the preferences of the large target market, marketing planners could attain better communication strategies that would appeal to the ethical and religious values of consumers. This understanding could also assist as a guide for designing more appropriate and appealing message content. This study, and previous studies, indicates that most respondents have known about the existence of Islamic banking and are aware of other Islamic methods of finance. But these studies also show that the majority of people are unaware of the specific methods of finance such as mudarabah, sukuk, and takaful. The primary implication for marketers is that this requires educational programmes to help improve the awareness and knowledge related to these methods of finance for the target market. Communication messages should be tailored according to degree of religiosity to garner positive responses that are relevant to the target audience.

The next section discusses the limitations of this study that should be taken into account when assessing the findings and implications, followed by the future research direction.

\subsection{Limitations of the Research Study}

This study has some limitations, as does all empirical research. The limitations need to be considered, while the findings of this study are interpreted and applied. While this study can assist the global financial industry and Islamic financial institutions in particular, to develop business and marketing strategies, the study's results are limited to Bangladesh, where Islamic finance is not comprehensively practiced. The findings of the study are also limited to 
retail consumers, thus generalisation of the results as they apply to business or corporate clients must be made carefully. There is a possibility that the behavioural patterns of consumers in other economic, social and political environments could vary from those revealed in this study. Therefore, generalising the findings of this research is limited to other less or more developed Shariah-law countries or democratic Muslim countries.

Information for independent and dependent variables was reported by the same respondents that could source the common method bias. Moreover, religiosity measurement items could produce social desirability biases because of the sensitive nature of the topic (Mokhlis, 2009). In this connection, the study examines the common method variance threat as a concern about social desirability in self-reports on sensitive topics. Based on the common method variance test, it can be argued that the findings are safe from common method bias. It is challenging to question Muslim respondents about their religious activities and behaviour (Khraim, et al., 1999). However, this study did not face any difficulties in this regard. This is because of the prior approval and endorsement from the department head and lecturers of universities, managers of corporate offices and secretaries of retired employee associations.

The scope of the study was limited to Islamic financial products and thus the results may not be sufficiently generalised to include other non-financial products. In addition, this study does not cover all the variables of interest in a consumer behaviour model as it is difficult to include all possible determinants in one single model. Also, as a survey instrument, the questionnaire was kept comparatively short to encourage respondents to participate in the survey.

An additional limitation is found in the demographic profile of research respondents, compared with the total Bangladeshi population. The descriptive analysis discloses that most of the survey participants are male, rather than female. Approximately $85 \%$ of respondents identified as male, as family heads in Bangladesh are generally male. Therefore, the result of the study may not be entirely representative of the total population of Bangladesh. In a maledominated society, males control women's lives and behaviour and women are almost invisible in public life. The larger representation of male consumers is not seen as a major limitation, however.

It is expected that the main findings of this study will be of interest in the religiosityconsumers' behaviour area, regardless of the limitation stated above. The present findings 
contribute to useful insights into this aspect of consumer behaviour and the combination of other factors is left for future research.

\subsection{Directions for Further Research}

The role of religiosity in influencing certain aspects of consumer buying attitude and purchase intention, as well as the importance of increasing marketing researchers' understanding of the relationship between religiosity and consumer behaviour, appears obvious. This study provides a foundation for further research on religiosity and consumer behaviour.

The combination of socio-culture and marketing brings many opportunities for future research and the outcomes of this study have exposed a number of interpretations for additional exploration. This study recommends that future research should investigate the differences in purchase intention among Muslim consumers in international settings. Identifying and investigating the similarities and differences in purchase intention between Muslim consumers in Bangladesh and other Islamic countries or Western countries would be beneficial for understanding the potential different effects of religiosity on buying behaviour and its impact in varying country contexts. There is a common misconception that Muslim consumers have shared characteristics that are essential and fixed and distinguish them from other consumers. But such a perception provides only superficial and out-dated insights into identity and behaviour and does not contribute much to understanding the real nature of people. Therefore, if Muslims have no shared characteristics, identifying the differences requires a clear understanding of whether or not Muslim consumers are actually distinct from general consumers (Sandikci, 2011).

In this study, consumers' preferences and purchase intentions towards conventional financial products were not examined. Future research should perhaps investigate this aspect of consumer behaviour and compare Muslim consumers' preferences for both Islamic and conventional financial products. This comparative study examining how religiosity affects consumer purchase intention would suggest possible implications for marketing planners. Additional research would contribute a new dimension to the work that has already been reported and synthesised on product selection decision and purchase intention, thus providing marketers with an in-depth knowledge of the buying behaviour of religious Muslim consumers. 
Additional future research could include other motivational factors for selecting Islamic financial products, apart from religion. IFP selection criteria could be recommendations of family and friends, location of bank, profit return, service quality, perceived value etc. (Khan, et al., 2007; Kishada \& Wahab, 2013; Metawa \& Almossawi, 1998). Thus, considering religiosity alone may not provide a complete picture of consumer behaviour and results may be skewed due to the absence of other key factors.

It is suggested that future research explores factors influencing the buying behaviour of different IFPs. Sometimes it is impractical to depend only on quantitative data as religious behaviour is very personal in its nature and through qualitative data an in-depth picture of consumers' religious values and motivational factors can be revealed. As there are few studies on the relationship between religiosity and consumer behaviour, qualitative research may help to explore the reasons behind the scenario. In order to understand the depth of consumer behaviour, a qualitative method could be combined with quantitative research.

\subsection{Conclusion}

Religiosity has been observed to be gaining momentum in the global business environment (McDaniel and Burnett, 1990). Recent marketing and consumer behaviour studies emphasise the importance of religiosity as an instructive construct in predicting human behaviour and strongly suggest a possible relationship between religiosity and particular aspects of consumer behaviour (Alam, et al., 2011; Mansori, 2012; Mokhlis, 2009; Moschis \& Ong, 2011). Although religiosity can influence consumers' behaviour, and buying decisions in particular, the effectiveness of religiosity as a determinant for differentiating consumers remains almost unexplored. As a result of this oversight, marketing theory and practice is not completely established. In this regard, this study endeavours to provide some initial suggestions to confirm that religiosity is one of the most important and pervasive forces to influence consumer behaviour. The study commenced with the use of a 'religiosity-Consumer Behaviour' conceptual model. The model theoretically provided the conceptual ground to develop a greater knowledge and investigate Muslim consumers' religiosity, buying attitudes and purchase intentions of IFPs. This study provides evidence that religiosity has overall influence on consumer behaviour in an Islamic context. The study also reached interesting conclusions regarding the effects of religiosity on consumer behaviour involving respondents across three generational cohorts in a democratic Muslim country, Bangladesh. Religiosity, in 
general, can be meaningfully associated with consumer buying behaviour both from buying attitude and purchase intention aspects, supporting previous mixed reviews considering the inclusion of this construct when investigating consumer behaviour. This study also indicates that consumer buying attitude has a partial mediating effect on the association between religiosity and consumer purchase intention towards IFPs. Furthermore, the effect of religiosity on buying behaviour is not significant in all categories of IFPs and generational cohort also partially moderates this relationship. In addition, this study closed the gap in information about how to measure religiosity in order to predict consumers' buying behaviour and proved that religiosity plays a vital role in determining Muslim consumer's buying attitudes and purchase intentions of IFPs. Overall, the findings extend the understanding of the effects of religiosity on Muslim consumers' buying attitudes and purchase intentions towards IFPs and provide significant implications for managerial practice and policy and the direction of further research. 


\section{Appendixes}

\section{Appendix A1: Copy of Participant Information Sheet in English}

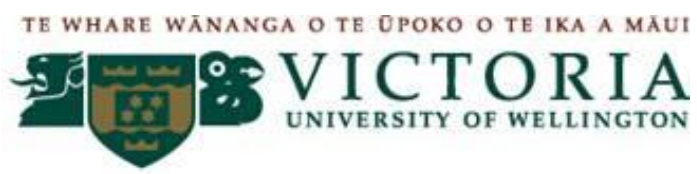

School of Marketing and International Business

$\underline{\text { PARTICIPANT INFORMATION SHEET }}$

\section{Religiosity, Generational Cohort and Buying Behaviour of Islamic Financial Products in Bangladesh}

\section{PhD Candidate: Farhana Newaz}

\section{Supervisors: Professor Kim-Shyan Fam}

\section{Dr. Revti Raman}

Thank you for showing an interest in this project - before you proceed, please read the information below:

My name is Farhana Newaz and I am a PhD candidate at the School of Marketing and International Business, Victoria University of Wellington, New Zealand. This survey is being undertaken as part of my $\mathrm{PhD}$ degree at Victoria University of Wellington, New Zealand. In order to decide whether or not you want to participate in this research study, you should understand what is involved. This form gives detailed information about the research study.

\section{WHAT IS THIS FORM?}

This form is to respect and acknowledge your rights, and to inform you of what the research is about. This study has been approved by Victoria University's Human Ethics Committee.

\section{WHY IS THIS RESEARCH BEING DONE?}

As part of a doctoral degree at Victoria University of Wellington I am undertaking this research project leading to a thesis.

\section{WHAT IS THE PURPOSE OF THIS STUDY?}

The purpose of this study is to examine consumers' attitude and purchase intention towards Islamic Financial Products. 

STUDY?

Participation from you would involve completing this questionnaire by using pencil and paper method. Your participation is completely voluntary. The questionnaire should take around 15 minutes to complete, and it can be terminated at any time.

\section{WHAT WILL HAPPEN TO THE INFORMATION YOU GIVE?}

All information you provide will be kept confidential and accessible only to me and my supervisors, Professor Kim-Shyan Fam and Dr. Revti Raman. Information collected will form the basis of my research project. Results of this questionnaire will contribute to my thesis and appear in academic journals or may be presented at academic conferences. However, only aggregated results will be reported. The survey does not collect any identifying information from participants thus it not possible for any respondent to be identified. The thesis will be submitted for examination to the School of Marketing and International Business and deposited in the University Library.

Throughout the project, the data will be stored in a locked cabinet at the School of Marketing and International Business. The raw data will be kept secured for 3 years upon the completion of the thesis before being destroyed.

A summary of the results will be posted at the website of School of Marketing and International Business http://vuw.ac.nz/smib at the end of the project.

By submitting the completed questionnaire, you consent to participate.

IF YOU HAVE ANY QUESTIONS OR NEED FURTHER INFORMATION, WHOM CAN YOU CONTACT?

$\underline{\text { PhD Candidate: }}$

Farhana Newaz

PhD Candidate

School of Marketing \&

International Business

Victoria University

of Wellington

PO Box 600

Wellington 6140

New Zealand

+6444635233 ex 8820

Farhana.newaz@vuw.ac.nz
SUPERVISOR:

Dr. Kim-Shyan Fam

Professor

School of Marketing \&

International Business

Victoria University

of Wellington

PO Box 600

Wellington 6140

New Zealand

+6444636459

kim.fam@vuw.ac.nz

\section{SUPERVISOR:}

Dr. Revti Raman

Lecturer

School of Marketing \&

International Business

Victoria University

of Wellington

PO Box 600

Wellington 6140

New Zealand

+6444637452

revti.raman@vuw.ac.nz 


\section{Appendix A2: Cover Letter in English}

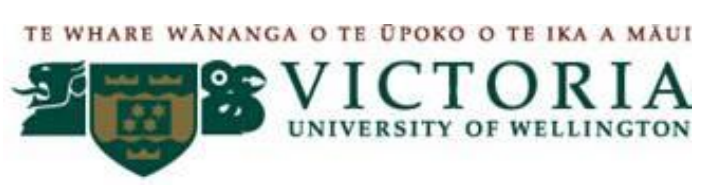

10 October, 2011

Dear Participant,

Subject: $\quad$ Participant Information Sheet

Researcher: Farhana Tahmida Newaz: School of Marketing and International Business, Victoria University of Wellington

This is Farhana Tahmida Newaz, a PhD candidate in the School of Marketing and International Business at the Victoria University of Wellington, New Zealand. The project I am undertaking is: Religiosity, Generational Cohort and Buying Behaviour of Islamic Financial Products in Bangladesh. This survey is being undertaken as part of my $\mathrm{PhD}$ degree at Victoria University of Wellington, New Zealand. The University requires that ethics approval be obtained for research involving human participants.

It is my pleasure to inform that you have been chosen to participate in this study. Participation from you would involve completing this questionnaire by using pencil and paper method. Your participation is completely voluntary and there is no traceable information collected in the research. The questionnaire should take around 15 minutes to complete, and it can be terminated at any time. I would appreciate if you could give your cooperation by devoting your precious time to the survey. It must be stressed here that the data obtained from this survey will contribute to my thesis and appear in academic journals or may be presented at academic conferences and all the information will be strictly confidential. Any raw data on which the results of the project depend will be retained in secure storage for 3 years, after which time it will be destroyed.

A summary of the results will be posted at the website of School of Marketing and International Business http://vuw.ac.nz/smib at the end of the project.

By submitting the completed questionnaire, you consent to participate.

Should you have any queries or wish to know more about this study, feel free to contact me,

Farhana Tahmida Newaz (PhD Candidate)

School of Marketing \& International Business

Victoria University of Wellington

PO Box 600, Wellington 6140, New Zealand

+6444635233 ex: 8820

farhana.newaz@vuw.ac.nz

Your kind cooperation and contribution to my study is highly appreciated.

Thank you. 


\section{Appendix A3: Copy of Survey Questionnaire in English}

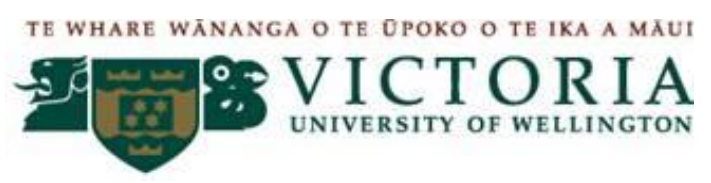

\section{QUESTIONNAIRE}

\section{Section A. Religious commitment}

Please indicate your reactions on a 7-point scale to the following statements regarding your religious commitment:

(1-strongly disagree, 2-disagree, 3-disagree somewhat, 4-undecided, 5-agree somewhat, 6-agree, 7-strongly agree)

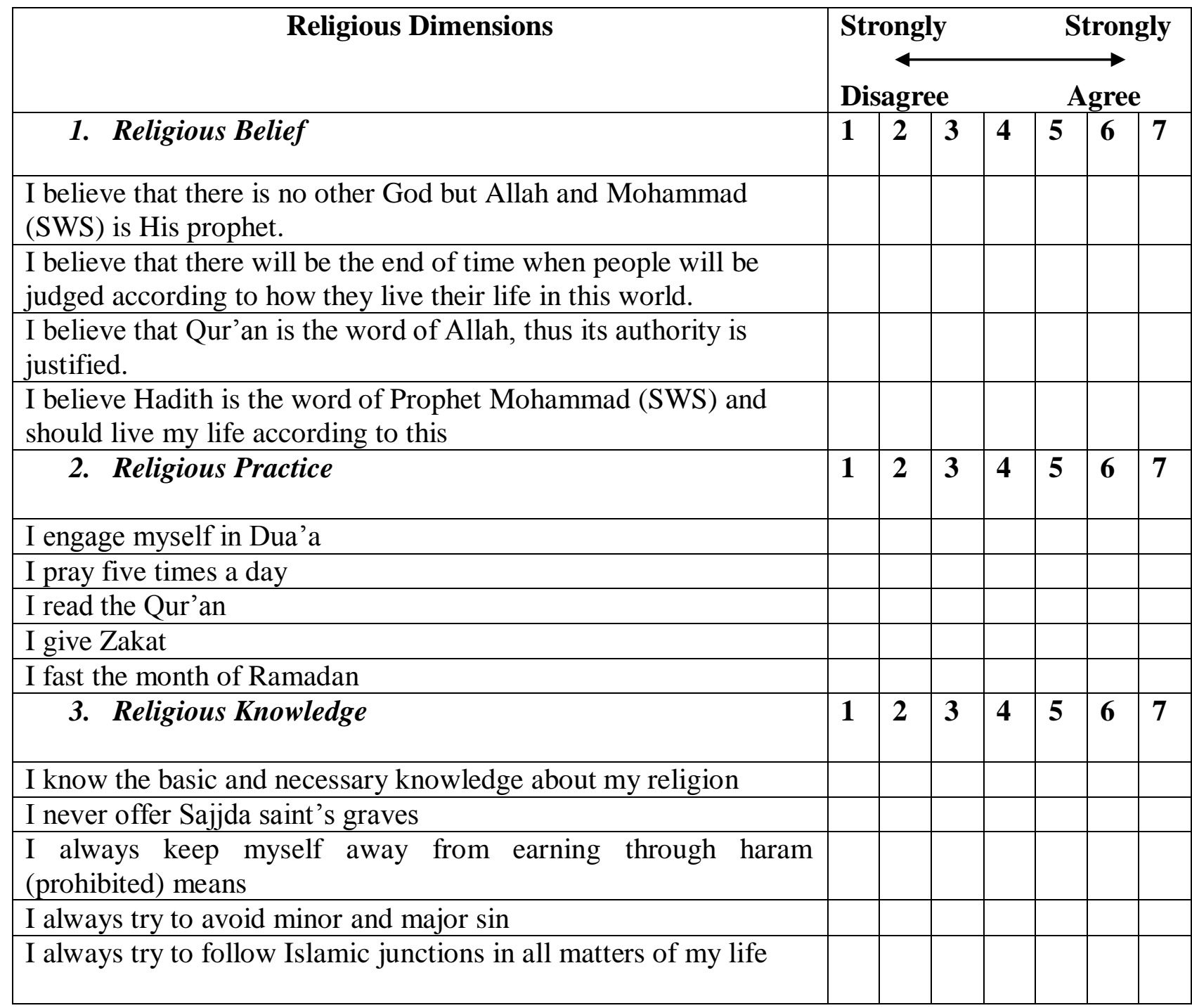




\begin{tabular}{|c|c|c|c|c|c|c|c|}
\hline Religious Dimensions & & ong & & & & tro & \\
\hline 4. Religious Experience & 1 & 2 & 3 & 4 & 5 & 6 & 7 \\
\hline $\begin{array}{l}\text { I feel sorrow and dissatisfaction when I do something against my } \\
\text { faith }\end{array}$ & & & & & & & \\
\hline I have feeling of being tempted by devil & & & & & & & \\
\hline I have feeling of being afraid of Allah & & & & & & & \\
\hline $\begin{array}{l}\text { I have feeling of being punished by Allah for something doing } \\
\text { wrong }\end{array}$ & & & & & & & \\
\hline I feel pleasure by seeing others following Islamic teaching & & & & & & & \\
\hline $\begin{array}{l}\text { Religion is especially important to me because it answers many } \\
\text { questions about the meaning of life }\end{array}$ & & & & & & & \\
\hline 5. Consequences & 1 & 2 & 3 & 4 & 5 & 6 & 7 \\
\hline $\begin{array}{l}\text { It is my duty to give respect to others and give them their rights } \\
\text { according to Islamic injunctions }\end{array}$ & & & & & & & \\
\hline I try to avoid any activity, which hurt others & & & & & & & \\
\hline I always try to help those who need my help & & & & & & & \\
\hline I try to be honest and fair with others & & & & & & & \\
\hline I always avoid humiliating others & & & & & & & \\
\hline
\end{tabular}

\section{Section B: Buying Attitude}

1. Please indicate your reactions on a 7-point scale to the following statements regarding your buying attitude towards Islamic financial products:

(1-strongly disagree, 2-disagree, 3-disagree somewhat, 4-undecided, 5-agree somewhat, 6-agree, 7-strongly agree)

\begin{tabular}{|c|c|c|c|c|c|c|c|}
\hline Statements & 1 & 2 & 3 & 4 & 5 & 6 & 7 \\
\hline $\begin{array}{l}\text { Islamic finance operates in accordance with the principles of } \\
\text { Islamic law (or Shariah) }\end{array}$ & & & & & & & \\
\hline Islamic finance follows interest free principle & & & & & & & \\
\hline Islamic finance follows profit and risk sharing principle & & & & & & & \\
\hline $\begin{array}{l}\text { For investment, uncertainty, risk or speculation is prohibited in } \\
\text { Islamic finance }\end{array}$ & & & & & & & \\
\hline $\begin{array}{l}\text { Islamic finance follows that capital must have a social and ethical } \\
\text { purpose beyond pure and unfettered return }\end{array}$ & & & & & & & \\
\hline Islamic finance is in harmony with my religious values & & & & & & & \\
\hline
\end{tabular}


2. Below is a list of different categories of Islamic financial products which have been known to comply with Islamic Shariah. How likely are you intending to prefer these products to purchase? Where 1 means you find them most unlikely and 7 means you find them most likely.

\begin{tabular}{|c|c|c|c|c|c|c|c|}
\hline Product Category & \multicolumn{5}{|c|}{ Most Unlikely } & \multicolumn{2}{|c|}{ Most Likely } \\
\hline $\begin{array}{l}\text { Islamic Deposit Products } \\
\text { (e.g. current account, savings account, term deposit } \\
\text { and savings bond) }\end{array}$ & 1 & 2 & 3 & 4 & 5 & 6 & 7 \\
\hline $\begin{array}{l}\text { Islamic Credit Products } \\
\text { (e.g. loans, hire purchase, leasing and mortgage) }\end{array}$ & 1 & 2 & 3 & 4 & 5 & 6 & 7 \\
\hline $\begin{array}{l}\text { Islamic Capital Market Products } \\
\text { (e.g. share, securities, bond, treasury) }\end{array}$ & 1 & 2 & 3 & 4 & 5 & 6 & 7 \\
\hline $\begin{array}{l}\text { Islamic Insurance Products } \\
\text { (e.g. general and life insurance) }\end{array}$ & 1 & 2 & 3 & 4 & 5 & 6 & 7 \\
\hline
\end{tabular}

\section{Section C: Purchase Intention}

Please indicate your reactions on a 7-point scale to the following statements regarding your purchase intention towards Islamic financial products:

(1-strongly disagree, 2-disagree, 3-disagree somewhat, 4-undecided, 5-agree somewhat, 6-agree, 7-strongly agree)

\begin{tabular}{|c|c|c|c|c|c|c|c|}
\hline Statements & 1 & 2 & 3 & 4 & 5 & 6 & 7 \\
\hline $\begin{array}{l}\text { I am eager to learn more about this product related to Islamic } \\
\text { Shariah }\end{array}$ & & & & & & & \\
\hline I am interested to use Islamic financial products \& services & & & & & & & \\
\hline $\begin{array}{l}\text { I am interested to use Islamic financial products \& services in the } \\
\text { future }\end{array}$ & & & & & & & \\
\hline I will use Islamic financial products \& services someday & & & & & & & \\
\hline I will definitely recommend Islamic personal financing to others & & & & & & & \\
\hline
\end{tabular}




\section{Section D: Generational Cohort}

Please choose one of the following statements that best describes you.

\begin{tabular}{|l|l|}
\hline Statement & Tick \\
\hline $\begin{array}{l}\text { In my opinion, life is really not supposed to be fun and conformity is good. It is } \\
\text { good to be self-disciplined, traditional, money saver, give importance on safety and } \\
\text { security and to make personal sacrifice. }\end{array}$ & \\
\hline $\begin{array}{l}\text { In my opinion, it is good to be rational, self-reliant, and adaptable. I'm } \\
\text { entrepreneurial, risk averse and value safety and security and strive for comfort in } \\
\text { life. }\end{array}$ & \\
\hline $\begin{array}{l}\text { In my opinion, I'm a stimulated person on instant gratification. I have been depicted } \\
\text { as eager and tech savvy, requiring fun and challenges in life and have strong } \\
\text { preference for digital content and social interaction. }\end{array}$ & \\
\hline
\end{tabular}

\section{Section E: Demographics Section}

1. Which year were you born?

2. Your present Age: Years
3. Your Gender:
[1] Male
[2] Female

4. Please indicate your marital status
[1] Single
[2] Married
[3] Divorced/widowed

5. What is your occupation?

[1] Self-employed [2] Government employee [3] Private sector employee

[4] Housewife/retired/unemployed [5] Student

6. Please indicate your highest education level

[1] Higher Secondary School [2] Honours/Diploma [3] Master degree and above 
7. In which of the following categories does your current monthly income fall?

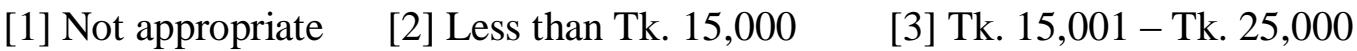

[4] Tk. 25,001 - Tk. 35,000 [5] Tk. 35,001 - Tk. 45,000 [6] Tk. 45,501 - Tk. 55,000

[7] Tk. 55,001 - Tk. 65,000 [8] Tk. 65, 001 and above

8. City you currently live in :

Thank you very much for your help and co-operation 


\title{
Appendix A4: Copy of Participant Information Sheet in Bengali
}

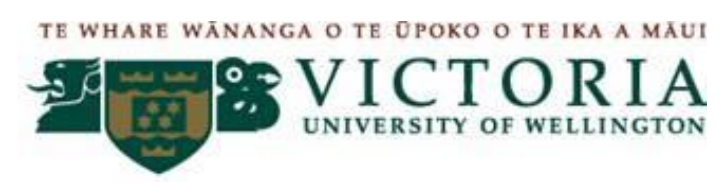

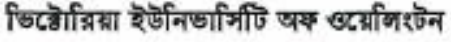

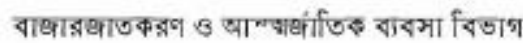

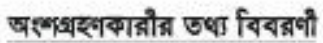

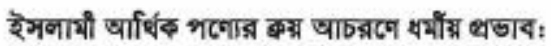

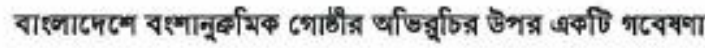 \\ (Religiosity, Generational Cohort and Buying Behaviour of Islamic Financial Products in \\ Bangladesh \\ পিএইर्णড ब्राथी: ফারशना नেওয়াজ

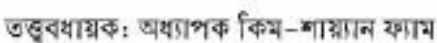 \\ ङ. রের্ত্ত রামান
}

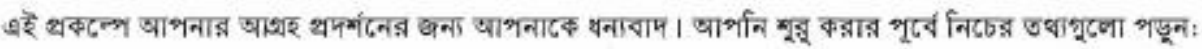

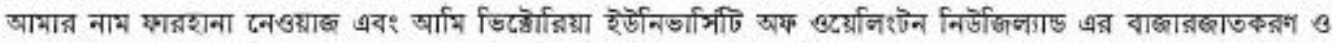

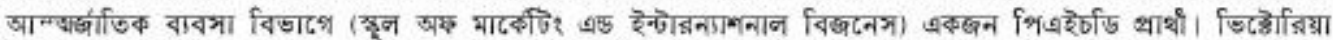

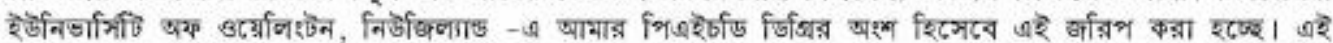

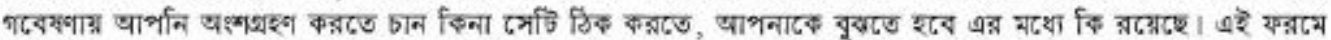

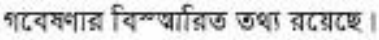

\section{बই ক্রম कি ?}

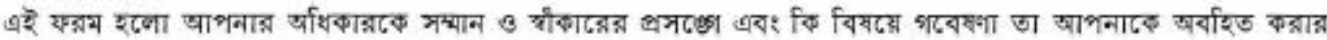

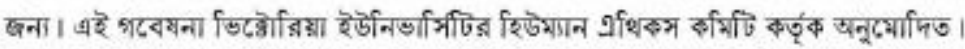

\section{কেन এই গবেষণা করা হর্ছে ?}

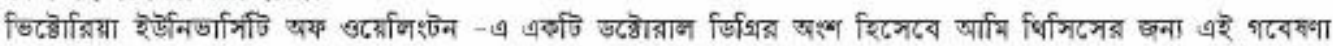

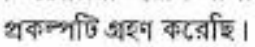

\section{এই গভেষणाब্ন উদ্्েশ্য কি ?}

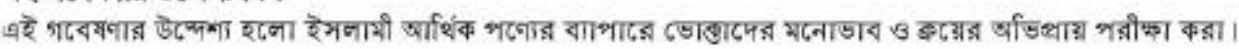

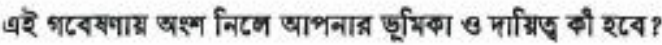

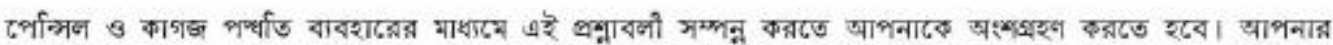

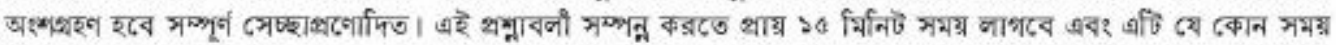
সमाণ कরा याढে। 


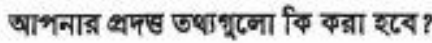

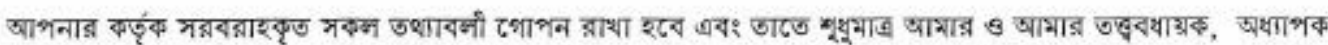

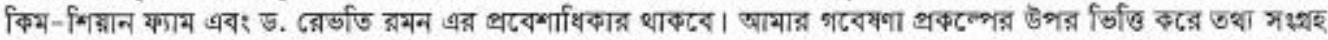

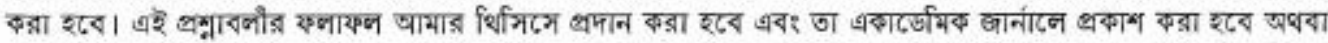

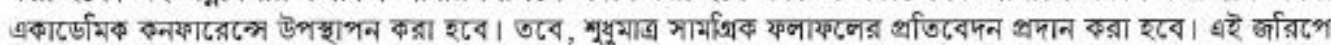

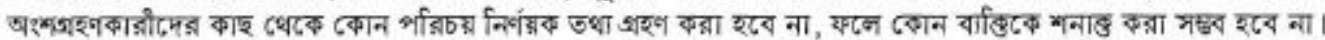

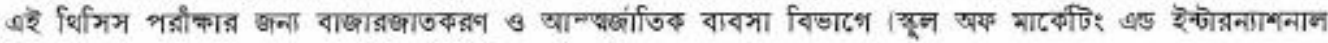

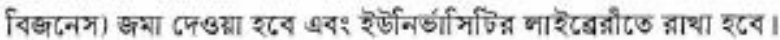

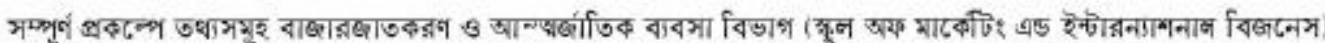

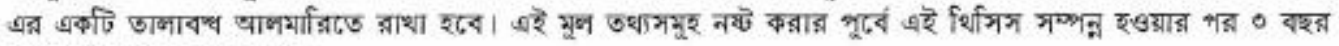

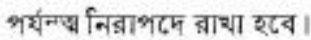

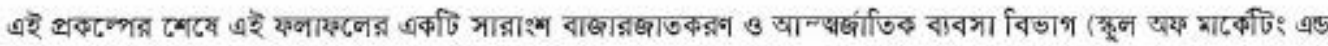

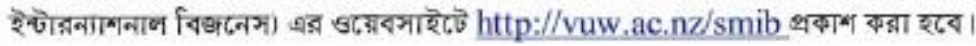

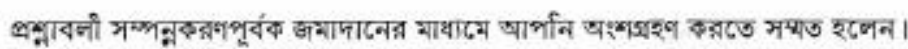

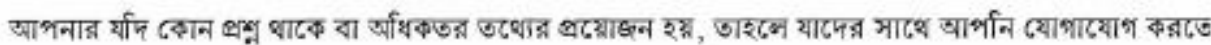
পाब্রে:

PhD Candidate:

Farhana Newaz

$\mathrm{PhD}$ Candidate

School of Marketing \& International Business Victoria University of Wellington

PO Box 600

Wellington 6140

New Zealand

+6444635233 ex 8820

Farhana.newaz@vuw.ac.nz

\section{SUPERVISOR:}

Dr. Kim-Shyan Fam

Professor

School of Marketing \&

International Business

Victoria University

of Wellington

PO Box 600

Wellington 6140

New Zealand

+6444636459

kim.fam@vuw.ac.nz

\section{SUPERVISOR:}

Dr. Revti Raman

Lecturer

School of Marketing \&

International Business

Victoria University

of Wellington

PO Box 600

Wellington 6140

New Zealand

+6444637452

revti.raman@vuw.ac.nz 


\section{Appendix A5: Cover Letter in Bengali}

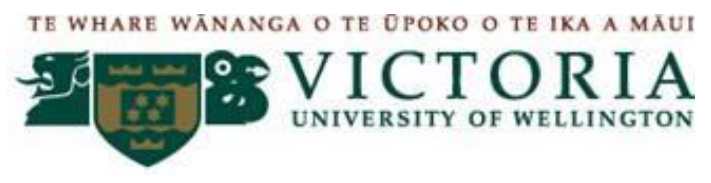

১০ अষ্টোবন্ন, ২০১১

প্রিয় অঞশগহগকারী,

\begin{tabular}{|c|c|}
\hline दिख? & অংশগ্রহশকারী \\
\hline & 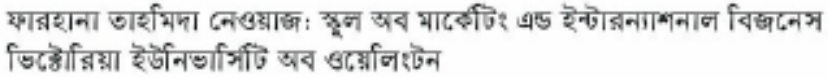 \\
\hline
\end{tabular}

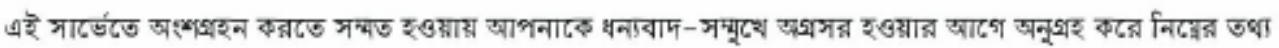
भड़ निन:

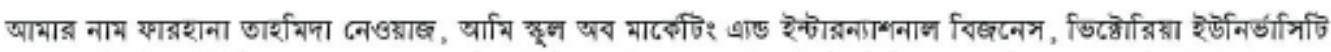

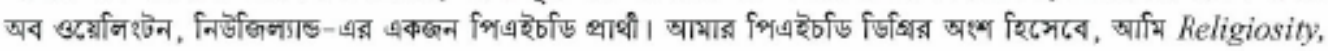
Generational Cohort and Buying Behaviour of Islamic Financial Products in Bangladesh ब्रকकन्भाিि হাঢত निद्ज़ा .

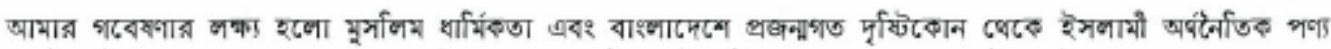

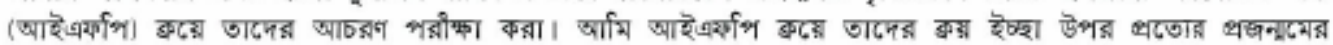

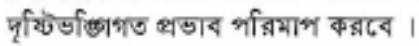

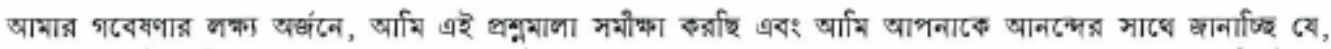

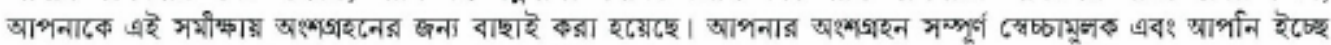

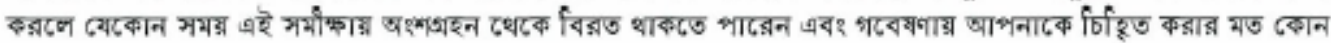

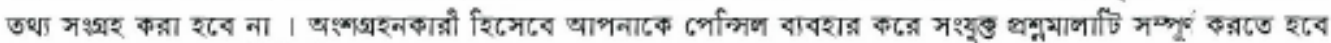

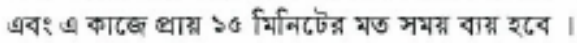

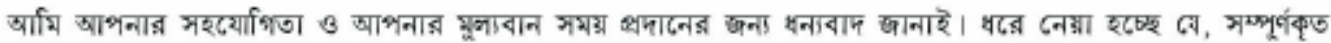

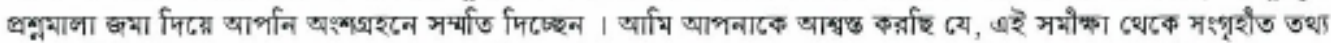

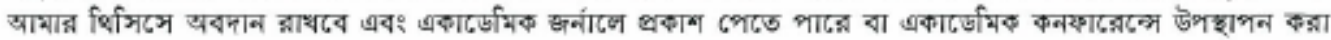

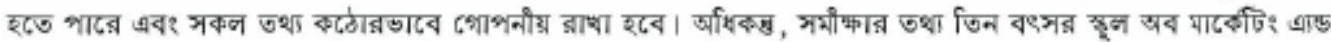

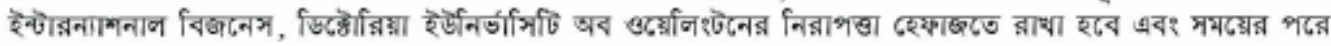

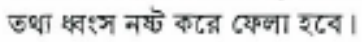

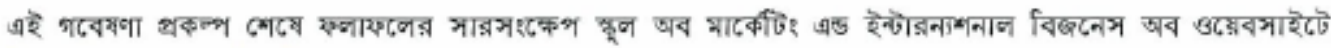

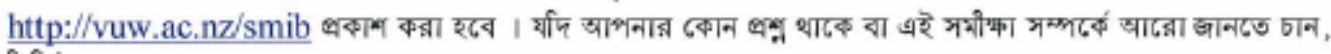

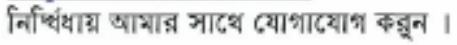

Farhana Tahmida Newaz (PhD Candidate)

School of Marketing \& International Business

Victoria University of Wellington

PO Box 600, Wellington 6140, New Zealand

+6444635233 ex: 8820;

farhana.newaz@@yuw.ac.nz

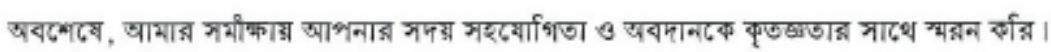

आभनाढ़ धनाबाम । 


\section{Appendix A6: Copy of Survey Questionnaire in Bengali}

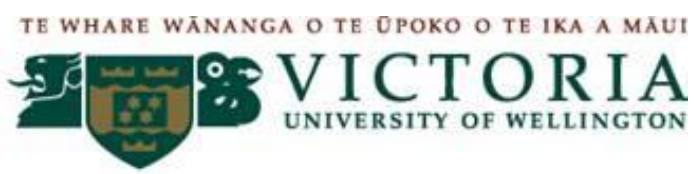

ध्रশ्नমाना

শাथा এ. ধर्माँয় অक्্ोंबाর

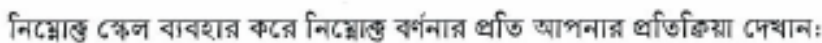

\begin{tabular}{|c|c|c|c|c|c|c|}
\hline $\begin{array}{l}\text { ১-প্রবল অিমত } \\
\text { পোষণ কর্ন }\end{array}$ & $\begin{array}{l}\text { २- जिমত } \\
\text { পোম্ন ক़ि }\end{array}$ & $\begin{array}{l}\text { ०- সাाাन्य } \\
\text { जिমত পোমণ } \\
\text { रর্র }\end{array}$ & $\begin{array}{l}\text { 8- সिथां } \\
\text { नেই }\end{array}$ & $\begin{array}{l}\text { ৫- কিষ্ণ্ট } \\
\text { এক্মত }\end{array}$ & ৩- এক্মত & $\begin{array}{c}\text { १- ধবनভাবে } \\
\text { এক্মত পোষন } \\
\text { কর্নি }\end{array}$ \\
\hline & & & \multicolumn{3}{|c|}{ ধববলভারে } & পবনভাবে \\
\hline
\end{tabular}

\begin{tabular}{|c|c|c|c|c|c|c|c|}
\hline ধर्याँয় आखण & \multicolumn{7}{|c|}{ ब्र्यार्थक्श } \\
\hline ১. ধর্মায় বিশ্বাস & s & २ & o & 8 & 4 & (4) & 9 \\
\hline 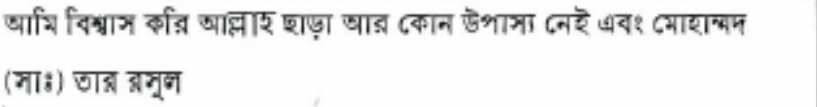 & & & & & & & \\
\hline 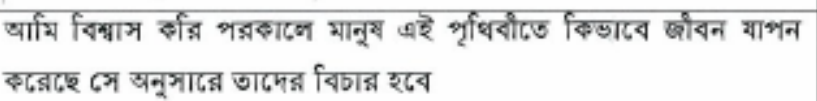 & & & & & & & \\
\hline 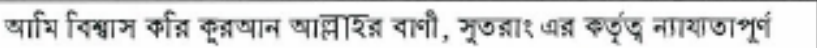 & & & & & & & \\
\hline 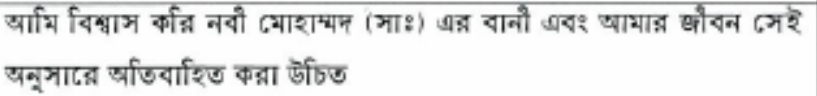 & & & & & & & \\
\hline २. ४र्याँस्म চण & s & ₹ & 0 & 8 & o & o & a \\
\hline 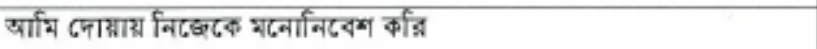 & & & & & & & \\
\hline জামি দ্রিনক পাচি ওয়াতু নামাজ র্्াড়़ & & & & & & & \\
\hline র্রাম কোরান পর্ाড় & & & & & & & \\
\hline জামি ঘাকাত দেই & & & & & & & \\
\hline 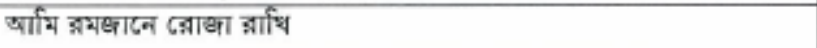 & & & & & & & \\
\hline ०. ४র্মায় জান & $s$ & ₹ & 0 & 8 & a & \& & 9 \\
\hline 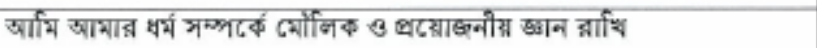 & & & & & & & \\
\hline 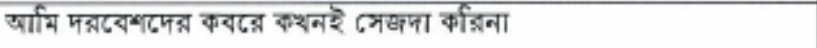 & & & & & & & \\
\hline 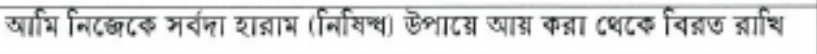 & & & & & & & \\
\hline 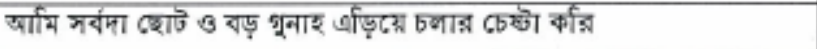 & & & & & & & \\
\hline জামি সামার জীবনের সকল বিষটয় ইসলামী আইন মেরে চলার চেষ্টার্কর & & & & & & & \\
\hline
\end{tabular}




\begin{tabular}{|c|c|c|c|c|c|c|c|}
\hline 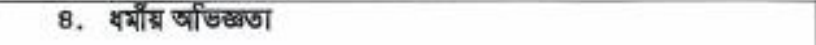 & 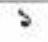 & २ & $\circ$ & 8 & s & s & 9 \\
\hline 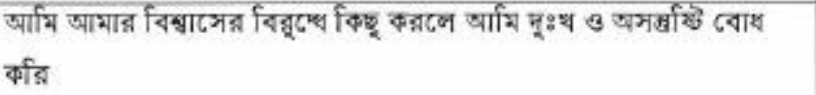 & & & & & & & \\
\hline 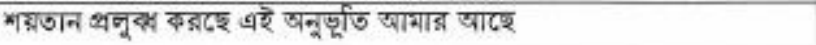 & & & & & & & \\
\hline 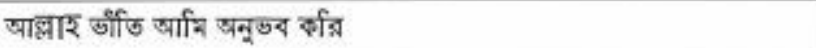 & & & & & & & \\
\hline থারাপ কিছু করভে আল্লাহ আমাবক শার্তি দিবেন এই বোধ আমার মাছে & & & & & & & \\
\hline 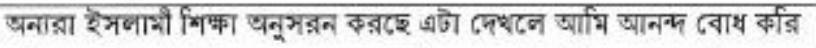 & & & & & & & \\
\hline 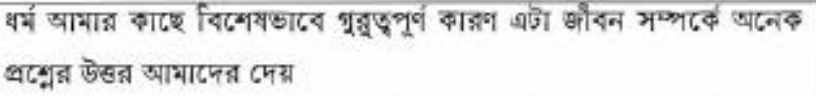 & & & & & & & \\
\hline ๑. एनाएक & $>$ & ২ & o & 8 & G & 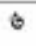 & q \\
\hline 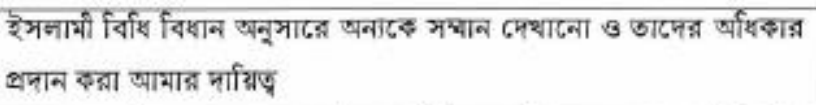 & & & & & & & \\
\hline 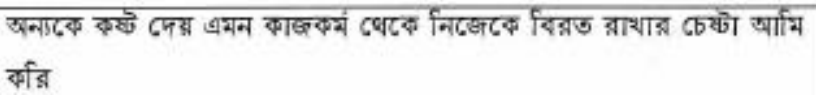 & & & & & & & \\
\hline 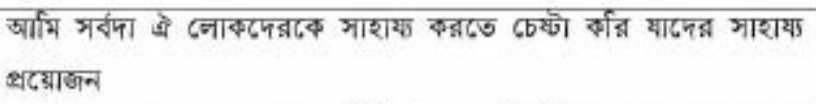 & & & & & & & \\
\hline রামি অন্যদের সাথে সং ও ন্যায়ানিয হতে চেষ্ষা কর্র & & & & & & & \\
\hline 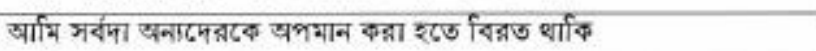 & & & & & & & \\
\hline
\end{tabular}

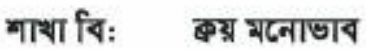

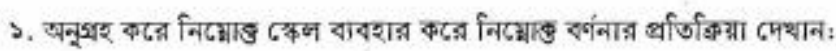

\begin{tabular}{|c|c|c|c|c|c|c|}
\hline 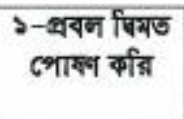 & $\begin{array}{l}\text { २- जिমত } \\
\text { পোমণ ঝরি }\end{array}$ & $\begin{array}{l}\text { ०- मामान्य } \\
\text { चिমত পোाषণ } \\
\text { दाর }\end{array}$ & $\begin{array}{l}\text { 8- সিস্যাত্ত } \\
\text { লেই }\end{array}$ & $\begin{array}{l}\text { •- किद्धुण } \\
\text { এক্মত }\end{array}$ & •- এক্ত & $\begin{array}{c}\text { ৭- ब্রবলভাবে } \\
\text { এক্মত পোষন } \\
\text { বর্নি }\end{array}$ \\
\hline
\end{tabular}

\begin{tabular}{|c|c|c|c|c|c|c|c|}
\hline বন্তব্য & s & २ & 0 & 8 & a & o & 9 \\
\hline 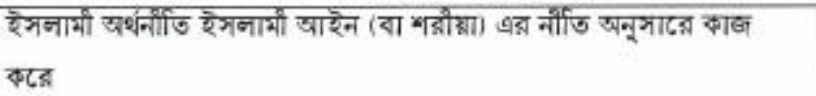 & & & & & & & \\
\hline ইসলামী অর্ঘনাঁত সুদমুক্ত নীতিত অনুসর্র কढর & & & & & & & \\
\hline 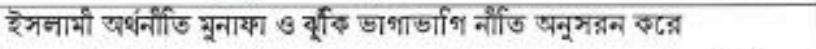 & & & & & & & \\
\hline 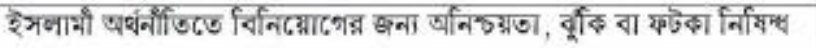 & & & & & & & \\
\hline 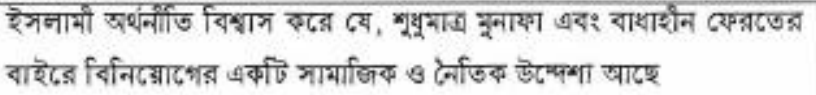 & & & & & & & \\
\hline 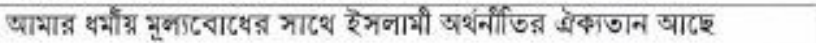 & & & & & & & \\
\hline
\end{tabular}




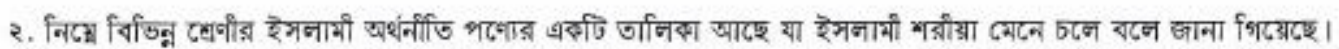

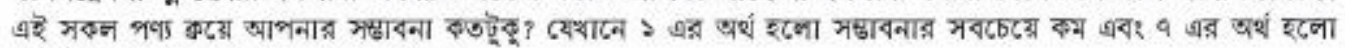

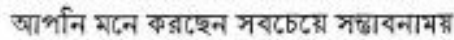

\begin{tabular}{|c|c|c|c|c|c|c|c|}
\hline \multirow{2}{*}{ 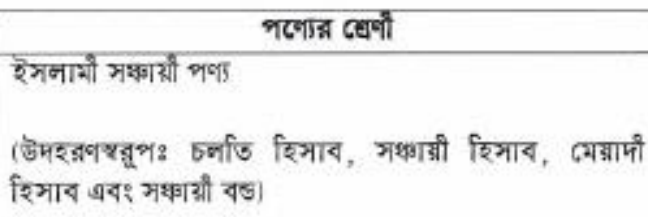 } & \multicolumn{4}{|c|}{ সবচে৫্সে অসম্টাবনাময়স্র } & \multicolumn{3}{|c|}{ সবচচঢয় সম্বাবনাময়স } \\
\hline & I & ₹ & 0 & 8 & 4 & b & 9 \\
\hline 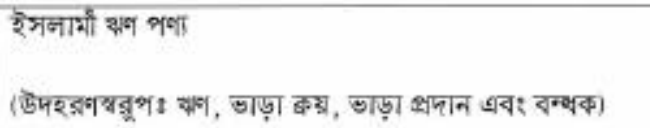 & s & २ & 0 & 8 & 4 & s & 9 \\
\hline 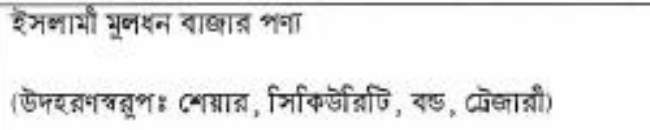 & s & २ & 0 & 8 & $\Leftrightarrow$ & $b$ & 9 \\
\hline 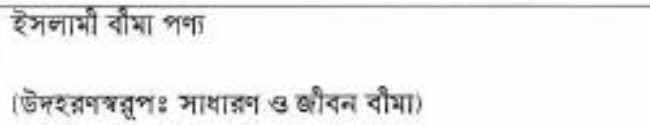 & $s$ & ₹ & 0 & 8 & 6 & 0 & 9 \\
\hline
\end{tabular}

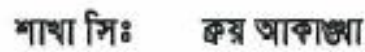

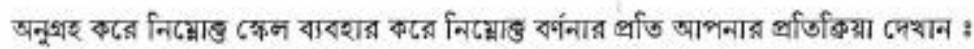

\begin{tabular}{|c|c|c|c|c|c|c|}
\hline $\begin{array}{l}\text { ১-প্রবল ঘिমত } \\
\text { পোমণ কর্ন }\end{array}$ & $\begin{array}{l}\text { २- षিমত } \\
\text { পোষণ হ্রিন }\end{array}$ & $\begin{array}{c}\text { ०- সायान्य } \\
\text { বिমত পোষণ } \\
\text { कর }\end{array}$ & $\begin{array}{l}\text { 8- সिन्धाज } \\
\text { नেই }\end{array}$ & $\begin{array}{l}\text { ৫- दिश्रूण } \\
\text { এक्यত }\end{array}$ & ৪ - একমত & $\begin{array}{c}\text { १- পবনলভাবে } \\
\text { এক্মত পোষন } \\
\text { कর্ন }\end{array}$ \\
\hline
\end{tabular}

\begin{tabular}{|c|c|c|c|c|c|c|c|}
\hline বत्ठद्या & s & २ & ० & 8 & \& & ○ & 9 \\
\hline 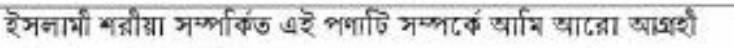 & & & & & & & \\
\hline 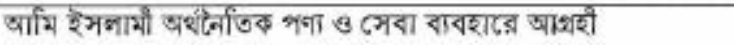 & & & & & & & \\
\hline 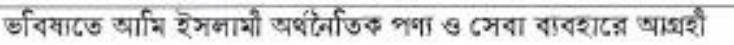 & & & & & & & \\
\hline রামি ইসলামী অর্থটৈরিতক পণা ও সেবা কোন ৬কসসময় ব্যবহার ক্রব & & & & & & & \\
\hline 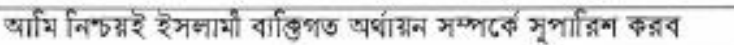 & & & & & & & \\
\hline
\end{tabular}




\section{শাথा फि : ब बसनाগত জाएত}

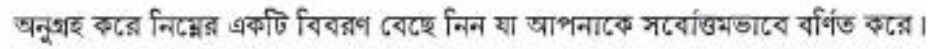

\begin{tabular}{|c|c|}
\hline বিবর্নণ & টিক \\
\hline 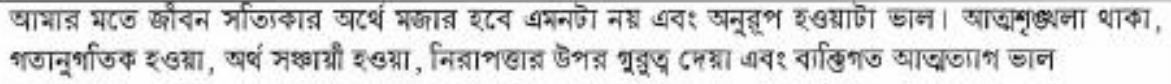 & \\
\hline 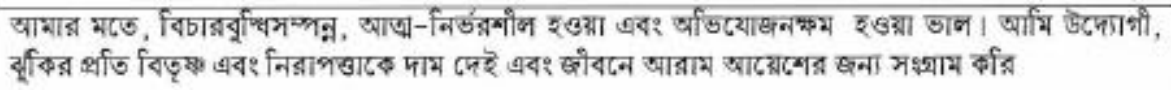 & \\
\hline 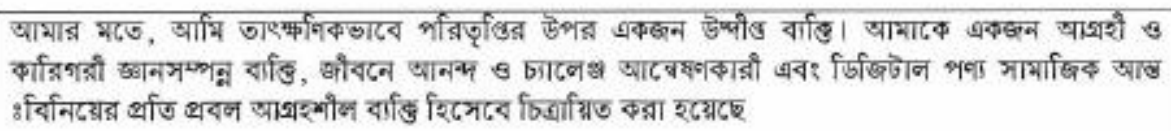 & \\
\hline
\end{tabular}

\section{শाथा ই : অनर्णाज़क শाथा}

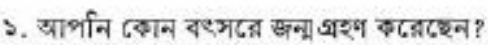

२. আाপनाइ বর্তমान বয়স : বংসর
०. आপनाর निঋ :
[\$] भूद्रय
[२] नारी

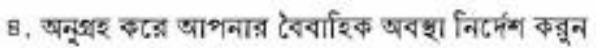
[১] अविবाशिज
[२] বिব্রাহিত
[0] তালাধপ্রাত্ব/বিধবা/বিপতীক

()) धाপनाর পেশা कि?
[\$] ग्बनिज़़्ाधिज

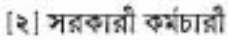
[0] প্রাইख্ট थाতত কমंচाরী
[8] গৃহ্নিন/অবসরপ্রাণ্ত/বেলার
(ब) शाब/शाबी

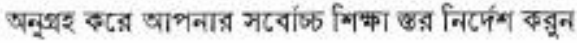
[\$] উচ্চ साथाशिक বिদ্যাाजয়
[२] मथान/जि(ल्োমा

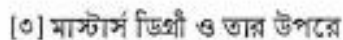


৭. আপনার বর্তমান আয় নিম্নের কোন প্রেণীতে পরে ?
[১] উপयूक্ত नহ
[२] ১৫,০০০ টাকার এর কম
[०] ১৫, ০০১-২৫, ০০০ টাदा
[8] २४, ০০১-০৫, ০০০ টাকা
$[6] 00,00>-80,000$ টाका

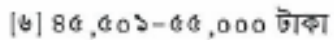
$[9] 06,00>-60,000$ हाबा
[४]৫६,००১-৭४,००० টाका
[\$] ৭৫,০০০ টাধা এবः উপরে।
४. যে শহরে বর্তমাढন ख্রার্পিন বসবাস করছেন: 


\section{Appendix A7: Summary of Organization and Respondent Information}

\begin{tabular}{|c|c|c|}
\hline City & & $\begin{array}{l}\text { No of } \\
\text { Respondents }\end{array}$ \\
\hline \multicolumn{3}{|l|}{ Sylhet } \\
\hline & Shahjalal University (BBA) & 38 \\
\hline & Shahjalal University (MBA) & 26 \\
\hline & Sonali Bank & 22 \\
\hline & Social Investment Bank Limited & 28 \\
\hline & Jalalabad Gas Transmission and Distribution System Ltd & 17 \\
\hline & CARE Bangladesh & 31 \\
\hline & Retired Emplyee Association & 67 \\
\hline & & 229 \\
\hline \multicolumn{3}{|l|}{ Khulna } \\
\hline & Khulna University (BBA) & 53 \\
\hline & Khulna University (MBA) & 12 \\
\hline & Janata Bank Ltd & 22 \\
\hline & Premier Bank Ltd. & 28 \\
\hline & BTCL & 20 \\
\hline & Akij Tobacco & 30 \\
\hline & Retired Employee Association & 74 \\
\hline & & 239 \\
\hline \multicolumn{3}{|l|}{ Chittagong } \\
\hline & Chittagong University (BBA) & 32 \\
\hline & Chittagong University (MBA) & 31 \\
\hline & Rupali Bank Ltd. & 21 \\
\hline & United Commercial Bank Ltd. & 26 \\
\hline & PDB (Chittagong) & 23 \\
\hline & Grameen Phone (Chittagong) & 28 \\
\hline & Retired Employee Association & 66 \\
\hline & & 227 \\
\hline \multicolumn{3}{|l|}{ Rajshahi } \\
\hline & Rajshahi University (BBA) & 63 \\
\hline & Rajshahi University (MBA) & 59 \\
\hline & Janata Bank Ltd (Rajshahi) & 21 \\
\hline & Islami Bank Limited & 28 \\
\hline & PDB (Rajshahi) & 23 \\
\hline & Beximco Pharma (Rajshahi) & 35 \\
\hline & Retired Employee Association & 59 \\
\hline & & 288 \\
\hline \multicolumn{3}{|l|}{ Dhaka } \\
\hline & Dhaka University (BBA) & 56 \\
\hline & Dhaka University (MBA) & 29 \\
\hline & Janata Bank & 27 \\
\hline & United Comercial Bank Ltd/SCB & 48 \\
\hline & PDB (Dhaka) & 20 \\
\hline & Beximco Pharma (Dhaka) & 41 \\
\hline & Retired Emplyee Association & 88 \\
\hline & & 309 \\
\hline
\end{tabular}




\section{Appendix A8: Structural Model for different categories of IFPs}

\section{Model A (Islamic Deposit Products):}

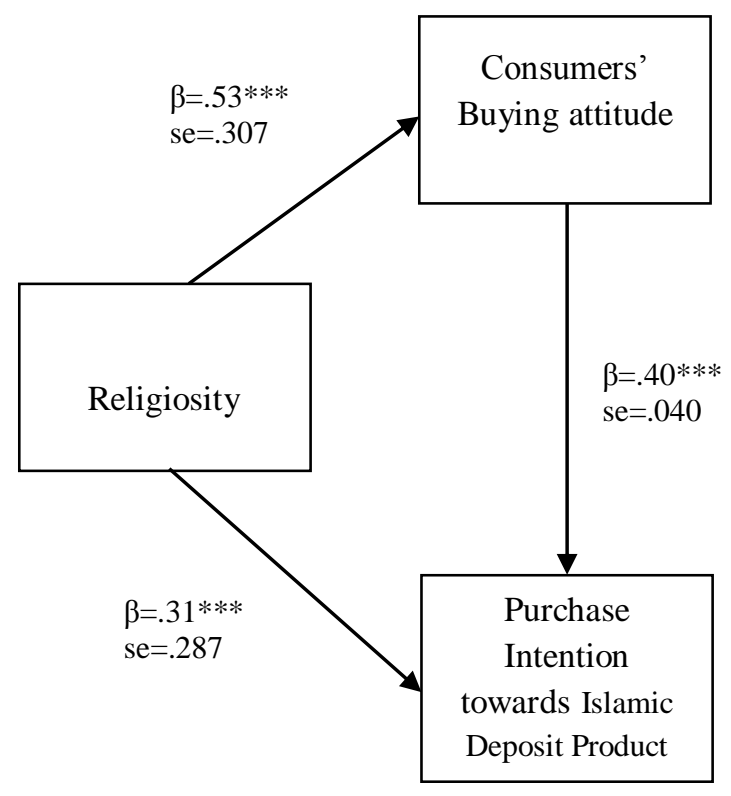

Model C (Islamic Capital Market Products):

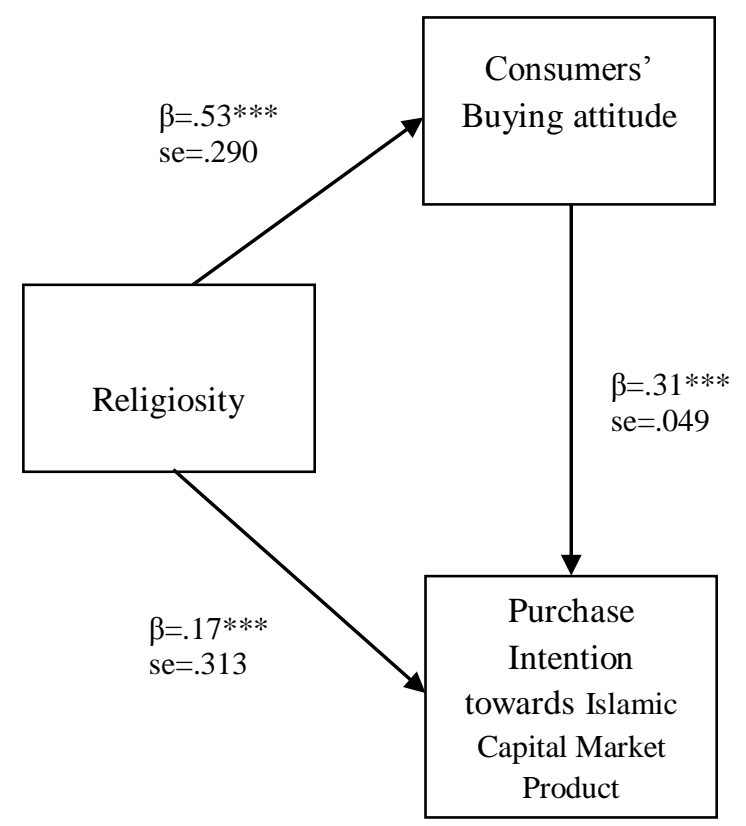

Model B (Islamic Credit Products):

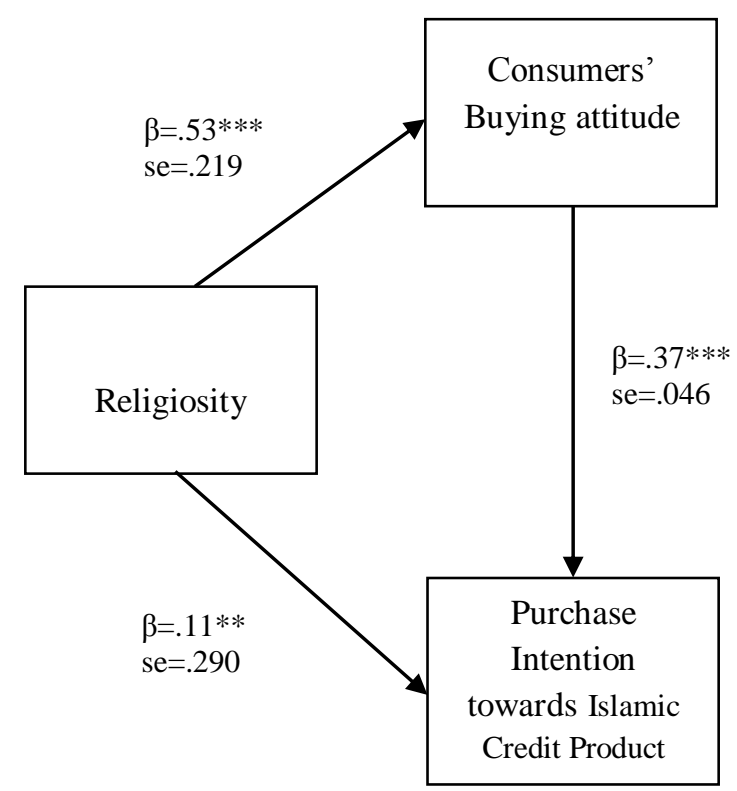

Model D (Islamic Insurance Products):

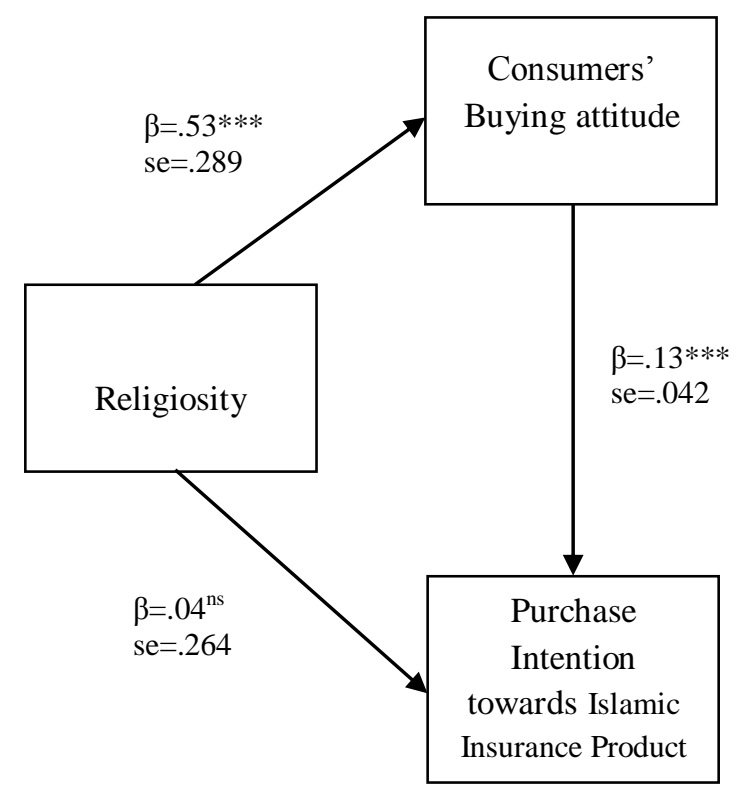

\begin{tabular}{|l|l|l|l|l|}
\hline Goodness of Fit Indicators: & Model A & Model B & Model C & Model D \\
\hline $\mathrm{X}^{2} / \mathrm{df}$ & 4.805 & 4.380 & 4.439 & 4.360 \\
\hline Comparative fit index (CFI) & .938 & .944 & .943 & .943 \\
\hline Tucker-Lewis index (TLI) & .927 & .934 & .933 & .933 \\
\hline Root-mean-squared error of approximation (RMSEA) & .540 & .051 & .052 & .051 \\
\hline
\end{tabular}

\section{Legend:}

$\beta=$ Standardized path (beta) coefficient; se = standard error; **significant at $p<.05 ; * * *$ significant at $p<.001 ; n s=$ not significant 


\section{References}

Ahluwalia, I. J., \& Hussain, Z. (2004). Development achievements and challenges. Economic and Political Weekly, 39, 4013-4022.

Ahmad, A. (1992). Qur'anic Concepts of Human Psyche. Pakistan: The International Institute of Islamic Thought and Institute of Islamic Culture.

Ahmad, A. R. Y. (2010). Islamic Modes of Finance and the Role of Sukuk. QFinance.

Ahmad, A. U. F. (2006). Legislations and Issues on Islamic Banking in Bangladesh. Paper presented at the First International Forum on Islamic Economics, Finance and Business for Young Scholars.

Ahmad, A. U. F., \& Hassan, M. K. (2007). Regulation and Performance of Islamic Banking in Bangladesh. Thunderbird International Business Review, 49(2), 251-277.

Ahmad, K. (1977). Islam: Its Meaning and Message. New Delhi: Ambika Publication.

Ahmad, N., \& Haron, S. (2002). Perceptions of Malaysian corporate customers towards Islamic banking products and services. International Journal of Islamic Financial Services, 3(4), 13-29.

Ahmed, A. (2008). Marketing of halal meat in the United Kingdom: Supermarkets versus local shops. British Food Journal, 110(7), 655-670.

Ahmed, A. (2010). Global financial crisis: an Islamic finance perspective. International Journal of Islamic and Middle Eastern Finance and Management, 3(4), 306-320.

Ahmed, E., Rahman, Z., \& Ahmed, R. I. (2006). Comparative analysis of loan recovery among nationalized, private, and Islamic commercial banks of Bangladesh. BRAC University Journal, 3(35).

Ahmedji, D. (2011). The Growing Pains of Islamic Finance: Deloitte.

Ajzen, I. (1991). The Theory of Planned Behavior. Organizational Behavior and Human Decision Processes, 50(2), 179-211.

Ajzen, I., \& Fishbein, M. (1980). Understanding attitudes and predicting social behavior. Englewood Cliffs, NJ: Prentice-Hall.

Ajzen, I., \& Fishbein, M. (2000). Attitudes and the attitude-behaviour relation: Reasoned and automatic processes. European Review of Social Psychology, 11, 1-33.

Akdede, S. H., \& Hotunluoğlu, H. (2008). Economic Development and Religiosity: An Investigation of Turkish Cities. Paper presented at the International Conference on Emerging Economic Issues in a Globalizing World.

Al-Hawari, M., Hartley, N., \& Ward, T. (2005). Measuring banks' automated service quality: a confirmatory factor analysis approach. Marketing Bulletin, 16(1), 1-19. 
Al-Hyari, K., Alnsour, M., Al-Weshah, G., \& Haffar, M. (2012). Religious beliefs and consumer behaviour: from loyalty to boycotts. Journal of Islamic Marketing, 3(2), 155-174.

Al-Sultan, W. (1999). Financial characteristics of interest-free banks and conventional banks. The University of Wollongong.

Alam, S. S., Janor, H., Zanariah, C. A. C. W., \& Ahsan, M. N. (2012). Is Religiosity an Important Factor in Influencing the Intention to Undertake Islamic Home Financing in Klang Valley? World Applied Sciences Journal, 19(7), 1030-1041.

Alam, S. S., Mohd, R., \& Hisham, B. (2011). Is religiosity an important determinant on Muslim consumer behaviour in Malaysia? Journal of Islamic Marketing, 2(1), 83-96.

Alba, J. W., \& Hutchinson, J. W. (1987). Dimensions of consumer expertise. Journal of Consumer Research, 411-454.

Ali, S. N. (2008). Islamic Finance and Economics as Reflected in Research and Publications. Review of Islamic Economics, 12(1), 151-168.

Ali, S. (2008). Second and Third Generation Muslims in Britain: A Socially Excluded Group? Identities, Integration and Community Cohesion. England: Nuffield College, University of Oxford.

Ali, S. S. (2005). Islamic Capital Market Products: Developments and Challenges. Jeddah: Islamic Development Bank: Islamic Research and Training Institute.

Ali, S. S. (2011). Isalamic Banking in the MENA Region. The World Bank: Islamic Development Bank- Islamic Research and Training Institute.

Allport, G. W. (1958). The Nature of Prejudice. New York: Anchor Books.

Alwin, D. F. (1998). The political impact of the Baby Boom: Are there persistent generational differences in political beliefs and behavior?. GENERATIONS-SAN FRANCISCO-AMERICAN SOCIETY ON AGING-, 22, 46-54.

Amin, H. (2012). An Analysis on Islamic Insurance Participation. Jurnal Pengurusan, 34, 1120.

Amin, H., Ghazali, M. F., \& Supinah, R. (2010). Determinants of Qardhul Hassan Financing Acceptance Among Malaysian Bank Customers: An Empirical Analysis International Journal of Business and Society, 11(1), 1-16.

Amin, H., Rahman, A. R. A., Sondoh, S. L., \& Hwa, A. M. C. (2011). Determinants of customers' intention to use Islamic personal financing: The case of Malaysian Islamic banks. Journal of Islamic Accounting and Business Research, 2(1), 22-42.

Anderson, J. C., \& Gerbing, D. W. (1988). Structural equation modeling in practice: A review and recommended two-step approach. Psychological bulletin, 103(3), 411.

Arbuckle, J. L. (2010). Amos 18.0 User's Guide. USA: Amos Development Corpororation. 
Argue, A., Johnson, D. R., \& White, L. K. (1999). Age and religiosity: Evidence from a three-wave panel analysis. Journal for the Scientific Study of Religion, 423-435.

Armstrong, K. (2001). The Battle for God: A History of Fundamentalism. New York: Ballantine Books.

Arnould, E., Price, L., \& Zikhan, G. (2004). Consumers, 2nd ed. New York: McGraw- Hill.

Arsenault, P. M., \& Patrick, M. L. (2008). Are the shoes appropriate to wear?: A study of cohort values. Journal of Targeting, Measurement and Analysis for Marketing, 16(2), 99-107.

Asiegbu, I. F., Powei Daubry, M., \& Iruka, C. H. (2012). Consumer Attitude: Some Reflections on Its Concept, Trilogy, Relationship with Consumer Behavior, and Marketing Implications. European Journal of Business and Management, 4(13), 3850.

ATKearney (2007). Addressing the Muslim Market. A. T. Kearney. Inc.

Baetz, M., Larson, D. B., Marcoux, G., Bowen, R., \& Griffin, R. (2002). Canadian psychiatric inpatient religious commitment: an association with mental health. Canadian Journal of Psychiatry, 47(2), 159-166.

Bagozzi, R. (2003). Positive and negative emotions in organizations. Positive organizational scholarship: Foundations of a new discipline, 12, 176-193.

Bagozzi, R. P. (1994). Principles of marketing research: Blackwell Cambridge, Oxford, Mass.

Bagozzi, R. P., \& Phillips, L. W. (1982). Representing and testing organizational theories: A holistic construal. Administrative Science Quarterly, 27(3), 459-489.

Bagozzi, R. P., \& Yi, Y. (1991). Multitrait-multimethod matrices in consumer research. Journal of Consumer Research, 17(426-439).

Baig, A. K., \& Baig, U. K. (2013). The Effects of Religiosity on New Product Adoption. International Journal of Research in Business and Social Science, 2(2), 28-37.

Bailey, J. M., \& Sood, J. (1993). The effect of religious affiliation on consumer behavior: a preliminary investigation. Journal of Managerial Issues, 5(3), 328- 352.

Bangladesh Bank (2012). Annual Report:The Real Economy Dhaka: Bangladesh Bank: The central Bank of Bangladesh.

Bangladesh Economic Review (2011). Bangladesh Economic Review. Bangladesh: Finance Division: Ministry of Finance: Government of The People's Republic of Bangladesh.

Barber, N., Kuo, P.-J., Bishop, M., \& Goodman Jr, R. (2012). Measuring psychographics to assess purchase intention and willingness to pay. Journal of Consumer Marketing, 29(4), 280-292. 
Baron, R. M., \& Kenny, D. A. (1986). The moderator-mediator variable distinction in social psychological research: Conceptual, strategic, and statistical considerations. Journal of personality and social psychology, 51(6), 1173.

Baruch, Y., \& Holtom, B. C. (2008). Survey Response Rate Levels and Trends in Organizational Research. Organizational Research, 61(1139).

Batson, C. D., Schoenrade, P., \& Ventis, W. L. (1993). Religion and the Individual: A Social Psychological Perspective. New York: Oxford University Press.

Bass, S. A. (2000). Emergence of the third age: Toward a productive aging society. Journal of aging \& social policy, 11(2-3), 7-17.

BBS. (2012) Socio-Economic and Demographic Report. Bangladesh: Bangladesh Bureau of Statistics (BBS); Statistics and Informatics Division (SID): Ministry of Planning

Beit-Hallahmi, B., \& Argyle, M. (1997). The psychology of religious belief: Behaviour and experience. New York: Routledge.

Belzen, J. A. (1999). The cultural psychological approach to religion: contemporary debates on the object of the discipline. Theory \& Psychology, 9(2), 229-255.

Bentler, P. M. (2004). Maximal Reliability for Unit-weighted Composites: Department of Statistics, UCLA.

Bergan, A., \& McConatha, J. T. (2000). Religiosity and life satisfaction. Activities, Adaptation and Aging, 24(3).

Bhagat, K. J. (2012). Consumer Behavior of Teenagers with Reference to Fast Moving Consumer Goods (FMCG) in the Mumbai Region-Maharashtra, India. Paper presented at the Proceedings of International Conference on Business Management \& IS.

Bidwell (2009). Cohorts: Age-Based Marketing. Florence: Bidwell ID.

Billah, M. M., \& Patel, S. (2003). An Opportunity for ICMF Members to Provide Islamic Insurance (Takaful) Products. The International Cooperative and Mutual Insurance Federation (ICMIF) publications.

Billah, M. M. s. (2007). 24 Islamic banking and the growth of takaful. Handbook of Islamic Banking, 401.

Billings, D., \& Kowalski, K. (2004). Teaching learners from varied generations. The Journal of Continuing Education in Nursing, 35(3), 104- 105.

Bley, J., \& Kuehn, K. (2004). Conventional Versus Islamic Finance: Student Knowledge and Perception in the United Arab Emirates. International Journal of Islamic Financial Services, 5(4).

Bloch, P. H., \& Richins, M. L. (1983). A Theoretical Model for the Study of Product Importance Perceptions Journal of Marketing, 47, 69-81. 
Bollen, K. A. (1989). Structural equations with latent variables. New York: John Wiley \& Sons.

Bonne, K., Vermeir, I., Bergeaud-Blackler, F., \& Verbeke, W. (2007). Determinants of halal meat consumption in France. British Food Journal, 109(5), 367-386.

Boone, C., Brouwer, A., Jacobs, J., Van Witteloostuijn, A., \& De Zwaan, M. (2012). Religious pluralism and organizational diversity: an empirical test in the city of Zwolle, the Netherlands, 1851-1914. Sociology of Religion, 73(2), 150-173.

Bowen, P. (1998). Themes and issues in Hinduism: Continuum International Publishing Group.

Boyd, H. W., Walker, O. C., Mullins, J., \& Larre' che', J. C. (2002). Marketing Management, A Strategic Decision-Making Approach. Columbus, OH: McGraw-Hill/Irwin.

Boyd, W., Leonard, M., \& White, C. (1994). Customer preferences for financial services: An analysis. International Journal of Bank Marketing, 12(1), 9- 15.

Braun-LaTour, K. A., LaTour, M. S., \& Zinkhan, G. M. (2007). Using childhood memories to gain insight into brand meaning. Journal of Marketing, 71(2), 45-60.

Brown, T. A. (2006). Confirmatory factor analysis for applied research: Guilford Press.

BSCAA (2013). Background Note: Bangladesh. US: U.S. Department of State: Bureau of South and Central Asian Affairs.

Budiman, S. (2012). Analysis of consumer attitudes to purchase intentions of counterfeiting bag product in Indonesia. International Journal of Management, Economics and Social Sciences (IJMESS), 1(1), 1-12.

Burnham, K. P., \& Anderson, D. R. (2004). Multimodel inference understanding AIC and

BIC in model selection. Sociological methods \& research, 33(2), 261-304.

Byrne, B. M. (2001). Structural Equation Modeling with AMOS: Basic concepts, applications, and programming. Mahwah, NJ: Lawrence Erlbaum Associates.

Byrne, B. M. (2010). Structural equation modeling with AMOS: Basic concepts, applications, and programming (2nd ed.). NY: Routledge.

Byron, R. K. (2012). Bangladesh's per capita income rises to \$848. The Daily Star.

Carvalho, C. A. (2008). Impact of Consumer Attitude in Predicting Purchasing Behaviour, A paper available at <http://iaso.com.br/pdf/Impact\%20of\%20Consumer\%20Attitude\%20in\%20Predicting $\% 20$ Purchase\%20Behaviour.pdf $>$, accessed on 18th of December, 2013.

Case, R., \& Yang, W. (2009). A study to examine differences between in person and online survey data collection methodologies. Choregia: Sport Management International Journal, 5(2), 5-20. 
Chapra, M. (2008). The Islamic Vision of Development in the Light of Maqasid Al-Shari'ah. USA: The International Institute of Islamic Thought.

Chau, P. Y. (1997). Reexamining a model for evaluating information center success using a structural equation modeling approach. Decision Sciences, 28(2), 309-334.

Chen, F. F. (2007). Sensitivity of goodness of fit indexes to lack of measurement invariance. Structural Equation Modeling, 14(3), 464-504.

Cheung, G. W., \& Rensvold, R. B. (2002). Evaluating goodness-of-fit indexes for testing measurement invariance. Structural Equation Modeling, 9(2), 233-255.

Chin, W. (2000). Partial least squares for IS researchers: an overview and presentation of recent advances using the PLS approach. Paper presented at the ICIS.

Chin, W. W. (1998). Commentary: Issues and opinion on structural equation modeling. MIS quarterly, vii-xvi.

Choi, Y. (2010). Religion, religiosity, and South Korean consumer switching behaviors. Journal of Consumer Behaviour, 9(3), 157-171.

Choudhury, Z. M. (2013). Bangladesh in 2013- Economic Development: Prospects and Pitfalls Vibrant Bangladesh (Vol. 6). Washington, DC: Embassy of the Peoples' Republic of Bangladesh.

Chowdhury, S. A. (2013). Maternal and Child Health in Bangladesh Vibrant Bangladesh (Vol. 6). Washington, DC: Embassy of the Peoples' Republic of Bangladesh.

Cliff, N. (1966). Orthogonal rotation to congruence. Psychometrika, 31(1), 33-42.

Codrington, G. (2011). Detailed introduction to generational theory in Asia. Tomorrow Today.

Cohen, J. (1988). Statistical power analysis for the behavioral sciencies: Routledge.

Comrey, A. L., \& Lee, H. B. (1992). A first course in factor analysis. Hillsdale, NJ: Erlbaum.

Comşa, M. (2010). How to compare means of latent variables across countries and waves: Testing for invariance measurement. An application using Eastern European societies. Sociológia, 42(6), 639-669.

Conger, J. A. (1997). Changing of the Guard: How Generational Shifts Will Transform Organizational Life. San Francisco: Jossey- Bass.

Cool, K., Dierickx, I., \& Jemison, D. (1989). Business strategy, market structure and riskreturn relationships: A structural approach. Strategic Management Journal, 10(6), 507-522.

Cowan, C. D. (1990). Why statisticians need their probabilities - getting into regression. Marketing Research, 65-68. 
Creswell, J. W. (1994). Research design: Qualitative and quantitative approaches. Thousand Oaks, CA: Sage.

Cutler, B. D. (1991). Religion and marketing: important research area or a footnote in the literature? Journal of Professional Services Marketing, 8(1), 153-164.

CUTS (2003). Investment Policy in Bangladesh - An Agenda for Action Jaipur, India: Centre for Competition, Investment \& Economic Regulation.

Czinkota, M. R., \& Kotabe, M. (2001). Marketing Management. Cincinnati, OH: SouthWestern College Publishing.

Dann, S. (2007). Branded generations: baby boomers moving into the seniors market. Journal of Product \& Brand Management, 16(6), 429-431.

Dar, B.A. (1963). "The ethical teachings of the Qur'an" in M.M. Sharif, A History of Muslim Philosophy. Wiesbaden: Otto Harrassowitz. 1: 155-178.

Darden, W. R. (1980). A patronage model of consumer behavior (pp. 43-S42): American Marketing Association Chicago.

Davidov, E., \& Depner, F. (2011). Testing for measurement equivalence of human values across online and paper-and-pencil surveys. Quality \& Quantity, 45(2), 375-390.

Davis, F. D., Bagozzi, R. P., \& Warshaw, P. R. (1989). User Acceptance of Computer Technology: A Comparison of Two Theoretical Models. Management Science, 35(8), 982- 1003.

De Mooij, M. (2010). Consumer behavior and culture: Consequences for global marketing and advertising. Asia-Pacific, Singapore: Sage Publication.

Delener, N. (1989). Religious differences in cognitions concerning external information search and media usage, in Marketing: Positioning for the 1990s. Paper presented at the Proceedings of the Annual Meeting of the Southern Marketing Association.

Delener, N. (1990a). The Effects of Religious Factors on Perceived Risk in Durable Goods Purchase Decisions. Journal of Consumer Marketing, 7(3), 27-38.

Delener, N. (1990b). An examination of the religious influences as predictors of consumer innovativeness. Journal of Midwest Marketing 5(167-178).

Delener, N. (1994). Religious contrasts in consumer decision behaviour patterns: Their dimensions and marketing implications. European Journal of Marketing, 28(5), 36.

DeMaio, T. (1980). Refusals: Who, Where and Why. Public Opinion Quarterly, 44, 223-233.

Denton, L., \& Chan, A. K. (1991). Bank selection criteria of multiple bank users in Hong Kong. International Journal of Bank Marketing, 9(5), 23- 35.

DeVaney, S. A., \& Chiremba, S. T. (2005). Comparing the Retirement Savings of the Baby Boomers and Other Cohorts. United States Department of Labor. 
Devlin, J. F. (2002a). An analysis of choice criteria in the home loans market. International Journal of Bank Marketing, 20(5), 212- 226.

Devlin, J. F. (2002b). Customer knowledge and choice criteria in retail banking. Journal of Strategic Marketing, 10(4), 273- 290.

Dibb, S., Simkin, L., Pride, W. P., \& Ferrell, O. C. (2001). Marketing Concepts and Strategies. Boston, MA: Houghton-Mifflin Company.

Dimitrov, D. M. (2003). Validation of Cognitive Structures: A Structural Equation Modelling Approach. Multivariate Research, 38(1), 1-23.

Dodds, W. B., Monroe, K. B., \& Grewal, D. (1991). Effects of price, brand, and store information on buyers' product evaluations. Journal of Marketing Research, 307-319.

Donahue, M. J. (1985). Intrinsic and Extrinsic Religiousness: The Empirical Research. Journal for the Scientific Study of Religion, 24(4), 418-423.

Dou, W. G., Wang, G., \& Zhou, N. (2006). Generational and regional differences in media consumption patterns of Chinese Generation X Consumers. Journal of Advertising, $35(2), 101-110$.

Doyle, P. (2002). Marketing Management and Strategy (3rd ed.). England: Pearson Education.

Durkheim, E. (1912). The Elementary Forms of Religious Life. London: Allen and Unwin.

Dusuki, A. W., \& Abdullah, N. I. (2007). Why do Malaysian customers patronise Islamic banks? International Journal of Bank Marketing, 25(3), 142-160.

Economist (2012). Bangladesh and development: The path through the fields: The Economist.

Edris, T. A., \& Meidan, A. (1990). On the reliability of psychographic research: encouraging signs for measurement accuracy and methodology in consumer research. European Journal of Marketing, 24(3), 23-41.

Edris, T. (1997). Services Considered Important to Business Customers and Determinants of Bank Selection in Kuwait: A Segmentation Analysis. nternational Journal of Bank Marketing, 15(4), 126-134.

Edwards, D. J. (1998). Types of case study work: A conceptual framework for case-based research. Journal of Humanistic Psychology, 38(3), 36-70.

Egri, C. P., \& Ralston, D. A. (2004). Generation cohorts and personal values: A comparison of China and the United States. Organization Science, 15(2), 210-220.

El-Gamal, M. A. (2006). Islamic Finance: Law, Economics and Practice (Vol. 17): Cambridge University Press.

El-Gamal, M. A. (2007). Incoherence of contract-based Islamic financial jurisprudence in the age of financial engineering. Wis. Int'l LJ, 25, 605. 
El-Qorchi, M. (2005). Islamic finance gear up. Finance and Development, 42(4), 46-50.

Ellison, C. (1991). Religious Involvement and Subjective Well-Being. Journal of Health and Social Behavior, 32(1), 89-99.

Ellison, C., Gay, D., \& Glass, T. (1989). Does Religious Commitment Contribute to Individual Life Satisfaction? Social Forces, 68(100-123).

Engel, J. F. (1976). Psychographic research in a cross-cultural non-product setting. Advances in Consumer Research 3. Association for Consumer Research, 98-101.

Ernst, \& Young (2012). Industry growth and preparing for regulatory change. Paper presented at the 7th Annual World Takaful Conference.

Erol, C., \& El-Bdour, R. (1989). Attitudes, behaviour, and patronage factors of bank customers towards Islamic banks. International Journal of Bank Marketing, 7(6), 3137.

Erol, C., Kaynak, E., \& Radi, E.-B. (1990). Conventional and Islamic banks: patronage behaviour of Jordanian customers. International Journal of Bank Marketing, 8(4), 2535 .

Essoo, N., \& Dibb, S. (2004). Religious Influences on Shopping Behaviour: An Exploratory Study. Journal of marketing management, 7(8), 683.

Ester, P., Vinken, H., \& Diepstraten, I. (2000). Collective memories, personal biographies, and the new millennium. Paper presented at the Proceedings, 23rd Annual Scientific Meeting of the International Society for Political Psychology (ISPP), Seattle, WA, July.

Ethica (2012). Ethica Brings Global Islamic Finance Certification to Bangladesh. Dubai, UAE: Institute of Islamic Finance.

Fahmida, L. (2012). "Evolution Of Exchange Rate Regime: Impact On Macro Economy Of Bangladesh. Asian Institute of Technology Thailand.

Falk, R. F., \& Miller, N. B. (1992). A primer for soft modeling: University of Akron Press.

Fam, K. S., Waller, D. S., \& Erdogan, B. Z. (2004). The Influence of Religion on Attitudes Towards the Advertising of Controversial Products. European Journal of Marketing $38(5 / 6), 537-555$.

Fam, K. S., Waller, D. S., Ong, F. S., \& Yang, Z. (2008). Controversial product advertising in China: perceptions of three generational cohorts. Journal of Consumer Behaviour, 7(6), 461-469.

Farquhar, J., \& Meidan, A. (2010). Marketing of Financial Services: Palgrave Macmillan.

Faulkner, J. E., \& DeJong, G. D. (1966). Religiosity in 5-D: An Empirical Analysis. Social Forces, 45(2), 246-254. 
Fishbein, M., \& Ajzen, I. (1975). Belief, attitude, intention and behavior: An introduction to theory and research.

Fong, V. (2004). Only hope: Coming of age under China's one-child policy: Stanford University Press.

Fontaine, J. R. J., Duriez, B., Luyten, P., Corveleyn, J., \& Hutsebaut, D. (2005). Consequences of a Multidimensional Approach to Religion for the Relationship Between Religiosity and Value Priorities. The International Journal for the Psychology of Religion, 15(2), 123-143.

Fornell, C. (1982). A second generation of multivariate analysis - An overview. New York: Praeger.

Fornell, C., \& Larcker, D. F. (1981). Evaluating structural equation models with unobservable variables and measurement error. Journal of Marketing Research, 3950.

Fornell, C., \& Yi, Y. (1992). Assumptions of the two-step approach to latent variable modeling. Sociological Methods \& Research, 20(3), 291-320.

Foxall, G. R., Goldsmith, R. E., \& Brown, S. (1998). Consumer psychology for marketing (Vol. 1): Cengage Learning EMEA.

Fukuyama, Y. (1961). The Major Dimensions of Church Membership. Review of Religious Research, 2(4), 154-161.

Furseth, I., \& Repstad, P. (2006). An Introduction to the Sociology of Religion. Classical and Contemporary Perspectives. Aldershot: Ashgate.

Gait, A., \& Worthington, A. (2007). A Primer on Islamic Finance: Definitions, Sources, Principles and Methods. Hyderabad: ICFAI Press.

Gait, A., \& Worthington, A. (2008). An empirical survey of individual customers, business firm and financial institution attitudes towards Islamic methods of finance. International journal of Social Economics, 35(11), 783-808.

Gait, A. H., \& Worthington, A. (2009a). A Primer on Islamic Finance: Definitions, Sources, Principles and Methods. Department of Accounting, Finance and Economics, Griffith University.

Gait, A. H., \& Worthington, A. W. (2009b). Libyan Business Firm Attitudes towards Islamic Methods of Finance. Discussion Papers in Finance from Griffith University, Department of Accounting, Finance and Economics

Gait, A. H. A. (2009). Libyan Attitudes towards Islamic Methods of Finance: An Empirical Analysis of Retail Consumers, Business Firms and Banks. Griffith Business School.

Garver, M. S., \& Mentzer, J. T. (1999). Logistics research methods: employing structural equation modeling to test for construct validity. Journal of Business Logistics, 20, 3358. 
Gay, D. A., \& Lynxwiler, J. P. (2013). Cohort, Spirituality, and Religiosity A Cross-sectional Comparison. Journal of Religion \& Society, 2, 15.

Geertz, C. (1966). Religion as a Cultural System. In M. Banton (Eds.), in Antrhopolical Approaches to the study of Religion.

Geertz, C. (1973). The Interpretation of Cultures: Selected Essays by Clifford Geertz. New York: Basic Books, Inc.

Gefen, D., Straub, D. W., \& Boudreau, M.-C. (2000). Structural equation modeling and regression: Guidelines for research practice. Communications of the Association for Information Systems, 4, 1-76.

Gellner, E. (1981). Muslim Society. Cambridge: Cambridge University Press.

Gentry, J. W., Tansuhaj, P., Manzer, L. L., \& John, J. (1988). Do geographic subcultures vary culturally? Advances in Consumer Research 15, 411-417.

George, J. F. (2004). The theory of planned behavior and Internet purchasing. Internet Research, 14(3), 198-212.

Gerrard, P., \& Cunningham, J. B. (1997). Islamic banking: a study in Singapore. International Journal of Bank Marketing, 15(6), 204-216.

GIFF (2012). Internationalisation of Islamic Finance: Bridging Economies. Paper presented at the Global Islamic Finance Forum.

GIFR (2011). Global Islamic Finance Report. UK: BMB Islamic Publication.

Global Edge (2012). Global Insights: Bangladesh. US: Michigan State University.

Glock, C. Y. (1962). On the Study of Religious Commitment. Journal of Religious Education, 57(4), 98.

Glock, C. Y. (1972). On the Study of Religious Commitment, in J. E. Faulkner (ed.). Religion's Influence in Contemporary Society, Readings in the Sociology of Religion, 38-56.

Glock, C. Y., \& Stark, R. (1965). Religion and Sociaty in Tension. Chicago: Rand McNally.

Gorsuch, R. L., \& Smith, C. S. (1983). Attributions of Responsibility to God: An Interaction of Religious Beliefs and Outcomes. Journal for the Scientific Study of Religion, 22(4), 340-352.

Gregory, G. D., Munch, J. M., \& Peterson, M. (2002). Attitude functions in consumer research: comparing value-attitude relations in individualist and collectivist cultures. Journal of Business Research, 55(11), 933-942.

Grewal, B. K. (2013). Overview of the Islamic Financial Landscape: Globally and in Europe: Kuwait Finance House Research Limited. 
Grewal, R., Mehta, R., \& Kardes, F. R. (2000). The Role Social-Identity Function of Attitudes in Consumer Innovativeness and opinion leadership. Journal of Economic and Psychology 21, 233-252.

Gruber, A. (1970). Purchase intent and purchase probability. Journal of Advertising Research, 10(1), 23-27.

Grunert, S. C., \& Juhl, H. J. (1995). Values, environmental attitudes and buying of organic foods. Journal of Economic Psychology, 16(1), 39-62.

Gursoy, D., Maier, T. A., \& Chi, C. G. (2008). Generational differences: An examination of work values and generational gaps in the hospitality workforce. International Journal of Hospitality Management, 27(3), 448-458.

Haider, J., \& Azhar, M. (2010). Islamic Capital Market: Sukuk and its Risk Management in the Current Scenario. Umea University, Sweden.

Hair, J. F., Black, W. C., Babin, B. J., Anderson, R. E., \& Tatham, R. L. (2006). Multivariate data analysis (6th ed.). Upper Saddle River, NJ: Pearson Education Inc.

Hair, J. F. J., Anderson, R. E., Tatham, R. L., \& Black, W. C. (1998). Multivariate Data Analysis. Upper Saddle River, NJ: Prentice Hall.

Hamouri, Q. (1991). Rationality, time and accounting. Essays in Islamic Economic Analysis: Selected Readings, 67-81.

Hamzeh, I. I. (2009). Islamic Finances: Mainstream Alternative to Conventional Finance. Athens Information Technology, Athens, Greece.

Hanzaee, K. H., \& Ramezani, M. R. (2011). Intention to halal products in the world markets. Interdisciplinary Journal of Research in Business, 1(5), 1-7.

Haque, A., Osman, J., \& Ismail, A. Z. (2009). Factor influences selection of Islamic banking: a study on Malaysian customer preferences. American Journal of Applied Sciences, $6(5), 922$.

Haque, A., Rahman, S., \& Yasmin, F. (2012). Exploring the Relationship between Religiosity, Ethnocentrism and Corporate Image: Young Muslim Consumers Perspective. Journal of Business and Policy Research 7(1), 60-71.

Harlam, B. A., \& Lodish, L. M. (1995). Modeling consumers' choices of multiple items. Journal of Marketing Research, 404-418.

Harman, H. H. (1976). Modern factor analysis. Chicago: University of Chicago Press.

Harold, H. (2004). The Experience of Hijab. Cairo, Egypt: Al-Falah Foundation for Translation, Publication and Distribution.

Haron, S., Ahmad, N., \& Planisek, S. L. (1994). Bank patronage factors of Muslim and nonMuslim customers. International Journal of Bank Marketing, 12(1), 32-40. 
Harrell, G. D., \& Frazier, G. L. (1999). Marketing: connecting with customers: Prentice Hall Englewood Clffs, NJ.

Harris, J. M., \& Blisard, N. (2001). Analyzing the Impact of Generational Effects on Consumer Expenditures for Meats: A Cohort Approach. Journal of Food Distribution Research, 32(1), 64-73.

Hasan, D., Akif, S., Subhani, D., Imtiaz, M., \& Osman, M. (2012). Consumer Criteria for the Selection of an Islamic Bank: Evidence from Pakistan. International Research Journal of Finance and Economics 94.

Hashim, A. (1980). The Creed of Islam (3rd ed.). Dhaka: Islamic Foundation Dhaka.

Hashim, N. M., \& Mizerski, D. (2010). Exploring Muslim consumers' information sources for fatwa rulings on products and behaviors. Journal of Islamic Marketing, 1(1), 3750 .

Hassan, K., \& Mahlknecht, M. (2011). Islamic capital markets: products and strategies (Vol. 609): John Wiley \& Sons.

Hassan, M. K. (1999). Islamic banking in theory and practice: The experience of Bangladesh. Managerial Finance, 25(5), 60-113.

Hassan, R. (2007). On Being Religious: Patterns of Religious Commitment in Muslim Societies. The Muslim World, 97(3), 437-478.

Hawkins, D. I., Best, R. J., \& Coney, K. A. (2004). Consumer Behaviour: Building Market Strategy (9th ed.): McGraw-Hill/Irwin.

Hawkins, D. I., Best, R. J., \& Kenneth, K. A. (2001). Consumer Behavior: Building Marketing Strategy: McGraw-Hill College.

Hegazy, I. A. (1995). An Empirical Comparative Study between Islamic and Commercial Banks' Selection Criteria in Egypt. International Journal of Commerce and Management, 5(3), 46-61.

Herbig, P., \& Yelkur, R. (1998). Hispanic and Anglo difference in consumer behavior. Journal of International Marketing and Marketing Research, 23(1), 47-56.

Hill, P. C., Dill, C. A., \& Davenport, E. C. (1988). A reexamination of the bogus pipeline. Educational and Psychological Measurement, 48(3), 587-601.

Himmelfarb, H. S. (1975). Measuring Religious Involvement. Social Forces, 53(606-618).

Hirschman, E. C. (1981). American Jewish Ethnicity: Its Relationship to Some Selected Aspects of Consumer Behavior. The Journal of Marketing, 45(3), 102-110.

Hirschman, E. C. (Ed.). (1983). Religious affiliation and consumption process: An initial paradigm. Greenwich, CT: JAI Press.

Hoe, S. L. (2008). Issues and procedures in adopting structural equation modeling technique. Journal of Applied quantitative methods, 3(1), 76-83. 
Hoelter, J. W. (1983). The analysis of covariance structures goodness-of-fit indices. Sociological Methods \& Research, 11(3), 325-344.

Holbrook, M. B., \& Schindler, R. M. (1989). Some Exploratory Findings on the Development of Musical Tastes. Journal of Consumer Research. Journal of Consumer Research, 16(1), 119-124.

Holbrook, M. B., \& Schindler, R. M. (1994). Age, Sex and Attitude toward the Past as Predictors of Consumers: Aesthetic Tastes for Cultural Products. Journal of Marketing Research, 31, 412-422.

Holdcroft, B. B. (2006). What is religiosity. Catholic Education: A Journal of Inquiry and Practice, $10(1)$.

Hong, S., Malik, M. L., \& Lee, M.-K. (2003). Testing configural, metric, scalar, and latent mean invariance across genders in sociotropy and autonomy using a non-Western sample. Educational and Psychological Measurement, 63(4), 636-654.

Howard, J. A., \& Sheth, J. N. (1969). The theory of buyer behavior (Vol. 14): Wiley New York.

Hox, J. J., \& Bechger, T. M. (1998). An introduction to structural equation modeling. Family Science Review, 11(354-373).

Hoyer, W. D., \& MacInnis, D. J. (2001). Consumer Behaviour (2nd ed.): Houghton Mifflin Company.

Hoyle, R. H. (1995). Structural equation modeling: Concepts, issues, and applications: Sage.

Hu, L. t., \& Bentler, P. M. (1999). Cutoff criteria for fit indexes in covariance structure analysis: Conventional criteria versus new alternatives. Structural Equation Modeling: A Multidisciplinary Journal, 6(1), 1-55.

Hu, M. (2012). Married People Are More 'Racist' Than Unmarried People (GSS) [Blog at WordPress.com. The Quintus Theme].

Hung, K. H., Gu, F. F., \& Yim, C. K. B. (2007). A Social Institutional Approach to Identifying Generation Cohorts in China with a Comparison with American Consumers. Journal of International Business Studies 38(5), 836-853.

Hwang, W. Y., Chang, C. B., \& dan Chen, G. J. (2004). The Relationship of Learning Traits, Motivation and Performance-Learning Response Dynamics. Computers and Education, 42, 267-287.

IDB (2012). Key Socio-Economic Statistics on IDB Member Countries. Kingdom of Saudi Arabia: Data Resources and Statistics Department, Islamic Development Bank.

IFSB (2013). Islamic Financial Services Industry Stability Report: Islamic Financial Services Board. 
IFSB, IDB, \& IRTI (2010). Islamic Finance and Global Financial Stability: Islamic Financial Services Board, Islamic Development Board, Islamic Research and Training Institute: April 2010.

Ilyas, S. (1992). Dimensions of Muslim religiosity: Measurement considerations. Islamabad, Pakistan: International Institute of Islamic Thought.

Imady, O., \& Seibel, H. D. (2006). Principles and Products of Islamic Finance. Working Paper, No. 2006-1, Development Research Center, University of Cologne, Germany.

Ing-Long, W., \& Jian-Liang, C. (2005). An extension of trust and TAM model with TPB in the initial adoption of on-line tax: an empirical study. International Journal of Human-Computer Studies, 62(6), 784- 808.

Inglehart, R. (1977). The silent revolution. Changing values and political styles among Western Publics. Princeton: Princeton University Press.

Inglehart, R. (1997). Modernization and Postmodernization: Cultural, Economic, and Political Change in 43 Societies. Princeton, NJ: Princeton University Press.

Iqbal, Z. (1997). Islamic Financial System. Finance and Development, 34, 42-45.

Islam, S. M. M., \& Biswas, S. (2009). Exchange Rate and Its Impacts On GDP and Inflation in Bangladesh ASA University Review, 3(2).

Ismail, K., Vivishna, S., Khurram, W., \& Jafri, S. K. A. (2012). Evaluating Consumer Purchase Intentions for Genetically Modified Food in Malaysia: A Comparative Study of Muslim and Non-Muslim Consumers. Journal of Applied Sciences, Engineering and Technology.

Jaffer, S., Ismail, F., Noor, J., \& Unwin, L. (2010). Takaful (Islamic Insurance): Concepts, Challenges, and Opportunities. United States: Milliman.

Jahan, A., Dhar, B. K., \& Ahmed, F. (2012). Challanges and Potentials of Capital Market Investment: A Study from Bangladesh Perspective. International Journal of Business and Management Tomorrow, 2(9).

Jahya, N. (2004). Factors That Influence Muslim Consumers Preference towards Islamic Banking Products or Facilities: Theory of Reasoned Action. University Sains Malaysia, Malaysia.

Jamaludin, N. (2013). Religion and Individual Investment Choice Decision: The Case of Malaysia. International Journal of Business and Social Science, 4(1), 104-113.

Jobber, D. (2001). Principles \& Practice of Marketing. New York, NY: McGraw-Hill International (UK) Limited.

Johnson, B. R., Jang, S. J., Larson, D. B., \& Li, S. D. (2001). Does Adolescent Religious Commitment Matter? A Reexamination of the Effects of Religiosity on Delinquency. Journal of Research in Crime and Delinquency, 38(1), 22-43. 
Johnson, S. A., \& Romanello, M. L. (2005). Generational diversity teaching and learning approaches. Nurse Educator, 30(5), 212- 216.

Jöreskog, K. G. (1993). Testing structural equation models. Newbury Park, CA: Sage Publications.

Jöreskog, K. G., \& Sörbom, D. (1988). PRELIS a Program for Multivariate Data Screening and Data Summarization. A Preprocessor for LISREL. Mooresville: Scientific Software, Inc.

Jöreskog, K. G., \& Sörbom, D. (1997). LISREL 8: A guide to the program and applications SPSS: Chicago, IL

Joshi, S. (2004). Female Household-Headship in Rural Bangladesh: Incidence, Determinants and Impact on Children's Schooling. Yale University Economic Growth Center Discussion Paper(894).

Joy, A., Kim, C., \& Laroche, M. (1991). Ethnicity as a factor influencing use of financial services. International Journal of Bank Marketing, 9(4), 10- 17.

Kahf, M., \& Khan, T. (1993). Principles of Islamic Finance: Research Paper No. 16. Islamic Research and Training Institute, Islamic Development Bank, Jeddah.

Kahle, L. R., Kau, A., Tambyah, S., Tan, S., \& Jung, K. (2005). Religion, religiosity, and values: implications for consumer behavior. Paper presented at the The La Londe Seminar, 32nd International Research Seminar in Marketing, La Londe-les-Maures.

Karim, J. A., Rahman, S. A., \& Ariffin, Z. Z. (2011). Do Muslims Purchase Muslim Products? Muslim Centric Ness: An Exploratory Study. Paper presented at the International Conference on E-business, Management and Economics, Singapore.

Kasper, H., van Helsdingen, P., \& Gabbott, M. (2006). Services Marketing Management: A Strategic Perspective. Chichester, UK: John Wiley \& Sons, Ltd.

Katz, D. (1960). The functional approach to the study of attitudes. Public Opinion Quarterly 163-204.

Kaur, A., \& Medury, Y. (2013). SEM Approach to Teen Influence in Family Decision Making. Contemporary Management Research, 9(3), 323-342.

Kaynak, E., Kucukemiroglu, O., \& Hyder, A. S. (2000). Consumers' Country-of-Origin (COO) Perceptions of Imported Products in a Homogenous Less-Developed Country. European Journal of Marketing, 34(9/10), 1221-1241.

Kelloway, E. K. (1998). Using LISREL for structural equation modeling: A researcher's guide: Sage.

Kenny, D. A. (1979). Correlation and causality (chapters 3-5 ed.). New York: Wiley.

Khan, H., \& Bashar, O. K. M. R. (2008). Islamic Finance:Growth and Prospects in Singapore. U21 Global Working Paper Series, No. 001/2008. 
Khan, M. A. (2006). Consumer behaviour and advertising management. India: New Age International.

Khan, M. H. (2010). Bangladesh: Economic Growth in a Vulnerable LAO. Washington: The World Bank.

Khan, M. M., \& Bhatti, M. I. (2008). Islamic banking and finance: on its way to globalization. Managerial finance, 34(10), 708.

Khan, M. S. N., Hassan, M. K., \& Shahid, A. I. (2007). Banking behavior of Islamic bank customers in Bangladesh. Journal of Islamic Economics, Banking and Finance, 3(2), 159-194.

Khasru, S. M. (2013). Bangladesh: An Under- Valued Brand in Need for Recognition Vibrant Bangladesh (Vol. 6). Washington, DC: Embassy of the Peoples' Republic of Bangladesh.

Khraim, H. (2010). Measuring Religiosity in Consumer Research From an Islamic Perspective. Journal of Economic \& Administrative Sciences, 26(1), 52-78.

Khraim, H. S., Mohamad, O., \& Jantan, M. (1999, July 16-17). Measuring religiosity in consumer research. Paper presented at the Third Asian Academy of Management Conference, Kuala Terengganu, Malaysia.

Kim, J., LaRose, R., \& Peng, W. (2009). Loneliness as the cause and the effect of problematic Internet use: The relationship between Internet use and psychological well-being. CyberPsychology \& Behavior, 12(4), 451-455.

Kim, Y. K., \& Kang, J. (2001). The effects of ethnicity and product on purchase decision making. Journal of Advertising Research 41(2), 39-48.

King, M., \& Hunt, R. (1972). Measuring the Religious Dimension: Studies in Congregational Involvement. Dallas: Southern Methodist University.

King, M. B. (1967). Measuring the religious variable: Nine proposed dimensions. Journalfor the Scientific Study of Religion, 6, 173-190.

Kishada, Z. M. E., \& Wahab, N. A. (2013). Factors Affecting Customer Loyalty in Islamic Banking: Evidence from Malaysian Banks. International Journal of Business and Social Science, 4(7), 264-273.

Klein, K., \& Cheuvront, B. (1990). The subject-experimenter contract: A reexamination of subject pool contamination. Teaching of Psychology, 17(3), 166-169.

Kline, R. B. (2011). Principles and practice of structural equation modeling (3rd ed.). New York: Guilford press.

Kotler, P. (1994). Marketing Management (8th ed.). Englewood Cliffs:New Jersey: Princeton Hall.

Kotler, P., Brown, L., Adam, S., \& Armstrong, G. (2004). Marketing. NSW: Pearson Education Australia. 
Koufteros, X. A. (1999). Testing a model of pull production: a paradigm for manufacturing research using structural equation modeling. Journal of Operations Management, 17(4), 467-488.

Krauss, S. E., Hamzah, A. H., Suandi, T., Noah, S. M., Mastor, K. A., Juhari, R., . . Manap, J. (2005). The Muslim Religiosity-Personality Measurement Inventory (MRPI)'s Religiosity Measurement Model: Towards Filling the Gaps in Religiosity Research on Muslims. Pertanika Journal of Social Science and Humanity, 13(2), 131-145.

Kritz, G., \& Arsenault, P. M. (2006). Teaching cohort analysis: an important marketing management tool. Marketing Education Review, 16(2), 37.

La Barbera, P. (1987). Consumer Behavior and Born Again Christianity. Research in Consumer Behavior, 2, 193-222.

LaBarbera, P. A., \& Stern, J. (1990). The relationship between Jewish religious intensity and repeat purchasing behavior. Paper presented at the Proceedings of the Annual Meeting of the Southern Marketing Association.

Laroche, M., Kim, C., \& Zhou, L. (1996). Brand familiarity and confidence as determinants of purchase intention: an empirical test in a multiple brand context. Journal of Business Research, 37(2), 115-120.

Lawson-Body, A., Willoughby, L., \& Logossah, K. (2010). Developing an instrument for measuring e-commerce dimensions. Journal of Computer Information Systems, 51(2), 2.

Lee, E.-J., Fairhurst, A., \& Dillard, S. (2002). Usefulness of ethnicity in international consumer marketing. Journal of International Consumer Marketing, 14(4), 25-48.

Lehto, X. Y., Jang, S. S., Achana, F. T., \& O'Leary, J. T. (2008). Exploring tourism experience sought: a cohort comparison of baby boomers and the silent generation. Journal of Vacation Marketing, 14(3), 237-252.

Lenski, G. (1961). The Religious Factor: A Sociological Study of Religion's Impact on Politics, Economics and Family Life: Connecticut: Greenwood Press.

Lesser, L. B. (1988). Economic Reconstruction after Independence. A Country Study: Bangladesh: Federal Research Division, Library of Congress.

Lietz, P. (2010). Research into questionnaire design: A summary of the literature. International Journal of Market Research, 52(2), 249- 272.

Light, D., Keller, S., \& Calhoun, C. (1989). Sociology. New York: Alfred A. Knopf.

Lin, M., Lucas, H. C., \& Shmueli, G. (2013). Too big to fail: large samples and the P-value problem. Information Systems Research.

Lindridge, A. (2005). Religiosity and the construction of a cultural-consumption identity. The Journal of Consumer Marketing, 22(2/3), 142. 
Littrell, M. A., Ma, Y. J., \& Halepete, J. (2005). Genearation X, Baby Boomers, and Swing: Marketing Fair Trade Apparel. Journal of Fashion Marketing and Management, 9(4), 407.

Loo, M. (2010). Attitudes and Perceptions towards Islamic Banking among Muslims and Non-Muslims in Malaysia: Implications for Marketing to Baby Boomers and XGeneration. International Journal of Arts and Sciences, 3(13), 453- 485.

Loroz, P. S. (2006). The generation gap: a Baby Boomer vs Gen Y comparison of religiosity, consumer values, and advertising appeal effectiveness. Advances in Consumer Research, 33(1), 308-309.

Lu, J., Yu, C. S., Liu, C., \& Yao, J. E. (2003). Technology acceptance model for wireless internet. Internet Research, 13(3), 206- 222.

Lu, L., \& Alon, I. (2004). Analysis of the Changing Trends in Attitudes and Values of the Chinese: The Case of Shanghai's Young and Educated. Journal of International and Area Studies, 11(2), 67- 88.

MacCallum, R. C. (1995). Model specification: Procedures, strategies, and related issues. Thousand Oaks, CA: Sage.

MacCallum, R. C., Browne, M. W., \& Sugawara, H. M. (1996). Power analysis and determination of sample size for covariance structure modeling. Psychological methods, 1(2), 130.

Mahiuddin, K. M. (2009). The Parliamentary Committee System in Bangladesh An Analysis of its Functioning Ruprecht-Karls-Universität Heidelberg Germany.

Mahmood, S. A. I. (2010). Public procurement and corruption in Bangladesh. Confronting the challenges and opportunities. Journal of public administration and policy research, 2(6), 103-111.

Mamun, D. M. Z. (2011). Prospects and Problems of Islamic Banking from Bank's Perspective: A Study of Bangladesh. Paper presented at the 8th International Conference on Islamic Economics and Finance.

Mannheim, K. (1952). Essays on the Sociology of Knowledge. London: Routledge \& Kegan Paul Ltd.

Mansori, S. (2012). Impact of religion affiliation and religiosity on consumer innovativeness; the evidence of Malaysia. World Applied Sciences Journal, 17(3), 301-307.

Marinov, M. (Ed.). (2007). Marketing in the Emerging markets of Islamic Countries: Palgrave Macmillan.

Markides, K. S., \& Cole, T. (1984). Change and Continuity in Mexican American Religious Behavior: A Three-Generation Study. Social Science Quarterly, 65, 618-625.

Marsh, H. W., Hau, K. T., \& Wen, Z. L. (2004). In search of golden rules: Comment on hypothesis testing approaches to setting cut-off values for fit indexes and dangers in 
overgeneralising Hu and Bentler (1999) findings. Structural Equation Modeling, 11, 320-341.

Maruyama, G. (1998). Basics of structural equation modeling. Thousand Oaks: Sage.

Mathieson, K. (1991). Predicting user intention: comparing the technology acceptance model with the theory of planned behavior. Information Systems Research, 2(3), 173- 191.

Matzler, K., \& Waiguny, M. (2005). Consequences of customer confusion in online hotel booking. Information and Communication Technologies in Tourism 2005, 306-317.

Maududi, A. A. (1960). Towards Understanding Islam (K. Ahmed, Trans.). Lahore: Islamic Publications Ltd.

Maurer, B. (2001). Engineering an Islamic Future: Speculations on Islamic Financial Alternatives. Anthropology Today, 17(1), 8-11.

Maxwell, J. A. (1996). Qualitative research design. Newbury Park, CA: Sage.

Mayasami, R. C., \& Kwon, W. J. (1999). An analysis of Islamic Takaful Insurance- A cooperative Insurance Mechanism. Journal of Insurance Regulation, 18(1), 109-132.

McDaniel, S., \& Burnett, J. (1990). Consumer religiosity and retail store evaluative criteria. Journal of the Academy of Marketing Science, 18(2), 101-112.

McDaniel, S. W., \& Burnett, J. J. (1991). Targeting the Evangelical Market Segment. Journal of Advertising Research, 31(4), 26-33.

McKenzie, B. D. (2001). Self-Selection, Church Attendance, and Local Civic Participation. Journal for the Scientific Study of Religion, 40(3), 479-488.

McQuitty, S. (2004). Statistical power and structural equation models in business research. Journal of Business Research, 57(2), 175-183.

Meredith, G., \& Schewe, C. (1994). The Power of Cohorts. American Demographics, 16, 2228.

Meredith, G. E., Schewe, C. D., \& Karlovich, J. (2002). Defining markets, defining moments: America's 7 generational cohorts, their shared experiences, and why businesses should care: Wiley.

Meredith, W. (1993). Measurement invariance, factor analysis and factorial invariance. Psychometrika, 58(4), 525-543.

Metawa, S., \& Almossawi, M. (1998). Banking Behaviour of Islamic Bank Customers: Perspectives and Implications. International Journal of Bank Marketing, 16(7), 299315.

Metwally, M. (1996). Attitudes of Muslims Towards Islamic Banks in a Dual-Banking System. American Journal of Islamic Finance, 6, 11-17. 
Michell, P., \& Al-Mossawi, M. (1995). The mediating effect of religiosity on advertising effectiveness. Journal of Marketing Communications, 1, 151-162.

Michell, P., \& Al-Mossawi, M. (1999). Religious Commitment Related to Message Contentiousness. International Journal of Advertising 18(4), 427-443.

Middlehurst, R., \& Woodfield, S. (2004). The Role of Transnational, Private, and For-Profit Provision in Meeting Global Demand for Tertiary Education: Mapping, Regulation and Impact Canada: Commonwealth of Learning.

Miller, A. S. (1994). Dynamic Indicators of Self-perceived Conservatism. The Sociological Quarterly, 35(1), 175-182.

Miller, A. S., \& Hoffmann, J. P. (1995). Risk and religion: An explanation of gender differences in religiosity. Journal for the Scientific Study of Religion, 63-75.

Mitchell, S. (2003). American Generations: Who They Are. How They Live. What They Think (4th ed.). Ithaca, NY: New Strategist Publications.

Mittelstaedt, J. D. (2002). A framework for understanding the relationships between religions and markets. Journal of Macromarketing, 22(1), 6-18.

Moberg, D. O. (1971). Spiritual Well-Being: Background and issues. Paper presented at the White House Conference on Aging.

Mohammad, N. (2011). Technological Education in Bangladesh: An Approach for Environmental Sustainability Paper presented at the International Conference on Future Information Technology Sinagapore.

Mohieldin, M. (2012). Realizing the potential of Islamic finance: Economic Premise, The World Bank.

Mokhlis, S. (2006a). The Effect of Religiosity on Shopping Orientation: An Exploratory Study in Malaysia. Journal of American Academy of Business, Cambridge, 9(1), 64.

Mokhlis, S. (2006b). The influence of religion on retail patronage behavior in Malaysia. Universiti of Sterling, UK.

Mokhlis, S. (2009). Relevancy and Measurement of Religiosity in Consumer Behavior Research. International Business Research, 2(3), 75-84.

Moniruzzaman, M. (2012). Growth Trends of Major Development Indicators in Postindependent Bangladesh: An Economic Analysis. Bangladesh Journal of Public Administration, 21(2), 13-43.

Morwitz, V. G., Steckel, J. H., \& Gupta, A. (2007). When do purchase intentions predict sales? International Journal of Forecasting, 23(3), 347-364.

Moschis, G. P., \& Ong, F. S. (2011). Religiosity and consumer behavior of older adults: A study of subcultural influences in Malaysia. Journal of Consumer Behaviour, 10(1), 8-17. 
Moshrefjavadi, M. H., Dolatabadi, H. R., Nourbakhsh, M., Poursaeedi, A., \& Asadollahi, A. (2012). An Analysis of Factors Affecting on Online Shopping Behavior of Consumers. International Journal of Marketing Studies, 4(5), 81-98.

Moss, G., \& Vinten, G. (2001). Choice and preferences: testing the effect of nationality. Journal of Consumer Behaviour, 1(2), 198-207.

Motta, P. C., Rossi, M. Z. G., \& Schewe, C. D. (2002). Generational marketing: exploring cohort-programmed values and their implications on cross-cultural variations in consumer behavior between Brazil and United States. Revista Portuguesa de Marketing, 12, 11-21.

Muhamad, N., \& Mizerski, D. (2010). The constructs mediating religions' influence on buyers and consumers. Journal of Islamic Marketing, 1(2), 124-135.

Muhamad, N., \& Mizerski, D. (2012). Modern Religious Verdicts: Who Bothers and Who's Not? . Paper presented at the Australian and New Zealand Marketing Conference 2012, Sharing the Cup of Knowledge.

Muhamad, N., \& Mizerski, D. (2013). The Effects of Following Islam in Decisions about Taboo Products. Psychology \& Marketing, 30(4), 357-371.

Muhamad, R., Melewar, T., \& Alwi, S. F. S. (2012). Segmentation and brand positioning for Islamic financial services. European Journal of Marketing, 46(7/8), 900-921.

Mukhtar, A., \& Butt, M. M. (2012). Intention to choose Halal products : the role of religiosity. Journal of Islamic marketing, 3(2), 108-120.

Munshi, J. (1990). A Method for Constructing Likert Scales CA: Sonoma State University.

Nabatchi, T. (2007). Deliberative democracy: The effects of participation on political efficacy: ProQuest.

Naisbitt, J., \& Aburdene, P. (1990). Megatrends 2000: Ten New Directions for the 1990s. New York, NY: William Morrow and Co.

Naser, K., Jamal, A., \& Al-Khatib, K. (1999). Islamic banking: a study of customer satisfaction and preferences in Jordan. International Journal of Bank Marketing, $17(3), 135-151$.

Nasr, S. (2011). Islamic Finance in Arab World: Challanges and Prospects. Paper presented at the Cambridge Business \& Economics Conference (CBEC).

Nawi, F. A. M., Yazid, A. S., \& Mohammed, M. O. (2013). A Critical Literature Review for Islamic Banks Selection Criteria in Malaysia. International Business Research, 6(6), p143.

NBR (2008). Islamic Finance: Global Trends and Challenges. The National Bureau of Asian Research, 18(4).

NewHorizon (2009). Global Perspective on Islamic Banking \& Insurance: Institute of Islamic Banking and Insurance. 
Nix, T. W., \& Gibson, J. G. (1989). Does a hospital's religious affiliation affect choice of hospital and patient satisfaction? Journal of Health Care Marketing, 9(2), 40-41.

Noble, S. M., \& Schewe, C. D. (2003). Cohort segmentation: an exploration of its validity. Journal of Business Research, 56(12), 979-987.

Norman, G., \& Streiner, D. (2003). PDQ Statistics. BC Decker. Inc., Hamilton, Ontario, Canada.

Novethic (2008). Islamic Finance and SRI: Any Crossover? Novethic: Working Paper.

Nudelman, A. E. (1971). Dimensions of Religiosity: A Factor-Analytic View of Protestants, Catholics and Christian Scientists. Review of Religious Research, 13(1), 42-56.

Nunnally, J. C., \& Bernstein, I. H. (1994). Psychometric Theory (3rd ed.). New York: McGraw-Hill.

O'Connell, C. M. (1975). Dimensions of Religiosity Among Catholics. Review of Religious Research, 16(3), 198-207.

Obaidullah, M. (2005). Islamic Financial Service, Islamic Economic Research Centre, King Abdulaziz University, Jeddah, Saudi Arabia.

OIC. (2012) Islamic Finance in OIC Member Countries. Ankara, Turkey: Organization of Islamic Cooperation (OIC Outlook Series): SESRIC.

Okumuş, H. Ş. (2005). Interest-free banking in Turkey: a study of customer satisfaction and bank selection criteria. Journal of Economic Cooperation, 26(4), 51-86.

OliverWyman. (2009). The Next Chapter in Islamic Finance Higher Rewards but Higher Risks: Oliver Wyman.

Omer, H. (1992). The Implication of Islamic Beliefs and Practice on Islamic Financial Institutions in the UK. Unpublished $\mathrm{PhD}$ Dissertation, Loughborough University.

Ong, A. D., \& Weiss, D. J. (2000). The Impact of Anonymity on Responses to Sensitive Questions. Journal of Applied Social Psychology, 30(8), 1691-1708.

Osman, I., Ali, H., Zainuddin, A., Rashid, W. E. W., \& Jusoff, K. (2009). Customers satisfaction in Malaysian Islamic banking. International Journal of Economics and Finance, 1(1), 197-202.

Otterson, M. (2010). Knowledge not the same as religious experience. The Washington Post.

Park, J., \& Gursoy, D. (2012). Generation effects on work engagement among US hotel employees. International Journal of Hospitality Management, 31(4), 1195-1202.

Parment, A. (2013). Generation Y vs. Baby Boomers: Shopping behavior, buyer involvement and implications for retailing. Journal of Retailing and Consumer Services, 20(2), 189-199. 
Patton, M. Q. (1990). Qualitative research and evaluation methods (2nd ed.). Newbury Park, CA: Sage.

Pedhazur, E. J. (1982). Multiple Regression in Behavioral Research: Explanation and Prediction. New York: Holt, Rinehart and Winston. Coaching Eiticacy and Youth Sport, 41.

Pedhazur, E. J., \& Schmelkin, L. P. (1991). Measurement, design, and analysis: An integrated approach. Hillsdale, NJ: Erlbaum.

Peng, G. C., \& Nunes, J. M. B. (2007, 9-10 July 2007). Using PEST analysis as a tool for refining and focusing contexts for information systems research". Paper presented at the 6th European Conference on Research Methodology (ECRM) for Business and Management Studies, Lisbon, Portugal.

Pentecost, R., \& Andrews, L. (2010). Fashion retailing and the bottom line: The effects of generational cohorts, gender, fashion fanship, attitudes and impulse buying on fashion expenditure. Journal of Retailing and Consumer Services, 17(1), 43-52.

Pepinsky, T. B. (2013). Development, Social Change, and Islamic Finance in Contemporary Indonesia. World Development 41(1), 157-167.

Petroulas, E., Brown, D., \& Sundin, H. (2010). Generational characteristics and their impact on preference for management control systems. Australian Accounting Review, 20(3), 221-240.

Petty, R. E., Unnava, R. H., \& Strathman, A. J. (1991). Theories of attitude change. Handbook of consumer behavior, 241-280.

Pew Research (2010). Religion Among the Millennials Introduction and Overview. Washington: Religion and Public Life Project. Pew Research Center.

Podsakoff, P. M., MacKenzie, S. B., Lee, J.-Y., \& Podsakoff, N. P. (2003). Common method biases in behavioral research: a critical review of the literature and recommended remedies. Journal of applied psychology, 88(5), 879.

Pol, L. G. (1991). Demographic contributions to marketing: an assessment. Journal of the Academy of Marketing Science, 19(1), 53-59.

Porter, M. E., \& Schwab, K. (2009). The Global Competitveness Report (2008-2009): World Economic Forum.

Preston, C. C., \& Colman, A. M. (2000). Optimal number of response categories in rating scales: reliability, validity, discriminating power, and respondent preferences. Acta psychologica, 104(1), 1-15.

Pride, W. M., \& Ferrell, O. (1991). Marketing: concepts and strategies (7th ed.): Houghton Mifflin Company.

Quintana, S. M., \& Maxwell, S. E. (1999). Implications of recent developments in structural equation modeling for counseling psychology. The Counseling Psychologist, 27(4), 485-527. 
Rahim, F. A., \& Amin, H. (2011). Determinants of Islamic insurance acceptance: An empirical analysis. International Journal of Business and Society, 12(2), 37-54.

Rahman, A. (2009). Consumer Credit as Lifestyle Activities Facilitators for Consumers of Bangladesh. International Business Research, 2(4).

Rahman, J., \& Yusuf, J. (2010). Economic growth in Bangladesh: experience and policy priorities. Journal of Bangladesh Studies, 12(1).

Rahman, S. (2010). R\&D needs a strong push: Analysts suggest a significant outlay in national budget. The Daily Star,

Rajagopalan, R., \& Heitmeyer, J. (2005). Ethnicity and consumer choice: a study of consumer levels of involvement in Indian ethnic apparel and contemporary American clothing. Journal of Fashion Marketing and Management, 9(1), 83-105.

Ramayah, T., Ling, C. Y., Norazah, M. S., \& Ibrahim, M. (2005). Determinants of intention to use an online bill payment system among MBA students. E-Business, 9(80- 91).

Ramayah, T., \& Mohd, S. N. (2006). Intention to use mobile PC among MBA students: Implications for technology integration in the learning curriculum. UNITAR EJournal, 1(2), 1- 10.

Ramayah, T., Noor, M. N. M., Nasurdin, A. M., \& Hasan, H. (2003). Students' choice intention of a higher learning institution: an application of the theory of reasoned action (TRA). Malaysian Management Journal, 7(1), 47- 62.

Ramayah, T., Noor, M. N. M., Nasurdin, A. M., \& Sin, Q. B. (2004). The relationships between belief, attitude, subjective norm, intention, and behavior towards infant food formula selection: the views of the Malaysian mothers. Gadjah Mada International Journal of Business, 6(3), 405- 418.

Rammal, H. G., \& Zurbruegg, R. (2007). Awareness of Islamic banking products among Muslims: the case of Australia. Journal of Financial Services Marketing, 12(1), 6574.

Razzaque, M. A., \& Chaudhry, S. N. (2013). Religiosity and Muslim consumers' decisionmaking process in a non-Muslim society. Journal of Islamic Marketing, 4(2), 198217.

Redzuan, H., Rahman, Z. A., \& Aidid, S. (2009). Economic determinants of family takaful consumption: Evidence from Malaysia. International Review of Business Research Papers, 5(5), 193-211.

Rehman, A., \& Shabbir, M. S. (2010). The Relationship Between Religiosity and New Product Adoption. Journal of Islamic Marketing, 1(1), 6- 69.

Reisenwitz, T., \& Iyer, R. (2007). A comparison of younger and older baby boomers: investigating the viability of cohort segmentation. Journal of Consumer Marketing, 24(4), 202-213. 
Rentz, J. O., Reynolds, F. D., \& Stout, R. G. (1983). Analyzing Changing Consumption Patterns with Cohort Analysis. Journal of Marketing Research (JMR), 20(1).

Rhodes, R. E., \& Courneya, K. S. (2003). Investigating multiple components of attitude, subjective norm, and perceived control: an examination of the theory of planned behaviour in the exercise domain. The British Journal of Social Psychology, 42, 129146.

Richard, J. E. (2008). The impact of customer relationship management (CRM) technology on business-to-business customer relationships. Victoria University of Wellington, New Zealand.

Rindfleisch, A. (1994). Cohort generational influences on consumer socialization. Advances in Consumer Research, 21(1), 470-476.

Rodniam, J. (2007). The Social Ecology Model of Drug Use and Delinquency Among Thai Adolescents: ProQuest.

Rodriguez, C. M. (1993). Relevancy, Measurement and Modelling of Religiosity in Consumer Behaviour: The Case of Peru. In G. Albaum et al. (eds.). Proceedings of the Fourth Symposium on Cross-Cultural Consumer and Business Studies, Kahuka, Hawaii.

Rogelberg, S. G., \& Stanton, J. M. (2007). Introduction: Understanding and dealing with organizational survey nonresponse. Organizational Research Methods, 10, 195-209.

Rogler, L. H. (2002). Historical Generations and Psychology: The Case of the Great Depression and WWII. The American Psychologist, 57(12), 1013-1023.

Roy, S., \& Banerjee, G. (2007). Islamic insurance out of reach of Indian Muslims. Live Mint and the Wall Street Journal.

Rubens, M., \& Motta, P. C. (2005). Exploratory findings of cohort effects: preferences for cultural products. Readings Book, Global Business and Technological Association, Lisbon, 1060-1099.

Rucker, D. D., Preacher, K. J., Tormala, Z. L., \& Petty, R. E. (2011). Mediation analysis in social psychology: Current practices and new recommendations. Social and Personality Psychology Compass, 5(6), 359-371.

Ryder, N. B. (1965). The cohort as a concept in the study of social change. American sociological review, 843-861.

Saaty, A. S., \& Ansari, Z. A. (2008). Takaful-An Islamic Way of Insurance: Developments, Growth, Challenges and Issues: King Abdulaziz University.

Sadiq, K., \& Black, A. (2012). Embracing Sharia-Compliant Products through Regulatory Amendment to Achieve Parity of Treatment. Sydney Law Review, 34, 189.

Saeed, M., Ahmed, Z. U., \& Mukhhar, S. M. (2001). International Marketing Ethics from an Islamic Perspective: A value maximization approach. Journal of Busines Ethics, 32(127-142). 
Saha, S. (2012). Islamic funds gain stronger foothold. The Daily Star.

Salleh, M. S. (2012). Religiosity in Development: A Theoretical Construct of an IslamicBased Development. International Journal of Humanities and Social Science Vol. 2 No. 14 pp 266, 274.

Sandikci, Ö. (2011). Researching Islamic marketing: past and future perspectives. Journal of Islamic Marketing, 2(3), 246-258.

Sarker, A. A. (2000). Regulation of Islamic banking in Bangladesh: role of Bangladesh bank. International Journal of Islamic Financial Services, 2(1), 67.

Sarker, A. A. (2005). Islamic Banking in Bangladesh: Achievements and Challenges. Journal of Islamic Economics and Finance, 1(1).

Schewe, C. D., \& Meredith, G. (1994). Segmenting global markets by generational cohorts: Determining motivations by age. Journal of Consumer Behaviour 4(1), $51-63$.

Schewe, C. D., \& Meredith, G. (2004). Segmenting global markets by generational cohorts: Determining motivations by age. Journal of Consumer Behaviour, 4(1), 51-63.

Schewe, C. D., \& Noble, S. M. (2000). Market segmentation by cohorts: the value and validity of cohorts in America and abroad. Journal of Marketing Management, 16(129- 142).

Schindler, R. M., \& Holbrook, M. B. (1993). Critical periods in the development of men's and women's tastes in personal appearance. Psychology \& Marketing, 10(6), 549-564.

Schlosser, A. E. (2003). Experiencing products in the virtual world: the role of goal and imagery in influencing attitudes versus purchase intentions. Journal of Consumer Research, 30(2), 184-198.

Schreiber, J. B., Nora, A., Stage, F. K., Barlow, E. A., \& King, J. (2006). Reporting structural equation modeling and confirmatory factor analysis results: A review. The Journal of Educational Research, 99(6), 323-338.

Schumacker, R. E., \& Lomax, R. G. (2004). A beginner's guide to structural equation modeling (2nd ed.). Mahwah, NJ: Lawrence Erlbaum Associates.

Schuman, H., Akiyama, H., \& Knauper, B. (1998). Collective Memories of Germans and Japanese about the Past Half Century. Surveying Memory Processes, 6(4), 227-257.

Schuman, H., \& Scott, J. (1989). Generations and collective memories. American sociological review, 359-381.

Schwartz, S., \& Sagie, G. (2000). Value Consensus and Inportance, A Cross-National Study. Journal of Cross-Cultural Psychology, 31(4), 465- 497.

Schwartz, S. H. (2005). Basic Human Values: Theory Methods, and Applications. Paper presented at the International Congress For the Study of Sources and Development of Pro-Social and Anti-Social Motivation. 
Schwartz, S. H., \& Ros, M. (1995). Values in the West: A theoretical and empirical challenge to the individualism-collectivism cultural dimension. World Psychology, 1, 99-122.

Scott, J., \& Zac, L. (1993). Collective memories in Britain and the United States. Public Opinion Quarterly, 57(3), 315-331.

Segars, A. H. (1997). Assessing the Unidimensionality of Measurement: A Paradigm and Illustration Within the Context of Information Systems Research. Omega, International Journal of Management Science, 25(1), 107-121.

Selamat, Z., \& Abdul-Kadir, H. (2012). Attitude and Patronage Factors of Bank Customers in Malaysia: Muslim and non-Muslim Views. Journal of Islamic Economics, Banking and Finance, 8(4).

Shaharudin, M. R., Pani, J. J., Mansor, S. W., Elias, S. J., \& Sadek, D. M. (2010). Purchase Intention of Organic Food in Malaysia; A Religious Overview. International Journal of Marketing Studies, 2(1), 96-103.

Shamsuzzaman, M. (2012). Bangladesh: High expectations: Islamic Finance News.

Shanmugaratnam, T. (2012). Opportunities facing Islamic finance and challenges in managing capital flows in Asia Paper presented at the 8th World Islamic Economic Forum.

Shao, C. Y., Baker, J. A., \& Wagner, J. (2004). The effects of appropriateness of service contact personnel dress on customer expectations of service quality and purchase intention: The moderating influences of involvement and gender. Journal of Business Research, 57(10), 1164-1176.

Sharma, J., \& Singh, A. (2012). Absorptive Capability and Competitive Advantage: Some Insights from Indian Pharmaceutical Industry. International Journal of Management and Business Research, 2(3), 175-192.

Sheahan, P. (2005). Generation $Y$ : thriving and surviving with Generation $Y$ at work: Prahran, Victoria: Hardy Grant.

Sheth, J. N. (1983). An integrative theory of patronage preference and behavior. In W. R. Darden \& R. F. Lusch (Eds.), Patronage Behavior and Retail Management (pp. 9-28). North Holland: New York.

Shih, Y. Y., \& Fang, K. (2004). The use of decomposed theory of planned behavior to study internet banking in Taiwan. Internet Research, 14(3), 213- 223.

Shim, S., \& Kotsiopulos, A. (1992). Patronage behavior of apparel shopping: Part I. Shopping orientations, store attributes, information sources, and personal characteristics. Clothing and Textiles Research Journal, 10(2), 48-57.

Shook, C. L., Ketchen, D. J., Hult, G. T. M., \& Kacmar, K. M. (2004). An assessment of the use of structural equation modeling in strategic management research. Strategic Management Journal, 25(4), 397-404. 
Shukor, S. A., \& Jamal, A. (2013). Developing Scales for Measuring Religiosity in the Context of Consumer Research. Middle-East Journal of Scientific Research (Research in Contemporary Islamic Finance and Wealth Management), 13, 69-74.

Siddiqui, S. A., \& Athemy, A. (2008). Resolving Controversial Issues and Setting Goals for Islamic Insurance: An Evaluation of Takaful Companies of Brunei. Journal of Islamic Economics, Banking and Finance, 3(2), 129-158.

Siguaw, J. A., \& Simpson, P. M. (1997). Effects of religiousness on Sunday shopping and outshopping behaviours: a study of shopper attitudes and behaviours in the American South. International Review of Retail, Distribution and Consumer Research, 7(1), 2340.

Siguaw, J. A., Simpson, P. M., \& Joseph, M. (1995). Religiosity effects on shopping behaviors: a comparative study of the U.S. and New Zealand. Paper presented at the Proceedings, Institute for Operations Research and Management Sciences (INFORMS) International Conference Singapore.

Sivo, S. A., Fan, X., Witta, E. L., \& Willse, J. T. (2006). The search for" optimal" cutoff properties: Fit index criteria in structural equation modeling. The Journal of Experimental Education, 74(3), 267-288.

Slowikowski, S., \& Jarratt, D. G. (1997). The impact of culture on the adoption of high technology products. Marketing Intelligence \& Planning 15(2), 97-105.

Smith, M. C., \& Frankenberger, K. D. (1991). The effects of religiosity on selected aspects of consumer behavior. In T. Schellinck (ed.). Proceedings of the Annual Conference of the Administrative Sciences Association of Canada, 12(6), 274-283.

Smith, W. R. (1956). Product differentiation and market segmentation as alternative marketing strategies. The Journal of Marketing, 21(1), 3-8.

Soesilowati, E. S. (2010). Behavior of Muslims in Consuming Halal foods: Case of Bantenese Muslim. Paper presented at the Sharia Economics Research Day.

Solomon, M. R. (2004). Consumer Behaviour, Buying, Having and Being (6th ed.): Pearson Prentice Hall.

Solomon, M. R., \& Stuart, E. W. (2003). Marketing, Real People, Real Choices. Englewood Cliffs, NJ: Prentice-Hall.

Sood, J., \& Nasu, Y. (1995). Religiosity and nationality: An exploratory study of their effect on consumer behavior in Japan and the United States. Journal of Business Research, $34(1), 1-9$.

Speed, R., \& Smith, G. (1992). Retail financial services segmentation. Services Industries Journal, 12(3), 368- 383.

Stark, R. S., \& Glock, C. Y. (1968). American Piety. Berkeley: University of California Press. 
Statistics Canada (2003). Survey Methods and Practices. Ottawa: Authority of the Minister responsible for Statistics Canada.

Steenkamp, J.-B. E., \& Baumgartner, H. (1998). Assessing measurement invariance in crossnational consumer research. Journal of Consumer Research, 25(1), 78-107.

Steffensen, J. (2013). Islamic Finance: Sources of Growth and Prospects for Global Development Washington, D.C.: The National Bureau of Asian Research (NBR).

Stipkova, M., \& Vane, J. (2013). The National Religious Environment and the Orthodoxy of Christian Beliefs: A Comparison of Austria, the Czech Republic and Slovakia. Sociologický časopis/Czech Sociological Review(03), 403-425.

Streiner, D. L. (2005). Finding our way: an introduction to path analysis. The Canadian Journal of Psychiatry/La Revue canadienne de psychiatrie, 50(2), 115-122.

Sulaiman, M. (2003). The influence of riba and zakat on Islamic accounting. Indonesia Management and Accounting Review, 2(2), 149- 167.

Sundararajan, V., \& Errico, L. (2002). Islamic Financial Institutions and Products in the Global Financial System: Key Issues in Risk Management and Challenges Ahead. IMF Working Paper, Monetary and Exchange Affair Department.

Swartz, N. P., \& Coetzer, P. (2010). Takaful: An Islamic insurance instrument. Journal of Development and Agricultural Economics, 2(10), 333-339.

Swatos, W. H. (1998). Encyclopedia of religion and society. Walnut Creek, CA: Altamira Press.

Swimberghe, K., Sharma, D., \& Flurry, L. (2009). An exploratory investigation of the consumer religious commitment and its influence on store loyalty and consumer complaint intentions. Journal of Consumer Marketing, 26(5), 340-347.

Taib, F. M., Ramayah, T., \& Razak, D. A. (2008). Factors influencing intention to use diminishing partnership home financing. International Journal of Islamic and Middle Eastern Finance and Management, 1(3), 235- 248.

Taks, M., \& Shreim, M. (2009). The influence of Islam on shopping behaviour for sports apparel: An empirical study of Muslim immigrants. Paper presented at the 17th EASM Conference.

Tan, C. T., \& Chua, C. (1986). Intention, attitude and social influence in bank selection: A study in an Oriental culture. International Journal of Bank Marketing, 4(3), 43- 54.

Taylor, M. (2010). Working with the Generations: Generational Issues in the American Workplace, from http://www.arkansastransit.com/siteimages/2010/11/WorkplaceHandout-2010.pdf

Taylor, S., \& Todd, P. (1995). Understanding the information technology usage: A test of competing models. Information Systems Research, 6(2), 144-176. 
Tayyebi, A. (2009). Eclipse by thr Crescent Moon: Islamic FInance provides some light in the Global Financial Crisis. Financial Services Review, ACCA Global, June.

Tenenhaus, M. (2008). Component-based structural equation modelling. Total Quality Management Science, 19, 871-886.

Teo, T., Lee, C. B., Chai, C. S., \& Wong, S. L. (2009). Assessing the intention to use technology among pre-service teachers in Singapore and Malaysia: A multigroup invariance analysis of the Technology Acceptance Model (TAM). Computers \& Education, 53(3), 1000-1009.

Teo, T. S. H., \& Pok, S. H. (2003). Adoption of WAP-enabled mobile phones among internet users. The International Journal of Management Science, 31, 483-498.

The Banker (2009). Top 500 Islamic Financial Institutions, November.

The Banker (2011). Top 500 Islamic Financial Institutions. Special Supplement: , from www.thebanker.com

Ting, H., De Run, E. C. \& Fam, K.-S. (2012, 19-21 December). Identifying Generational Cohorts in Sarawak. Paper presented at the 5th International Borneo Business Conference, Tawau, Sabah.

Tourangeau, R. (2000). The psychology of survey response: Cambridge University Press.

Trading Economics (2012). Bangladesh GDP Growth Rate. New York City, Lisboa Trading Economics.

UKIFS (2012). Islamic Finance. The UK Islamic Finance Secretariat: Gatehouse Bank.

Ullman, J. B. (Ed.). (2001). Structural equation modeling. Needham Heights, MA: Allyn \& Bacon.

UN, PRB, UNDESA, \& UNDP (2012). Rio + 20: National Report on Sustainable Development. Dhaka: Ministry of Environment and Forests, Peoples' Republic of Bangladesh.

UNDP (2012). Empowered Lives: Resilient Bangladesh. Dhaka: UNDP Bangladesh.

UNPD (2008). World Urbanization Prospects: The 2007 Revision Population Division of the Department of Economic and Social Affairs of the United Nations Secretariat.

Van der Heijden, H., Verhagen, T., \& Creemers, M. (2003). Understanding online purchase intentions: contributions from technology and trust perspectives. European Journal of Information Systems, 12(1), 41-48.

Van Raaij, W. F., \& Verhallen, T. M. (1994). Domain-specific market segmentation. European Journal of Marketing, 28(10), 49-66.

Vandenberg, R. J., \& Lance, C. E. (2000). A review and synthesis of the measurement invariance literature: Suggestions, practices, and recommendations for organizational research. Organizational Research Methods, 3(1), 4-70. 
Venardos, A. M. (2006). Islamic Banking and Finance in Southeast Asia: Its Development and Future. Singapore: World Scientific Publishing.

Verbit, M. F. (Ed.). (1970). The Components and Dimensions of Religious Behavior: Toward a Reconceptualization of Religiosity. New York: Random House.

Vitell, S. J., Paolillo, J. G., \& Singh, J. J. (2005). Religiosity and consumer ethics. Journal of Business Ethics, 57(2), 175-181.

Vitell, S. J., \& Paolillo, J. G. P. (2003). Consumer Ethics: The Role of Religiosity. Journal of Business Ethics, 46(2), 151-162.

Wang, H., \& Wu, G. (2002). Consumer Ethnocentrism: An Empirical Study in China and Its Marketing Management Implications. Beijing: Economic Management Press.

Ward, D. (2005). An Overview of Strategy Development Models and the Ward-Rivani Model. Economics Working Papers, 1-24.

Warde, I. (2010). Islamic finance in the global economy: Edinburgh University Press.

Warshaw, P. R. (1980). A new model for predicting behavioral intentions: An alternative to Fishbein. Journal of Marketing Research, 153-172.

Watson, P., Hood Jr, R. W., Morris, R. J., \& Hall, J. R. (1984). Empathy, religious orientation, and social desirability. The Journal of psychology, 117(2), 211-216.

Weill, L., \& Godlewski, C. (2012). Why do large firms go for Islamic loans? Bank of Finland, BOFIT Institute for Economies in Transition.

Werch, C. E. (1990). Two procedures to reduce response bias in reports of alcohol consumption. Journal of Studies on Alcohol and Drugs, 51(4), 327.

Westland, J. C. (2010). Lower bounds on sample size in structural equation modeling. Electronic Commerce Research and Applications, 9(6), 476-487.

Wilkes, R. E., Burnett, J. J., \& Howell, R. D. (1986). On the meaning and measurement of religiosity in consumer research Journal of the Academy of Marketing Science 14(1), 47-56.

Williams, A., Coupland, J., Folwell, A., \& Sparks, L. (1997). Talking about Generation X: Defining Them as They Define Themselves. Journal of Language and Social Psychology, 16(3), 251-277.

Williams, K. C., \& Page, R. A. (2011). Marketing to the generations. Journal of Behavioral Studies in Business, 5(1), 1-17.

Wilson, R. (1997). Islamic finance and ethical investment. International Journal of Social Economics, 24(11), 1325-1342.

World Bank (2012). World Bank Open Data: free and open access to data about development in countries around the globe: The World Bank. 
World Bank (2013). Macroeconomics and Economic Growth in South Asia: Growth in Bangladesh: The World Bank.

World Factbook (2013). Map and Quick Facts courtesy of the CIA World Factbook. USA: Central Intelligence Agency.

Worthington, E. L., Wade, N. G., Hight, T. L., Ripley, J. S., McCullough, M. E., Berry, J. W., et al. (2003). The religious commitment inventory-10: development, refinement and validation of a brief scale for research and counseling. Journal of Counseling Psychology, 50(1), 84-96.

Yang, B., Lester, D., \& James, S. (2007). Attitudes toward buying online as predictors of shopping online for British and American respondents. CyberPsychology \& Behavior, 10(2), 198-203.

Yap, K. B. (2011). 13 Islamic banking: the convergence of religion, economic self-interest and marketing. Handbook of Islamic Marketing, 226.

Yardley, J. (2003, December 21). "A New Cultural Revolution in China . . Or Is It? New York Times, 10.

Youssef, M. A., Kortam, W., Aish, E. A., \& El-Bassiouny, N. (2011). Measuring IslamicDriven Buyer Behavioral Implications: A Proposed Market-Minded Religiosity Scale. Journal of American Science, 7(8).

Yun, Z., Verma, S., Pysarchik, D. T., Yu, J., \& Chowdhury, S. (2008). Cultural influences on new product adoption of affluent consumers in India. The International Review of Retail, Distribution \& Consumer Research, 18(2), 203- 220.

Yusof, E. F. E. (2008). Are Islamic banks in Malaysia really 'Islamic'? Germany: Munich Personal RePEc Archive.

Yusoff, M., \& Shamsuddin, A. S. (2003). Muslim consumer attitude towards Islamic Finance products in a Non Muslim Country. Jurnal Kemanusiaan(2), 94-103.

Yusoff, M. E., Shamsuddin, A. S., Zaidin, N., \& Baharun, R. (Eds.). (2008). Acceptance of Islamic Finance Product: A Study on Muslim Consumers Attitude in a Non Muslim Country (1st ed.). Johor Darul Ta'zim, Malaysia: PENERBIT: Universiti Teknologi Malaysia.

Zaher, T., \& Hassan, M. K. (2001). A Comparative Literature Survey of Islamic Finance and Banking. Financial Markets, Institutions and Instruments, 10, 155-199.

Zainuddin, Y., Jahyd, N., \& Ramayah, T. (2004). Perception of Islamic banking: does it differ among users and non users. Jurnal Manajemen dan Bisnis, 6(2), 135-149.

Zimbardo, P. G., \& Ruch, F. (1979). Psychology and Life (10th ed.). Glenview, IL: Scott: Foresman and Company. 
Zumbo, B. D., Sireci, S. G., \& Hambleton, R. K. (2003). Re-visiting exploratory methods for construct comparability: Is there something to be gained from the ways of old. Paper presented at the Symposium Construct Comparability Research: Methodological Issues and Results, National Council on Measurement in Education. 